\title{
WestVirginiaUniversity
}

THE RESEARCH REPOSITORY @ WVU

Graduate Theses, Dissertations, and Problem Reports

2004

\section{Control system design for a C-130 Ro-Ro sensor deployment platform}

\author{
Robert Paul Hayes \\ West Virginia University
}

Follow this and additional works at: https://researchrepository.wvu.edu/etd

\section{Recommended Citation}

Hayes, Robert Paul, "Control system design for a C-130 Ro-Ro sensor deployment platform" (2004). Graduate Theses, Dissertations, and Problem Reports. 1491.

https://researchrepository.wvu.edu/etd/1491

This Thesis is protected by copyright and/or related rights. It has been brought to you by the The Research Repository @ WVU with permission from the rights-holder(s). You are free to use this Thesis in any way that is permitted by the copyright and related rights legislation that applies to your use. For other uses you must obtain permission from the rights-holder(s) directly, unless additional rights are indicated by a Creative Commons license in the record and/ or on the work itself. This Thesis has been accepted for inclusion in WVU Graduate Theses, Dissertations, and Problem Reports collection by an authorized administrator of The Research Repository @ WVU. For more information, please contact researchrepository@mail.wvu.edu. 


\title{
CONTROL SYSTEM DESIGN FOR A C-130 RO-RO SENSOR DEPLOYMENT PLATFORM
}

\author{
by
}

\section{Robert Paul Hayes}

Thesis submitted to the College of Engineering and Mineral Resources

at West Virginia University in partial fulfillment of the requirements

for the degree of

\author{
Master of Science \\ in \\ Electrical Engineering
}

\author{
Approved by \\ Dr. Roy S. Nutter, Jr., Committee Chairperson \\ Dr. James E. Smith \\ Dr. Powsiri Klinkhachorn
}

Lane Department of Computer Science and Electrical Engineering

\author{
Morgantown, West Virginia \\ 2004
}

Keywords: C-130, Sensor Deployment Platform, Control System Design 


\title{
Abstract \\ CONTROL SYSTEM DESIGN FOR A C-130 RO-RO SENSOR DEPLOYMENT PLATFORM
}

\author{
by Robert Paul Hayes
}

\begin{abstract}
A WVU team of engineers designed and built a palletized system that will be used to deploy surveillance sensors from a C-130 cargo airplane. There will be two pallets, one that will house the Operator Station and one that will carry a mechanical arm with a Sensor Pod, where the sensors will reside. This pallet will be placed on the C-130 rear door, which will be opened while in flight. The mechanical arm is designed to rotate the Sensor Pod underneath the door so the sensors can observe the ground.

Computer/Electrical engineers were asked to design the control circuit for the Sensor Pallet, providing the user with a user interface to control deployment of the mechanical arm and Sensor Pod. The mechanical arm should also be deployable in an automated process, controlled by a computerized system. They were also responsible for designing the circuit to provide power to the system, interfacing with the power generated on the C-130 cargo airplane.

The thesis "Control System Design for a C-130 Ro-Ro Sensor Deployment Platform" details the power distribution circuit design, the control circuit design and the design of the automated process program.
\end{abstract}




\section{Dedication}

I would like to dedicate my thesis to the Commander in Chief of this great nation, George W. Bush, and all the brave men and women that are fighting for freedom and the war against terror in Afghanistan and Iraq. They are fighting to make this world a better, safer place to live for all mankind. They are fighting to make sure that we stay free, just as our founding fathers fought for our freedom more than 200 years ago. They are fighting to bring democracy to those that are suffering in countries less fortunate than our

own. And as a result, some of our nation's finest have paid the ultimate sacrifice. Let us keep our President and our courageous troops in our prayers and in our hearts. 


\section{Acknowledgements}

First, I would like to thank my family, who has supported me throughout my nineteen years of formal education. My mother Judith, my father Dennis, and my brother Nathan have helped me through twelve years of school and six years of college here at West Virginia University. I also need to thank my grandparents, Warren and Madge Albin and Erman and Norma Hayes, for their continued support of their grandson. I also need to thank my friends, Jason and Tiffany Lysne and Brian and Laura Hetzer, for being there for me through the years. I would, of course, also like to thank a person near and dear to me, Stacy Migdol, for having so much patience with me and listening to all of my problems while I have worked diligently to complete my research and thesis. She certainly amazes and inspires me; her perseverance never overwhelmed by what life hands her.

This publication would not have been possible without the dedicated efforts of many individuals. In the spirit of multiple-agency collaboration, I would like to acknowledge contributions made by Bruce Corso, Program Manager for the DoDCNTPO, and Maj. Michael Thomas, Technical Projects Manager for the NGB-CD. Sincere thanks also go to Col. James Hoyer, Col. Frye and all members of the WV-NG and ANG who provided guidance for the planning and development of this technology. Finally, the author would like to express gratitude to all the WVU participants for their timeless efforts that have insured the success of this program.

Also, I must thank my committee members, Dr. Roy S. Nutter, Dr. James E. Smith, and Dr. Powsiri Klinkhachorn, for helping and supporting me through this research process. I especially need to thank Dr. Nutter and Dr. Smith for giving me the 
opportunity to work on a project as interesting and far-reaching as Project Oculus. I have learned so much working on this project in the past year; the experience was more valuable than any I have received in the classroom. I have thoroughly enjoyed the experience.

I would be remiss not to thank the rest of the members of the Project Oculus team. You guys are the best engineers I know, and I am a better engineer and a better person for having worked with you. Thank you for being great coworkers and friends.

And finally, I need to thank my Lord God and give Him praise. I hope that I may glorify His name through my work and my life. To God be the glory, great things $\mathrm{He}$ hath done.

And last but not least... LET'S GO MOUNTAINEERS!!!!!! 


\section{Table of Contents}

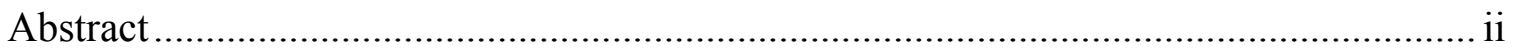

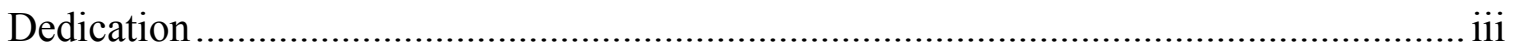

Acknowledgements .......................................................................................... iv

Table of Contents ................................................................................................ vi

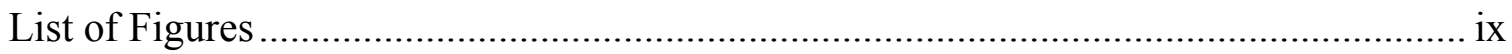

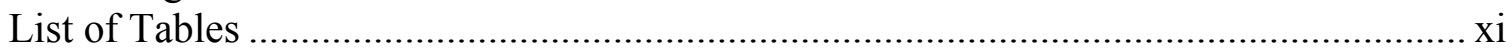

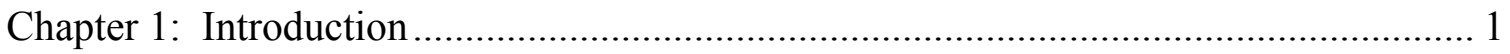

1.1 C-130 Sensor Deployment Systems Study …………………………………….... 2

1.1.1 $137^{\text {th }}$ National Guard Airlift Wing Sensor Pallet............................................. 2

1.1.2 $146^{\text {th }}$ National Guard Airlift Wing Sensor Pallet............................................ 4

1.1.3 $152^{\text {nd }}$ National Guard Airlift Wing Sensor Pallet ............................................ 4

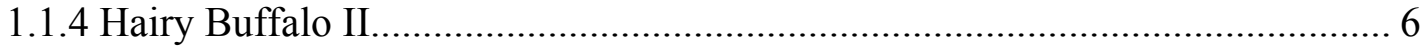

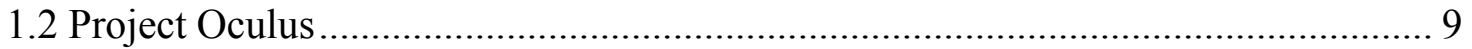

1.3 Project Oculus Deployment Procedure …………................................................ 11

1.4 Automatic and Manual Modes........................................................................... 14

1.5 Statement of the Thesis Project Problem ................................................................. 16

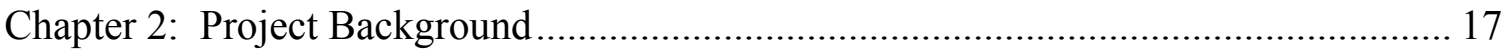

2.1 General Overview of Project Oculus .................................................................... 18

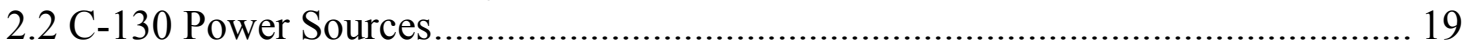

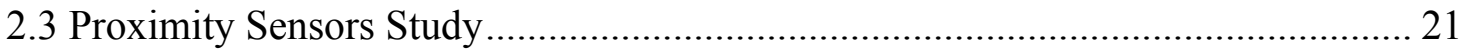

2.3.1 Inductive Proximity Sensors ....................................................................... 21

2.3.2 Capacitive Proximity Sensors .................................................................. 23

2.3.3 Photoelectric Proximity Sensors ................................................................ 24

2.3.3.1 Through-Beam Photoelectric Sensors...................................................... 24

2.3.3.2 Retro-Reflective Photoelectric Sensors ................................................... 25

2.3.3.3 Diffuse Photoelectric Sensors ……………….................................... 26

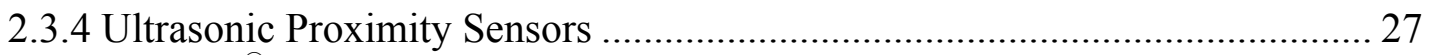

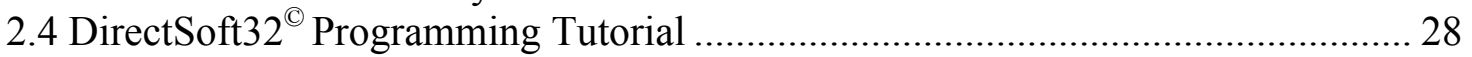

2.4.1 Introduction to Ladder Programming ……………....................................... 28

2.4.2 DirectSoft32 ${ }^{\mathcal{O}}$ - Getting Started ..................................................................... 29

2.4.3 Entering Contacts/Conditions onto Ladder Rungs ........................................... 33

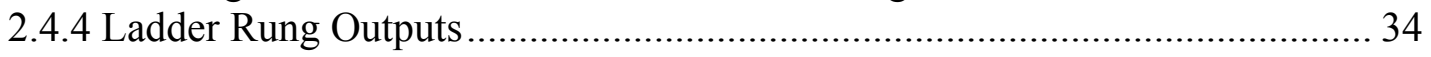

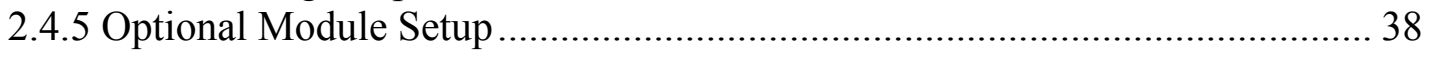

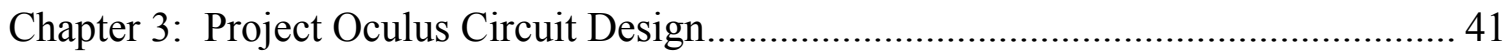

3.1 Operator Station Power Distribution Circuit ............................................................ 41

3.1.1 Input Power for Project Oculus.................................................................... 42

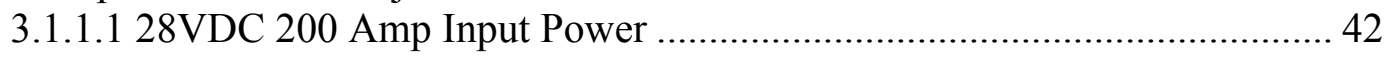

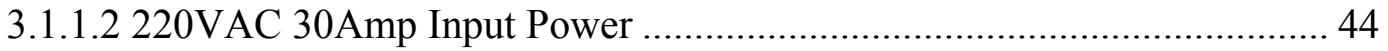

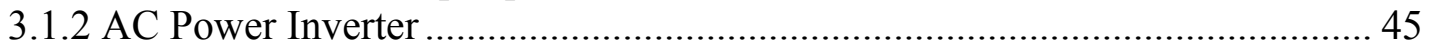

3.1.2.1 Vanner TSC24-4500D Inverter Overview.............................................. 45

3.1.2.2 Inverter Efficiency and Power Budge Study .......................................... 47 
3.1.2.3 TSR-2 Remote Control for the TSC24-4500D Inverter ............................ 48

3.1.3 Operator Station Circuit Design.................................................................... 48

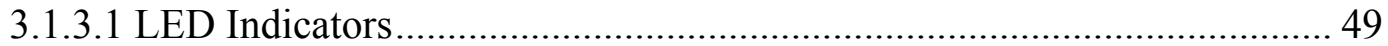

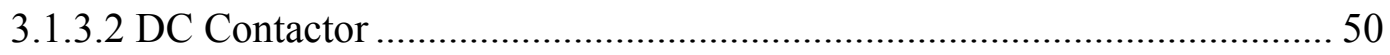

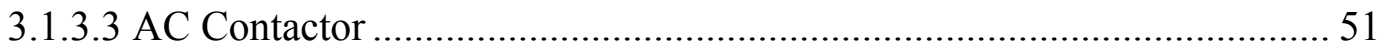

3.1.4 110VAC 60Hz Outlet Circuit ................................................................. 51

3.1.5 Operator Station Panel Design...................................................................... 53

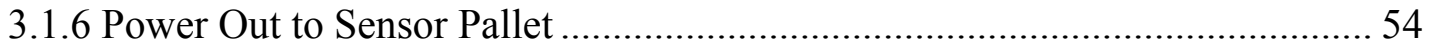

3.2 Sensor Pallet Control - Hardware and Circuit Design ......................................... 56

3.2.1 Translation and Rotational Motor Power Sources ........................................... 56

3.2.1.1 Translation Motor Power Source ........................................................... 57

3.2.1.2 Rotation Motor Power Source ……………….................................... 57

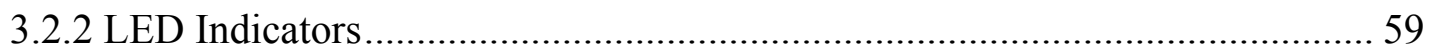

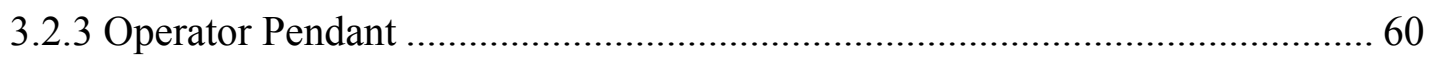

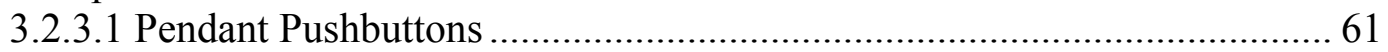

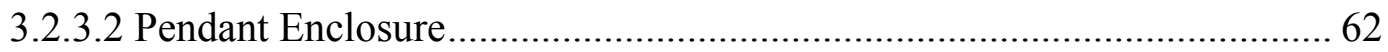

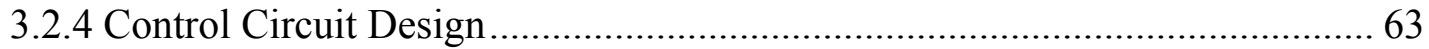

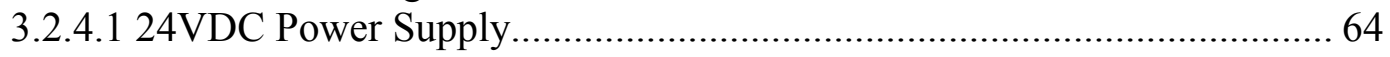

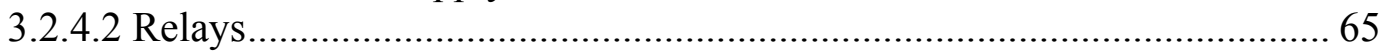

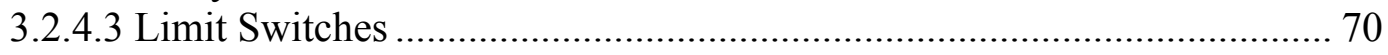

3.2.4.4 Pendant Circuit Design ............................................................................ 71

Chapter 4: Automatic Mode Hardware Design …………............................................. 73

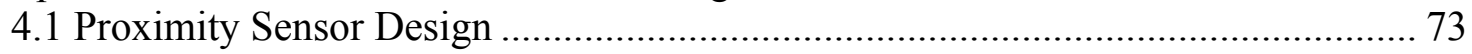

4.1.1 Proximity Sensor Design Criteria ………………........................................ 74

4.1.2 Choosing a Proximity Sensor …………………..................................... 75

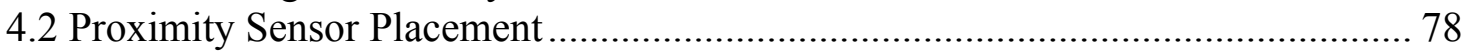

4.2.1 Placement of the Translation Proximity Sensors ............................................. 78

4.2.2 Placement of the Rotation Proximity Sensors ……………………………...... 79

4.3 Final Deployment Positioning - Current Sensor ..................................................... 81

4.3.1 Solution - Current Sensor ............................................................................ 81

4.4 Programmable Logic Controller Design .................................................................. 82

4.4.1 Programmable Logic Controller Design Criteria........................................... 83

4.4.2 Choosing a Programmable Logic Controller ................................................... 83

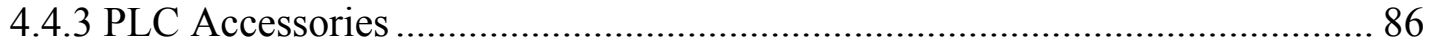

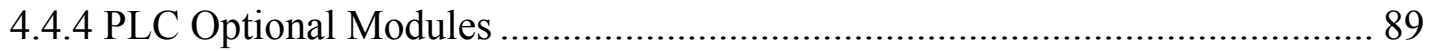

Chapter 5: Automatic Mode Software Design.............................................................. 93

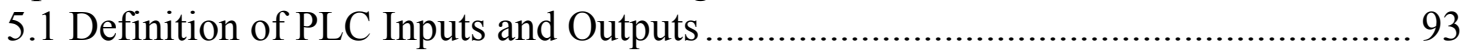

5.2 Automatic Mode Program Design ………….................................................... 96

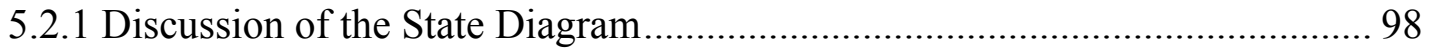

5.2.1.1 State Diagram - System Deployment Procedure ...................................... 98

5.2.1.2 State Diagram - System Stowing Procedure .......................................... 100

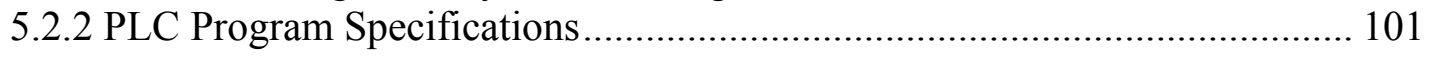

5.2.2.1 Timed Delays in the Program ............................................................... 102

5.2.2.2 LCD Screen Messages ......................................................................... 103 


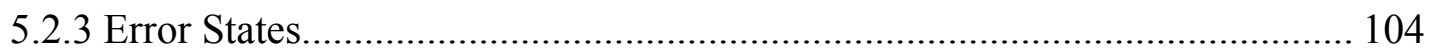

5.2.4 PLC Memory Locations Used in Program …………...................................... 104

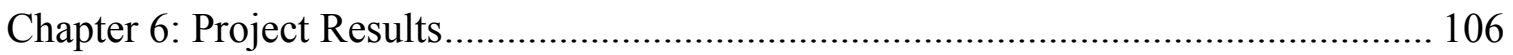

6.1 Testing the Operator Station Circuit................................................................ 106

6.2 Testing the Sensor Pallet Circuit and Program ................................................... 107

6.2.1 Testing the Sensor Pallet Power .................................................................. 108

6.2.2 Testing the Sensor Pallet in Manual Mode ................................................. 108

6.2.3 Testing the Sensor Pallet in Automatic Mode ............................................. 110

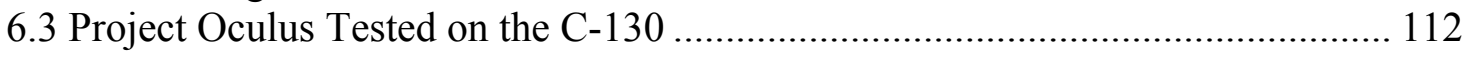

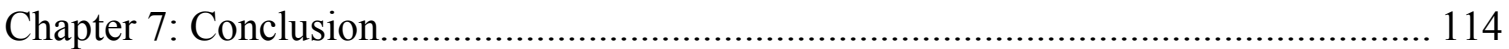

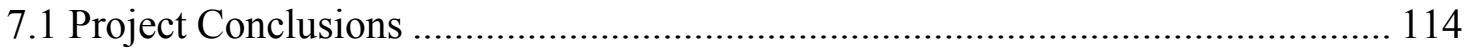

7.2 Recommendations for Future Work.................................................................... 114

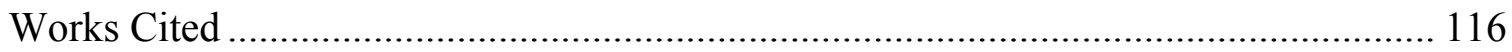

Appendix 1: Vanner TSC24-4500D Inverter Specifications ......................................... 120

Appendix 2: Project Oculus Power Budget .............................................................. 123

Appendix 3: Klixon Aircraft Circuit Breakers, 7274 Series........................................... 125

Appendix 4: Operator Station Circuit Diagrams ………………………………..... 130

Appendix 5: Automatic Mode Ladder Program ....................................................... 134

Appendix 6: Sensor Pallet Control Circuit Diagrams.................................................... 153

Appendix 7: GS2-22P0 Motor Controller Specifications ............................................... 157

Appendix 8: PS24-075D 24VDC Power Supply Specifications ..................................... 164

Appendix 9: QL2X1-D24 Series Relays Specifications ................................................. 166

Appendix 10: ABM6E42Z11 Mechanical Limit Switch Specifications ……………..... 170

Appendix 11: CT1-AP-1A Proximity Sensor Specification.......................................... 174

Appendix 12: CLN-50 Current Sensor Specifications..................................................... 176

Appendix 13: D0-06DD2 Programmable Logic Controller Specifications..................... 178

Appendix 14: F0-04AD-1 Analog Input Module Specifications.................................... 180

Appendix 15: D0-08CDD1 Digital Output Module Specifications................................. 182

Appendix 16: Quick Troubleshooting Handbook for Project Oculus ............................. 184

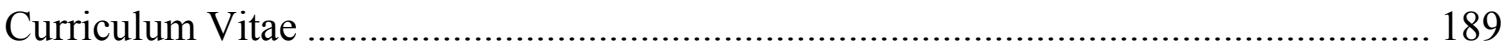




\section{List of Figures}

Figure 1.1: $137^{\text {th }}$ National Guard Airlift Wing Sensor Pallet .......................................... 2

Figure 1.2: $137^{\text {th }}$ National Guard Airlift Wing Sensor Pallet, Shown In Use.................... 3

Figure 1.3: $152^{\text {nd }}$ National Guard Airlift Wing Sensor Pallet........................................... 5

Figure 1.4: $152^{\text {nd }}$ Airlift Wing Sensor Pallet with Palletized Workstations ....................... 6

Figure 1.5: Hairy Buffalo II Sensor Pod and Operator Stations ........................................ 7

Figure 1.6: Hairy Buffalo II - Sensor Pod and Door Plug Unit ...................................... 8

Figure 1.7: Hairy Buffalo II Sensor Pod (Sensor Payload) ......................................... 9

Figure 1.8: Operator Station (Shown Without Rooftop) ............................................. 10

Figure 1.9: The Sensor Pallet Platform (Shown in Deployed Position) ......................... 11

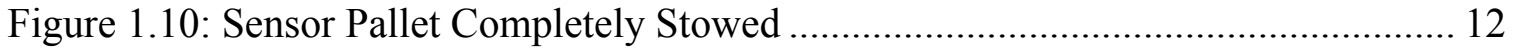

Figure 1.11: Completion of Step 1 -Translating Plate Moved 19" ................................. 12

Figure 1.12: Completion of Step 2 - Arm Rotated 206 ${ }^{\circ}$ under C-130 Ramp .................. 13

Figure 1.13: Completion of Step 3 - Sensor Pod Pulled Back Against C-130 Ramp Butt

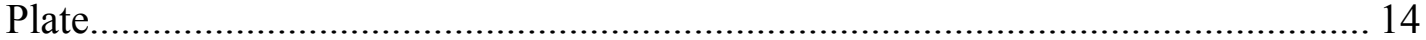

Figure 1.14: Pendant with Pushbutton/Switch Layout ............................................. 15

Figure 2.1: Components of an Inductive Proximity Sensor......................................... 22

Figure 2.2: Components of a Capacitive Proximity Sensor............................................ 23

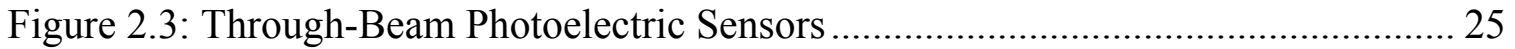

Figure 2.4: Retro-Reflective Photoelectric Sensors..................................................... 26

Figure 2.5: Diffuse Photoelectric Sensor ..................................................................... 27

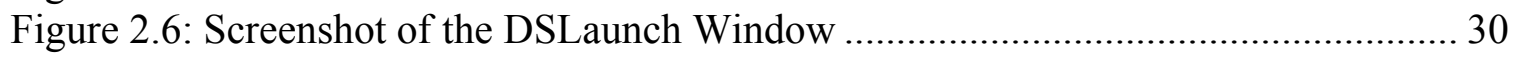

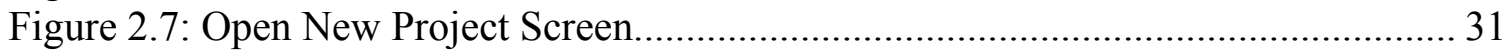

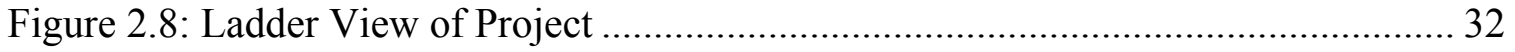

Figure 2.9: Program Editing Toolbar............................................................................ 32

Figure 2.10: Entering Normally Open/Closed Contacts ................................................ 33

Figure 2.11: Entering a Comparison Contact ............................................................. 34

Figure 2.12: Adding a Parallel Ladder Rung .............................................................. 34

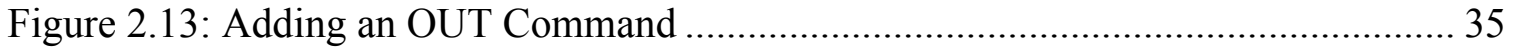

Figure 2.14: Defining an LCD Message ........................................................................ 35

Figure 2.15: Adding an LCD Command.................................................................. 36

Figure 2.16: Adding SET and RST Commands........................................................ 36

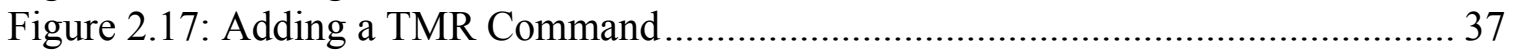

Figure 2.18: Special V-Memory Locations for D0-06DD2 Expansion Slots.................. 39

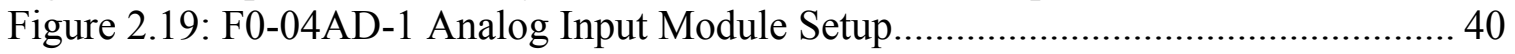

Figure 3.1: AN2552-3A 28VDC 200Amp Connector .................................................. 43

Figure 3.2: HBL430C12W 220VAC 30Amp Female Plug Power Connector ................. 44

Figure 3.3: HBL430B12W 220VAC 30Amp Male Chassis Mount Power Connector .... 45

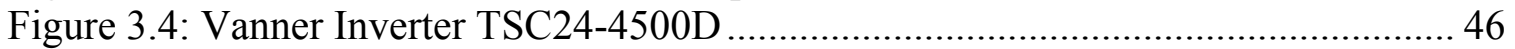

Figure 3.5: Vanner Inverter TSC24-4500D Front Panel .............................................. 46

Figure 3.6: TSR-2 Remote Control for the TSC24-4500D Inverter.............................. 48

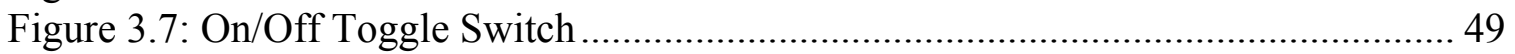

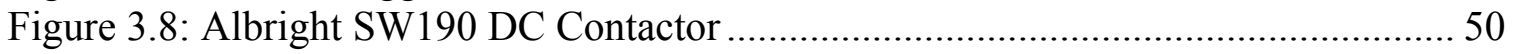

Figure 3.9: GH15FT-3-00A AC Contactor and GH15S11 Auxiliary Contact ................. 51

Figure 3.10: Klixon 7274-11 Aircraft Circuit Breaker ................................................ 52 
Figure 3.11: Klixon 7274-11 Circuit Breaker Components............................................ 52

Figure 3.12: Operator Station Panel Design ................................................................. 54

Figure 3.13: HBL430R12W 120/240VAC 60Hz 30Amp Female Chassis Mount Power

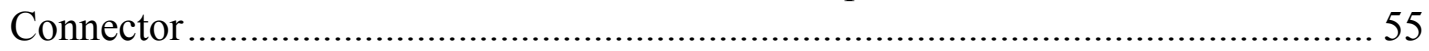

Figure 3.14: HBL430P12W 120/240VAC 60Hz 30Amp Male Plug Power Connector .. 55

Figure 3.15: GS2-22P0 Motor Controller ................................................................. 57

Figure 3.16: GS2-22P0 Motor Controller Wiring Diagram............................................. 59

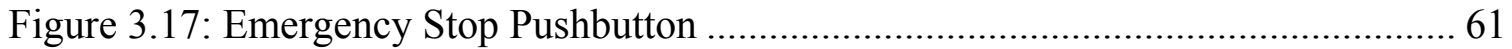

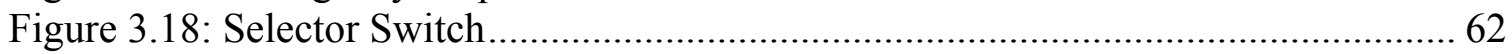

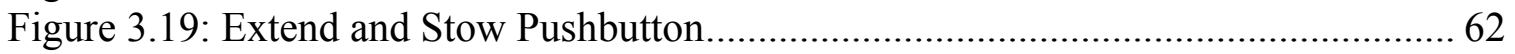

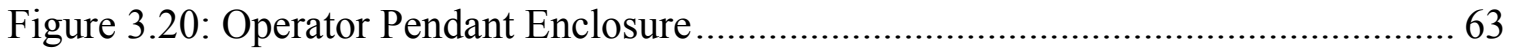

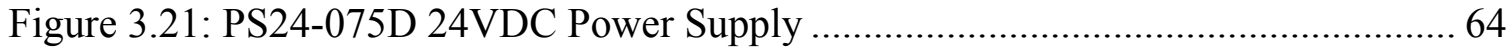

Figure 3.22: Block Diagram of R-TCW and R-TCCW Relays ........................................ 66

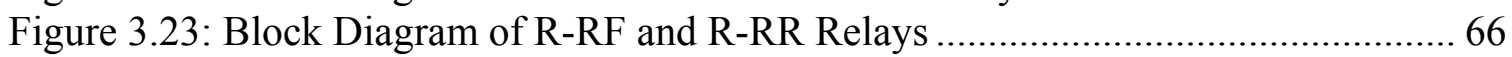

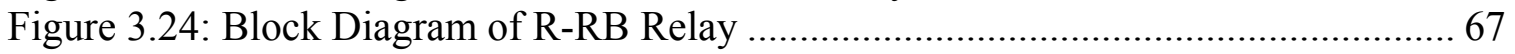

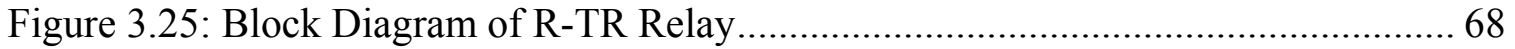

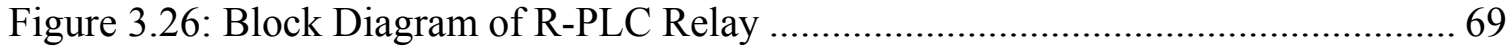

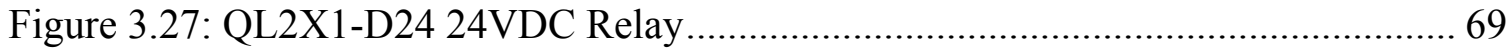

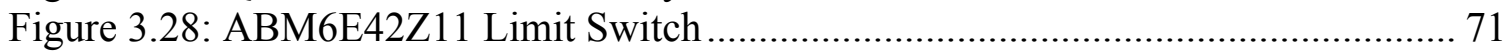

Figure 4.1: CT1-AP-1A Proximity Sensor ………………......................................... 77

Figure 4.2: CT1-AP-1A Equivalent Output Circuit...................................................... 77

Figure 4.3: Placement of Proximity Sensors on the Sensor Pallet................................... 80

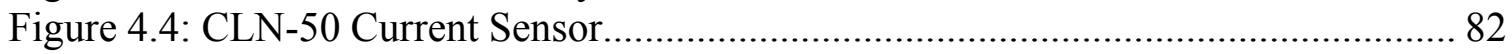

Figure 4.5: D0-06DD2 Programmable Logic Controller............................................... 84

Figure 4.6: Equivalent Input Circuit on the D0-06DD2 PLC ......................................... 85

Figure 4.7: Equivalent Output Circuit on the D0-06DD2 PLC ...................................... 85

Figure 4.8: D0-06LCD LCD Display for the D0-06DD2 PLC ...................................... 87

Figure 4.9: D2-DSCBL Programming Cable for the D0-06DD2 PLC............................. 88

Figure 4.10: F0-04AD-1 Analog Input Module............................................................ 89

Figure 4.11: Current Sensor to F0-04AD-1 Analog Input Module Circuit ...................... 90

Figure 4.12: D0-08CDD1 Digital Output Module ......................................................... 91

Figure 4.13: Equivalent Output Circuit for the D0-08CDD1 ......................................... 91

Figure 5.1: D0-06DD2 PLC General Wiring Diagram............................................... 95

Figure 5.2: PLC Program State Diagram................................................................... 97

Figure 6.1: Manual Mode Testing Procedure ……………......................................... 109

Figure 6.2: Sensor Pallet in Operation on C-130 in Charleston, WV ............................. 113 


\section{List of Tables}

Table 2.1: Overview of Power Outlets in C-130 Cargo Bay ........................................... 20

Table 3.1: Specifications for the Vanner TSC24-4500D Inverter .................................. 47

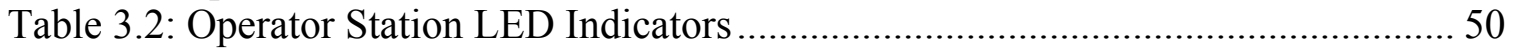

Table 3.3: Klixon 7274-11 Aircraft Circuit Breaker Specifications................................. 53

Table 3.4: GS2-22P0 Motor Controller Specifications.................................................... 58

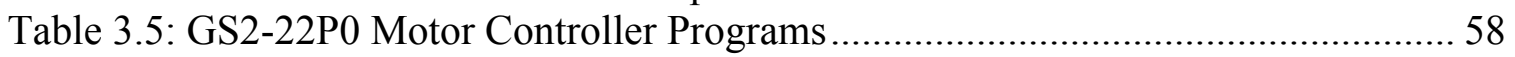

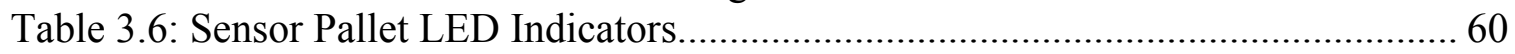

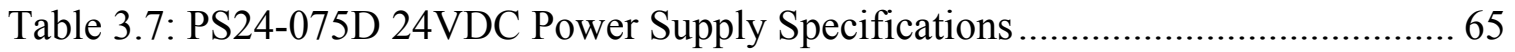

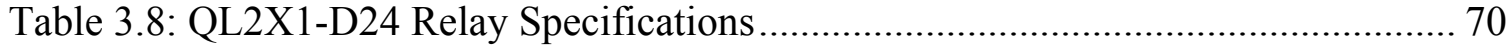

Table 4.1: Specifications of the CT1-AP-1A Proximity Sensor...................................... 78

Table 4.2: Specifications of the D0-06DD2 Programmable Logic Controller ................. 86

Table 5.1: D0-06DD2 PLC Input/Output Map ........................................................... 96

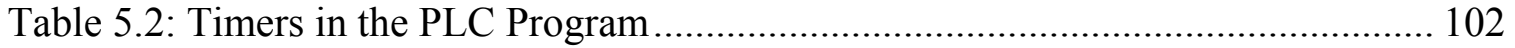

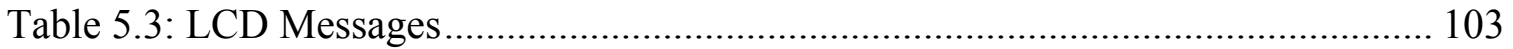

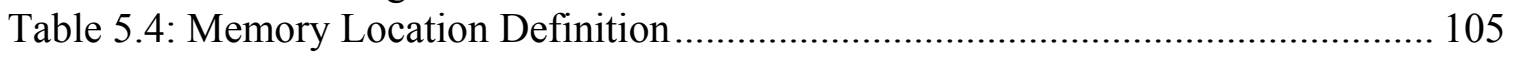




\section{Chapter 1: Introduction}

The people of the United States of America are continuously facing threats to their everyday way of life, including the constant spread of drug use among the American population and the threat of terrorism from groups like al Qaida. The Department of Defense and the National Guard are constantly searching for new ways to combat these dangers. The philosophy employed by these enforcement agencies is that of preventive action; find the terrorists or the fields of marijuana before they crop up on our city streets and before the profits are made to finance terrorism.

For several years now, there has been the need to quickly and economically deploy surveillance sensors such as a Forward-Looking Infrared (FLIR) turret, high-resolution digital cameras, video recording cameras, radar, multispectral imaging, and other sensors. The C-130 cargo airplane is an attractive candidate to deploy these sensors based on the availability of the airplane (there are many C-130's currently in service across the nation) and the large payload of the $\mathrm{C}-130$. The problem becomes where to mount the surveillance sensors on the large, vibrating freight carriers of the skies? Certainly, the people that own the C-130's and perform routine maintenance on them do not want to have to alter or modify the airplane in any way. That means that the sensors can not be attached to the bottom or the wings of the aircraft. This fact leaves only the rear doors of the airplane, which can be opened while in flight, as an area from which the sensors can be quickly and economically deployed. This concept, for a C-130 sensor deployment system built from commercial-off-the-shelf (COTS) components and to be used without modifying the aircraft, became Project Oculus, which was designed and built by the WVU-CIRA team of engineers. 


\subsection{C-130 Sensor Deployment Systems Study}

Deployment of surveillance sensors from a C-130 platform is not a new and novel idea originated by the WVU-CIRA engineers. On the contrary, there are several predecessors for Project Oculus to follow. Other systems have been developed by both National Guard units and by private industry, funded by the federal government.

\subsection{1 $137^{\text {th }}$ National Guard Airlift Wing Sensor Pallet}

One of the first sensor pallet systems developed for the C-130 is the reconnaissance system built by the $137^{\text {th }}$ National Guard Airlift Wing located in Oklahoma City, Oklahoma. This system did not have the same wide-sweeping goals as Project Oculus; this sensor pallet was only designed to deploy a $\mathrm{KC}-1 \mathrm{~B}$ mapping camera, a KS-87 framing camera, and a KA-91A panoramic camera [1]. An illustration of this system is shown in Figure 1.1 below.

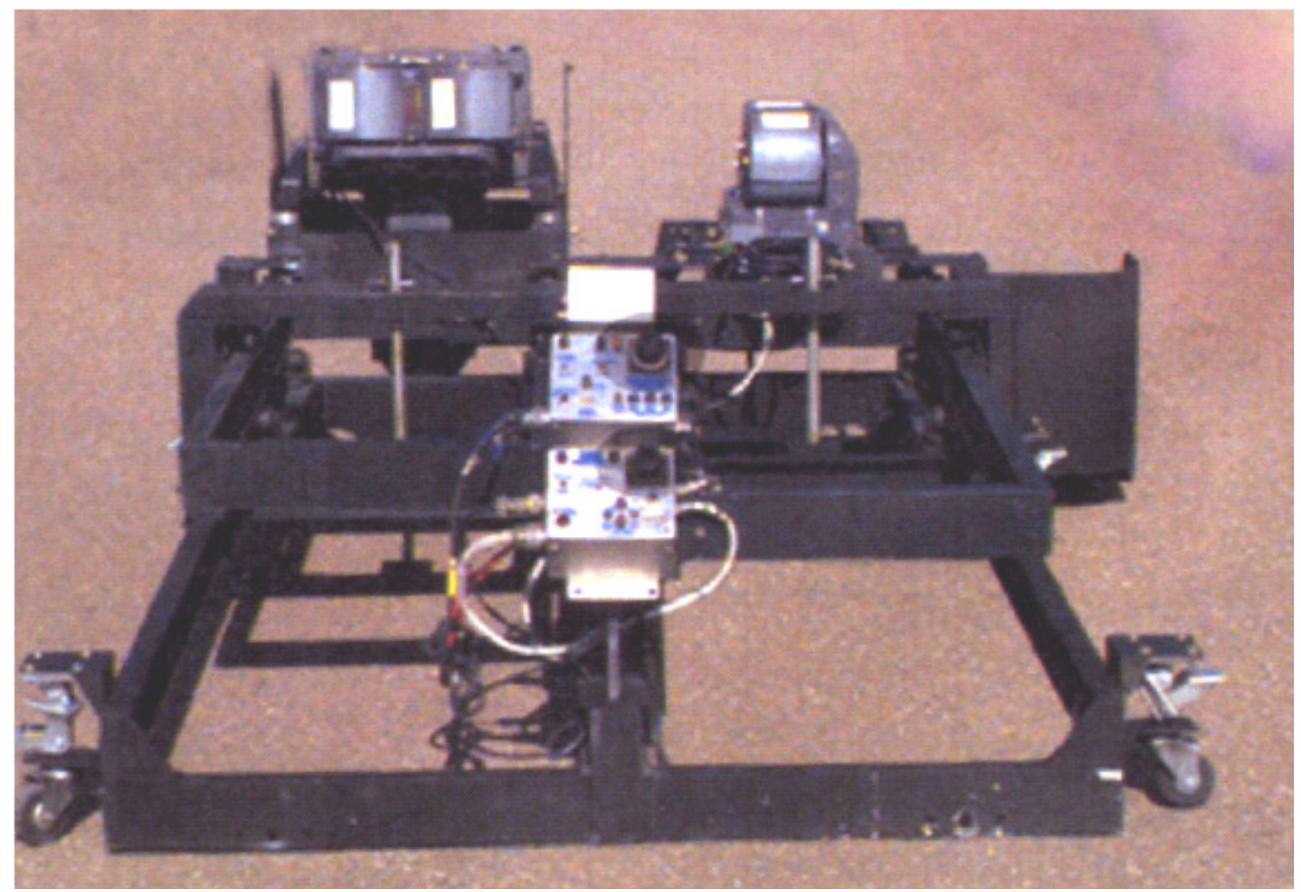

Figure 1.1: $137^{\text {th }}$ National Guard Airlift Wing Sensor Pallet [1] 
As seen in the illustration above, the sensors are not mounted on a basic pallet; instead, it is mounted on the rear door of the C-130 by the use of two mounting connections on the cargo door. To deploy the cameras, this system extends two arms out over the edge of the rear door to point the cameras at the ground below. This allows the cameras to view directly below the plane and any ground behind the plane's path. However, the cameras are limited by the rear cargo door and cannot look forward. With the extendable/retractable arms, the operators are able to reload the wet film cameras or even replace the camera entirely. The system is shown in use in Figure 1.2. The $137^{\text {th }}$ Airlift Wing has stopped production of this sensor deployment system and is no longer developing similar systems [1].

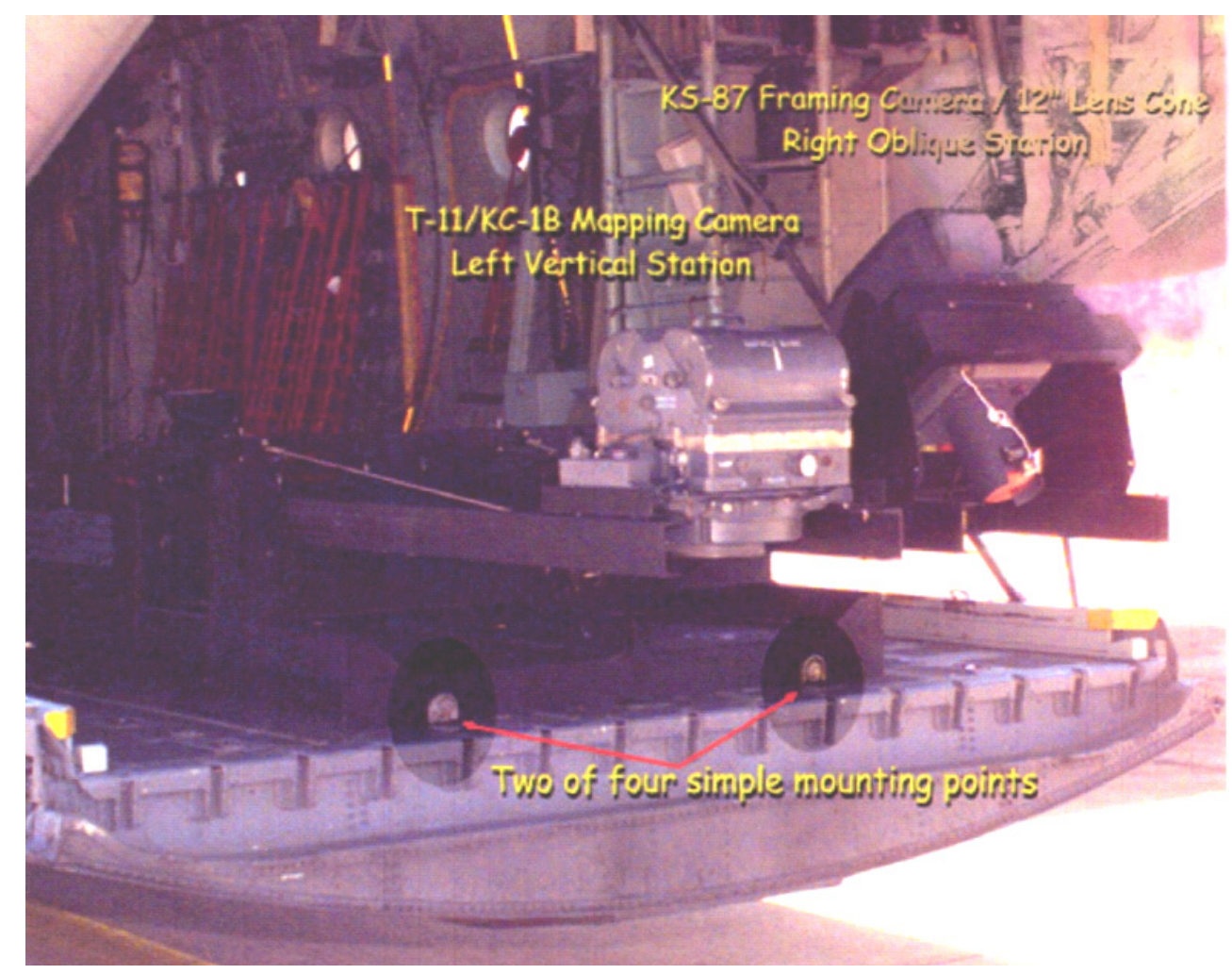

Figure 1.2: 137 $^{\text {th }}$ National Guard Airlift Wing Sensor Pallet, Shown In Use [1] 


\subsection{2 $146^{\text {th }}$ National Guard Airlift Wing Sensor Pallet}

Another sensor deployment system, similar to the system developed by the $137^{\text {th }}$ Airlift Wing, was created by the $146^{\text {th }}$ National Guard Airlift Wing, located in Port Hueneme, California. This pallet also accommodates a KS-87 framing camera and a KS91 panoramic camera; the system can also deploy a three camera configuration. Instead of the retractable arms that are present in the $137^{\text {th }}$ Airlift Wing's sensor pallet, the $146^{\text {th }}$ Airlift Wing's pallet must be mounted with the cameras already positioned hanging out over the end of the rear cargo door, from which the cameras can film the ground directly underneath the aircraft [1]. This concept limits the components that may fail while in use, but also limits the system's usability.

The $146^{\text {th }}$ Airlift Wing is currently testing a new system that will allow them to deploy Synthetic Aperture Radar (SAR) and infrared sensors. This system will be useable even with the rear cargo door closed, unlike the previous systems discussed. Illustrations of both systems developed by the $146^{\text {th }}$ Airlift Wing are unavailable [1].

\subsection{3 $152^{\text {nd }}$ National Guard Airlift Wing Sensor Pallet}

The $152^{\text {nd }}$ National Guard Airlift Wing, located in Reno, Nevada, has created a sensor pallet systems analogous to the one designed by the $137^{\text {th }}$ Airlift Wing. Commercial surveillance cameras, which could be the KS-87 camera, the KS-91 camera, or the KS-87 long lens camera, are mounted are two retractable arms and extended over the end of the rear cargo door, exactly like the $137^{\text {th }}$ Airlift Wing's sensor pallet [1]. This pallet is illustrated in Figure 1.3 shown below. 


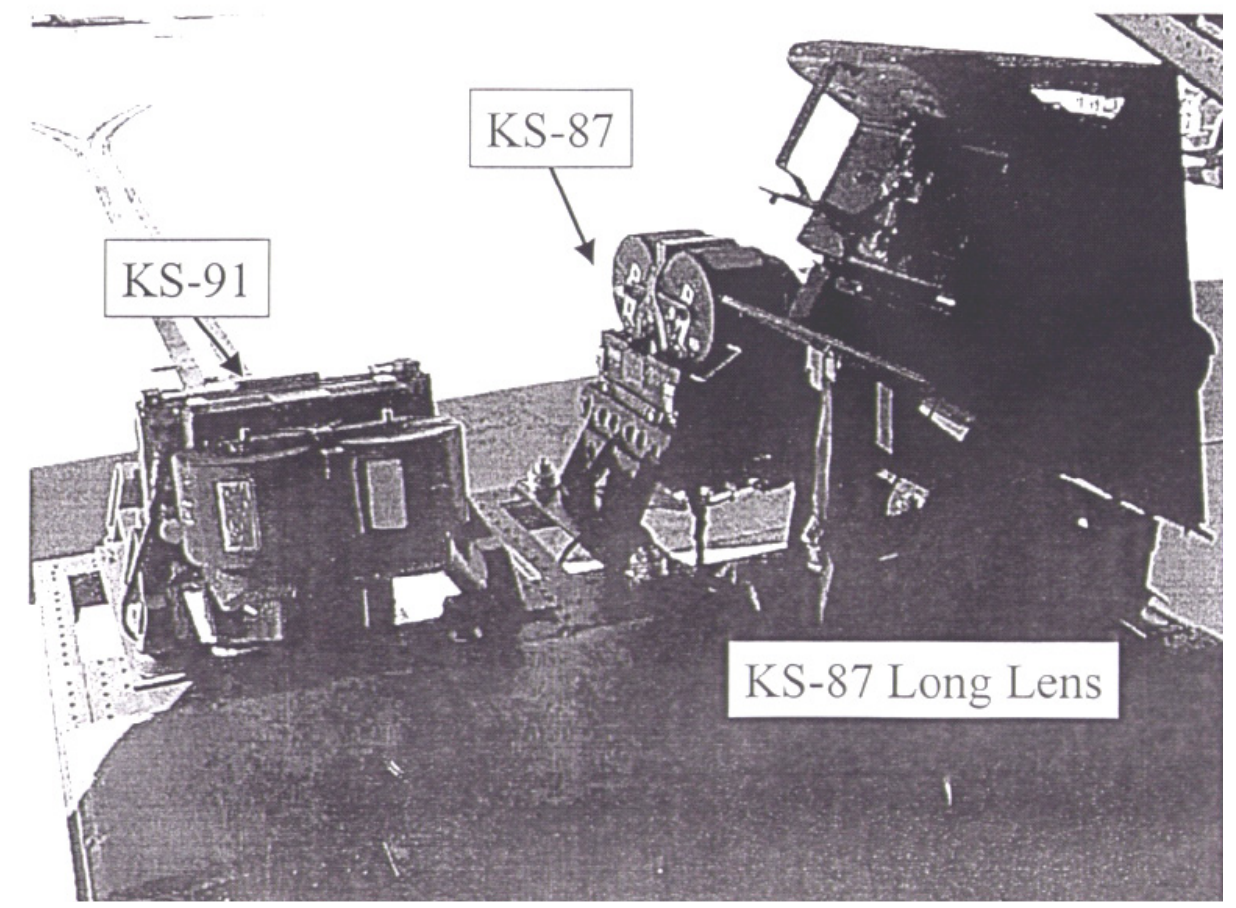

Figure 1.3: 152 ${ }^{\text {nd }}$ National Guard Airlift Wing Sensor Pallet [1]

However, the $152^{\text {nd }}$ Airlift Wing has expanded the scope of the normal sensor pallet configurations with the development of the SCATHE view system. The SCATHE system provides near real-time data by introducing the use of a gimbaled turret mounted beneath the nose of the airplane, an operator workstation built atop a pallet loaded into the cargo bay, and a communication link from the system to a ground base. The turret encompasses a FLIR unit, a spotter scope, and a laser rangefinder. Ongoing testing to add newer and better sensors to the system is still under way [1]. The system, shown with the palletized workstations, is illustrated in Figure 1.4 below. 


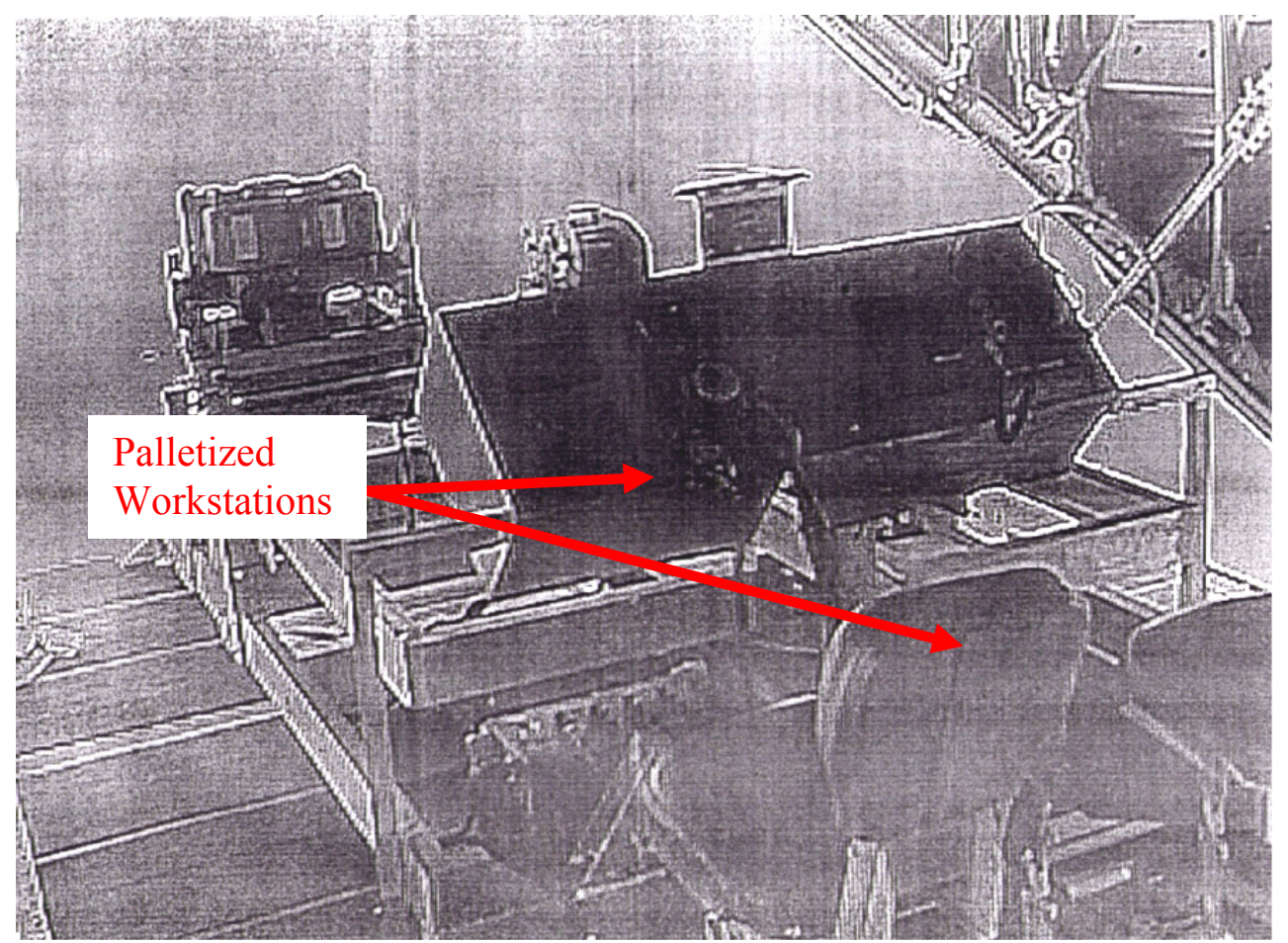

Figure 1.4: 152 ${ }^{\text {nd }}$ Airlift Wing Sensor Pallet with Palletized Workstations [1]

\subsubsection{Hairy Buffalo II}

The systems discussed above were all designed to mostly handle only the KS-87 framing camera, the KS-91 panoramic camera, and the $\mathrm{KC}-1 \mathrm{~B}$ mapping camera, and due to the mounting position on the rear cargo door, had a limited field of view (FOV) of only the ground directly underneath the plane. These systems were also only equipped with wet-film cameras, which do not provide the operators with real-time data. As can be seen with the $152^{\text {nd }}$ Airlift Wing's sensor pallet, the C-130 sensor deployment system was beginning to evolve to providing near real-time data to the operators, and the FOV of the system was increasing to include more of the ground below. However, attaching the gimbaled turret to the aircraft nose took time; therefore, a sensor deployment system that could position the sensors below the rear cargo door or C-130 fuselage was desired. 
The federal government began to fund C-130 sensor deployment projects with the introduction of the "Hairy Buffalo" mission. NAVAIR Inc. followed this system with Hairy Buffalo II. The system includes three operator stations built on an operator pallet, a C4 shelter designed to plug into a C-130 jump door for a fourth operator, and a wing mounted ISR sensor pod based on Lockheed Martin's SAMSON pod $[1,4]$. The system is shown below in Figure 1.5.

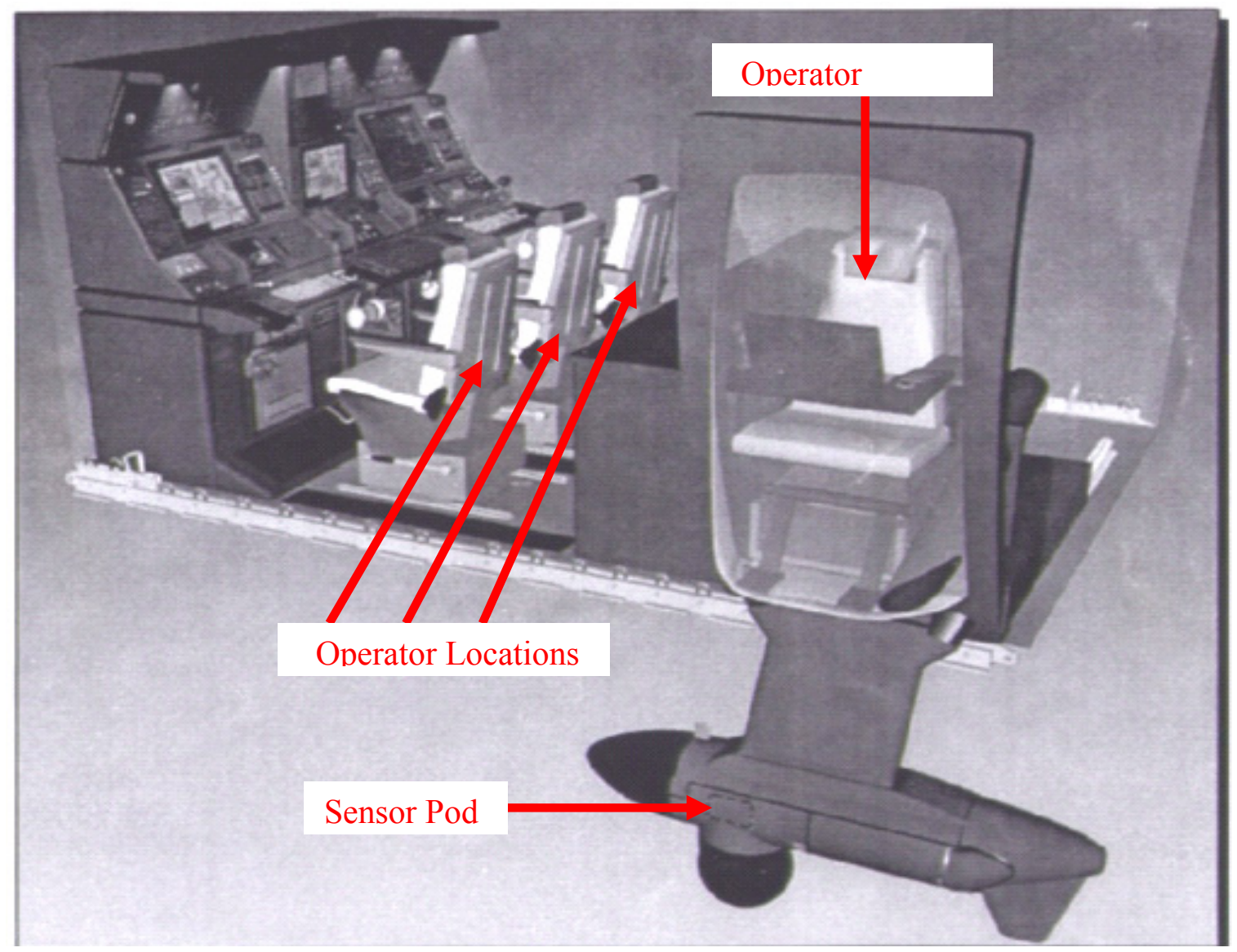

Figure 1.5: Hairy Buffalo II Sensor Pod and Operator Stations [1]

The sensor pod is mounted just below the C-130 jump door and is controlled by the operator seated in the customized AS-6 Door Plug. The sensor pod provides a full $360^{\circ}$ of ground coverage beneath the aircraft and can be modified to house any currently 
available sensor or future sensors, including Star Safire FLIR units, Lynx SAR radar, MODSAR radar, hyperspectral sensors, CA-260 EO digital framing cameras, and VHF/UHF antennas. The door plug itself is equipped with a GPS antenna that will relay exact coordinates of an event to a ground base [1,4]. The door plug and sensor pod components are illustrated in Figure 1.6.

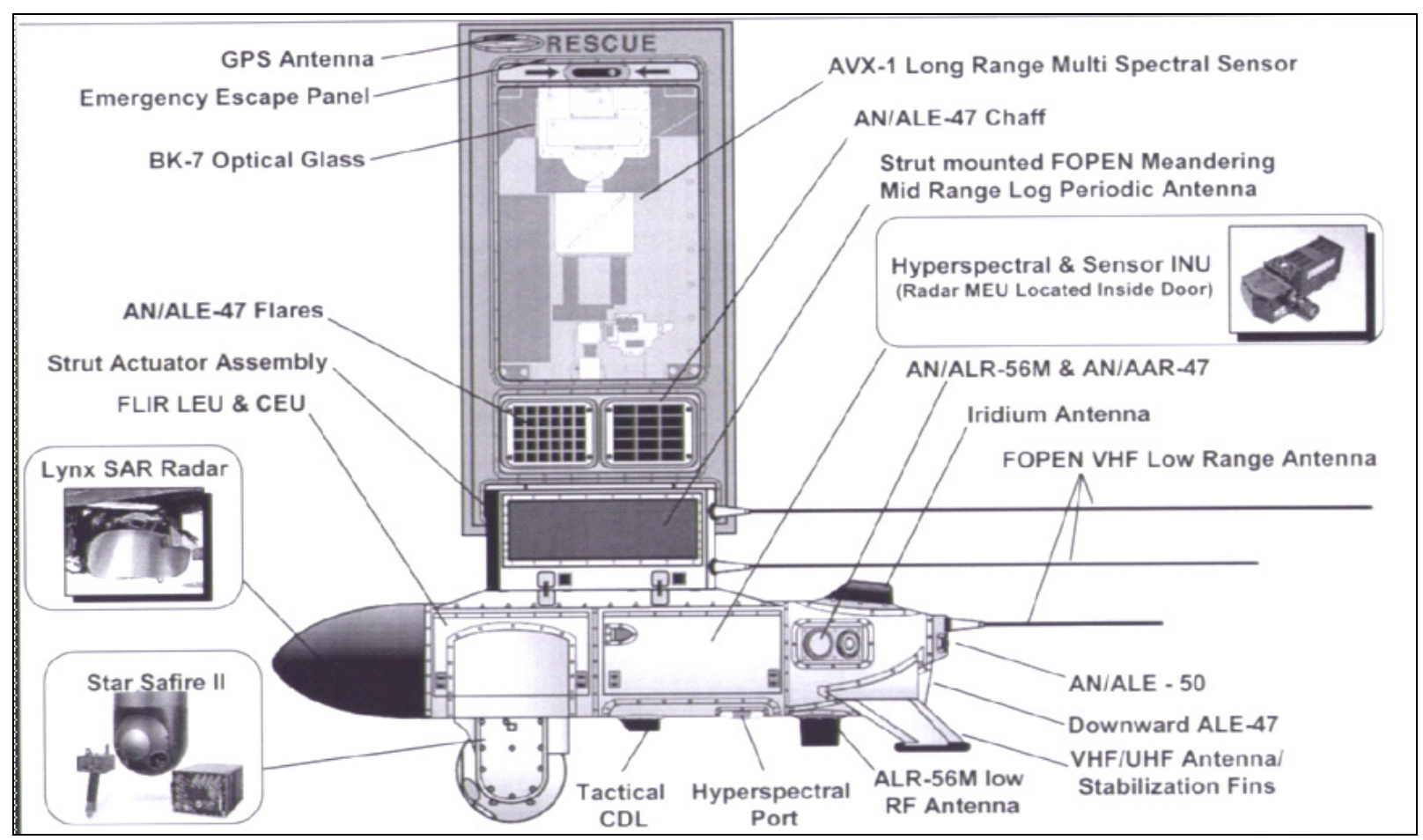

Figure 1.6: Hairy Buffalo II - Sensor Pod and Door Plug Unit [1]

The sensors can see out of the pod through cutouts in the bottom of the pod. The MODSAR radar is mounted in the front fairing to eliminate interference with other sensors. The sensor pod yields $14.7 \mathrm{ft}^{3}$ of volume for sensors and can weigh up to 600 lbs. with full sensor payload [1]. A closer view of the sensor pod with included sensors is shown in Figure 1.7 below. 


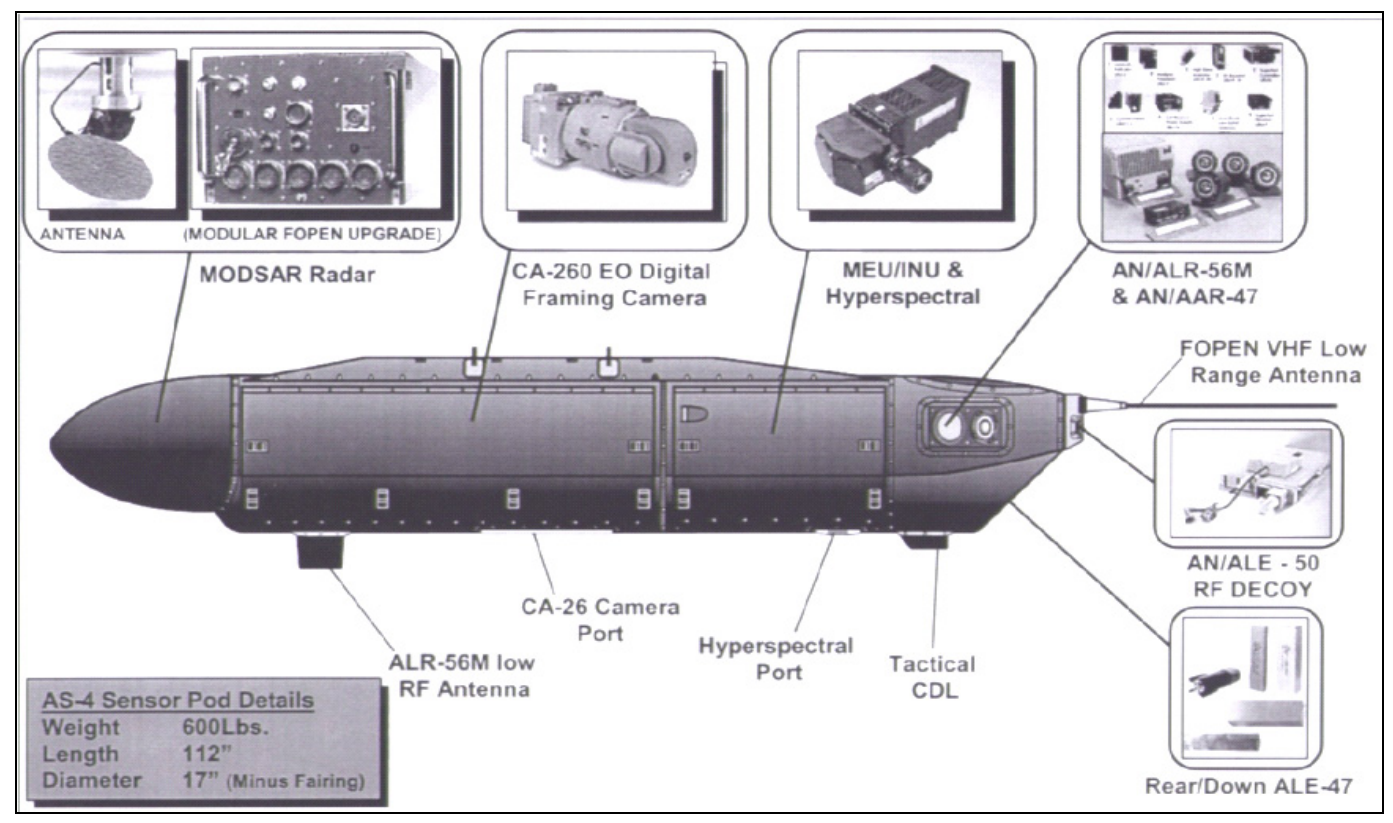

Figure 1.7: Hairy Buffalo II Sensor Pod (Sensor Payload) [1]

The AS-6 Door Plug cannot be installed without the entire removal of the C-130 jump door. Based on the fact that the system requires significant aircraft modification and an extensive amount of time and effort to become operational, the Hairy Buffalo II project and its federal government funding has been terminated [1]. Instead, funding for a system that does not require modifications to the aircraft and can be flown with minimal time and effort has been undertaken at West Virginia University with the emergence of Project Oculus.

\subsection{Project Oculus}

In the spring of 2003, the WVU-CIRA team of engineers proposed a solution to the sensor deployment problem. The proposal was to create a palletized system, using standard C-130 Gen-X freight pallets used by the military, with the slight modification of adding a $3 / 4$ " top plate on the pallet, rather than the standard $0.063 "$. One pallet would house sensor interface equipment, computer equipment, and the operators themselves, 
and is known as the "Operator Station." The Operator Station is shown in Figure 1.8, showing two of the operator's seats, two entry doors, three electronic equipment racks, and one side of the input/output power connector and sensor communication panels [3].

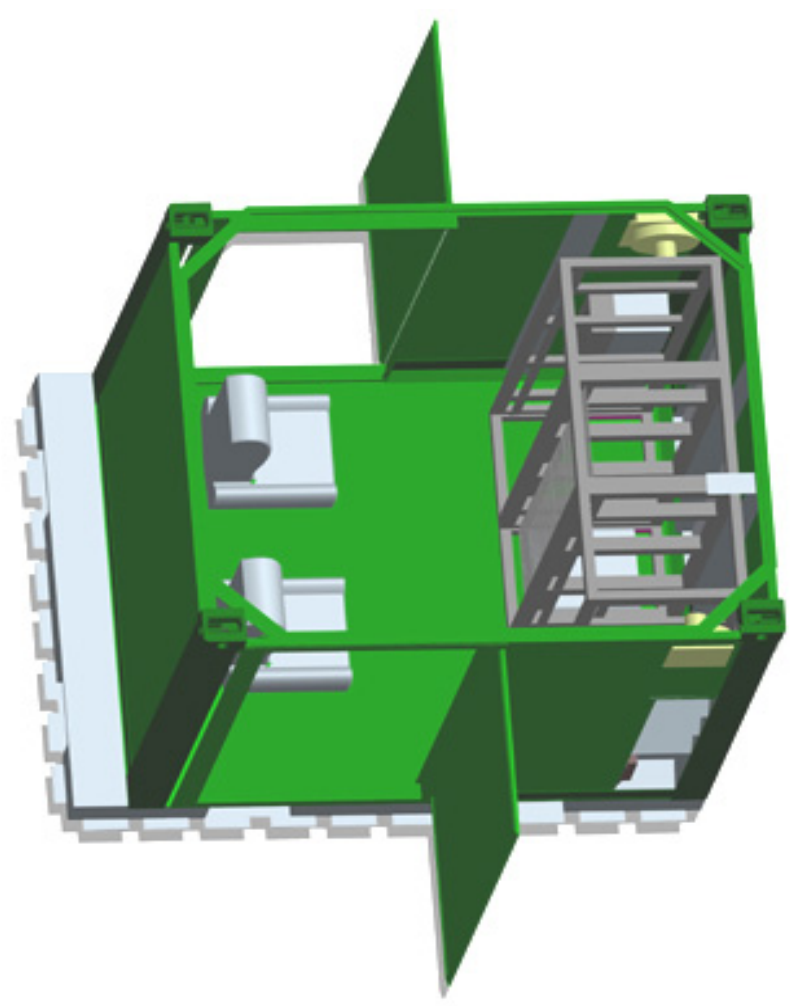

Figure 1.8: Operator Station (Shown Without Rooftop) [5]

The "Sensor Pallet", as the second pallet is called, would be the platform from which the surveillance sensors would be deployed. The sensors would be mounted into or on the outer edges of a "Sensor Pod", which would be bolted to the end of four mechanical stabilizing arms that will rotate out the open rear door of the C-130 and position itself against the butt plate on the exterior of the rear ramp. The mechanical arms will be on a shaft that is turned by a gearbox and a 2.0 HP 240 VAC motor. These components are placed on top of a translating plate that is moved by a $1 / 3$ HP 110 VAC 
motor. The translating plate and all other components will be mounted permanently on the Sensor Pallet [3]. This pallet is shown in Figure 1.9 below.

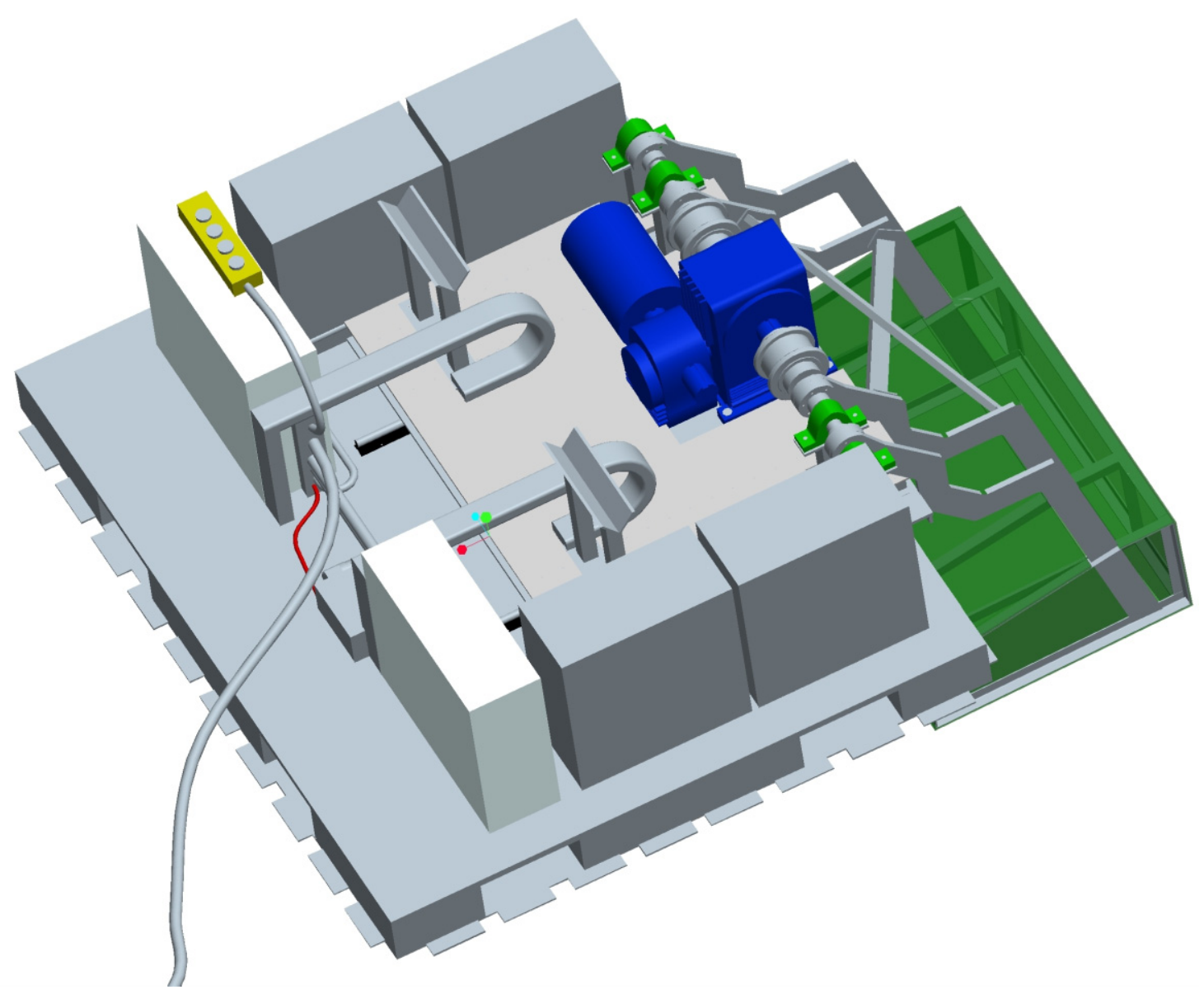

Figure 1.9: The Sensor Pallet Platform (Shown in Deployed Position) [5]

\subsection{Project Oculus Deployment Procedure}

The deployment procedure of the Sensor Pod from its fully stowed position to its fully extended position is a 3-step process. A profile view of the sensor pallet in its fully stowed position is shown in Figure 1.10 below. 


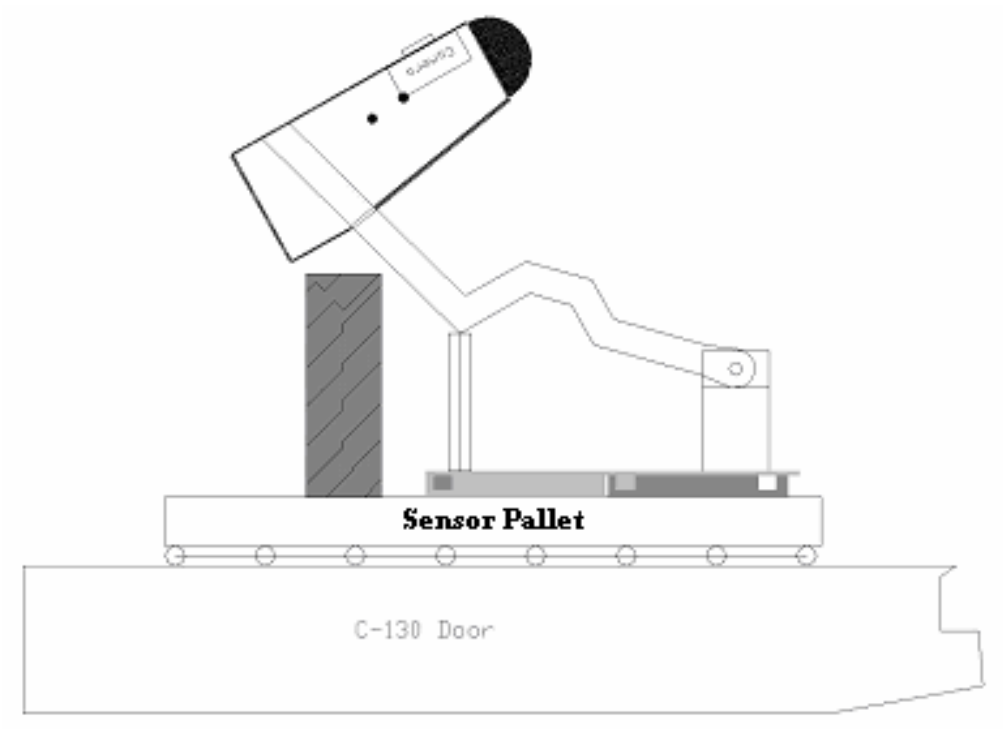

Figure 1.10: Sensor Pallet Completely Stowed [6]

Step 1 of the deployment procedure involves the movement of the translating plate. The translating plate travels 19 inches towards the back of the plane on stainless steel rails attached to the top of the pallet. It is imperative that the translating plate completes the movement so that when the arm is rotated, it does not strike the pallet or the C-130 door. A profile view of a completed Step 1 is shown in Figure 1.11.

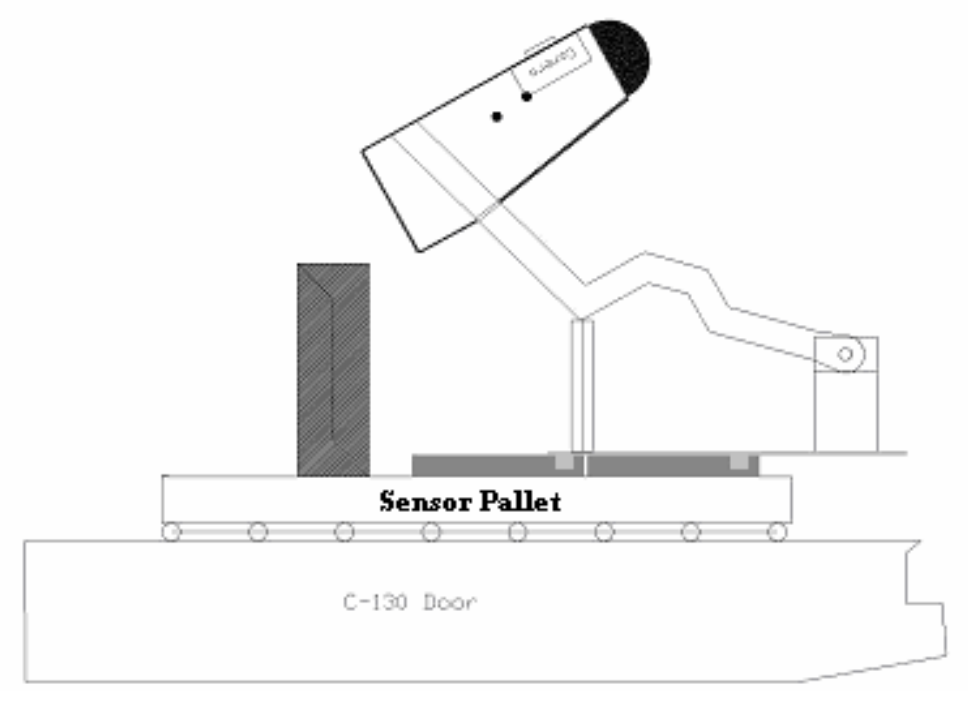

Figure 1.11: Completion of Step 1 -Translating Plate Moved 19” [6] 
Step 2 of the deployment procedure involves the rotation of the arm so that the sensor pod is positioned underneath the plane. The arm is rotated $206^{\circ}$ from its resting position to its position underneath the $\mathrm{C}-130$ door. A profile view of a completed Step 2 is shown in Figure 1.12.

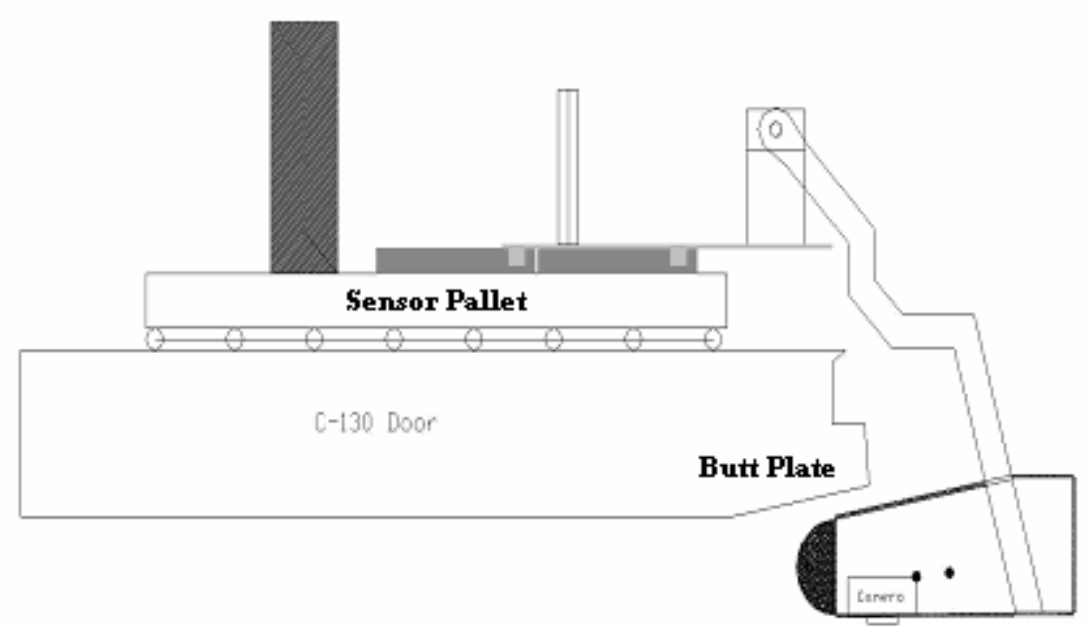

Figure 1.12: Completion of Step 2 - Arm Rotated $206^{\circ}$ under C-130 Ramp [6]

The final phase of the deployment procedure, Step 3, again involves movement of the translation plate. Here, the translating plate returns toward the front of the plane until the pod is pulled in tight against the butt plate on the exterior of the ramp. This provides stabilization of the sensor pod, which is important because of the sensitivity of the sensors mounted inside. A constant vibration or movement of the pod could cause pictures to be blurry, noisy signals, and so on. A profile view of a completed Step 3 is shown in Figure 1.13. 


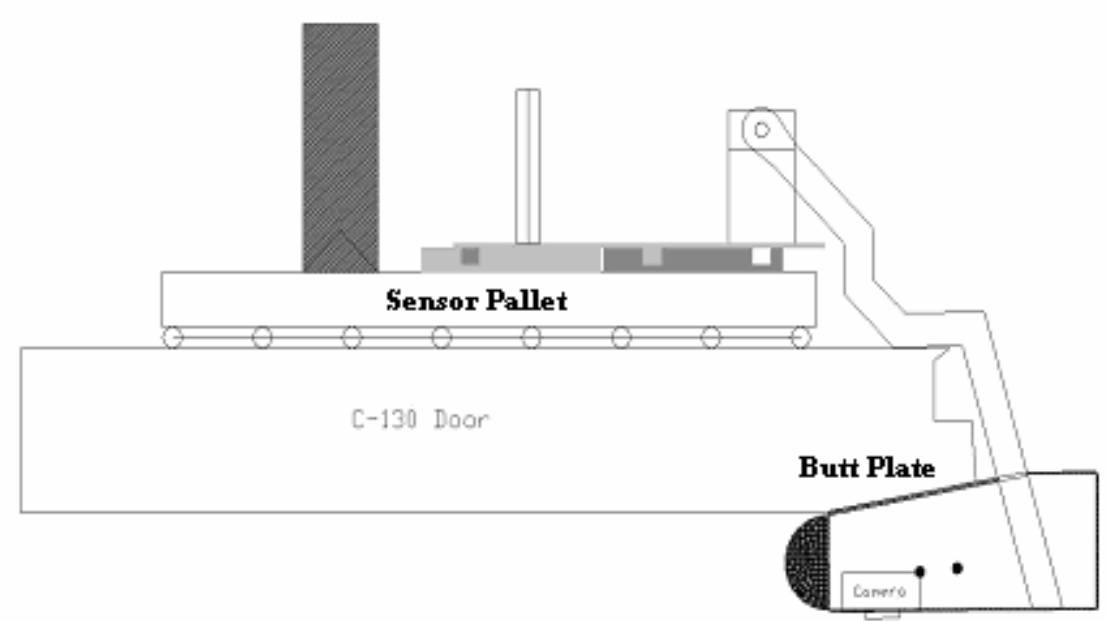

Figure 1.13: Completion of Step 3 - Sensor Pod Pulled Back Against C-130 Ramp Butt Plate [6]

The stowing procedure of the Sensor Pod performs these three steps in the exact opposite order. First, the translating plate moves outward to the fully extended position to give the arm room to rotate. Then, the arm rotates back to its resting position upon the arm supports. Finally, the translating plate travels backward to its fully stowed position, completing the stowing procedures.

\subsection{Automatic and Manual Modes}

During the design process, it was decided that the deployment and stowing procedures could be done in one of two modes: automatic mode or manual mode. Manual mode should be performed without the use of a computer; it is completely controlled by the system operator. Therefore, the system operator can precisely place the "mechanical arm" and/or translating plate in the exact position that he or she prefers. This could aid in maintenance on the sensor pod or the mechanical arm, or in sensor placement or maintenance inside the pod. 
Automatic mode is controlled by a computer; the only user inputs that control automatic mode are a single push of the Extend and Stow buttons. There will also be input from sensors to describe the location of the translating plate and the rotational arm.

Each mode is controlled from a user pendant, which consists of a combination of three pushbuttons and two switches. The pushbuttons are the Emergency Stop button, the Extend button, and the Stow button; the switches are the Automatic/Manual Mode switch and the Translate/Rotate switch. A diagram showing a picture of the pendant with the layout of the pushbuttons and switches is shown in Figure 1.14 below.

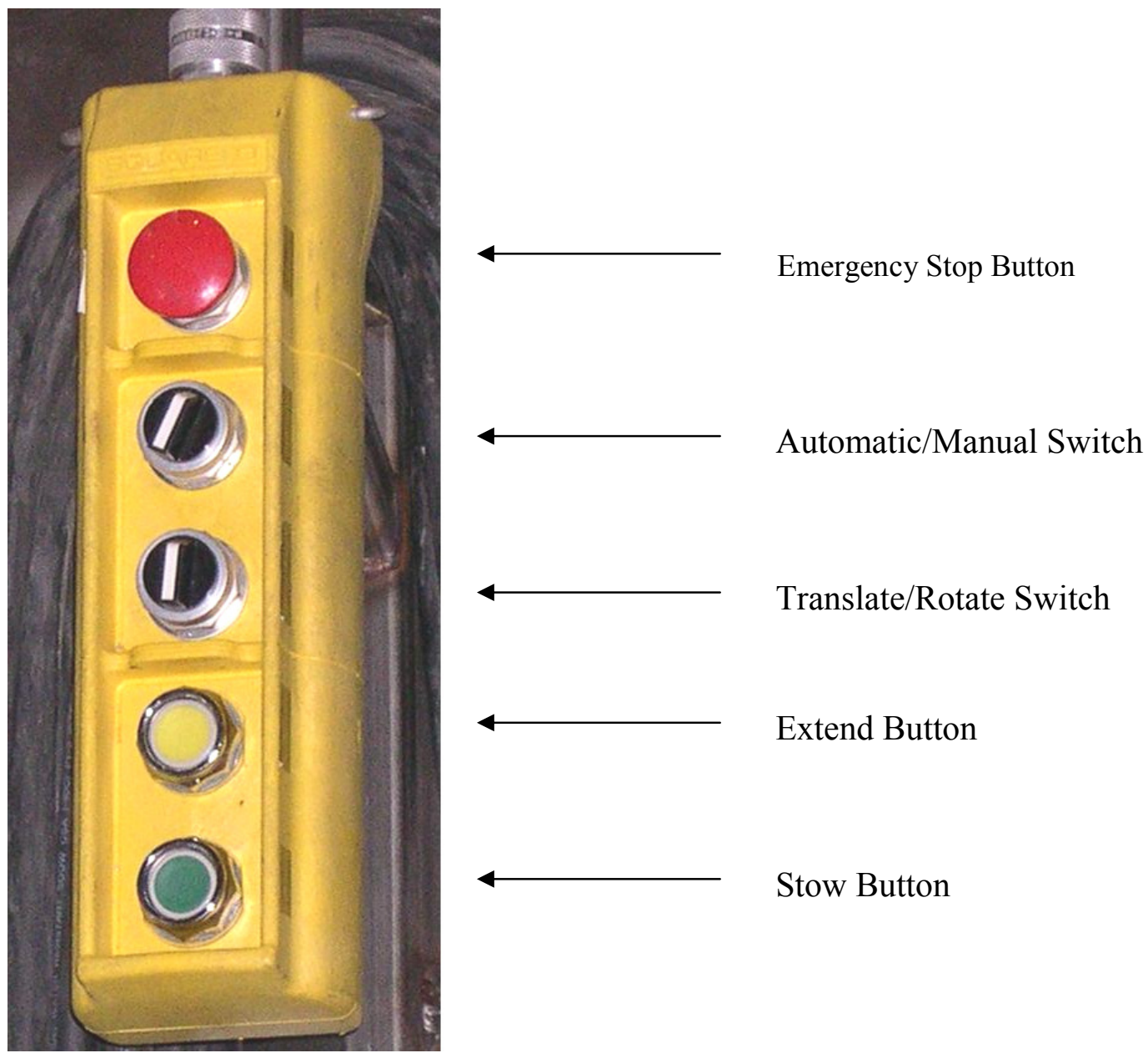

Figure 1.14: Pendant with Pushbutton/Switch Layout 


\subsection{Statement of the Thesis Project Problem}

Project Oculus required electrical design of rotational and translational motors power, interface design, automatic mode control, and sensors for detecting the translating plate and rotational arm positions.

The rest of this document is intended to detail the design of the sensor pallet electrical components and the development of the automatic mode Programmable Logic Controller (PLC) program. The circuit designed to implement the desired functions will be discussed, as well as the hardware chosen to build the circuit. Also, the development of the PLC software will be discussed thoroughly, complete with a tutorial on the use of the PLC programming software and ladder programming in general. All circuit diagrams, component data sheets, and the PLC program are available in the appendices at the end of the document. 


\section{Chapter 2: Project Background}

For Project Oculus to be a success, the WVU-CIRA electrical engineers had to do some preliminary background work before they could proceed. The first topic of discussion was about how the implementation of the system would take place. Basically, a general overview of what the system would look like must first be discussed.

The second subject that needed to be researched was for a power source for the system once it had been loaded onto the plane. The engineers needed to know the type of power that is generated and where the power outlets were located in the C-130 Ro-Ro cargo area.

Third, a study of the types of proximity sensors that are commercially available for the system must be conducted. When designing and building the control circuit for the Sensor Pallet, the engineers will be using some type of position sensors to sense the position of the sensor head. The various strengths and weaknesses of the different kinds of proximity sensors need to be identified so that the best position sensor for the job is chosen.

The last topic of discussion here will be programming PLC's, most notably, programming with the DirectSoft $32^{\odot}$ software. In Chapter 4 , it will be discussed that the D0-06DD2 PLC available from Automation Direct is chosen to run Automatic mode and that the DirectSoft32 ${ }^{\odot}$ software, designed specifically for programming with the DL06 PLC processor, is the tool that one uses to program this PLC. Before programming the PLC, the engineer had to learn how to use the software; this background discussion will teach the reader how to use the software as well. 


\subsection{General Overview of Project Oculus}

For the WVU-CIRA electrical engineers, there are several issues that must be solved during the design and building process of Project Oculus. Here, a quick overview of the problems and proposed solutions are discussed. The design of these circuits and programs are discussed further in future chapters.

First, the problem of supplying power to the sensor pallet had to be solved. The proposed solution is to use the 28VDC 200Amp power supply connector on the bulkhead of the C-130. The Operator Station would plug into this power source and then with the use of an inverter convert the DC power to split-phase 220VAC $60 \mathrm{~Hz}$. Using a power outlet connector on the external panel of the Operator Station, the Sensor Pallet can plug into the power generated in the Operator Station. Using the 220VAC split-phase, the translational motor can be supplied with $110 \mathrm{VAC} 60 \mathrm{~Hz}$ and the rotational motor can be supplied with 220VAC 60Hz.

Once the power is available to the motors on the sensor pallet, the question of controlling the motors through manual and automatic modes had to be designed. For the proposed solution, the pendant that was pictured before will be used with the same buttons and switches. The pendant will use a 24VDC signal to engage relays that send the $110 \mathrm{VAC} 60 \mathrm{~Hz}$ power to the translational motor or generates 3 -phase $220 \mathrm{VAC} 60 \mathrm{~Hz}$ power to the rotational motor.

Finally, how will automatic mode be controlled? Automatic mode will be run by a Programmable Logic Controller (PLC). It will respond to inputs from the user (Extend button or Stow button pushed) and sensors that identify the position of the translating plate and the rotational arm. These sensors will take the form of capacitive proximity 
sensors that will be strategically placed on the pallet and the translating plate. There will also be LED indicators mounted somewhere on the Sensor Pallet with the purpose of communicating the progress of the Sensor Pallet deployment procedure to the user. These LED's can be driven by the PLC or the proximity sensors, or a combination of both. The exact layout of LED's will be discussed in the design.

\subsection{C-130 Power Sources}

Project Oculus requires an ample amount of power to be functional. For an estimate of the power required by the system, please see Appendix 2 "Project Oculus Power Budget". Where will this power come from once the system has been loaded onto the plane? The WVU-CIRA electrical engineers needed to know this information before they could design the power interface circuit that will reside in the Operator Station.

After making a visit to the Air National Guard base in Charleston, WV, to study a $\mathrm{C}-130$, the engineers were able to gather the information they required. All C-130 airplanes generate both $28 \mathrm{VDC}$ and $115 / 200 \mathrm{VAC} 400 \mathrm{~Hz}$ power. Though some of the planes also supply $115 / 200 \mathrm{VAC} 60 \mathrm{~Hz}$ power, the Project Oculus engineering team could not design the system with the assumption that this power supply would be available onboard any given plane used to deploy the system. There are various power outlets available in the cargo bay area, as well. A summary of these power outlets, with voltage and current supplied, connector manufacturer, connector model number, and the calculated power available from that power outlet is shown below in Table 2.1. 
Table 2.1: Overview of Power Outlets in C-130 Cargo Bay

\begin{tabular}{|c|c|c|c|c|c|c|c|c|}
\hline Location & $\begin{array}{l}\text { Connector } \\
\text { Label }\end{array}$ & $\begin{array}{l}\text { Voltage } \\
\text { Label }\end{array}$ & $\begin{array}{l}\text { Current } \\
\text { Label }\end{array}$ & $\mathrm{AC}(\mathrm{Hz}) / \mathrm{DC}$ & Connector MFG & Connector Model & \begin{tabular}{|l|} 
Calc Power \\
(Watts)
\end{tabular} & Wire Size \\
\hline Jump Door & $\begin{array}{l}\text { DC outlet } \\
\text { Iron Lung } \\
\text { Galley }\end{array}$ & \begin{tabular}{|l}
$28 \mathrm{~V}$ \\
$28 \mathrm{~V}$ \\
$115 \mathrm{VAC}$ \\
\end{tabular} & $\begin{array}{l}10 \mathrm{~A} \\
25 \mathrm{~A} \\
20 \mathrm{~A}\end{array}$ & \begin{tabular}{|l}
$\mathrm{DC}$ \\
$\mathrm{DC}$ \\
$400 \mathrm{~Hz}$ \\
\end{tabular} & \begin{tabular}{|l} 
Hubbel \\
Amphenol \\
Bendix \\
\end{tabular} & \begin{tabular}{|l}
$7526 \mathrm{M} 2$ \\
MS 3102R-24-9S \\
MS 3102A-20-4S \\
\end{tabular} & $\begin{array}{r}280 \\
700 \\
2300 \\
\end{array}$ & $\begin{array}{l}10 \text { AWG } \\
4 \mathrm{AWG} \\
12 \mathrm{AWG}\end{array}$ \\
\hline $\begin{array}{l}\text { Winch Cable } \\
\text { (forward } \\
\text { bulkhead) }\end{array}$ & $\begin{array}{l}\text { DC outlet } \\
\text { rectangular } \\
\text { (small round) } \\
\text { (big round) } \\
\end{array}$ & $\begin{array}{l}28 \mathrm{~V} \\
28 \mathrm{~V} \\
28 \mathrm{~V} \\
115 / 200 \mathrm{VAC} \\
\end{array}$ & $\begin{array}{l}200 \mathrm{~A} \\
200 \mathrm{~A} \\
10 \mathrm{~A} \\
50 \mathrm{~A} \\
\end{array}$ & \begin{tabular}{|l}
$\mathrm{DC}$ \\
$\mathrm{DC}$ \\
$\mathrm{DC}$ \\
$400 \mathrm{~Hz}$ \\
\end{tabular} & \begin{tabular}{|l} 
AMFS America \\
Fleet Service \\
Hubbel \\
Bendix \\
\end{tabular} & \begin{tabular}{|l} 
? \\
AN2552-3A \\
$7526 \mathrm{M} 2$ \\
MS 3102R-22-22S \\
\end{tabular} & $\begin{array}{r}5600 \\
280 \\
5750 @ 115 \\
\end{array}$ & $\begin{array}{l}\text { "0" AWG } \\
10 \text { AWG } \\
8 \text { AWG }\end{array}$ \\
\hline $\begin{array}{l}\text { Forward Right } \\
\text { Side }\end{array}$ & $\begin{array}{l}\text { DC outlet } \\
\text { Iron Lung } \\
\text { Galley } \\
\text { (giant round) }\end{array}$ & $\begin{array}{l}28 \mathrm{~V} \\
28 \mathrm{~V} \\
115 \mathrm{VAC} \\
115 \mathrm{VAC}\end{array}$ & $\begin{array}{l}10 \mathrm{~A} \\
25 \mathrm{~A} \\
20 \mathrm{~A} \\
20 \mathrm{~A}\end{array}$ & $\begin{array}{l}\mathrm{DC} \\
\mathrm{DC} \\
400 \mathrm{~Hz} \\
400 \mathrm{~Hz}\end{array}$ & $\begin{array}{l}\text { Hubbel } \\
\text { Amphenol } \\
\text { Bendix } \\
\text { Bendix }\end{array}$ & $\begin{array}{l}7526 \mathrm{M} 2 \\
\text { MS 3102R-24-9S } \\
\text { MS 3102A-20-4S } \\
\text { MS 3102A-18-10S }\end{array}$ & $\begin{array}{r}280 \\
700 \\
2300 \\
2300\end{array}$ & $\begin{array}{l}10 \text { AWG } \\
4 \text { AWG } \\
12 \text { AWG } \\
14 \text { AWG }\end{array}$ \\
\hline
\end{tabular}

One power source in this table is significant. At the Winch Cable, located at the forward bulkhead, there is a "rectangular" power outlet, part number AN2552-3A, that supplies 28VDC 200A, for a total amount of power of 5600W. Preliminary calculations suggest that that should be enough power for Project Oculus to function. However, if this power source is used, a rather large and heavy cable (Table 2.1 refers to it as " 0 " AWG cable, but 2/O AWG cable will be used) will have to be used to connect the Winch Cable power outlet to the Operator Station. This might make the system cumbersome to use, a result that may make potential customers reluctant to use the system.

As an alternative solution, the engineers may be able to use a combination of the $400 \mathrm{~Hz}$ power supplies that are available. There are two power outlets available at the "forward right side" of the plane, the galley and a round connector, that provide up to $2300 \mathrm{~W}$ of $400 \mathrm{~Hz}$ power each. Because these outlets are not as high current as the AN2552-3A, the cables connecting to these outlets would not have to be nearly as thick and heavy. However, this poses a new problem; no computers, monitors, or radios operate on $400 \mathrm{~Hz}$ power. Therefore, there would have to be some sort of "frequency 
changer" residing in the Operator Station that could turn the $400 \mathrm{~Hz}$ power down to $60 \mathrm{~Hz}$. Though this sounds easily done, a frequency changer that could perform this operation and meet aircraft specifications would be a rather expensive solution. Thus, the AN25523A DC power outlet was chosen as the power source for the system while on the plane. This is discussed further in Chapter 3.

\subsection{Proximity Sensors Study}

There are several kinds of proximity sensors commercially available: mechanically, inductive, capacitive, photoelectric, and ultrasonic. Before the WVUCIRA electrical engineers can decide which proximity sensor is right for Project Oculus, a knowledgeable study about each type was conducted. Presented here are the findings of this study.

\subsubsection{Inductive Proximity Sensors}

Inductive proximity sensors are intended to be non-contact sensors that detect the presence, or lack thereof, of ferrous material. The ideal target for sensing is mild steel, more than $1 \mathrm{~mm}$ thick, and is at least the same diameter as the sensing face of the device. The four major components of an inductive proximity sensor are (1) a ferrite core with coil, (2) an oscillator, (3) a Schmitt trigger, and (4) an output amplifier [7]. These components are illustrated in Figure 2.1 shown below. 


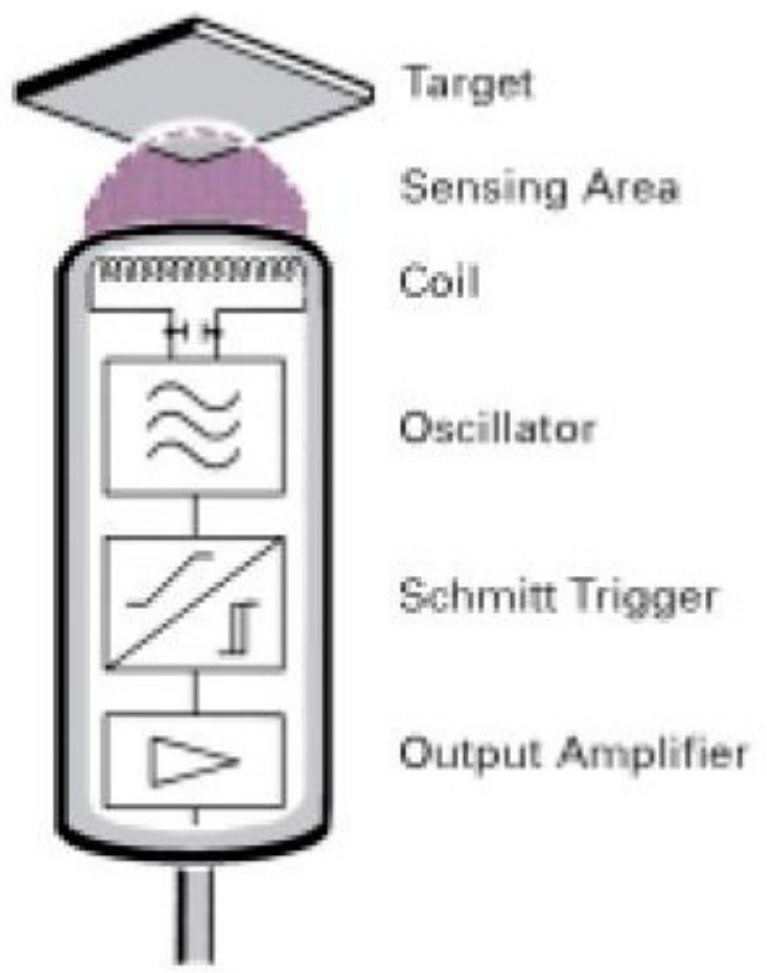

Figure 2.1: Components of an Inductive Proximity Sensor [7]

The inductive proximity sensor works by using a magnetic field. The oscillator creates a symmetrical oscillating magnetic field which radiates out through the coil array and extends out past the sensing face, making up the "sensing area" shown in Figure 2.1. Whenever a magnetic metal is placed in the sensing area, Eddy currents are induced on the face of the metal, hence the name "inductive" proximity sensor. This creates a power loss in the amplitude of the magnetic field produced by the oscillator, which is known as the Eddy Current Killed Oscillator (ECKO) principle. The reduced amplitude in the oscillations is "noticed" by the Schmitt trigger, which then generates and sends an output that the object has been detected [7].

Because of the limitations of magnetic fields, inductive proximity sensors have a very small sensing range from fractions of a millimeter to up to $60 \mathrm{~mm}$. The speed of an 
inductive proximity sensor is rather fast, as well; $10-20 \mathrm{~Hz}$ for most AC models, and 500$5 \mathrm{kHz}$ for DC models. Inductive proximity sensors are also rather rugged in design and nature, and they are equipped to handle any environment [7].

\subsubsection{Capacitive Proximity Sensors}

Capacitive proximity sensors give the user a few more options than the inductive proximity sensors. By design, capacitive sensors can sense any material and are not limited to detecting ferrous material like the inductive sensors. Capacitive sensors are comprised of (1) two plates (acting as an open capacitor), (2) an oscillator, (3) a Schmitt trigger, and (4) an output amplifier [7]. A diagram of the capacitive proximity sensor is shown in Figure 2.2 below.

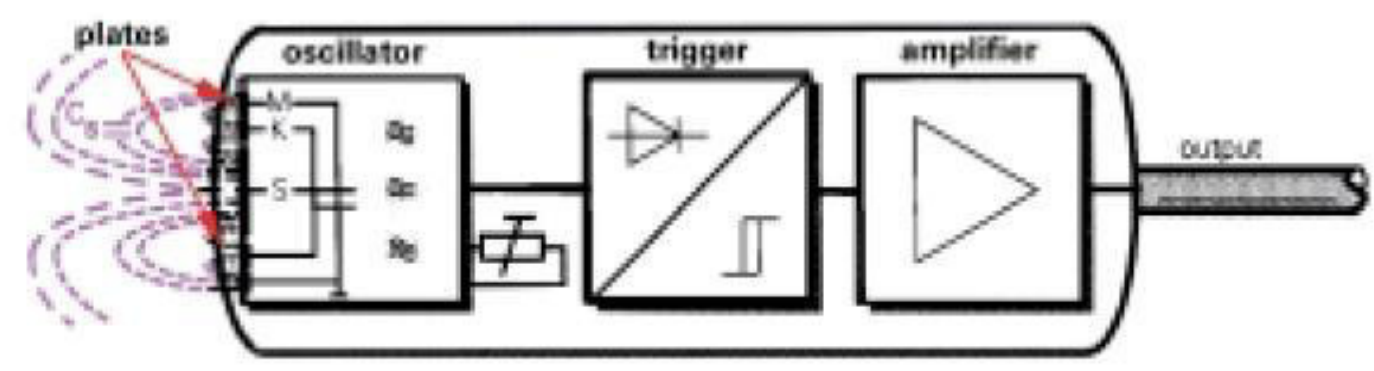

Figure 2.2: Components of a Capacitive Proximity Sensor [7]

The capacitive proximity sensor works by using the properties of the open capacitor. When an object enters the sensing area, the capacitance between the two plates increases and causes the oscillator to increase its oscillations. This is registered by the Schmitt trigger, which generates and sends the detecting output. The capacitive proximity sensor works in a "reverse" way as the inductive proximity sensor; the inductive sensor senses when the oscillations of the oscillator lose amplitude, the 
capacitive sensor senses when the amplitude of the oscillations of the oscillator increases $[7]$.

This operating principle of the capacitive sensor makes it slightly slower than the inductive sensor, usually ranging from $10-50 \mathrm{~Hz}$. Their sensing range is comparable to inductive sensors, ranging anywhere from 3-60 $\mathrm{mm}$ [7]. They are also ruggedly built and are ideal for any rough environment. Extra care must be taken when mounting these sensors, however; since they sense any material, they could pick up something else in the environment and be falsely triggered.

\subsubsection{Photoelectric Proximity Sensors}

Photoelectric proximity sensors are the fastest growing field of proximity sensors available. They have one of the greatest sensing distances obtainable, and can detect objects as small as $0.01 \mathrm{~mm}$ in diameter. Though there are several flavors of the photoelectric sensor, each one has a few basic parts: (1) an emitter, a light source such as an LED or a laser diode, (2) a photodiode or phototransistor receiver to detect this light source, and (3) supporting electronics to amplify the signal relayed from the receiver. The three kinds of photoelectric proximity sensors are Through-Beam sensors, RetroReflective sensors, and Diffuse sensors [7].

\subsubsection{Through-Beam Photoelectric Sensors}

Through-Beam sensors separate the light source and the receiver from one another. The light source is beamed to the receiver; detection occurs when an object passes through the beam of light and the receiver fails to receive the beam [7]. Figure 2.3 illustrates the use of a Through-Beam photoelectric sensor. 


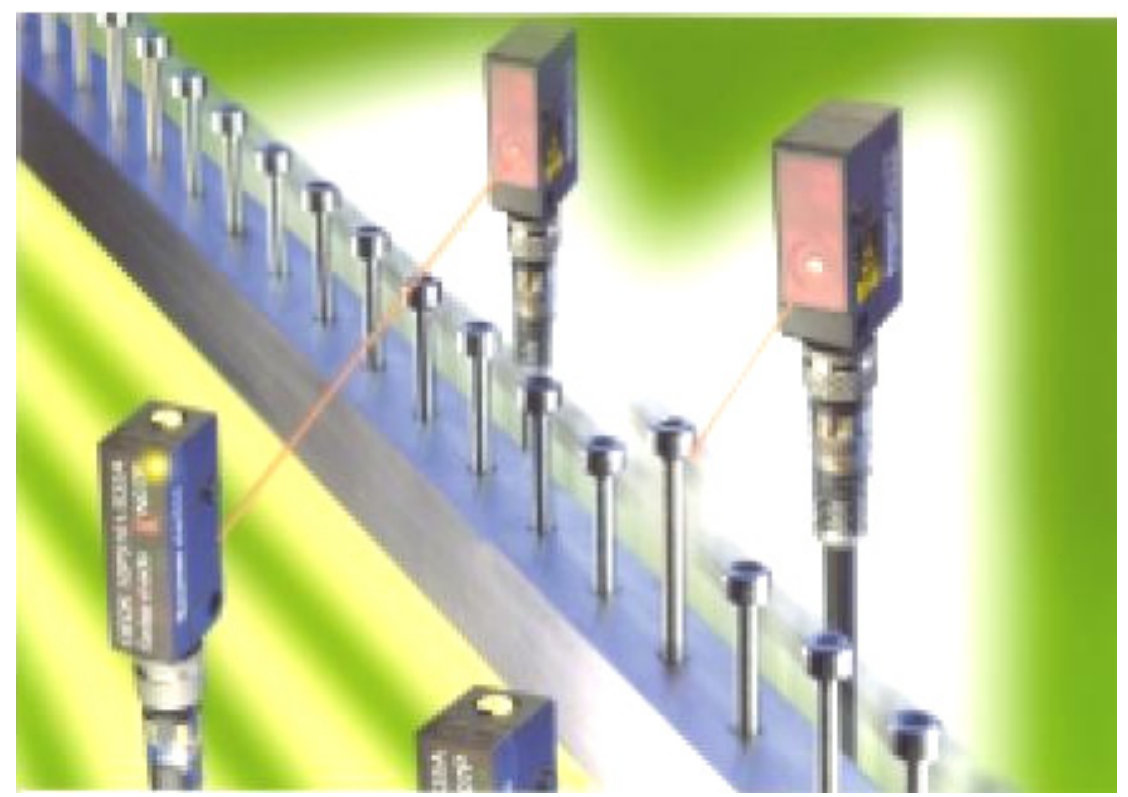

Figure 2.3: Through-Beam Photoelectric Sensors [7]

Depending on the light source, these units can offer detecting distances of up to $60 \mathrm{~m}$. Even at these distances, an object $3 \mathrm{~mm}$ in diameter can be sensed, and at closer ranges, an object only $0.01 \mathrm{~mm}$ in diameter can be detected. The speed of sensing is generally the same for all light sources, which is $500 \mathrm{~Hz}[7]$. These sensors are good for most environments; they can detect objects even with the presence of dirt or other contaminants in the air. However, this type of sensor requires the user to wire up both the transmitter and the receiver; the transmitter must have power to operate, and the receiver generates the output. This could be a drawback on the use of this sensor, depending on the application.

\subsubsection{Retro-Reflective Photoelectric Sensors}

The Retro-Reflective sensor works on the same general concept of the ThroughBeam sensor. Instead of mounting the receiver on the other side of the beam of light, 
however, the receiver and emitter are together in the same housing. The receiver sees the beam of light from a reflector mounted on the other side of the sensing area. Detection occurs when the beam is broken, meaning that the beam is no longer being reflected back to the receiver, causing the receiver to generate a detecting output [7]. Figure 2.4 illustrates the use of a Retro-Reflective photoelectric sensor.

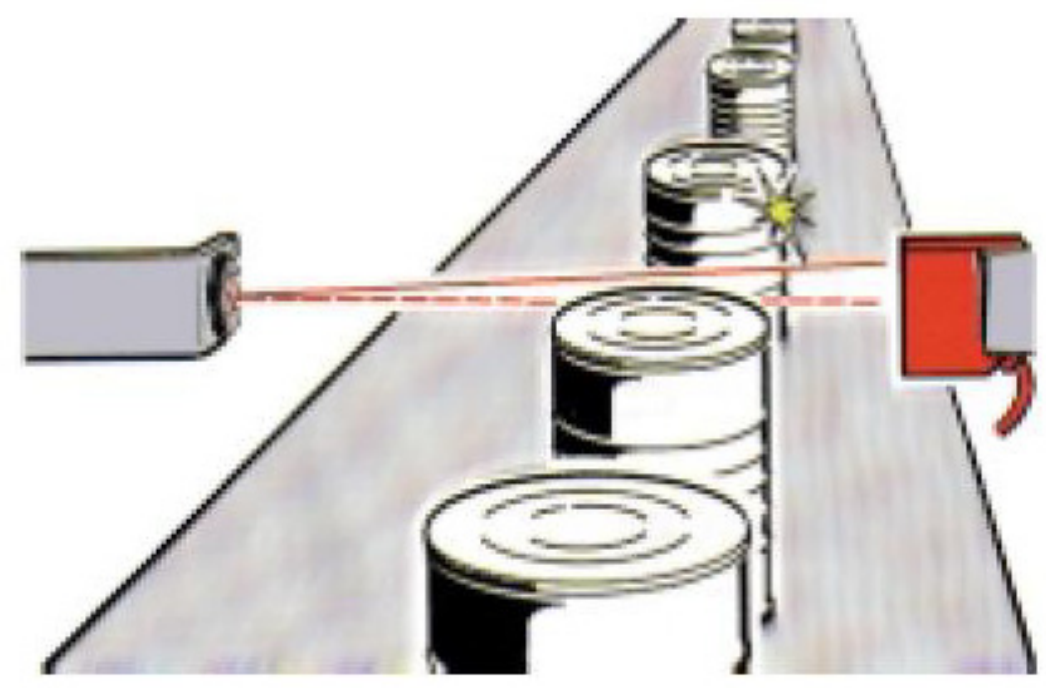

Figure 2.4: Retro-Reflective Photoelectric Sensors [7]

This is done to solve the problem with Through-Beam sensors, where it may be difficult to wire up both the transmitter and receiver; here, they are in the same area and should be easier to get to. Sensing distances for this type of sensor range up to $10 \mathrm{~m}$.

\subsubsection{Diffuse Photoelectric Sensors}

Diffuse sensors work on a little bit different concept as the Retro-Reflective sensors. Again, the transmitter and receiver are housed together. Instead of using a reflector for the beam, however, these sensors use the object itself as the reflector. Detection, then, does not occur when the beam is "broken"; rather, detection occurs when 
an object reflects the beam back to the receiver [7]. Figure 2.5 illustrates the use of a diffuse photoelectric sensor.

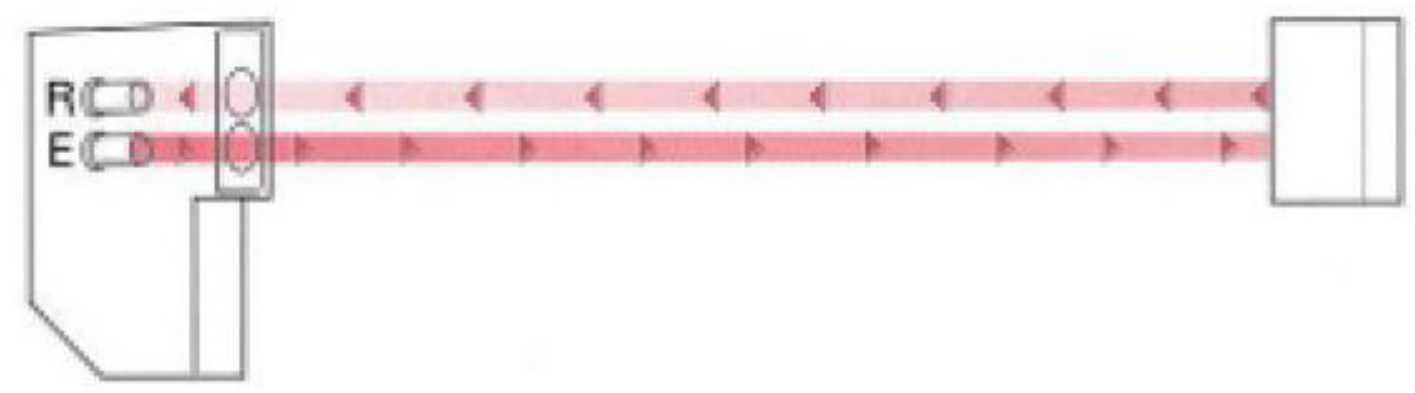

Figure 2.5: Diffuse Photoelectric Sensor [7]

This operating principle means that the diffuse sensor is limited by the object it is meant to detect. If the object does not reflect light, or is oriented in a certain fashion so that it does not reflect the light back to the receiver, the sensor will not work. Also, background objects could reflect the light back to the receiver and cause a false trigger. Therefore, these sensors cannot be used in all environments.

\subsubsection{Ultrasonic Proximity Sensors}

Ultrasonic sensors employ the use of sound waves instead of light beams to detect objects. Because they use sound waves, they are not limited by the objects color, transparency, or orientation; however, they are subject to the texture of the object. But for the most part, they can detect just about any object. They come in the same flavors as photoelectric sensors: Through-Beam, Retro-Reflective, and Diffuse [7].

Ultrasonic sensors use a special sonic transducer that not only emits a series of sonic pulses but also can receive the reflected sound waves. When the sensor "hears" the reflected pulses, it generates an output of detection. At the same time, this type of sensor 
can also tell the distance from the sensor to the detected object. This may be important information to know for certain types of applications. Sensing distances for these sensors range up to $2.5 \mathrm{~m}[7]$.

\subsection{DirectSoft32 ${ }^{\odot}$ Programming Tutorial}

In Chapter 4, the selection of the D0-06DD2 PLC as the device to control Automatic mode of deployment of the Sensor Pallet is discussed at length. Here, the use of the programming software for that PLC, which is called DirectSoft32 ${ }^{\circ}$, will be discussed. In this abbreviated tutorial, only the software features needed to program Project Oculus are covered. Subjects covered here are getting started with the software, intro to ladder programming, entering normally open/closed contacts, programming with PLC timers, and setting/resetting PLC memory locations. Whenever appropriate, screenshots will be included for the reader's convenience. For a complete overview of the software and its features, please see the user's manual that accompanied this software.

\subsubsection{Introduction to Ladder Programming}

Ladder programming is rather different from any other kind of programming. In many ways, ladder programming is easier than programming in one of the popular programming languages such as $\mathrm{C}, \mathrm{C}++$, or even Visual Basic. One of the major differences is that when running a program written in any of these languages, the program runs through once, finishes, and does not continue. With PLC ladder programming, the PLC continues to scan the inputs, running through the program over and over again, without the programmer having to include loops of any kind. This is an 
important feature because PLC users want the program to be running continuously, always checking the inputs and reacting accordingly.

The basic principle of ladder programming is to think of the program as one would think of an electrical circuit. The "power line" runs down the left side of the ladder programming window. To turn on the outputs, which are placed on the right end of each "ladder rung", the contacts or conditions placed on the ladder rung must be true, thereby relaying the power from the "power line" to the output. Therefore, if there are no conditions or contacts placed on the rung, the output will always be true. If any or all of the conditions on the rung are false, the output will not be turned on. Ladder rungs can also be placed in parallel; this way, an output can be turned on with several different combinations of contacts and conditions, just like a parallel electrical circuit.

The DirectSoft $32^{\odot}$ graphical interface software makes ladder programming rather easy. The next section will teach the reader how to use this programming software.

\subsubsection{DirectSoft32 ${ }^{\odot}$ - Getting Started}

Upon starting the DirectSoft32 ${ }^{\odot}$ software, the "DSLaunch" window is displayed. Figure 2.6 shows a screenshot of the DSLaunch window. 


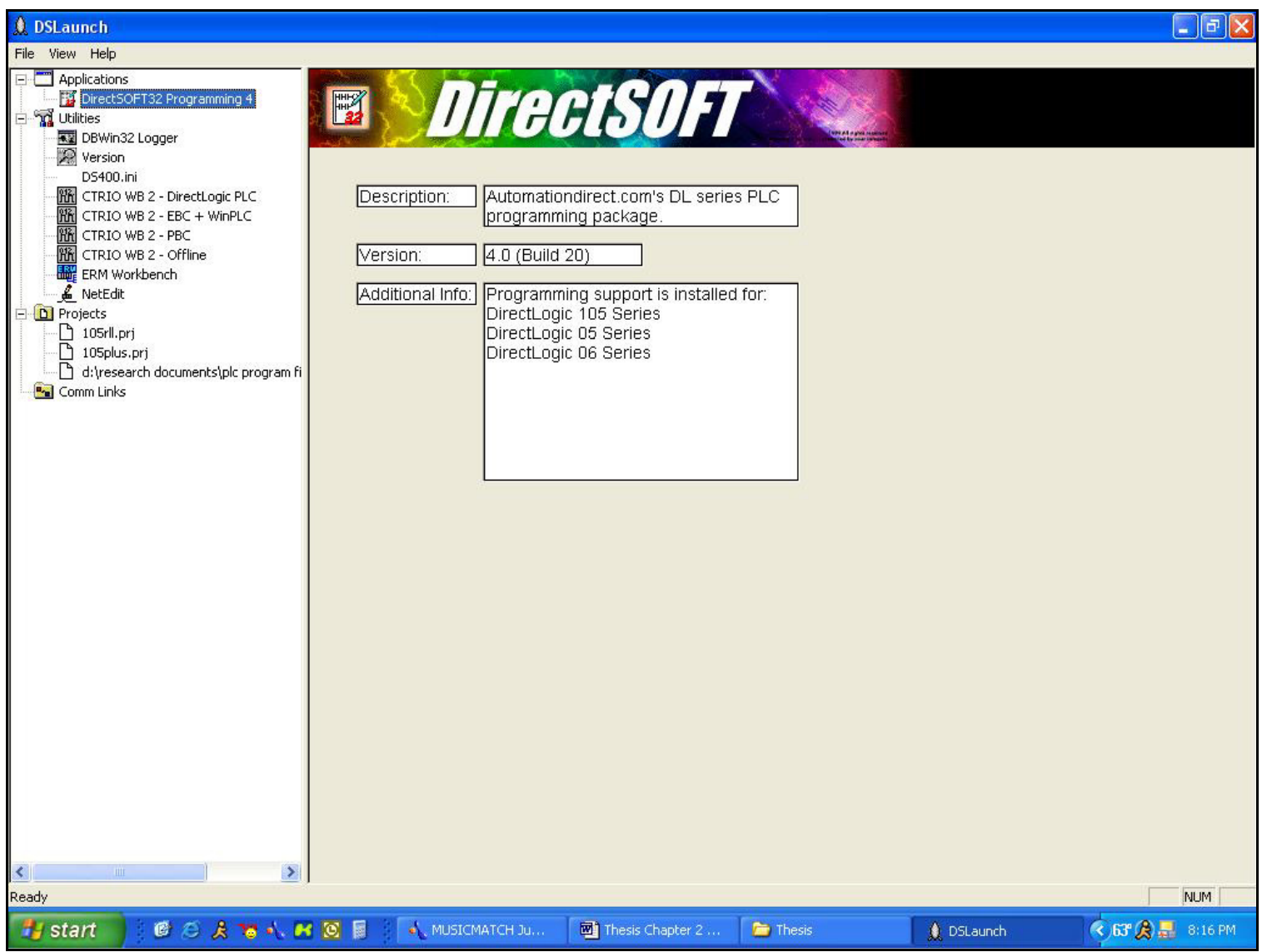

Figure 2.6: Screenshot of the DSLaunch Window

From this window, past projects can be viewed and opened, communication links to available PLC's can be viewed, and the utilities provided by the software can be manipulated. The programming application can be launched from this window by double-clicking "DirectSoft $32^{\odot}$ Programming 4" located at the top left corner of the screen. After double-clicking this icon, the screenshot shown in Figure 2.7 is displayed. 


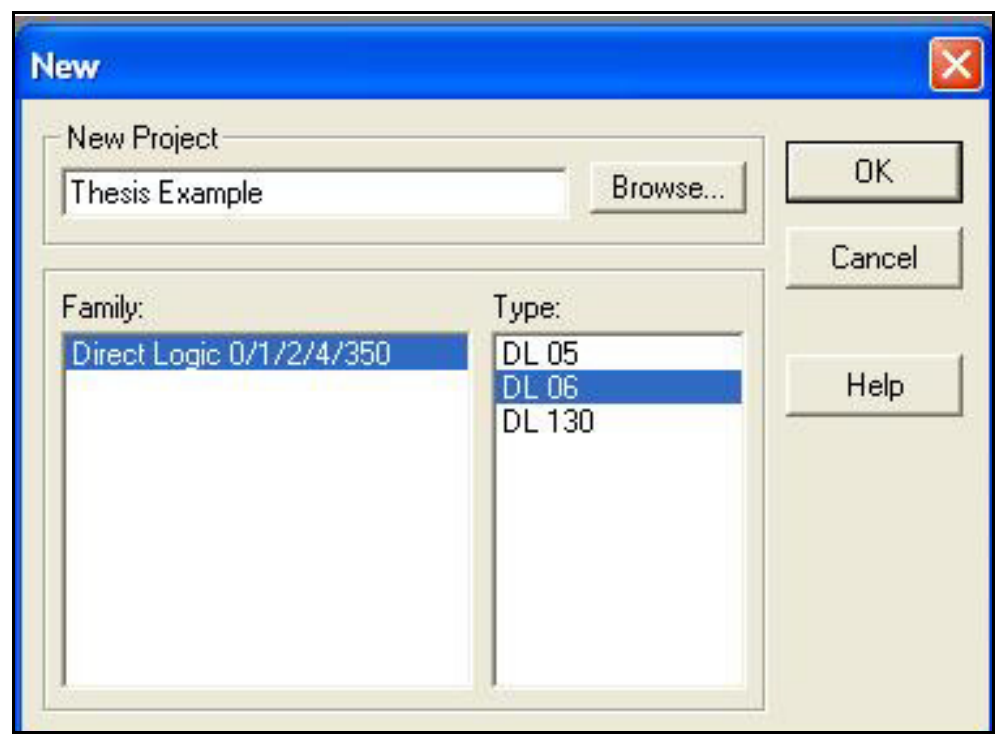

Figure 2.7: Open New Project Screen

This is the New Project screen. In the "New Project" title box, type the new project name; the example here will be called "Thesis Example". The D0-06DD2 PLC has the DL06 processor, so DL06 has to be chosen in "Type" as well. Once this is done, click the "OK" button to see the Ladder View of the new project, which is shown in Figure 2.8. 


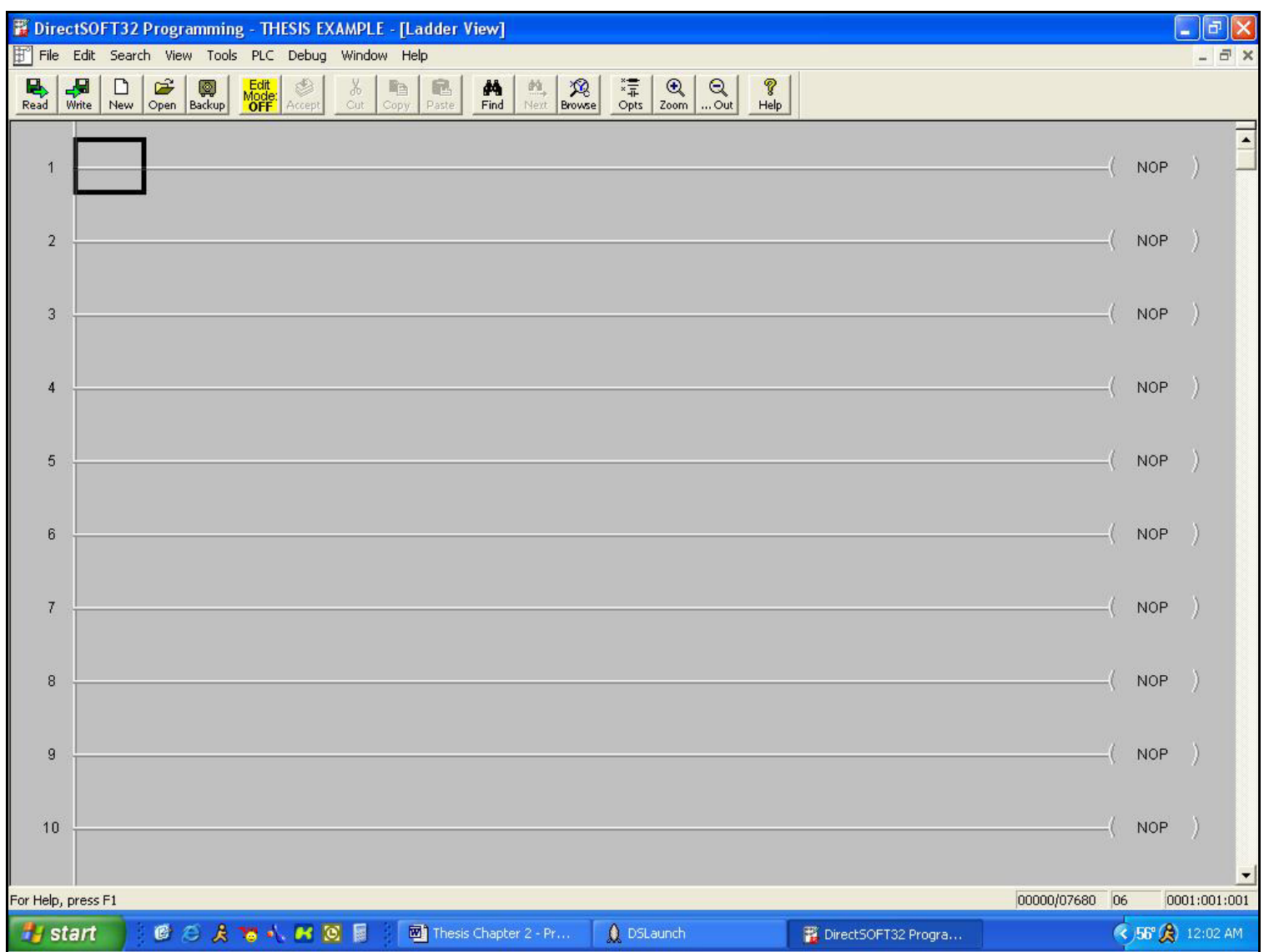

Figure 2.8: Ladder View of Project

Once the user has reached this point, he is ready to edit the new project. To edit the ladder program, the user must first click on the yellow "Edit Mode" button at the top of the screen. When it is yellow, it says "Edit Mode: OFF"; after clicking it, the button turns gray and says "Edit Mode: ON". When the Edit Mode is on, the user is supplied with a toolbar at the bottom of the screen, showing all the types of contacts that can be added to the program. This toolbar is shown in Figure 2.9 below.

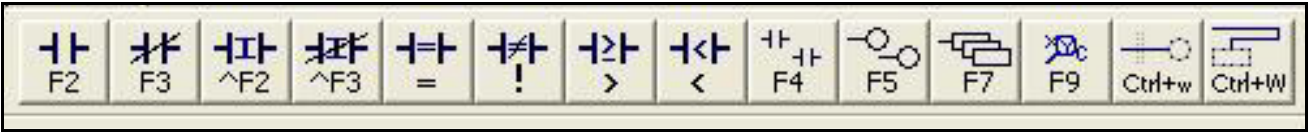

Figure 2.9: Program Editing Toolbar 


\subsubsection{Entering Contacts/Conditions onto Ladder Rungs}

To place a contact or condition on a ladder rung, the Edit Mode must first be turned on. Then, place the cursor on the ladder rung where the contact should be located. Next, identify whether the contact should be a normally open or normally closed contact. If a certain contact input should be "on" to make the output true, use the normally open contact. If the input should be "off", then use the normally closed contact. Once the correct contact has been chosen, the user should click on the corresponding button on the toolbar shown in Figure 2.9. The normally open contact is shown on the far left; the normally closed contact is the next one on the right. Once the correct button is clicked, the contact will appear on the ladder rung where the cursor was placed. At this point, the user should type in the input that should be scanned here; any input from X0-X23 will suffice. An example of each contact being entered is shown in Figure 2.10 below.
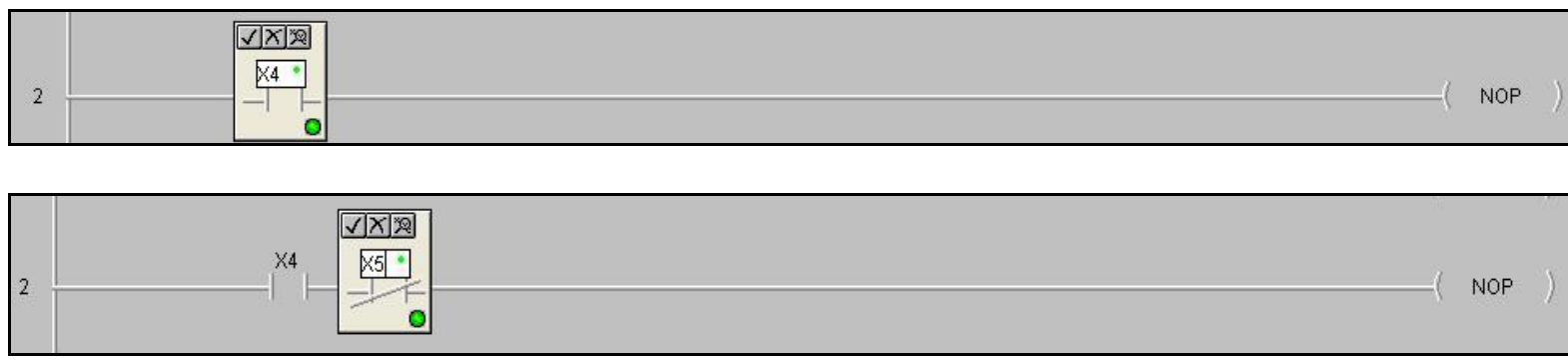

Figure 2.10: Entering Normally Open/Closed Contacts

The same process is used to enter a conditional statement on a ladder rung. The user can make a comparison, such as greater than, less than, equal to, or not equal to, between any two inputs or two memory locations. All the user needs to do is click on the corresponding button on the toolbar; the comparison buttons are the fifth through eighth buttons from the left. Once the button has been clicked, the "comparison contact" will 
appear where the cursor has been placed. Then the user can type in what inputs or memory locations that he wants to compare. Figure 2.11 shows the addition of a comparison contact.

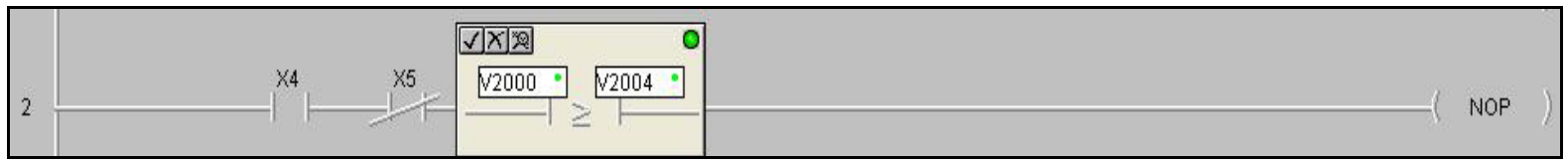

Figure 2.11: Entering a Comparison Contact

The user will also need to know how to enter parallel ladder rungs. To create a parallel ladder rung, first define the connection point from one ladder rung to the new parallel ladder rung and place the cursor at this point. Then, while holding down the Ctrl button, press the arrow keys to "draw" the rung into the program. The new ladder rung should be drawn until it terminates on the originating ladder rung or on the "power line." A parallel ladder rung is shown in Figure 2.12 below.

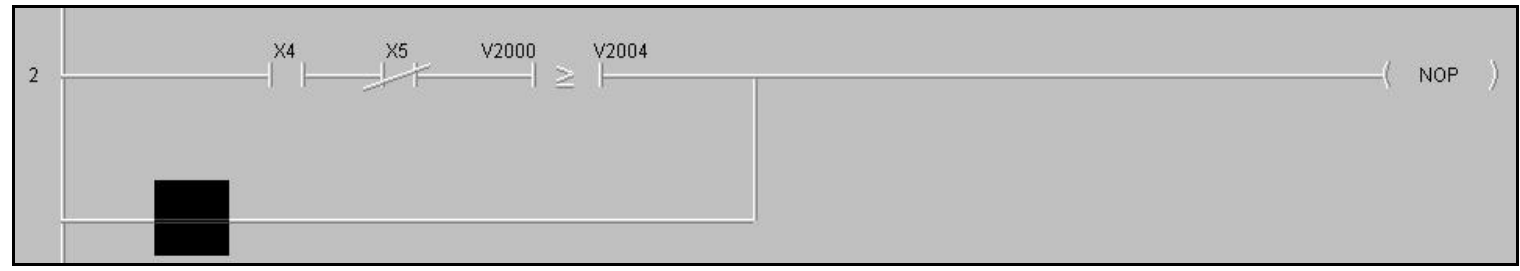

Figure 2.12: Adding a Parallel Ladder Rung

\subsubsection{Ladder Rung Outputs}

Now the user needs to learn how to set up outputs in a ladder program. The most basic output command, of course, is the "OUT" command. To program any output, first place the cursor on the output point of the ladder rung, normally designated with the letters "NOP" in parentheses. For the out command, just type the word "OUT" and press 
Enter. At this point, the software requires the user to type the output point that will be turned on, which can be any output from Y0-Y17. Figure 2.13 shows the adding of an "OUT" command.

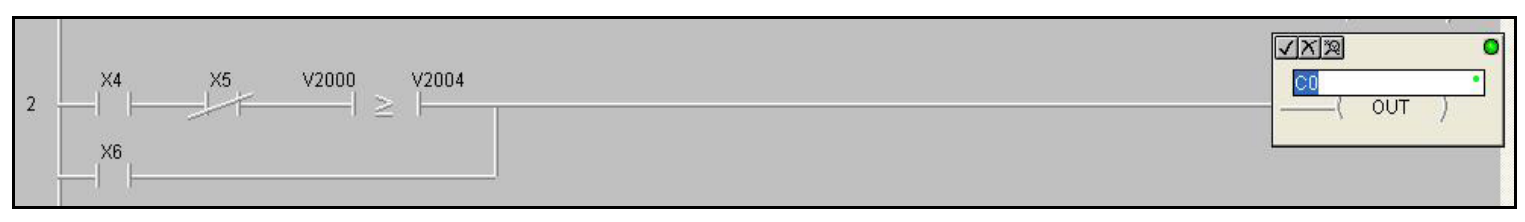

Figure 2.13: Adding an OUT Command

Another ladder rung output is writing messages to the LCD screen on the PLC. To begin, again place the cursor on an output point and type the letters "LCD". After pressing Enter, the screen shown in Figure 2.14 appears.

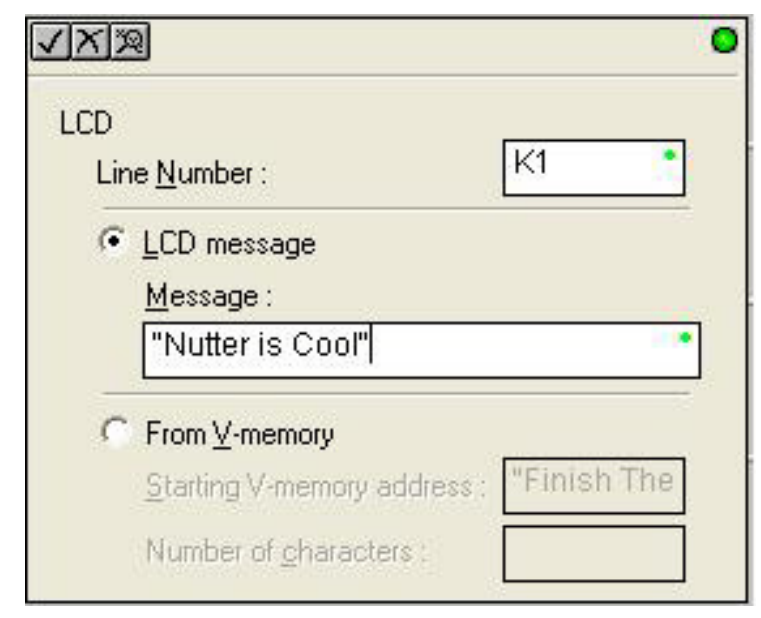

Figure 2.14: Defining an LCD Message

The LCD screen has two lines on which to display text. In this screen, the user can specify the line number on which to place the message. Using "K1" designates the first line; using "K2" designates the second line. Then, the message to be displayed is specified. In the message text box, the message should be typed, surrounded by 
quotation marks. The message is limited to 17 characters. Once finished filling out this screen, pressing the Enter button will finish adding the command. Figure 2.15 shows a completed LCD command statement.

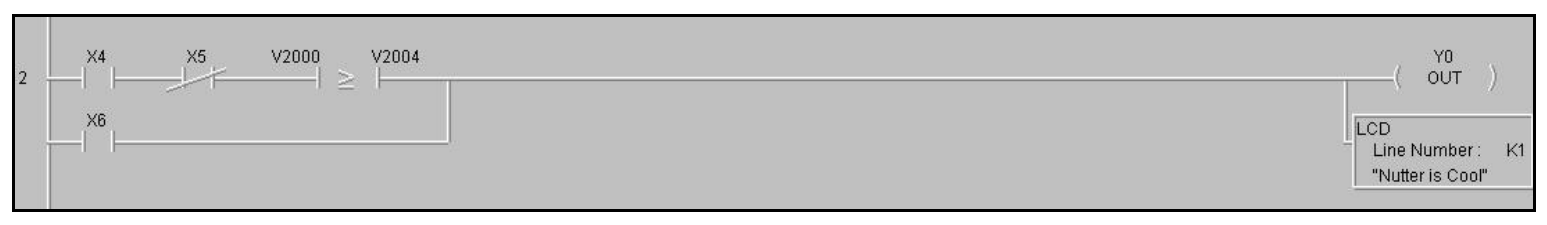

Figure 2.15: Adding an LCD Command

The next series of outputs deal with setting and resetting memory locations. To set a memory location, first highlight the output point with the cursor and then type "SET" and press Enter. At this point, the user can type in the memory location that he wants to set. Setting memory locations is important for applications like remembering button presses. To reset a memory location, again highlight the output point with the cursor and type "RST" before pressing Enter. Again, the user will be prompted to type in the memory location to reset. Figure 2.16 shows adding both a SET and RST command.
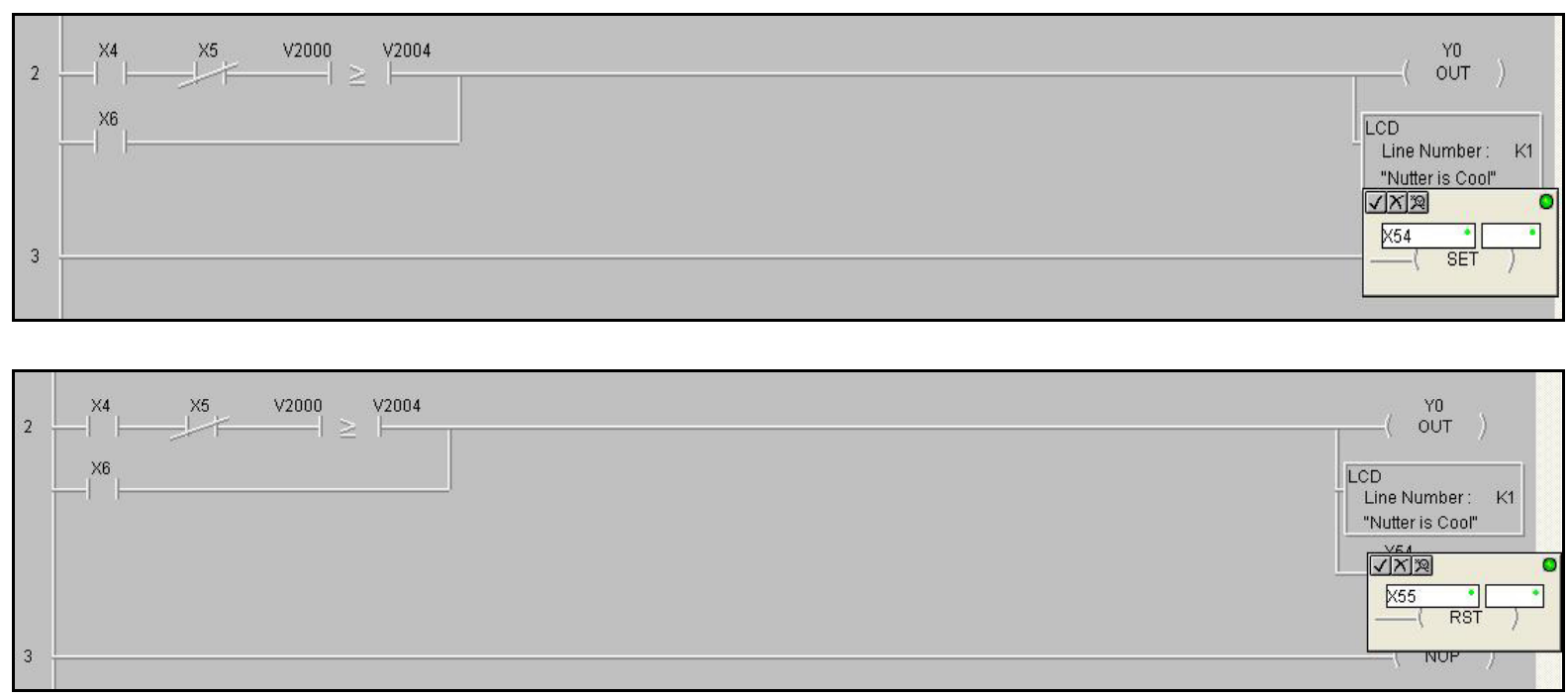

Figure 2.16: Adding SET and RST Commands 
The final output to be covered is timers. The D0-06DD2 PLC has 256 separate configurable timers available for use by the programmer. Each of the timers is numbered from T0-T377, based on the octal numbering system employed by the PLC. When the timer is in the output, that timer is set to a certain number of seconds, and the countdown begins immediately. To use the finished timer countdown, a normally open contact for that timer should be present on a ladder rung. To remember that the timer has finished its countdown, this normally open contact input could set a memory location at the output.

To program a timer, highlight the output point and type "TMR" before pressing Enter. The user will then be prompted to identify the timer to use and the number of seconds the timer will be programmed to count down. Time is specified in the following manner: if the user wants to program the timer for 3.0 seconds, he would type in K30 in the time field. This way, the user can specify fractions of a second; if the user wanted the timer to count 5.5 seconds, he would type K55. Figure 2.17 illustrates the adding of a timer to the program.

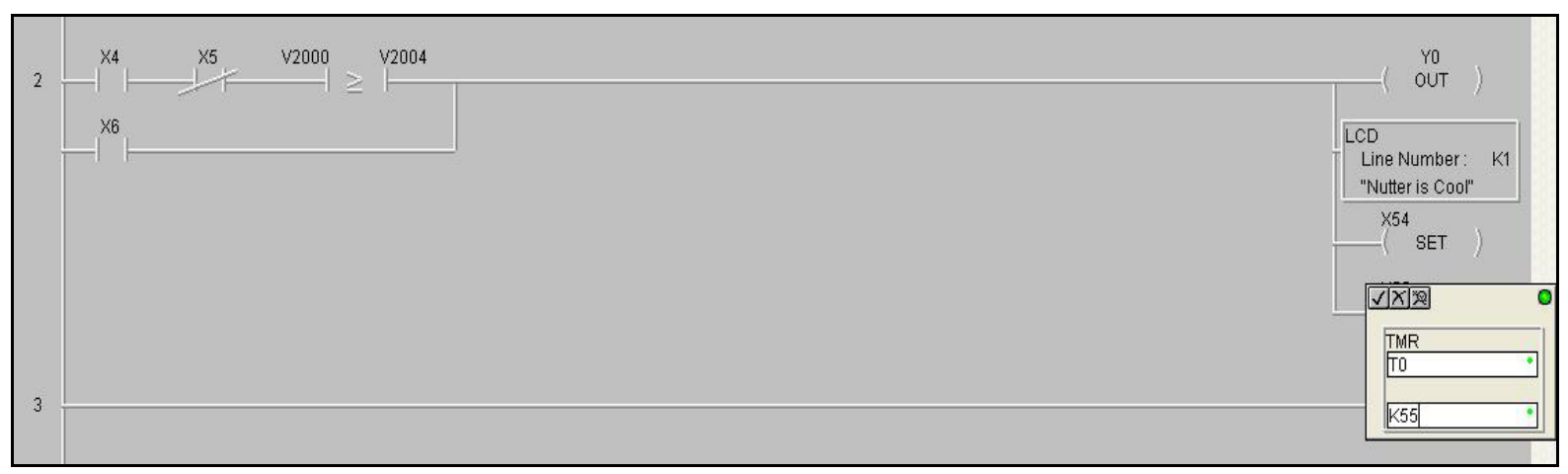

Figure 2.17: Adding a TMR Command 


\subsubsection{Optional Module Setup}

The D0-06DD2 PLC is equipped with four expansion slots for a multitude of optional modules that are designed to accommodate several different inputs and outputs. Two optional modules are used in the implementation of Automatic mode: the F0-04AD1 analog input board and the D0-08CDD1 digital input/output board. The D0-08CDD1 module is plug-and-play; the D0-06DD2 PLC automatically knows how to use the board for inputs and outputs. However, use of the F0-04AD-1 analog input module requires the programmer to instruct the D0-06DD2 PLC how to deal with the inputs from this module.

There are four instructions used when setting up the F0-04AD-1 module. The first instruction loads a constant that contains the number of channels to scan and the stored input data format requested by the user. This constant can be either K400 or K8400; the upper byte selects the data format $(0=\mathrm{BCD}$ and $8=$ Binary $)$ and the number of channels, here set to four for the 4-channel F0-04AD-1 [8].

Next, using the OUT command, this constant is stored in a special V-memory location assigned to expansion slot 1 of the D0-06DD2 PLC, which is the first slot on the left. The value stored in that $\mathrm{V}$-memory location configures the input data coming into that slot. All slots have an assigned V-memory location; the V-memory location corresponding to the expansion slot where the F0-04AD-1 must be used here [8]. Vmemory locations for the other slots can be found in Figure 2.18 below.

The third instruction is loading the octal value O2000 for the first V-memory location that will be used to store the incoming data, using the LDA command. By doing this, the incoming data from the 4-channels are designated as such: Channel 1 - V2000, 
Channel 2 - V2001, Channel 3 - V2002, Channel 4 - V2003. Any unused memory location can be used for this purpose; V2000 is used here in this system [8].

The final instruction outputs this value to a predetermined input pointer corresponding to the chosen expansion slot, using the OUT command. For the first expansion slot, the pointer is V-memory location V701 [8]. Figure 2.18 shown below shows the designated input pointer for each expansion slot.

\begin{tabular}{|l|c|c|c|c|}
\hline \multicolumn{5}{|c|}{ Analog Input Module } \\
\multicolumn{4}{|c|}{ DL06 Special V-memory Locations } \\
\hline Slot No. & 1 & 2 & 3 & 4 \\
\hline No. of Channels & V700 & V710 & V720 & V730 \\
\hline Input Pointer & V701 & V711 & V721 & V731 \\
\hline
\end{tabular}

Figure 2.18: Special V-Memory Locations for D0-06DD2 Expansion Slots [8]

In Chapter 4, the CLN-50 current sensor is discussed; this device creates the data that will be input to the F0-04AD-1 analog input module. This data will be compared to a value determined in Chapter 4, which is $10 \mathrm{~mA}$. However, the data that is stored in Vmemory location V2000 (Channel 1) is in Binary Coded Decimal (BCD) format. Therefore, 10mA needs to be converted to BCD and stored in the PLC memory for use in the program. The following formula converts $10 \mathrm{~mA}$ to $\mathrm{BCD}[8]$.

$$
\begin{gathered}
\mathrm{D}=(4095 / 16)(\mathrm{A}-4) \\
\mathrm{D}=(4095 / 16)(10 \mathrm{~mA}-4) \\
\mathrm{D}=255.93 * 6 \\
\mathrm{D}=1536
\end{gathered}
$$

To store this value, the constant K1536 is loaded and then stored to V-memory location V2004 using the OUT command [8]. In the Automatic mode program, V-memory locations V2000 and V2004 are compared to determine if the Sensor Pod has pulled up 
tightly against the butt plate on the C-130 door. These instructions are placed on an unconditional ladder rung at the beginning of the program. They are showed in Figure 2.19 below.

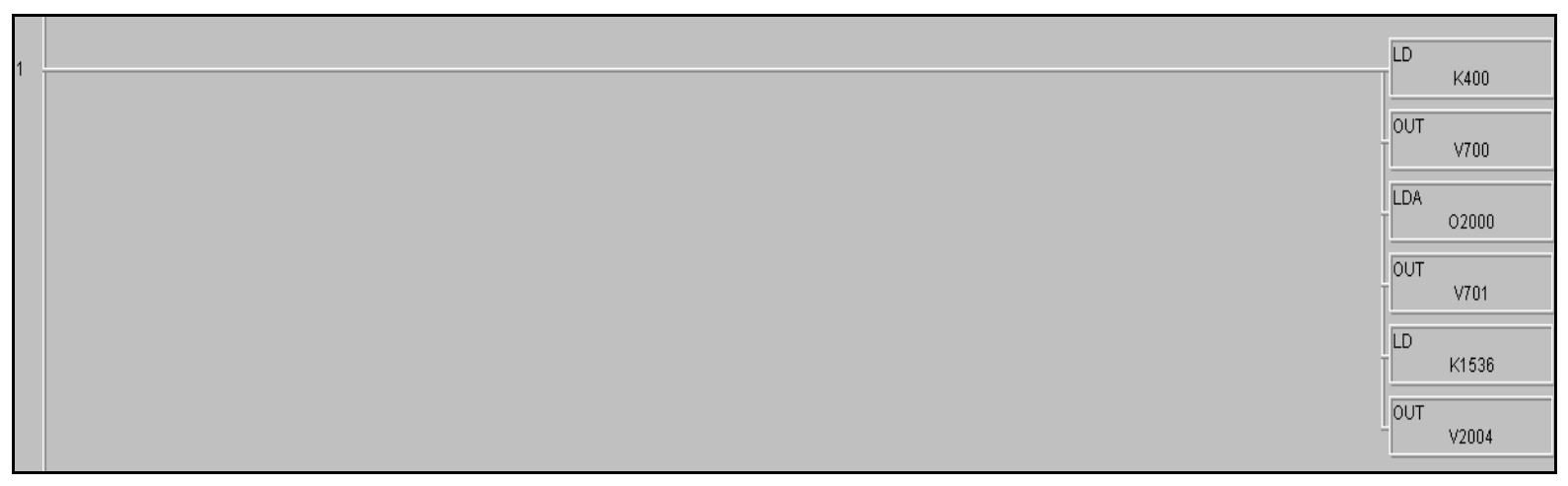

Figure 2.19: F0-04AD-1 Analog Input Module Setup

This concludes the project background section. The next chapter will begin to detail the circuit design that will power up and control Project Oculus. 


\section{Chapter 3: Project Oculus Circuit Design}

For Project Oculus to function correctly, the WVU-CIRA electrical engineers had several tasks to complete. First, the entire system, both the Operator Station and the Sensor Pallet, needs power in order to operate. As was discussed in the literature review presented in Chapter 2, most C-130 Ro-Ro airplanes only have two types of power available; 28VDC and $400 \mathrm{~Hz}$ AC power. There will most likely be a need for DC power to run certain sensors designed to operate on aircraft power, such as the Star Safire FLIR, but what about the computers, monitors, VCRs, and radios in the Operator Station and the motors on the Sensor Pallet? These devices all run off 110/220 VAC $60 \mathrm{~Hz}$ power, not $400 \mathrm{~Hz} \mathrm{AC}$ that is available on the plane. Therefore, the engineers need to design how to bring power into the system and invert it to $110 / 220 \mathrm{VAC} 60 \mathrm{~Hz}$ power that these devices can use. The second task to be undertaken by the WVU-CIRA electrical engineers is to design the control circuitry and user interface pendant to control Automatic and Manual modes on the Sensor Pallet. This chapter will discuss both of these tasks in depth, showing the circuit designs and hardware chosen to carry out the design.

\subsection{Operator Station Power Distribution Circuit}

There are several issues that must be addressed while designing the Operator Station power distribution circuit. First, what power sources are going to be used and how will that power enter the Operator Station? Should there be a fuse on the power input(s) to protect the circuitry and the operators sitting inside the station? Second, how will the $110 / 220 \mathrm{VAC} 60 \mathrm{~Hz}$ power be generated and supplied to the devices inside the Operator Station? In relation to this problem, will there be circuit breakers to protect the 
computers and other devices? Third, how will the Sensor Pallet receive the 110/220 VAC $60 \mathrm{~Hz}$ power that it needs to operate?

While answering these questions, other issues were raised. Should there be any indicators, in the form of LED's, to signify what kind of power is available to the system? Should the user be able to turn the power off and on? Where will these components reside in the Operator Station? All these topics will be resolved in the discussion of the design.

\subsubsection{Input Power for Project Oculus}

The first question to solve is the source of the input power to the system. Of course, the system needed to receive power on the C-130 Ro-Ro; therefore, one of the two available power sources on the plane had to be utilized. Of the sensors that would be deployed from the Sensor Pallet and the devices that would be placed in the Operator Station, nothing operated from $400 \mathrm{~Hz}$ AC power. Also, a "frequency changer" that would turn the $400 \mathrm{~Hz}$ AC power to $60 \mathrm{~Hz} \mathrm{AC}$ power was rather expensive. For these reasons, the electrical engineers decided to make use of the 28VDC 200 Amp power supply available on the plane when the system is in use.

\subsubsection{28VDC 200 Amp Input Power}

As was discussed in Chapter 2, there are several 28VDC power outlets available in the plane; it was decided that the normal plug-in point would be the connector at the bulkhead of the aircraft.

Now that the power source on the aircraft has been chosen, the electrical engineers had to determine the parts needed to connect to the power connector on the 
plane and plug into the Operator Station. The DC power connector on the Operator Station was chosen to match the connector on the aircraft's bulkhead. The 28VDC 200 Amp connector found there is a standard connector with the part number AN2552-3A. This part was purchased from Aircraft Spruce and mounted on the outside of the Operator Station on the "power-in" panel. The AN2552-3A DC power connector is shown in Figure 3.1 below.
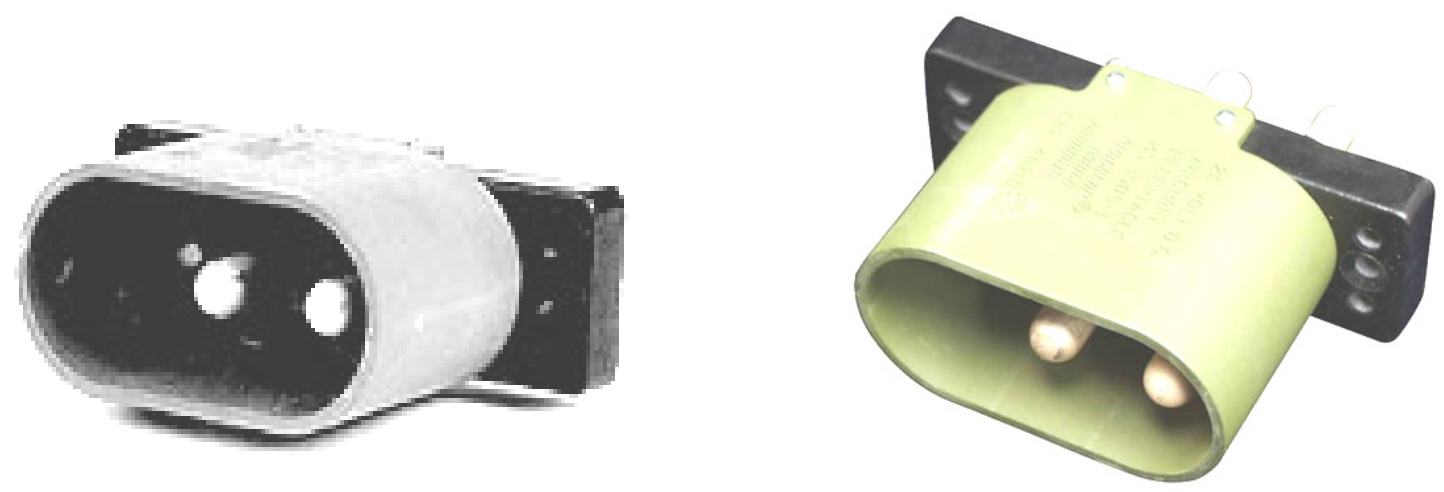

Figure 3.1: AN2552-3A 28VDC 200Amp Connector [9]

The plug that mates with the AN2552-3A is the AN2551 [9]. A cable with this plug connector at each end was constructed to connect the power source plug on the aircraft bulkhead to the Operator Station. The cable was built 60 feet long so that it would have enough slack to go up and over freight stored on the plane and still reach from the bulkhead to the Operator Station no matter where it was located in the freight area. The cable was made from two pieces of $2 / \mathrm{O}$ SOOW welding cable, one wire for the positive connection and one for the negative connection. 


\subsubsection{220VAC 30Amp Input Power}

The WVU-CIRA electrical engineers realized that there may not always be a 28VDC 200Amp power supply available to the system for power when it is on the ground and not in use. Therefore, the ability to interface to an alternative power source, 220VAC 30Amp single phase, was designed for the system. For safety purposes, the cable carrying current from the power source would have a female plug on the end; therefore, the male connector would be mounted on the Operator Station. The female plug chosen was the HBL430C12W, which is pictured in Figure 3.2 shown below.

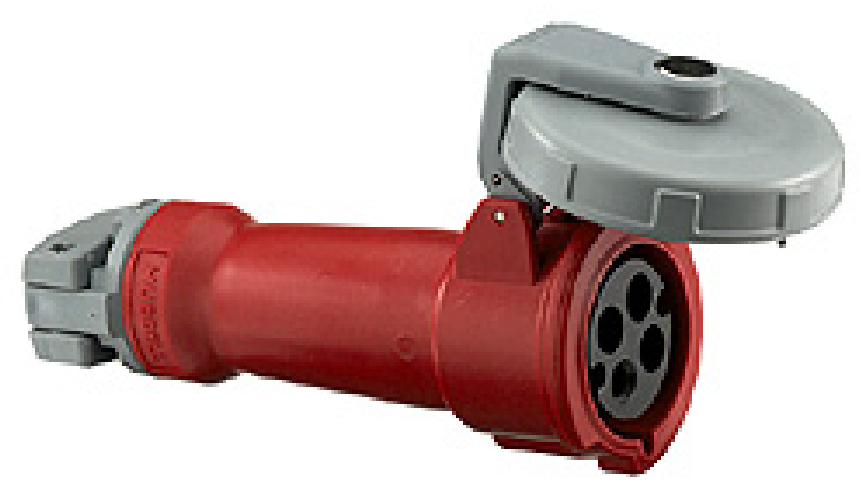

Figure 3.2: HBL430C12W 220VAC 30Amp Female Plug Power Connector [10]

This plug was placed on the end of a 60 foot piece of 10/4 SOOW welding cable. The other end that connects to the power source was not part of the finalized design. This is because there are several 220VAC power receptacles that the cable could have to interface with; therefore, there was no plug attached to that end.

The male connector that mates with the HBL430C12W is the HBL430B12W power connector. The HBL430B12W power connector was added to the "power-in" panel on the exterior of the Operator Station. This connector is pictured in Figure 3.3. 


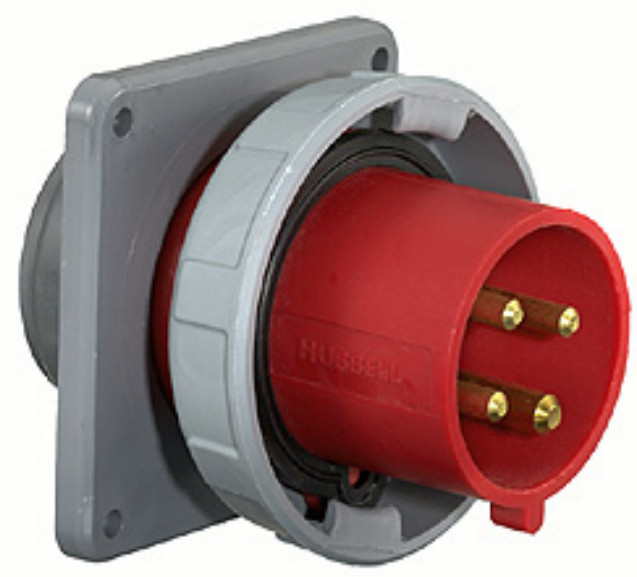

Figure 3.3: HBL430B12W 220VAC 30Amp Male Chassis Mount Power Connector [11]

\subsubsection{AC Power Inverter}

Now that the sources of power have been defined, the electrical engineers had to figure out what to do with it. Recall that most of the components in the Operator Station and the translational motor run off $110 \mathrm{VAC} 60 \mathrm{~Hz}$, and the rotational motor runs off $220 \mathrm{VAC} 60 \mathrm{~Hz}$. Therefore, an inverter is required to take the DC power available and make it $60 \mathrm{~Hz} \mathrm{AC}$.

\subsubsection{Vanner TSC24-4500D Inverter Overview}

To this effect, the Vanner, Inc. TruSine 4500 Inverter/Charger System model number TSC24-4500D was chosen to perform this task. The TSC24-4500D is pictured in Figure 3.4 shown below, and a drawing of the front panel is shown in Figure 3.5. 


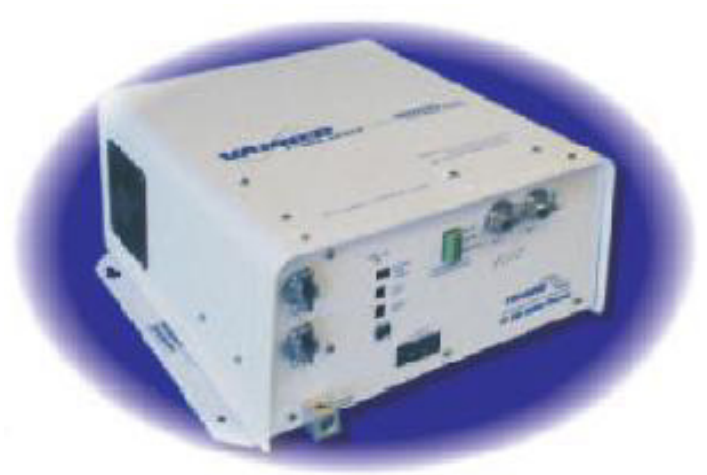

Figure 3.4: Vanner Inverter TSC24-4500D [12]

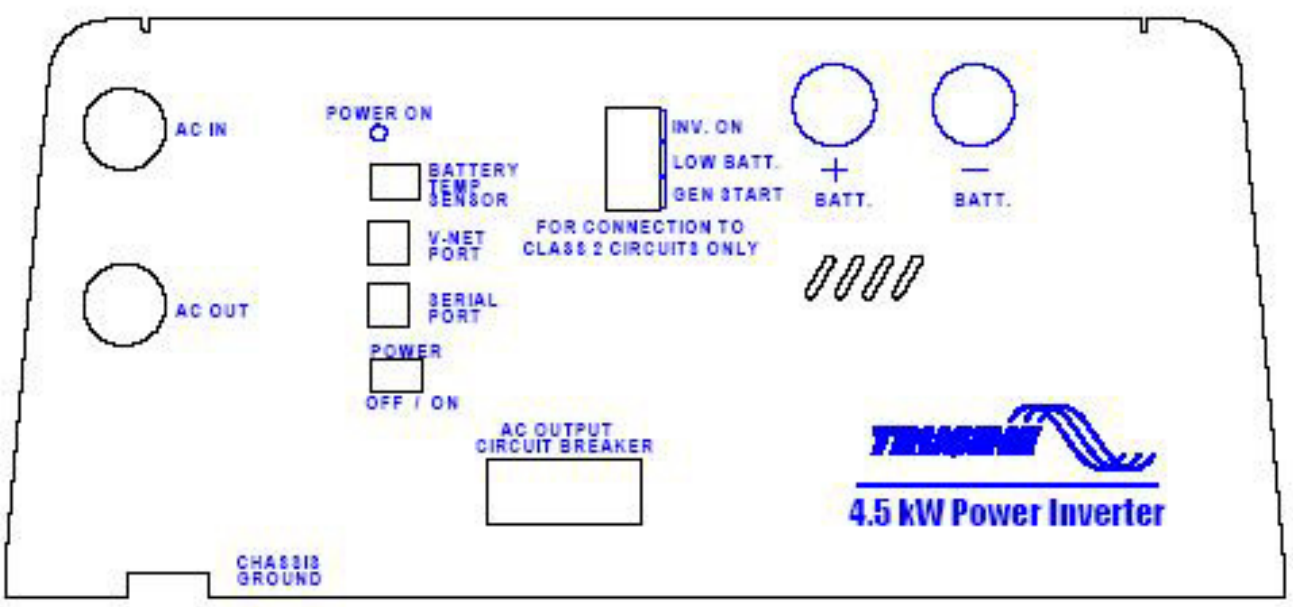

Figure 3.5: Vanner Inverter TSC24-4500D Front Panel [13]

This inverter is designed to take an input of either 21-34 VDC or 120/240 VAC single phase and provide an output of $120 / 240 \mathrm{VAC} 60 \mathrm{~Hz}$ [13]. In Table 3.1 shown below, several specifications for the TSC24-4500D are shown; for a complete specification sheet, view Appendix 1. 
Table 3.1: Specifications for the Vanner TSC24-4500D Inverter [13]

\begin{tabular}{|l|l|}
\hline \multicolumn{1}{|c|}{ Item } & \multicolumn{1}{c|}{ Specification } \\
\hline AC Input & $120 / 240 \mathrm{~V} \pm 10 \%, 3$-wire, $1 \varnothing$ \\
\hline DC Input & $21-34 \mathrm{VDC}$ \\
& No Load: 1.8 Amps \\
& Full Power: 210 Amps \\
\hline AC Output & $120 / 240 \mathrm{VAC} \pm 3 \%$ \\
Frequency & $60 \mathrm{~Hz} \pm 0.5 \%$ \\
L1 to Neutral & $2250 \mathrm{~W}(18.8 \mathrm{Amps})$ \\
L2 to Neutral & $2250 \mathrm{~W}(18.8 \mathrm{Amps})$ \\
L1 to L2 & $4500 \mathrm{~W}(18.8 \mathrm{Amps})$ \\
\hline Inverter Efficiency, @ $4500 \mathrm{~W}$ & $82.5 \%$ \\
\hline Dimensions & $17.5 ” \mathrm{H}$ x 19.0”W x 8.5”D \\
\hline Weight & $83 \mathrm{lbs}$. \\
\hline Mount & Wall or Shelf Mounting \\
\hline
\end{tabular}

\subsubsection{Inverter Efficiency and Power Budge Study}

In Table 3.1, the inverter efficiency at $4500 \mathrm{~W}$ is shown to be $82.5 \%$. This is an important specification to take into consideration; not all of the power is available to the system for use. The DC power available to the system from the C-130 bulkhead is:

$$
\begin{gathered}
\mathrm{P}_{\mathrm{DC} \text {-available }}=\mathrm{VI} \\
\mathrm{P}_{\mathrm{DC} \text {-available }}=28 \mathrm{~V} * 180 \mathrm{~A} \\
\mathrm{P}_{\mathrm{DC} \text {-available }}=5040 \mathrm{~W}
\end{gathered}
$$

But this power is limited by the efficiency of the inverter; the power that can be counted on for use by the system is calculated to be:

$$
\begin{gathered}
\mathrm{P}_{\text {inverter }}=\mathrm{P}_{\text {available }} * \text { Inverter Efficiency } \\
\mathrm{P}_{\text {inverter }}=5040 \mathrm{~W} * 82.5 \% \\
\mathrm{P}_{\text {inverter }}=4158 \mathrm{~W}
\end{gathered}
$$

Using the TSC24-4500D, only 4158W of AC power is guaranteed for use by the system. Based on this observation, it would be beneficial to conduct a power budget study for Project Oculus. The power budget is shown in Appendix 2. 


\subsubsection{TSR-2 Remote Control for the TSC24-4500D Inverter}

The TSC24-4500D is equipped with an optional TSR-2 remote control. The TSR-2 remote contains an alphanumeric LCD display and a functional keypad with up/down, left/right, Menu and ESC functions. Through the remote control, system status messages can be displayed, any faults that occur are reported, system functions can be enabled/disabled, and system set points may be examined and modified. The TSR-2 remote control is pictured in Figure 3.6 below.

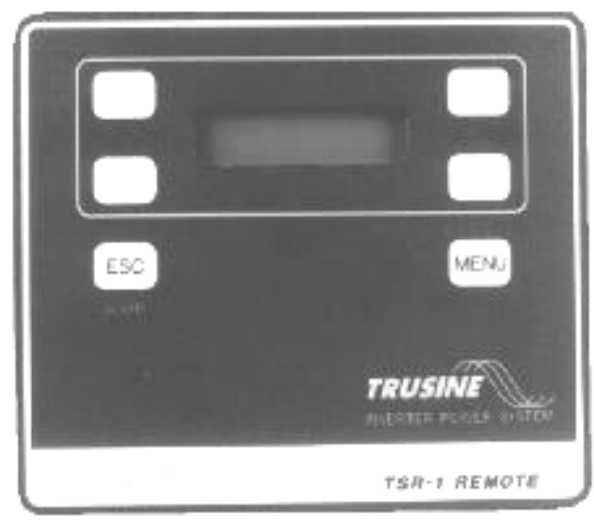

Figure 3.6: TSR-2 Remote Control for the TSC24-4500D Inverter [13]

\subsubsection{Operator Station Circuit Design}

Now the WVU-CIRA electrical engineers had to design the circuit that brings power to the Vanner TSC24-4500D inverter. Even though the inverter is built to sustain up to a $10,000 \mathrm{~W}$ surge [13], it is important to protect the electronics inside the Operator Station. Therefore, it was decided to place fuses on both the 28VDC input and the 110/220 VAC $60 \mathrm{~Hz}$ input. A 200 Amp DC fuse was placed on both the positive and negative line of the DC input, and a 30 Amp fuse was placed on both Line 1 and Line 2 of the $\mathrm{AC}$ input. 
In addition to fuses on the power input, the electrical engineers also designed a sort of "interlock" between the two inputs. The idea behind this interlock is to keep the inverter from seeing both AC and DC inputs. The interlock was designed using a DC contactor on the $\mathrm{DC}$ input circuit and an $\mathrm{AC}$ contactor on the $\mathrm{AC}$ input circuit. The operator inside the station can choose which power input to use by flipping on/off switches that control each input. The toggle switches that were chosen for the system, part number 23F 1895 from Newark Electronics, are shown in Figure 3.7.

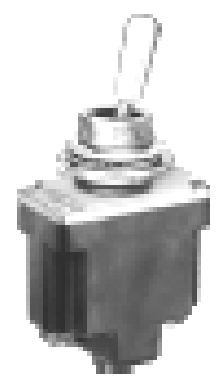

Figure 3.7: On/Off Toggle Switch [14]

\subsubsection{LED Indicators}

Also included in the design are LED indicators. Three red LED's will be installed on the DC input and on each line of the AC input. These LED's are designed to show the user which power sources are available to the system. In addition, three green LED's will be installed; one for DC and one for each of the two AC lines. Whenever the user flips on the DC or the AC power input, the green LED's will turn on to indicate that that power source has been turned on. To ensure that $220 \mathrm{VAC} 60 \mathrm{~Hz}$ and $28 \mathrm{VDC}$ power is available to the system, more green LED indicators were installed on the output from the TSC24-4500D inverter. The LED's that were picked for the Operator Station "Power In" and "Power Out" panels are outlined in Table 3.2 shown below. 
Table 3.2: Operator Station LED Indicators [11, 12]

\begin{tabular}{|l|c|c|c|c|}
\hline & Red DC LED & $\begin{array}{c}\text { Green DC } \\
\text { LED }\end{array}$ & Red AC LED & $\begin{array}{c}\text { Green AC } \\
\text { LED }\end{array}$ \\
\hline Voltage & $24 \mathrm{VDC}$ & $24 \mathrm{VDC}$ & $130 \mathrm{VAC}$ & $130 \mathrm{VAC}$ \\
\hline Current & $17 \mathrm{~mA}$ & $17 \mathrm{~mA}$ & $6 \mathrm{~mA}$ & $6 \mathrm{~mA}$ \\
\hline Size (Diameter) & $0.550 "$ & $0.550 "$ & $0.550 "$ & $0.550 "$ \\
\hline Part Number & $95 \mathrm{C} 0354$ & $95 \mathrm{C} 0356$ & $95 \mathrm{C} 0364$ & $95 \mathrm{C} 0365$ \\
\hline
\end{tabular}

This circuit design can be studied in Appendix 4 "C-130 Operator Station Power Schematic".

\subsubsection{DC Contactor}

The DC contactor chosen for the system was the Albright SW190. This contactor is a Double Pole Single Throw (DPST) normally open contactor with a maximum current rating of 200 Amps, which is the current rating of the 28VDC power source. The SW190 is shown in Figure 3.8 below.

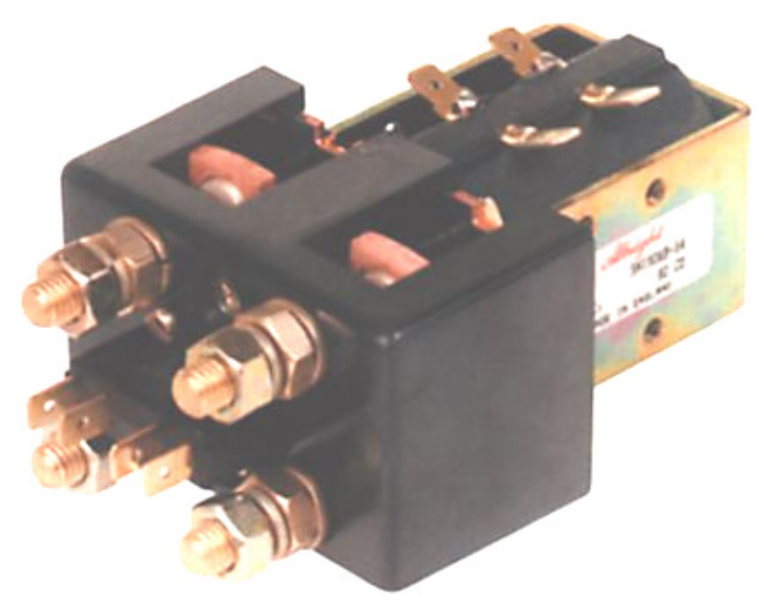

Figure 3.8: Albright SW190 DC Contactor [17] 


\subsubsection{AC Contactor}

The AC contactor chosen for the system was the GH15FT-3-00A contactor available from Automation Direct. This is a $120 \mathrm{~V} 60 \mathrm{~Hz}$ contactor; Line 1 and Line 2 from the AC input have their own contact. The contacts are rated at 32 Amps each [18], which is above the rating of each $\mathrm{AC}$ line that is fused at 30 Amps. However, this contactor does not have enough contacts to build the circuit shown in the diagram in Appendix 4. The GH15S11 auxiliary contacts, one normally open and one normally closed, available from Automation Direct, was added to solve this problem. The GH15S11 contact mounts on the side of the GH15FT-3-00A contactor [19]. The GH15FT-3-00A contactor and the GH15S11 auxiliary contact are shown in Figure 3.9 below.
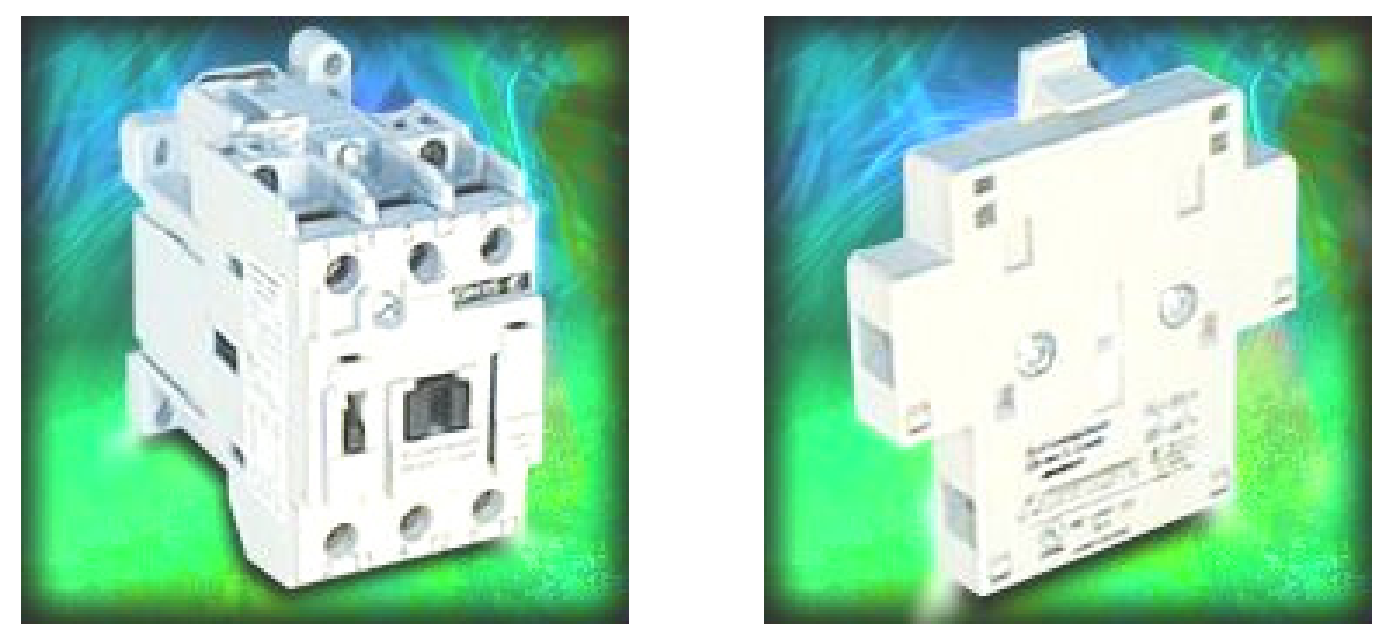

Figure 3.9: GH15FT-3-00A AC Contactor and GH15S11 Auxiliary Contact [14, 15]

\subsubsection{VAC 60Hz Outlet Circuit}

The devices mounted in the electronics racks, such as the computers, monitors, VCRs, and radio receivers, all run off $110 \mathrm{VAC} 60 \mathrm{~Hz}$ power. They are equipped with standard AC power plugs. Therefore, the Operator Station racks needed to be outfitted 
with outlet strips. Three outlet strips, measuring 60 " in length, were purchased from Wiremold. These outlet strips contain ten AC outlets spaced 6" apart. One outlet strip was mounted behind or near each of the three electronic racks.

To protect the devices in the electronic racks, every two outlets in the outlet strips were put on a 10 Amp circuit breaker. The circuit breakers that were used in the system were Klixon 7274-11-10 aircraft circuit breakers. One of these circuit breakers is pictured in Figure 3.10 shown below, and the components of the circuit breaker are shown in Figure 3.11.

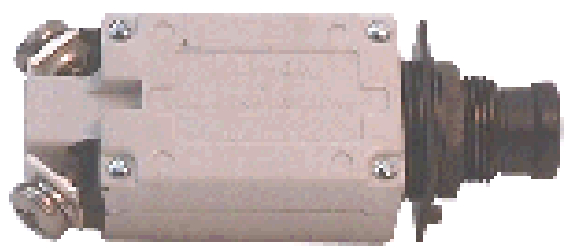

Figure 3.10: Klixon 7274-11 Aircraft Circuit Breaker [20]

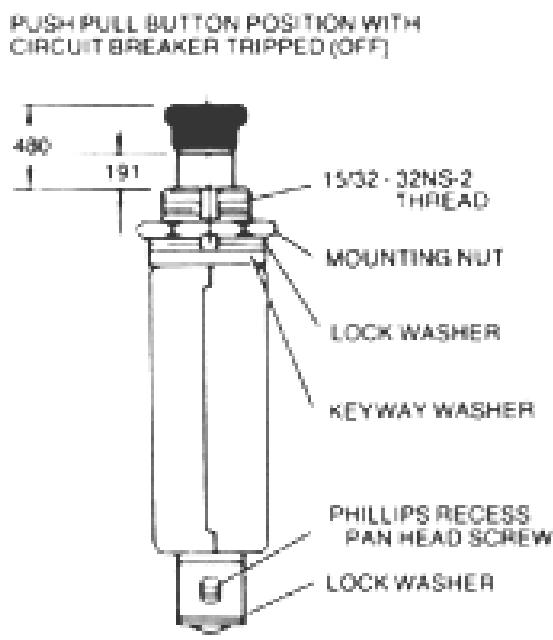

Figure 3.11: Klixon 7274-11 Circuit Breaker Components [20] 
These circuit breakers are designed specifically for use on aircraft. Some pertinent specifications for the Klixon 7274-11 are shown in Table 3.3. A full data sheet for the Klixon aircraft circuit breakers can be found in Appendix 3; dimensions of the circuit breakers and other important information can be found there.

Table 3.3: Klixon 7274-11 Aircraft Circuit Breaker Specifications [20]

\begin{tabular}{|l|l|}
\hline \multicolumn{1}{|c|}{ Item } & \multicolumn{1}{c|}{ Specification } \\
\hline Vibration & $10 \mathrm{G}$ minimum, 50-500 Hz \\
\hline Mechanical Shock & $35 \mathrm{G}$ \\
\hline Acceleration & $10 \mathrm{G}$ \\
\hline Weight & 33 grams \\
\hline Max Voltage Drop & \\
$10 \mathrm{Amp}$ & $0.28 \mathrm{~V}$ \\
$20 \mathrm{Amp}$ & $0.25 \mathrm{~V}$ \\
\hline Mil Spec Rating & \\
$7274-11-10$ & MS 22073-10 \\
$7274-11-20$ & N/A \\
\hline \multicolumn{2}{|c|}{} \\
\hline
\end{tabular}

\subsubsection{Operator Station Panel Design}

All these components that have been discussed, namely the LED indicators, the toggle switches, the circuit breakers, and the TSR-2 remote control to the inverter, have to be mounted somewhere in the Operator Station for ease of use. The area chosen to mount these components was in the top of the three electronic racks.

First, the TSC24-4500D power inverter was mounted in the top of the center rack. This means that the TSR-2 remote control should be mounted closely to it, as well as the LED indicators attached to the inverter output. A panel was then fashioned to house the TSR-2 inverter remote control and these LED indicators; this panel was mounted in front of the inverter in the top of the center rack. 
Second, the "Power In" LED indicators and the on/off toggle switches had to be mounted. Since the input power connectors are on the left hand side input panel, the "Power In" panel was mounted in the top of the left hand rack.

Finally, the aircraft circuit breakers had to be mounted. For the sake of symmetry, and the desire to move the circuit breakers up where operators couldn't kick or bump into the breakers, the circuit breakers were mounted in the top of the right hand rack. A panel with a piano hinge was fashioned to house the circuit breakers; the piano hinge is important so that the operators can get in behind the circuit breakers to check wiring and the like. The rough drawing of the finalized design of these panels is shown in Figure 3.12 below. The figure includes future optional $400 \mathrm{~Hz}$ input and output power LED indicators.
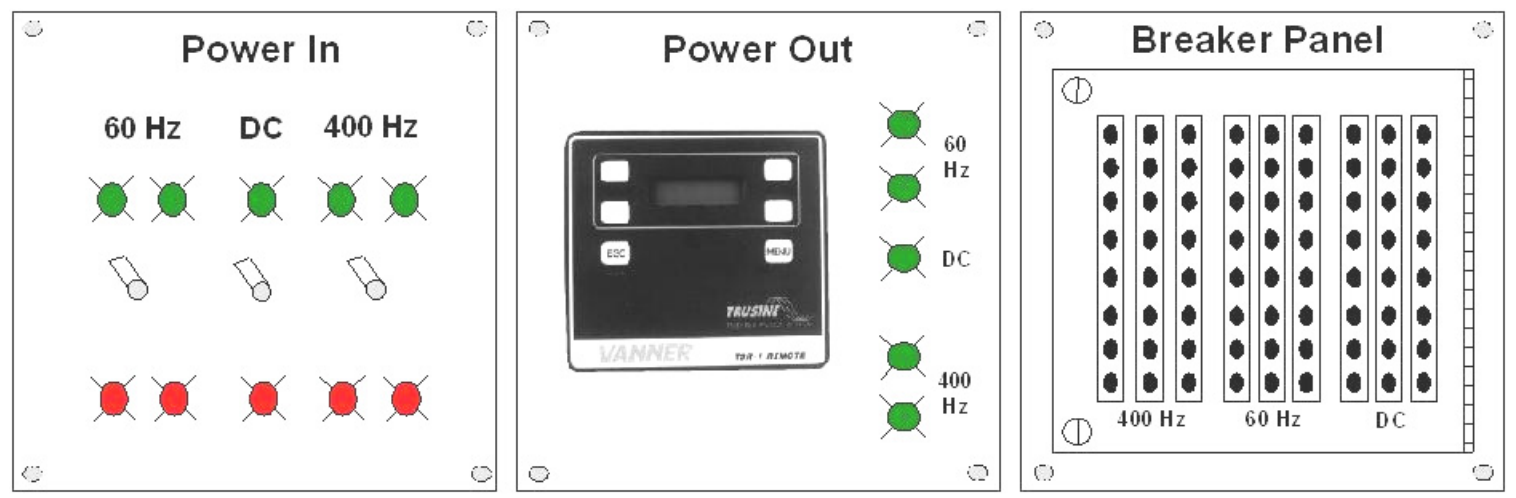

Figure 3.12: Operator Station Panel Design

\subsubsection{Power Out to Sensor Pallet}

The final part of the Operator Station power circuit design is the power out circuit to the Sensor Pallet. The power that will be sent to the Sensor Pallet is the 120/240VAC $60 \mathrm{~Hz}$ "split-phase" power generated by the TSC24-4500D inverter. Line 1 and Line 2 of this AC output is run to 20 Amp Klixon aircraft circuit breakers, part number 7274-11- 
20. From the circuit breakers, the lines are run to a chassis mount power connector. For safety reason, the female connector HBL430R12W was chosen for the system. The connector was mounted on the "communication panel" that was designed to mount connectors for sensor inputs from the Sensor Pallet to the computers housed inside the Operator Station. The HBL430R12W connector is pictured in Figure 3.13 shown below.

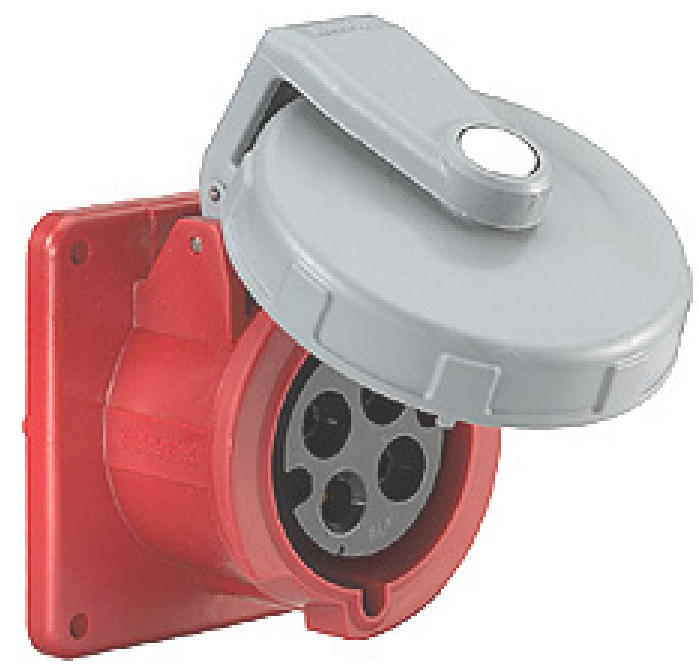

Figure 3.13: HBL430R12W 120/240VAC 60Hz 30Amp Female Chassis Mount Power Connector [21]

The HBL430R12W female chassis connector mates with the HBL430P12W male plug connector. This connector is attached to a 60 foot piece of 10/4 SOOW cable that runs to the Sensor Pallet. The HBL430P12W plug is shown in Figure 3.14 below.

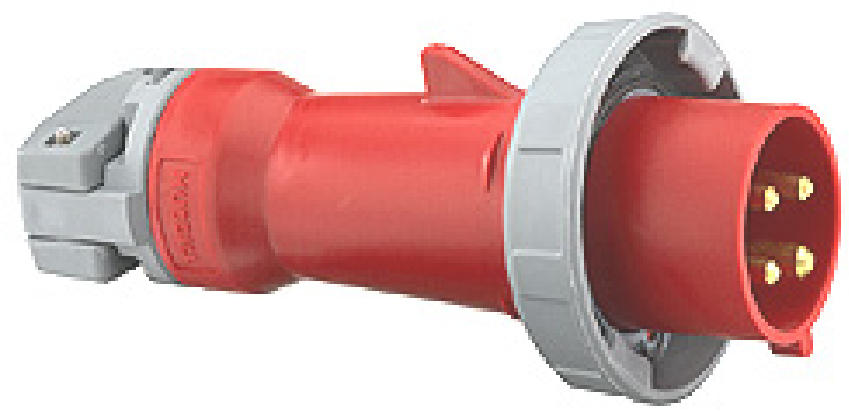

Figure 3.14: HBL430P12W 120/240VAC 60Hz 30Amp Male Plug Power Connector [22] 


\subsection{Sensor Pallet Control - Hardware and Circuit Design}

The Sensor Pallet control circuit needs to accomplish two tasks, running both Automatic and Manual modes. Automatic mode will mostly be covered in both Chapter 4 "Automatic Mode Hardware Design" and Chapter 5 "Automatic Mode Software Design." But in this section, several components for both modes of the circuit are determined.

The fundamental problem to be solved here is turning on the translation and rotational motors in the correct direction whenever the operator desires to do so. Therefore, a user interface pendant needs to be designed and built; through this pendant, a signal needs to be sent to relay $110 \mathrm{VAC} 60 \mathrm{~Hz}$ to the translation motor or power on the $220 \mathrm{VAC} 60 \mathrm{~Hz} 3$-phase rotational motor (engaging each motor in the correct direction depending on the operator's wishes).

\subsubsection{Translation and Rotational Motor Power Sources}

The control circuit that is designed has to supply the right power to each motor. As previously stated, the translation motor uses $110 \mathrm{VAC} 60 \mathrm{~Hz}$ for power in both clockwise and counterclockwise directions. The rotational motor uses $220 \mathrm{VAC} 60 \mathrm{~Hz} 3-$ phase power to operate. However, the power that is generated in the Operator Station and delivered to the Sensor Pallet is 220VAC 60Hz "split-phase", which means that there are two lines with 110VAC on each. Therefore, a 3-phase power source was found for the rotational motor. 


\subsubsection{Translation Motor Power Source}

The translation motor has four wires; a green ground wire, a white neutral wire, a blue wire that turns the motor clockwise, and a red wire that turns the motor counterclockwise. The translation motor also requires a $68 \mu \mathrm{F}$ starting capacitor; this capacitor is utilized by placing two $136 \mu \mathrm{F}$ capacitors in series on the red and blue input wires. Since the power coming from the Operator Station is 220VAC split-phase, just one of the lines gives $110 \mathrm{VAC} 60 \mathrm{~Hz}$ that can be used to operate the translation motor.

\subsubsection{Rotation Motor Power Source}

The rotation motor is more complicated than the translation motor. A 3-phase power source has been found to operate the motor. The WVU-CIRA electrical engineers decided to use a motor controller for this task; the GS2-22P0 motor controller, available from Automation Direct, was chosen for the system. The GS2-22P0 is pictured in Figure 3.15 below.

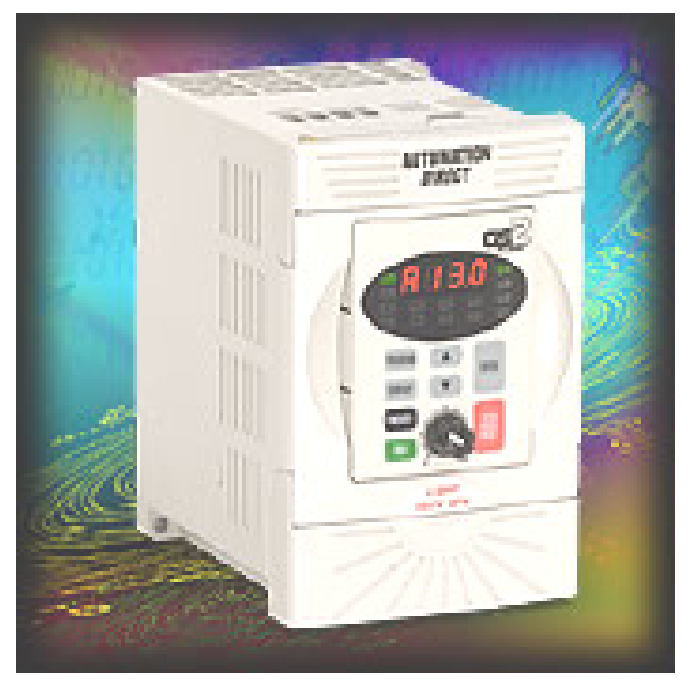

Figure 3.15: GS2-22P0 Motor Controller [23]

Specifications for the GS2-22P0 are shown in Table 3.4; more specs are in Appendix 7. 
Table 3.4: GS2-22P0 Motor Controller Specifications [24]

\begin{tabular}{|l|l|}
\hline \multicolumn{1}{|c|}{ Item } & \multicolumn{1}{|c|}{ Specification } \\
\hline $\begin{array}{l}\text { Motor Rating } \\
\text { Horsepower } \\
\text { Power }\end{array}$ & $2.0 \mathrm{HP}$ \\
\hline Rated Input Voltage & $1.5 \mathrm{~kW}$ \\
\hline Rated Output Voltage & $\begin{array}{l}\text { Single/Three Phase: } \\
200 / 208 / 220 / 230 / 240 \mathrm{VAC} \pm 10 \% \\
50 / 60 \mathrm{~Hz} \pm 5 \%\end{array}$ \\
\hline Rated Input Current & Corresponds to Input Voltage, 3-phase \\
\hline Rated Output Current & $15.7 / 8.8 \mathrm{~A}$ \\
\hline $\begin{array}{l}\text { Climate } \\
\text { Ambient Operating Temperature } \\
\text { (without derating) }\end{array}$ & $7.0 \mathrm{~A}$ \\
\hline Humidity & $-10^{\circ} \mathrm{C}$ to $50^{\circ} \mathrm{C}\left(14^{\circ} \mathrm{F}\right.$ to $\left.122^{\circ} \mathrm{F}\right)$ \\
\hline Vibration & $20^{2} \%$ to $90^{\circ} \%$ (no condensation) \\
\hline Location & $1 \mathrm{G}$ at less than $10 \mathrm{~Hz} ; 0.6 \mathrm{G}$ at $10-60 \mathrm{~Hz}$ \\
\hline Weight & Altitude $1,000 \mathrm{~m}$ or less \\
\hline Dimensions & $3.71 \mathrm{~b}$. \\
\hline
\end{tabular}

The GS2-22P0 is a programmable motor controller. Several parameters have to be set through programming. The programs can be accessed by using the "Program" and "Enter" keys on the keypad. Table 3.5 gives an outline of the programs and their correct value.

Table 3.5: GS2-22P0 Motor Controller Programs [25]

\begin{tabular}{|l|l|}
\hline \multicolumn{1}{|c|}{ Program } & \multicolumn{1}{c|}{ Value } \\
\hline P 0.00 Motor Nameplate Voltage & $220 \mathrm{~V}$ \\
\hline P 0.02 Motor Base Frequency & $60 \mathrm{~Hz}$ \\
\hline P 0.03 Motor Base RPM & $1750 \mathrm{RPM}$ \\
\hline P 0.04 Maximum Motor RPM & $1800 \mathrm{RPM}$ \\
\hline P 1.00 Stop Methods & 00 (Ramp to Stop) \\
\hline P 1.01 Acceleration Time & 5.0 seconds \\
\hline P 1.02 Deceleration Time & 0.1 seconds \\
\hline P 3.00 Source of Operation Command & $\begin{array}{l}01 \text { (Operation determined by external } \\
\text { control terminals. Keypad STOP is enabled.) }\end{array}$ \\
\hline P 3.01 Multi-Function Input Terminals & $\begin{array}{l}00 \text { DI1 - FWD/STOP } \\
\text { DI2 - REV/STOP }\end{array}$ \\
\hline
\end{tabular}


When setting programs $\mathrm{P} 3.00$ and P3.01 as outlined in Table 3.5, the digital inputs are wired up as shown in Figure 3.16.

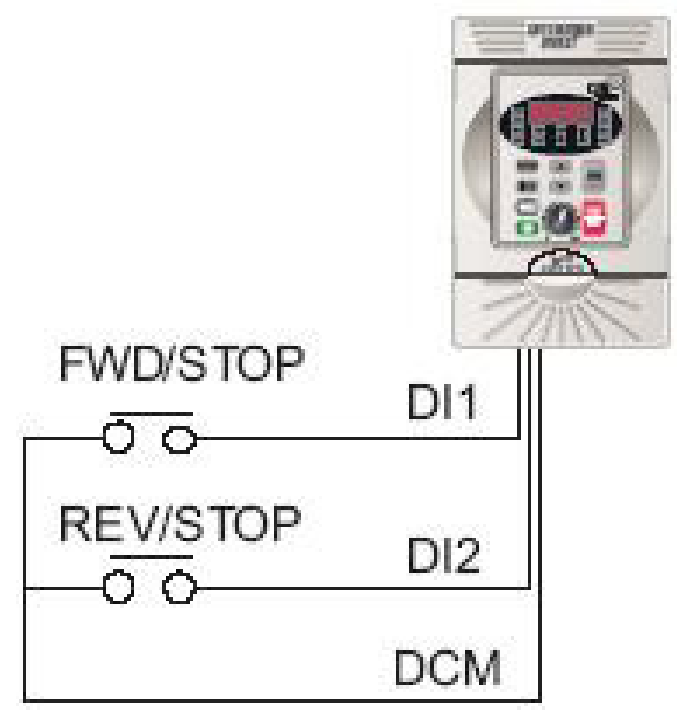

Figure 3.16: GS2-22P0 Motor Controller Wiring Diagram [25]

\subsubsection{LED Indicators}

The WVU-CIRA engineers decided that a good feature for the system deployment would be LED indicators to show the operator where the system was and what it was doing. A system of eight LED indicators was chosen. There would be three LED's for both translation and rotation, identifying to the user whether the system was in translation/rotation extended, translation/rotation stowed, translation/rotation operate mode. Also, there would be two LED's indicating whether the system was in Automatic or Manual mode. The LED colors are as follows: yellow for translation/rotation extended, green for translation/rotation stowed, and blue for translation/rotation operate. Also, there would be a red LED to indicate the system is in Manual mode and a green LED to indicate the system is in Automatic mode. 
How these LED's are turned on vary for different LED's. The Automatic mode and translate/rotate operate LED indicators are turned on by PLC outputs (further discussed in Chapters 4 and 5); the translate/rotate operate LED's will not be functional in manual mode. The Manual mode LED indicator will be turned on whenever the user selects "Manual" with the Automatic/Manual selector switch on the pendant. The extended and stowed LED indicators will be turned on by the various proximity sensors, which are further defined in Chapter 4. The LED's that will be used in the system are outlined in Table 3.6 below.

Table 3.6: Sensor Pallet LED Indicators [16]

\begin{tabular}{|l|c|c|c|c|}
\hline & Red DC LED & $\begin{array}{c}\text { Green DC } \\
\text { LED }\end{array}$ & Blue DC LED & $\begin{array}{c}\text { Yellow DC } \\
\text { LED }\end{array}$ \\
\hline Voltage & $24 \mathrm{VDC}$ & $24 \mathrm{VDC}$ & $24 \mathrm{VDC}$ & $24 \mathrm{VDC}$ \\
\hline Current & $17 \mathrm{~mA}$ & $17 \mathrm{~mA}$ & $17 \mathrm{~mA}$ & $17 \mathrm{~mA}$ \\
\hline Size (Diameter) & $0.550 "$ & $0.550 "$ & $0.550 "$ & $0.550 "$ \\
\hline Part Number & $95 \mathrm{C} 0354$ & $95 \mathrm{C} 0356$ & $95 \mathrm{C} 0357$ & $95 \mathrm{C} 0355$ \\
\hline
\end{tabular}

\subsubsection{Operator Pendant}

The operator pendant was introduced previously in Chapter 1. The concept is to have a "box" that houses certain buttons and switches to accomplish the task of running the Sensor Pallet. The pendant should have two pushbuttons; one to "extend" the Sensor Pod and one to "stow" the Sensor Pod. Of course, "extending" and "stowing" can occur with both translation and rotation; therefore, there should be a selector switch to determine if the user wants to operate the translation motor or the rotation motor. In addition, there are two modes that the user can deploy the Sensor Pod: Automatic and Manual. Thus, another selector switch should be present to switch between each mode. 
Finally, there should be one overriding pushbutton that will stop any motion; to that end, an emergency stop pushbutton should also exist in the operator pendant.

\subsubsection{Pendant Pushbuttons}

The pushbuttons and selector switches chosen for the operator pendant had to be watertight, commercially available, and able to fit inside the chosen pendant enclosure. Square D pushbuttons, selector switches, and the corresponding contact blocks were chosen, since they are equipped with rubber sealing gaskets and fit standard $30 \mathrm{~mm}$ holes in commercially available pendant enclosures. The emergency stop pushbutton, Grainger part number 2EN49, is pictured in Figure 3.17.

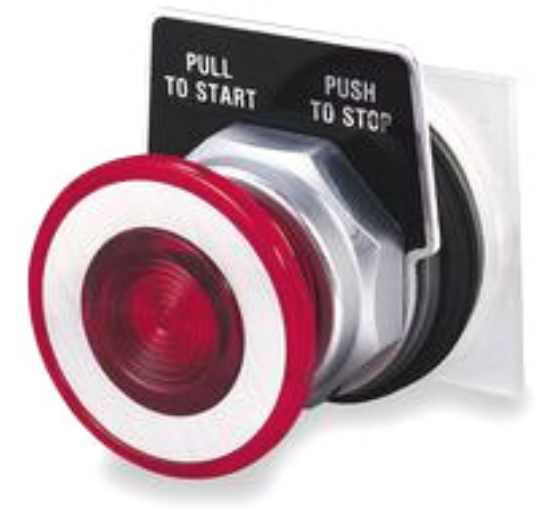

Figure 3.17: Emergency Stop Pushbutton [26]

The selector switch that will be used for both the Automatic/Manual switch and the Translate/Rotate switch, Grainger part number 5B445, is shown in Figure 3.18. 


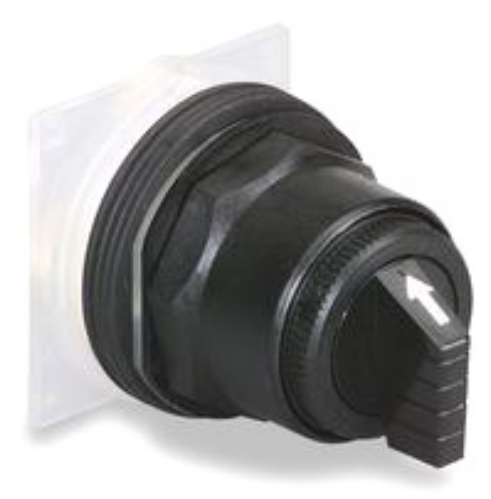

Figure 3.18: Selector Switch [27]

The pushbutton that will be used as both the "Extend" and "Stow" buttons, Grainger part number 5B517, is shown in Figure 3.19. This pushbutton is a "universal" model because it has several colored inserts; it was decided that the "Stow" button would assume the green colored insert (for safety, pod moving back into plane) and the "Extend" button would assume the yellow colored insert (for caution, pod moving out plane door).

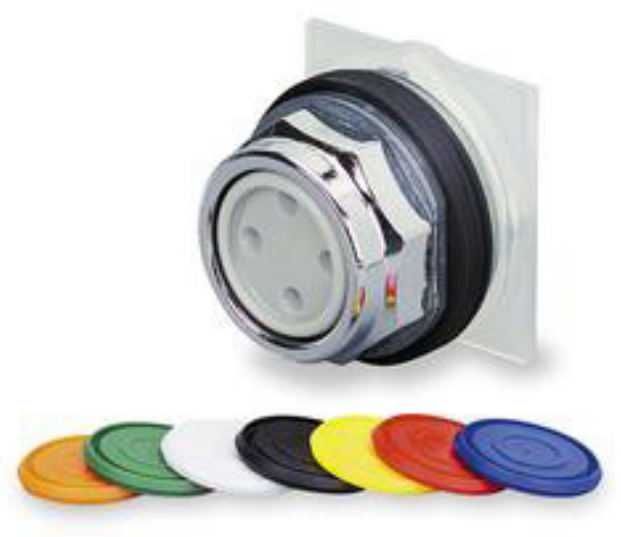

Figure 3.19: Extend and Stow Pushbutton [28]

\subsubsection{Pendant Enclosure}

The pendant enclosure chosen for the system had to be watertight, heavy duty, and would accommodate up to five $30 \mathrm{~mm}$ pushbuttons/switches. The Square D pendant 
enclosure, Grainger part number 2ER81, was chosen. This enclosure had only four $30 \mathrm{~mm}$ holes, but had a place at the top of the faceplate where another hole could be drilled out for a fifth pushbutton. This enclosure was also equipped with a watertight sealing rubber grommet around the faceplate. It is made out of heavy duty plastic, and this entire assembly meets NEMA 1, 3, 4, 4X, and 13 standards. This enclosure even had a $3 / 4$ " NPT conduit hole in the top for the pendant cable to enter [29]. The 2ER81 Square D pendant enclosure is pictured in Figure 3.20 below.

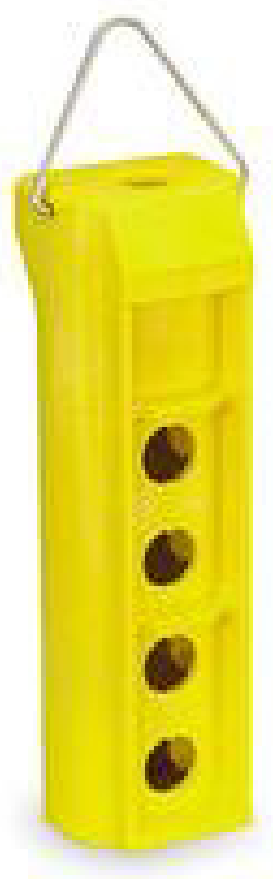

Figure 3.20: Operator Pendant Enclosure [29]

\subsubsection{Control Circuit Design}

The control circuit diagrams can be found in Appendix 6: "Sensor Pallet Control Circuit Diagrams." There are three general areas to explore: operator pendant circuit, the translation/rotation motor control circuit, and the PLC circuit. All these circuits work together to make Project Oculus a success. 
The WVU-CIRA electrical engineers had to decide how to relay the required power, or turn on the motor controller, at the right time. The answer was to use relays; for example, when the user wants the translation motor to operate in the "extend" direction, a certain signal will be sent to energize the "translation extend" relay and supply $110 \mathrm{VAC} 60 \mathrm{~Hz}$ to the counterclockwise input wire on the translation motor. With this idea in mind, what "signal" should be supplied? Relays with 24VDC coils were chosen; therefore, a +24VDC power supply was needed to generate the "signal."

\subsubsection{24VDC Power Supply}

The 24VDC power supply chosen for the system is the PS24-075D available from Automation Direct. This power supply is pictured in Figure 3.21 below.

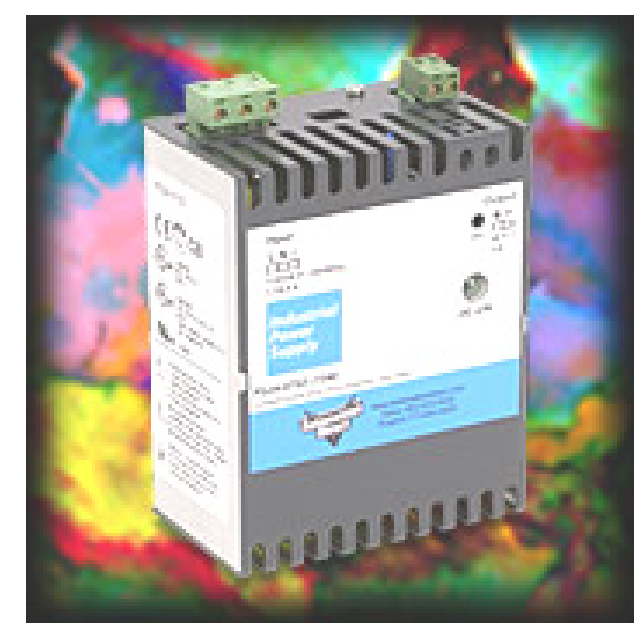

Figure 3.21: PS24-075D 24VDC Power Supply [30]

Important specifications for the PS24-075D are given in Table 3.7 below. Further specifications can be found in Appendix 8. 
Table 3.7: PS24-075D 24VDC Power Supply Specifications [31]

\begin{tabular}{|l|l|}
\hline \multicolumn{1}{|c|}{ Item } & \multicolumn{1}{c|}{ Specification } \\
\hline Input Voltage & $93-132 \mathrm{VAC}$ \\
& $187-264 \mathrm{VAC}$ \\
\hline Input Frequency & $47-63 \mathrm{~Hz}$ \\
\hline Input Current & \\
$115 \mathrm{VAC}$ & $3.0 \mathrm{~A}$ \\
230VAC & $1.7 \mathrm{~A}$ \\
\hline Efficiency & $84 \%$ \\
\hline Output Voltage & $24 \mathrm{VDC}$ \\
\hline Output Current (Max.) & $3.0 \mathrm{~A}$ \\
\hline Output Power & $75 \mathrm{~W}$ \\
\hline
\end{tabular}

\subsubsection{Relays}

To utilize the circuit "Motor Circuit Diagram" shown in Appendix 6, no fewer than seven relays will be used. To distinguish between each relay, they were given descriptive names which were later abbreviated, as can be seen by the circuit diagram in Appendix 6.

The first relays discussed will be the R-TCCW and the R-TCW relays. These acronyms stand for "Relay - Translation Counterclockwise" and "Relay - Translation Clockwise." Whenever these relays are energized by a +24VDC signal, they supply $110 \mathrm{VAC} 60 \mathrm{~Hz}$ to the respective input wires on the translation motor. A block diagram illustrating the use of the R-TCW and R-TCCW relays is shown in Figure 3.22. 


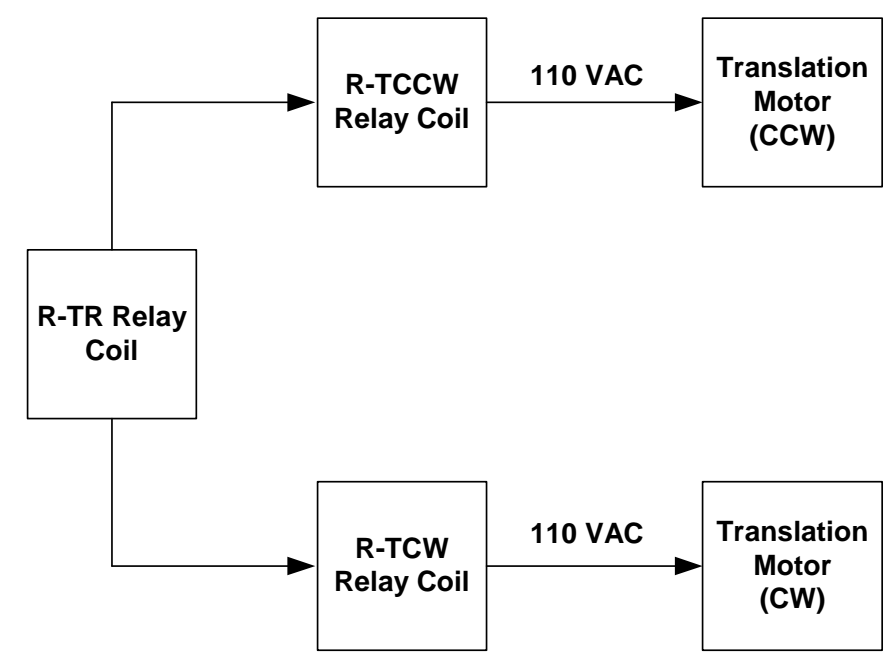

Figure 3.22: Block Diagram of R-TCW and R-TCCW Relays

The second relays discussed will be the R-RF and the R-RR relays. These acronyms stand for "Relay - Rotation Forward" and "Relay - Rotation Reverse." The R-RF relay controls digital input DI1 and the R-RR relay controls digital input DI2 on the GS2-22P0 motor controller. Whenever these relays are energized by a +24VDC signal, they close a circuit that shorts DC common to the digital inputs; refer to Figure 3.16 for wiring. A block diagram illustrating the use of the R-RF and R-RR relays is shown in Figure 3.23.

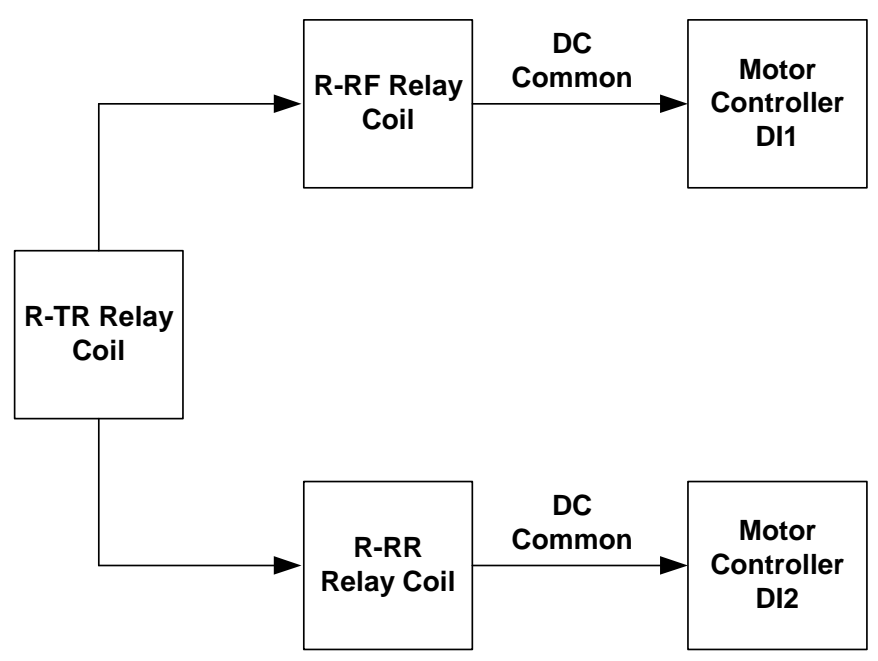

Figure 3.23: Block Diagram of R-RF and R-RR Relays 
Next, the R-RB relay will be discussed. This acronym stands for "Relay Rotation Brake." This relay is energized when the digital inputs on the motor controller receive a signal. It then relays $220 \mathrm{VAC} 60 \mathrm{~Hz}$ to the brake on the rotation motor, releasing the brake so that the motor can turn. A block diagram illustrating the use of the $\mathrm{R}-\mathrm{RB}$ relay is shown in Figure 3.24 below.

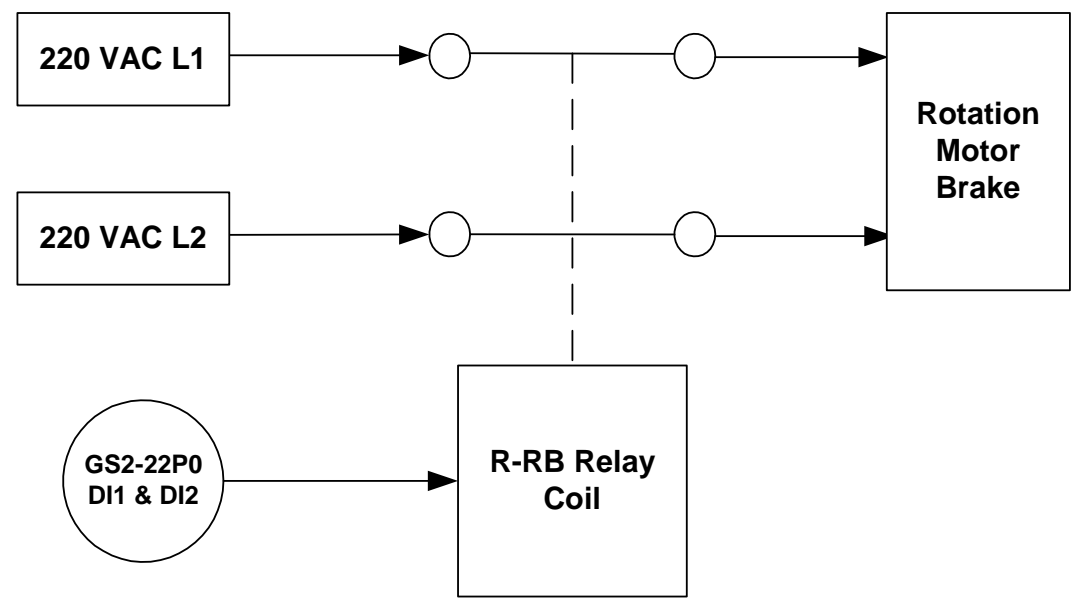

Figure 3.24: Block Diagram of R-RB Relay

To determine whether the translation or rotation relays receive the +24VDC signal from the Extend/Stow buttons on the pendant, the R-TR control relay is implemented. This acronym stands for "Relay - Translation/Rotation." The energizing signal for this relay comes from the Translate/Rotate selector switch on the pendant. When the relay is not energized, the $+24 \mathrm{VDC}$ signal is relayed from the Extend/Stow buttons is sent to the translation relays, R-TCW and R-TCCW. When the relay is energized, the +24VDC signal is relayed from the Extend/Stow to the rotation relays, R$\mathrm{RF}$ and R-RR. A block diagram illustrating the use of the R-TR relay is shown below in Figure 3.25. 


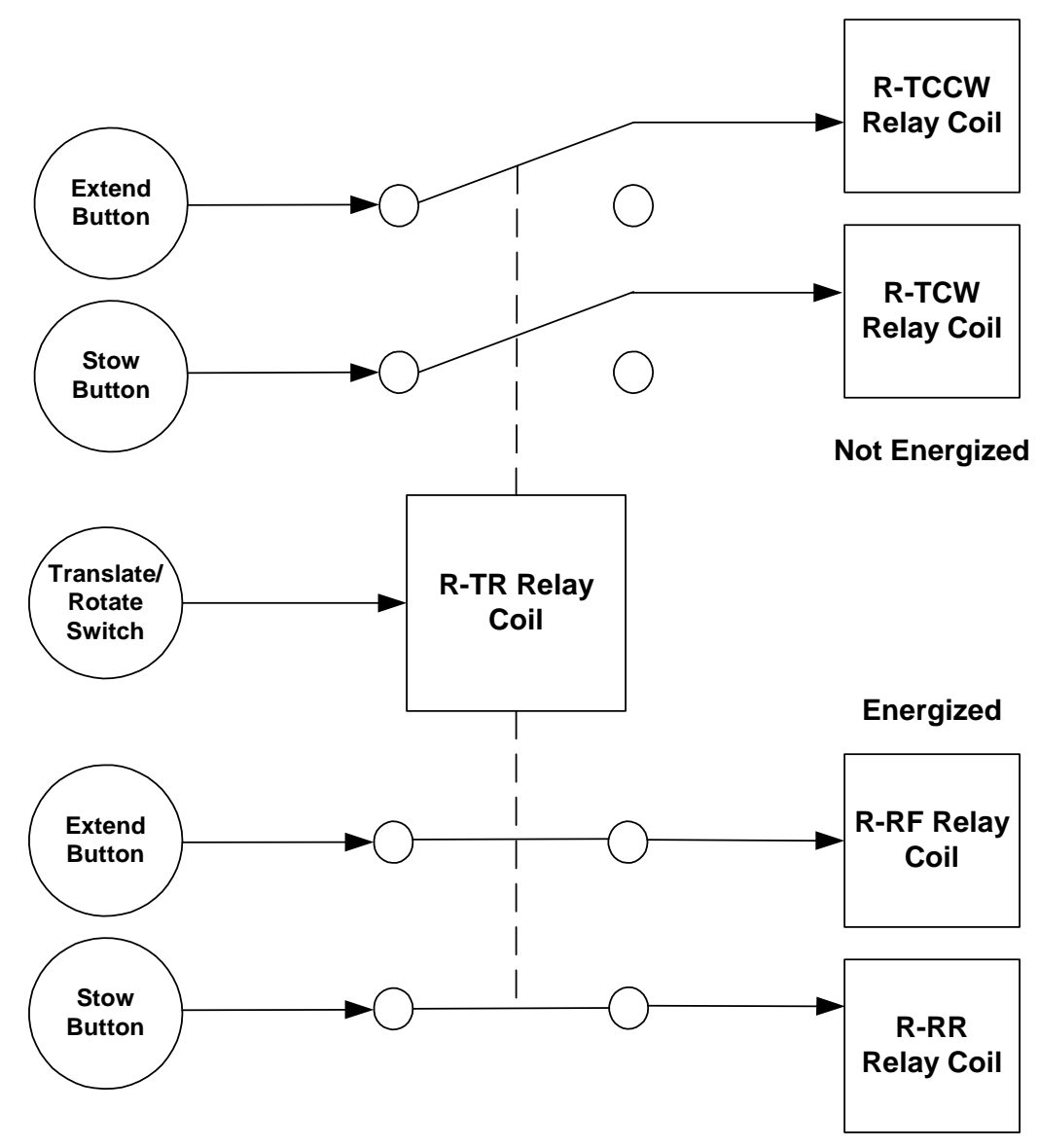

Figure 3.25: Block Diagram of R-TR Relay

The final relay to discuss is the R-PLC relay in the PLC circuit diagram. This acronym stands for "Relay - Programmable Logic Controller." This relay is energized when the Automatic/Manual selector switch on the pendant is set to "Automatic." When energized, this relay sends $220 \mathrm{VAC} 60 \mathrm{~Hz}$ to the PLC to turn it on and run Automatic mode. Automatic mode will be further discussed in Chapters 4 and 5. A block diagram illustrating the use of the R-PLC relay is shown below in Figure 3.26. 


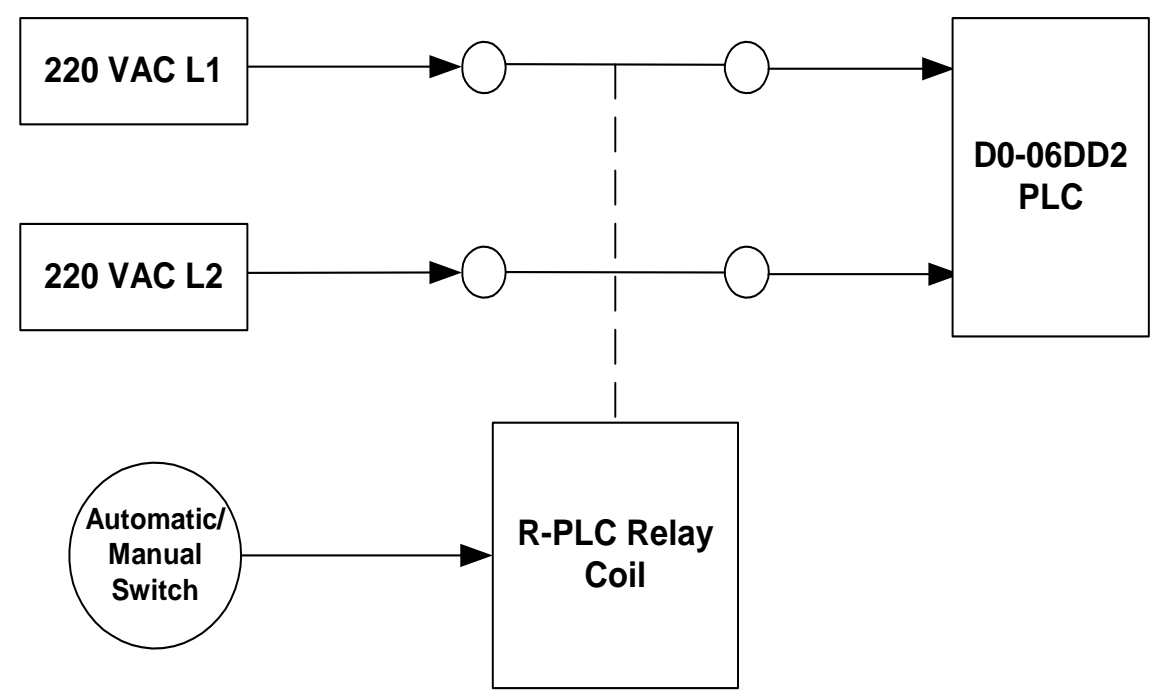

Figure 3.26: Block Diagram of R-PLC Relay

The relay chosen to perform all these tasks was the QL2X1-D24 available from Automation Direct. It is pictured in Figure 3.27 shown below.

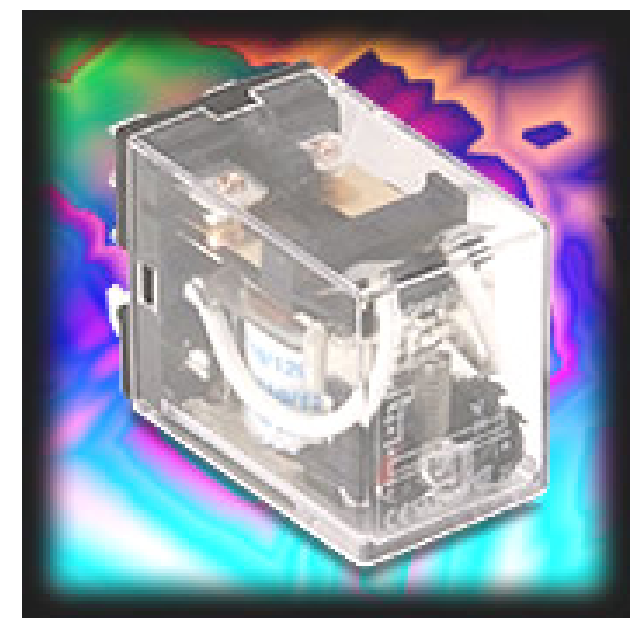

Figure 3.27: QL2X1-D24 24VDC Relay [32]

Important specifications for the QL2X1-D24 are given in Table 3.8 below. Further specifications can be found in Appendix 9. 
Table 3.8: QL2X1-D24 Relay Specifications [33]

\begin{tabular}{|c|c|}
\hline Item & Specification \\
\hline \multicolumn{2}{|c|}{ Contact Specifications } \\
\hline Contact Rating, Current & $10 \mathrm{~A}$ \\
\hline Contact Rating, Max. Voltage & $250 \mathrm{VAC} / 125 \mathrm{VDC}$ \\
\hline Configuration & 2PDT \\
\hline \multicolumn{2}{|c|}{ Coil Specifications } \\
\hline Coil Voltage & $24 \mathrm{VDC}$ \\
\hline Rated Current at $50 \mathrm{~Hz} / 60 \mathrm{~Hz}$ & $36.9 \mathrm{~mA}$ \\
\hline Coil Resistance & $650 \Omega$ \\
\hline Power Consumption & $0.9 \mathrm{~W}$ \\
\hline Options & LED Indicator, Diode Protection \\
\hline \multicolumn{2}{|c|}{ General Specifications } \\
\hline Operate Time & $25 \mathrm{~ms}$ \\
\hline Release Time & $25 \mathrm{~ms}$ \\
\hline Vibration Resistance & $10 \mathrm{~Hz}$ to $55 \mathrm{~Hz}$ \\
\hline Shock Resistance & $1,000 \mathrm{~m} / \mathrm{s}^{2}$ (approx. 100G) \\
\hline Ambient Temperature & $-25^{\circ} \mathrm{C}$ to $70^{\circ} \mathrm{C}\left(-13^{\circ} \mathrm{F}\right.$ to $\left.158^{\circ} \mathrm{F}\right)$ \\
\hline Ambient Humidity & $45 \%$ to $85 \%$ Relative Humidity \\
\hline Weight & $35 \mathrm{~g}(1.24 \mathrm{oz})$. \\
\hline Socket Needed & SQL08D \\
\hline
\end{tabular}

\subsubsection{Limit Switches}

To protect the operator from damaging the translation motor or any other part in the system, two mechanical limit switches were added to the design of the circuit. One limit switch was placed at the stowed position and the other switch was placed at the extended position of the translating plate's path of motion. Whenever the plate translates too far in either direction, the limit switch will be "tripped" and the motion will stop. This is done by putting the limit switches in line with the signal from the R-TR relay to the R-TCW and R-TCCW relays. The "stowed limit switch" is placed in line with the RTCW relay and the "extended limit switch" is placed in line with the R-TCCW relay.

The limit switch chosen for the system is the ABM6E42Z11 available from Automation Direct. It comes equipped with an aluminum chassis and a stainless steel 
roller actuator. It also has three cable entry holes that will accommodate $1 / 2$ " NPT conduit [34]. This limit switch is pictured in Figure 3.28 shown below.

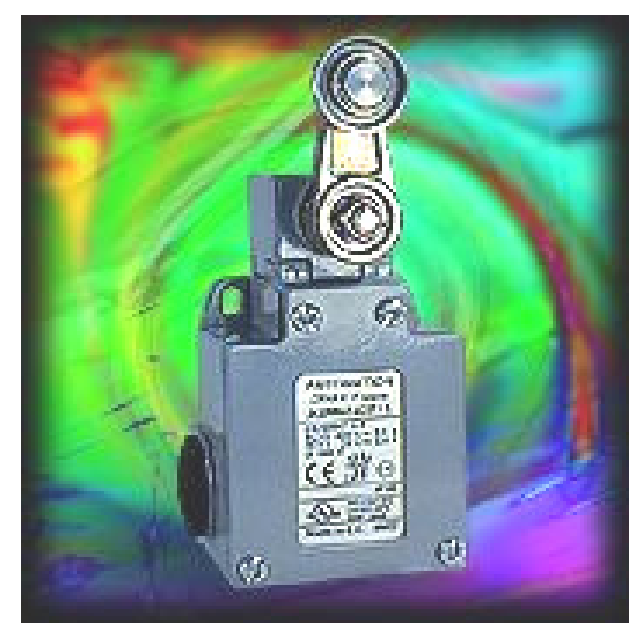

Figure 3.28: ABM6E42Z11 Limit Switch [34]

\subsubsection{Pendant Circuit Design}

The pendant has a combination of five pushbuttons and switches and several tasks to accomplish. The Extend and Stow buttons actually have to serve a dual purpose. When the system is in Manual mode, these buttons should relay the +24VDC signal directly to the respective translation relay; when the system is in Automatic mode, these buttons should send the +24VDC signal to the PLC (discussed further in Chapters 4 and 5). These separate functions can be realized by using two different contact blocks (Automatic and Manual) for both the Extend and Stow buttons.

First, the +24 VDC signal will be brought into the pendant. Since the Emergency Stop button is supposed to end all motion when pressed, this button is placed on the +24VDC signal line with a normally closed (NC) contact. When the button is pressed, the circuit is opened and the $+24 \mathrm{VDC}$ signal is not relayed through the other buttons; therefore, none of the relays are energized in the circuit and everything turns off. 
From the emergency stop button, the +24VDC signal is run through the Automatic/Manual selector switch. When the switch is on "Automatic", the +24VDC signal is relayed to three places: (1) the R-PLC relay, (2) the Extend button (Automatic NO contact), and (3) the Stow button (Automatic NO contact). Then, when either the Extend or Stow buttons are pushed, the circuit is closed and the +24VDC signal is relayed to the respective input on the PLC (inputs defined in Chapter 5).

When the switch is on "Manual", the +24VDC signal is relayed to three places: (1) +24VDC turns the red Manual LED Indicator on, (2) the Translate/Rotate switch, which should only receive power in Manual mode (this switch is inoperable in Automatic mode), and (3) the Extend button (Manual NC contact). When the Extend button is not being pressed, the signal is sent through the $\mathrm{NC}$ contact to the Stow button; this ensures that the user cannot send an "extend" and "stow" signal to the system at the same time in manual mode. When the Extend button is pressed, the +24VDC signal is relayed to the $\mathrm{R}-\mathrm{TCCW}$ relay; when the Stow button is pressed, the +24VDC signal is relayed to the RTCW relay. This entire process is illustrated in the drawing "C-130 Pendant Schematic" found in Appendix 6. 


\section{Chapter 4: Automatic Mode Hardware Design}

As discussed previously, a Programmable Logic Controller (PLC) will execute the automatic mode of deployment of the mechanical arm. First, though, the WVUCIRA engineers had to look at the operation of the mechanical arm and sensor pod itself and recall the deployment steps of the system presented earlier in Chapter 1. First, the translating plate has to travel 19 inches outward, moved by the $110 \mathrm{VAC} 60 \mathrm{~Hz}$ translating motor. Second, the mechanical arm has to be rotated $206^{\circ}$ to its final position under the C-130 door. Finally, the translating plate has to be moved backward until it presses up firmly against the butt plate on the door, providing stability to the sensor pod and the delicate electrical equipment stored inside. Though the engineers knew the initial translating distance and the rotational angle for every deployment procedure that the arm will undertake, the final distance that the pod must travel back to the butt plate can vary every time, depending on the type of C-130 that the system has been loaded upon and is operating from. This fact had to be taken into consideration; therefore, the use of a proximity sensor to determine the final translating distance back to the butt plate was impossible. Thus, the first task to be undertaken before writing code is to determine the placement of the proximity sensors to identify the position of the translating plate and the rotating arm, and then the second task would be to determine the solution to the problem of identifying when the sensor pod has pulled up tight against the butt plate.

\subsection{Proximity Sensor Design}

Now that it has been determined that automatic mode will use input from proximity sensors, the specific proximity sensors that will be used in the system needs to be determined. There are several determining factors to deciding on a proximity sensor. 
All factors should be considered during the design process. First, the WVU-CIRA engineers reviewed the proximity sensor design criteria, and then finally made a decision as to which proximity sensor to employ in the system.

\subsubsection{Proximity Sensor Design Criteria}

First, should the sensor be an NPN-type or PNP-type; in other words, should the sensor sink or source current when sensing? This needs to be considered with the specific PLC or computing equipment in mind. The PLC inputs either will sink or source current, so the proximity sensor needs to be picked accordingly.

Second, what kind of sensor should it be? There are a several types of proximity sensors, which were clearly defined and discussed in the literature review in Chapter 2. The most popular are inductive proximity sensors and capacitive proximity sensors. Inductive proximity sensors can only sense magnetic metals, while capacitive sensors can sense just about anything, including everything from non-magnetic metals to a person's finger.

Third, what should the sensing distance for the respective proximity sensors be? This question can relate back to what kind of sensor should be chosen, since different kinds of proximity sensors have vastly different sensing distances. Sensing distances can vary from a couple of millimeters to several meters in length. Adding complexity to this problem is the fact that the sensor needs to sense moving components; the translating plate and the rotating arm will be moving when the proximity sensor should sense them.

Finally, in what type of environment will the sensor be used? If the environment is electrically noisy, this could render the proximity sensor useless. However, this problem can be corrected with the use of a shielded sensor. Proximity sensors can be 
built with electrically shielded bodies so that exterior electrical noise cannot interfere with the delicate circuitry found inside the sensor. Also, the cable leading to the sensor can be shielded so that the signal from the sensor cannot be electrically interfered with as well. Considering the electrical environment that the sensor will be used in is extremely important because the noise interference will most likely cause a false positive signal to be generated on the signal line coming from the sensor.

\subsubsection{Choosing a Proximity Sensor}

All these design criteria were weighed in determining the right proximity sensor for the job. First, should the proximity sensor be NPN or PNP? The WVU-CIRA engineers decided that the PLC chosen would sink current at the inputs, so therefore a PNP proximity sensor, a sensor that sources current when sensing, should be chosen so that the two components interface properly.

Second, what kind of sensor should be chosen? The selection process came down to inductive or capacitive proximity sensors. The metal that the sensor will be sensing is aluminum; the rotating arm is made from aluminum, as well as the manual stops underneath the translating plate that the sensors will be seeing. The WVU-CIRA mechanical engineers chose to use aluminum because it is easier to work with and weighs less than stainless steel while also being corrosion resistant. However, aluminum is not a magnetic metal, which makes the use of an inductive proximity sensor impossible. Therefore, a capacitive proximity sensor will be needed.

Third, what sensing distance is required for the chosen proximity sensor? Since the proximity sensor will have to be picking up moving objects, albeit slow-moving objects, it should have a sensing distance that is far enough away so that it picks up the 
moving object and delivers the signal to the PLC in time for it to turn off the respective motor before the object collides with the sensor itself and damages it. A study of available sensors finds that a sensing distance of up to $15 \mathrm{~mm}$ is readily available.

Lastly, should the proximity sensor be built with a shielded body and a shielded cable? The C-130 itself is notorious for being electrically noisy, since it houses power generators and is outfitted with a lot of communications equipment. Also recall the intention of Project Oculus; to deploy sensors such as a FLIR, radar, and an antenna for communication, among various other pieces of equipment. Any of these sensors could cause a critical amount of electrical noise for the proximity sensors. In addition, the power to the rotational and translational motors should be considered. The rotational motor, as mentioned earlier, is a $2.0 \mathrm{HP}$ motor operating from $220 \mathrm{VAC} 60 \mathrm{~Hz}$ 3-phase power that is generated from a PWM inverter. This kind of power has the potential to create a serious amount of electrical noise. With all these possible sources of electrical noise that can cause havoc with the proximity sensor, it was decided that a proximity sensor with a shielded body and cable would be best for the job at hand.

The final design constraints for a proximity sensor are thus: a PNP capacitive proximity sensor with a sensing distance of up to $15 \mathrm{~mm}$ and comes equipped with a shielded body and cable. One product that meets these requirements is the CT1-AP-1A, a capacitive proximity sensor that encompasses most of these specified criteria and made available by Automation Direct. The CT1-AP-1A is pictured in Figure 4.1 shown below. 


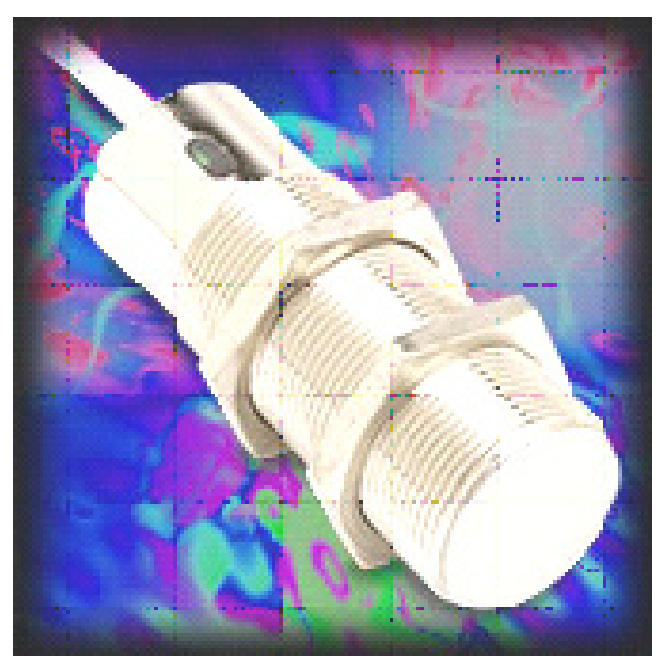

Figure 4.1: CT1-AP-1A Proximity Sensor [35]

The CT1-AP-1A has two status LED's in its base; a green "Power-On" LED and a red "Sensing" LED. The equivalent circuit for the PNP output is shown in Figure 4.2.

\section{PHP output}

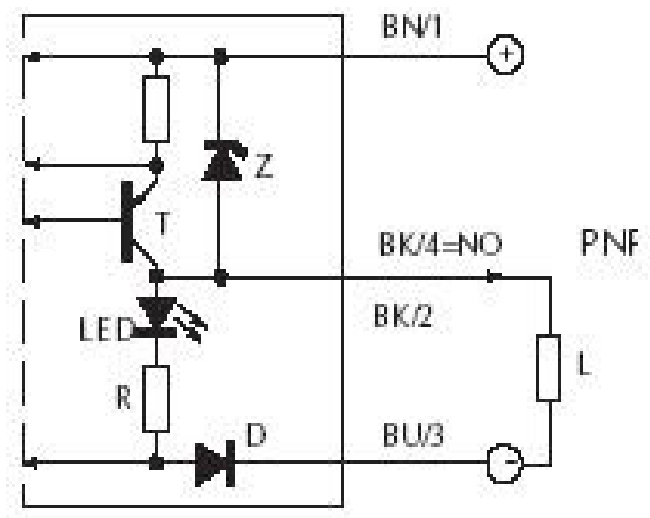

Figure 4.2: CT1-AP-1A Equivalent Output Circuit [36]

Relevant specifications for the CT1-AP-1A are given below in Table 4.1; further specifications can be found on the CT1-AP-1A data sheet supplied from Automation Direct shown in Appendix 11. 
Table 4.1: Specifications of the CT1-AP-1A Proximity Sensor [36]

\begin{tabular}{|l|l|}
\hline \multicolumn{1}{|c|}{ Item } & \multicolumn{1}{c|}{ Specification } \\
\hline Size of sensing face & $30 \mathrm{~mm}$ \\
\hline Power Source & $10-30 \mathrm{VDC}$ \\
\hline Maximum Source Current & $200 \mathrm{~mA}$ \\
\hline Output Type & PNP \\
\hline Shielded/Unshielded & Shielded Body, Unshielded 3-Wire Cable \\
\hline Sensing Distance & $\begin{array}{l}\text { Adjustable 2-15mm nominal sensing } \\
\text { distance }\end{array}$ \\
\hline NO or NC? & Normally Open Output \\
\hline Type of Sensor? & Capacitive \\
\hline
\end{tabular}

By examining the specifications of this specific sensor, the reader will notice that the 3-wire cable for the sensor is not shielded. However, this is easily fixed by replacing the supplied cable with a piece of shielded 3-conductor 18 AWG cable. The three wires in the cable are for +24 VDC and DC common, so that the sensor can be powered, and a signal line that will carry current whenever the sensor is sensing an object.

Now that a proximity sensor has been chosen, the engineers must decide where the sensors will be placed. This topic is discussed in the next section.

\subsection{Proximity Sensor Placement}

To determine the placement of the proximity sensors, the WVU-CIRA engineers first had to establish what positions needed to be sensed. It was decided that it was important to sense the instant when the translating plate or the rotating arm had finished a given movement.

\subsubsection{Placement of the Translation Proximity Sensors}

The movements that the translating plate would be performing during the extending and stowing procedures would be translating outward a full 19 inches and 
returning to its "home" position. Therefore, one proximity sensor would be needed at the "home" position and another would be needed at the 19 inch mark. This "home" position sensor was named the "Translation Stow Sensor," or otherwise known as the "T-Stow Sensor," and the sensor placed at the 19-inch mark was named the "Translation Extend Sensor," or otherwise known as the "T-Extend Sensor." It was decided that the proximity sensors would be a normally open circuit until the translating plate reached the sensor, at which time the proximity sensor would sense the plate was there and close the circuit.

\subsubsection{Placement of the Rotation Proximity Sensors}

The movements that the rotating arm would be performing during the extending and stowing procedures would be rotating outward $206^{\circ}$ to its position under the door and rotating back to the arm supports mounted on top of the translating plate. Therefore, one proximity sensor would be mounted on the arm support itself to see when the arm had reached its stowed position, and another would be placed on the front of the translating plate underneath the rotating shaft to sense when the arm had finished rotating $206^{\circ}$. The proximity sensor mounted on the arm support was named the "Rotation Stow Sensor," also known as the "R-Stow Sensor," and the proximity sensor mounted on the front of the translating plate was named the "Rotation Extend Sensor," also known as the "R-Extend Sensor." As before, it was decided that these proximity sensors would be a normally open circuit until the rotating arm reached the sensor, at which time the proximity sensor would sense the arm was there and close the circuit.

In the end, the important positions of the translating plate and the rotating arm should be known with the use of four simple proximity sensors. The placement of these sensors (shown in red) as discussed above is illustrated in Figure 4.3 shown below. 

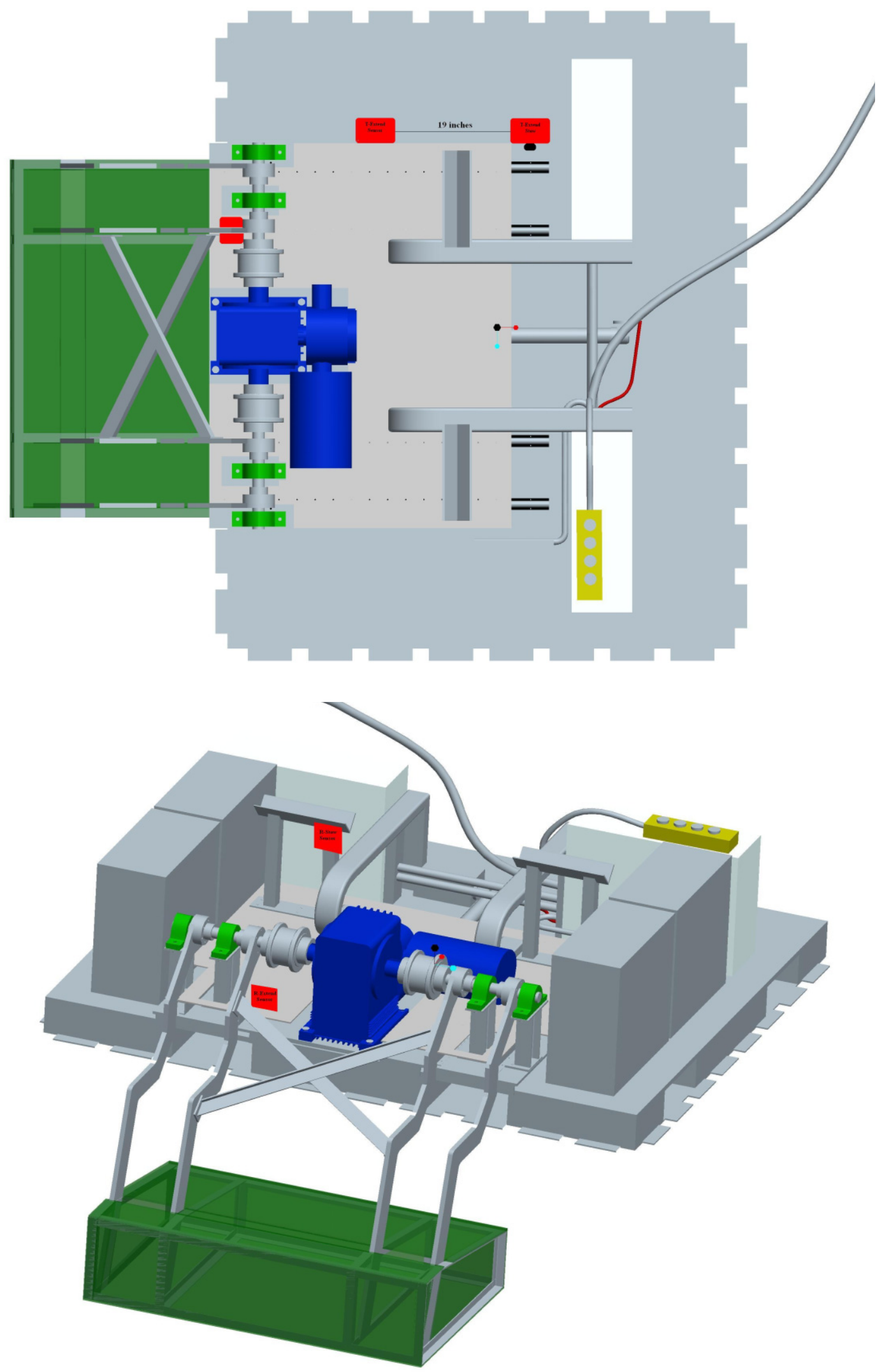

Figure 4.3: Placement of Proximity Sensors on the Sensor Pallet [5] 


\subsection{Final Deployment Positioning - Current Sensor}

The sensor pod is in its fully deployed position when it has finished rotating and pulled back up tight against the butt plate on the C-130 door. But in automatic mode, how will the PLC be told that the sensor pod has finished pulling up against the door? As discussed before, the use of a proximity sensor to perform this operation is impossible.

\subsubsection{Solution - Current Sensor}

To solve this problem, the WVU-CIRA engineers looked at the conditions surrounding the problem; in other words, what conditions exist when the sensor pod has pulled up against the door that did not exist before it happened? The sensor pod is pulled back against the door by using the 110VAC $60 \mathrm{~Hz}$ translational motor. Whenever the sensor pod pulls up against the door and cannot be moved any further, this causes the translational motor to "bind up," which results in a current spike to the motor. If the PLC could sense this current spike, then it would know that the sensor pod has reached its fully deployed state and therefore turn off the translation motor. To perform this operation, a current sensor can be used; the PLC should be able to be programmed to search for a specific range of current so it knows when to shut off the translation motor.

A Hall Effect current sensor was chosen to solve this problem. Regardless of the direction the translation motor is turning, the neutral wire to the motor is always carrying current; therefore, the neutral wire to the translation motor can be run through the Hall Effect current sensor to measure the current to the motor.

The Hall Effect current sensor chosen for the system was the CLN-50 from F.W. Bell. This sensor is pictured in Figure 4.4 shown below. 


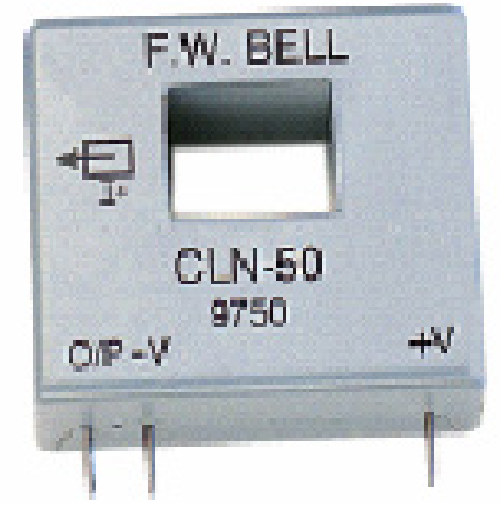

Figure 4.4: CLN-50 Current Sensor [37]

The CLN-50 is a small square device with a square hole in the middle where the currentcarrying wire will pass through the sensor. This current sensor has three pins; a pin each for $\mathrm{a}+\mathrm{V}$ and $-\mathrm{V}$ power source, and a third pin for the output $\mathrm{O} / \mathrm{P}$. The CLN-50 requires a $+/-12$ VDC power source. The power source is used as a reference voltage for the $\mathrm{O} / \mathrm{P}$; the current sensor can measure positive and negative current. Further specifications for the CLN-50 hall-effect current sensor can be found in Appendix 12, a data sheet provided by F.W. Bell.

\subsection{Programmable Logic Controller Design}

Now that all the other components for Automatic Mode have been selected, the heart and soul of the system must be chosen: the Programmable Logic Controller. Choosing a PLC for the job depends on several criteria, each of which was considered carefully by the WVU-CIRA engineers. 


\subsubsection{Programmable Logic Controller Design Criteria}

First, what kind of input does the PLC accept? This refers to whether the inputs sink or source current, and whether the inputs are AC or DC. Second, what kind of outputs does the PLC give? Again, this is in reference to whether the outputs sink or source current, and also whether the outputs are AC or DC. Third, does the PLC have the ability to accept different kinds of input? There can be a mixture of AC and DC inputs; this system may need a PLC that has this kind of flexibility in its inputs, whether the inputs come standard on the PLC or can be added through additional optional modules. A final specification that would be appreciated is to choose a PLC that is easy to program. Most commercially available PLCs use ladder logic to create their programs. Ladder logic is an easy way to define the certain outputs that should be turned on when specific inputs are present.

\subsubsection{Choosing a Programmable Logic Controller}

Now that the design criterion has been established, a choice for a PLC can be made. Based on the selection of the PNP proximity sensors and the design of the pendant circuit discussed in Chapter 3, the PLC inputs must sink current provided from a 24VDC power source. However, there is also a required input from the CLN-50 current sensor discussed in the previous section. The output provided from this sensor is an AC signal; therefore, the PLC chosen must accept analog input or have the ability to add an expansion module to do so.

As for the next requirement, the PLC outputs need to source DC current. This is based on the fact that the outputs need to energize $24 \mathrm{VDC}$ relays to run the translation

motor, a design that was discussed in Chapter 3, and also must drive 24VDC LED 
indicators, also discussed in Chapter 3. However, this does not define all needed outputs from the PLC. The PLC needs to be able to run the GS2-22P0 motor controller discussed in Chapter 3. Recall that the digital inputs used to control the motor controller source DC current; therefore, the PLC must be able to have two outputs that can sink current.

Keeping these requirements in mind, the D0-06DD2 PLC available from Automation Direct was chosen for Project Oculus. This unit is a cost effective yet easy to program as the solution to the problem at hand. The D0-06DD2 PLC is pictured in Figure 4.5 shown below.

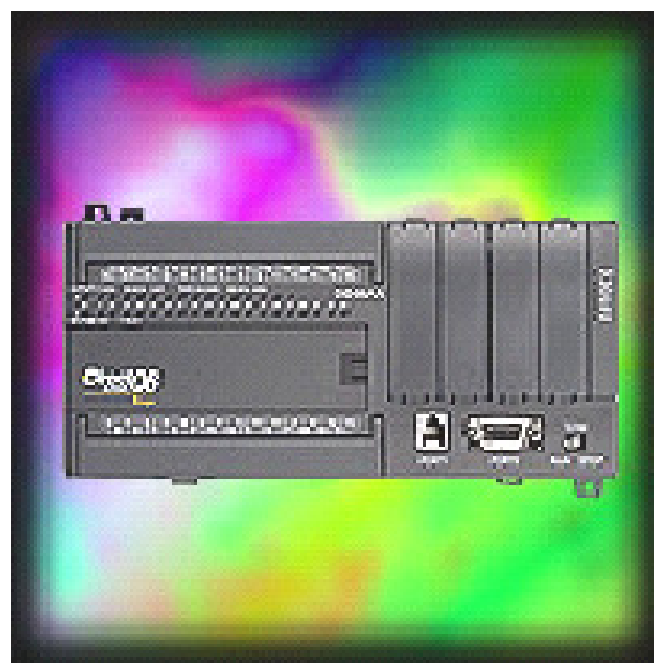

Figure 4.5: D0-06DD2 Programmable Logic Controller [38]

The D0-06DD2 PLC accepts up to 20 24VDC inputs and provides up to 16 24VDC outputs. The first four inputs (inputs $\mathrm{X} 0-\mathrm{X} 3$ ) to the unit are high-speed inputs; they are generally not going to be used for this system. The next 16 inputs (inputs X4X23) are standard inputs [39]. The equivalent circuit for these inputs is shown in Figure 4.6. 


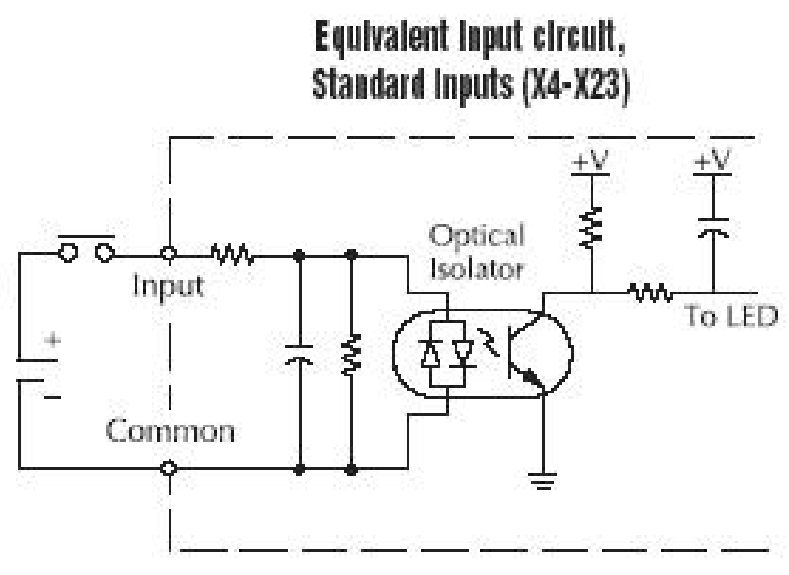

Figure 4.6: Equivalent Input Circuit on the D0-06DD2 PLC [39]

Of the 16 available outputs provided by the D0-06DD2 PLC, the first two outputs (outputs Y0-Y1) are configurable pulse outputs and will not be used in the system. The next 14 outputs (outputs Y2-Y17) are standard and will be used in the system [39]. The equivalent circuit for these standard outputs is shown in Figure 4.7 below.

\section{Equlvalent output clrcult \\ Standard output (Y2-Y17)}

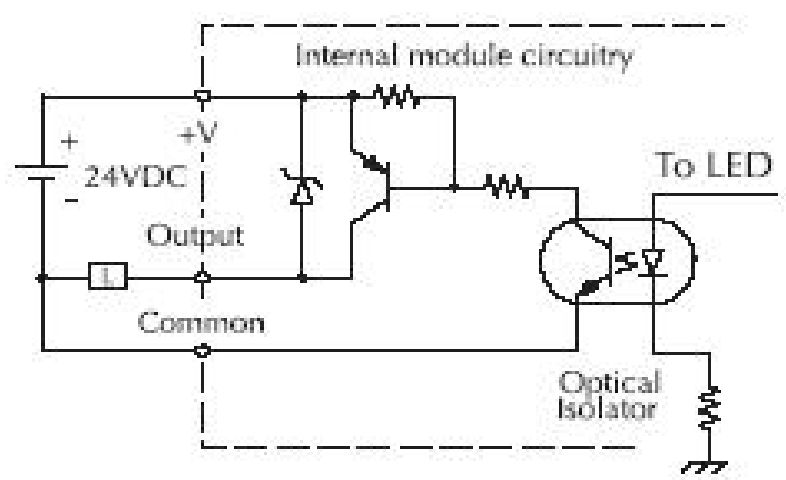

Figure 4.7: Equivalent Output Circuit on the D0-06DD2 PLC [39]

The D0-06DD2 PLC also has four expansion slots for additional optional modules. These expansion slots will be used for optional modules that will handle the 
AC input from the current sensor and provide the output needed for the digital inputs to the GS2-22P0 motor controller. These expansion modules will be discussed further in Section 4.4.4 PLC Optional Modules.

Relevant specifications for the D0-06DD2 PLC are given below in Table 4.2; further specifications can be found on the D0-06DD2 PLC data sheet supplied from Automation Direct shown in Appendix 13.

Table 4.2: Specifications of the D0-06DD2 Programmable Logic Controller [39]

\begin{tabular}{|c|c|}
\hline Item & Specification \\
\hline Power Supply & $110 / 220 \mathrm{VAC}$ \\
\hline Auxiliary DC Power Supply & 0.3A 24VDC Power Supply \\
\hline Communication Ports & $\begin{array}{l}\text { - } 2 \text { built-in RS232C ports } \\
\text { - } \mathrm{RS} 232 \mathrm{C} / \mathrm{RS} 422 / \mathrm{RS} 485 \text { secondary port }\end{array}$ \\
\hline Inputs & $\begin{array}{l}\text { - } 20 \text { DC inputs } \\
\text { - } 12-24 \text { VDC current sinking/sourcing } \\
\text { - } 5 \text { isolated commons (4 I/Ps per common) } \\
\text { - } 4 \text { configurable high-speed I/Ps }\end{array}$ \\
\hline Outputs & $\begin{array}{l}\text { - } 16 \mathrm{DC} \text { outputs } \\
\text { - } 12-24 \mathrm{VDC} \text { current sourcing } \\
\text { - } 1.0 \mathrm{~A} \text { per point maximum } \\
\text { - } 4 \text { non-isolated commons (4 O/Ps per } \\
\text { common) }\end{array}$ \\
\hline Expansion Slots & 4 option slots available \\
\hline $\mathrm{CPU}$ & DL06 CPU \\
\hline Programming Software & DirectSoft $32^{\odot}$ Software for the DL06 CPU \\
\hline DIN Rail Mountable? & Yes \\
\hline
\end{tabular}

\subsubsection{PLC Accessories}

Along with the D0-06DD2 PLC, several accessories needed to be added. First, this PLC affords the ability to add an LCD display to the front of the unit. When programming the unit, text can be written to the LCD display to inform the user of which step the PLC is performing at any given time. The LCD display that is available for the 
D0-06DD2 PLC is the D0-06LCD, also available from Automation Direct. It can display 16 characters across two rows, for a total display of 32 maximum characters [40]. The D0-06LCD LCD display is pictured in Figure 4.8 shown below.

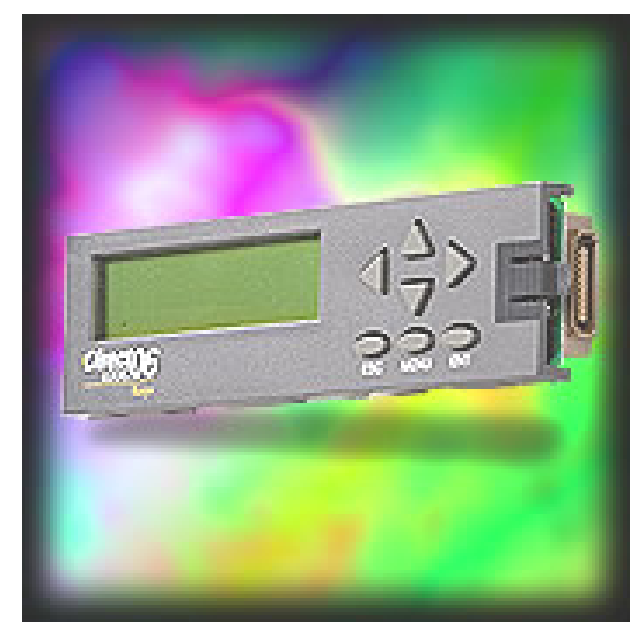

Figure 4.8: D0-06LCD LCD Display for the D0-06DD2 PLC [40]

The next accessory for the D0-06DD2 PLC that is needed is the programming cable. Once the programmer writes the controlling program on a personal computer, the programming cable is needed to transfer this program to the PLC. The programming cable for the D0-06DD2 is the D2-DSCBL, available from Automation Direct. It is a 12ft. (3.66m) RS232 shielded PC programming cable that is specifically used for DL05, DL06, DL205, D3-350, and D4-450 CPUs. It is equipped with a 9-pin D-shell female connector on one end that connects to the PC, and an RJ12 6P6C connector on the other end that attaches to the D0-06DD2 PLC via Port 1 [41]. This important cable is pictured in Figure 4.9. 


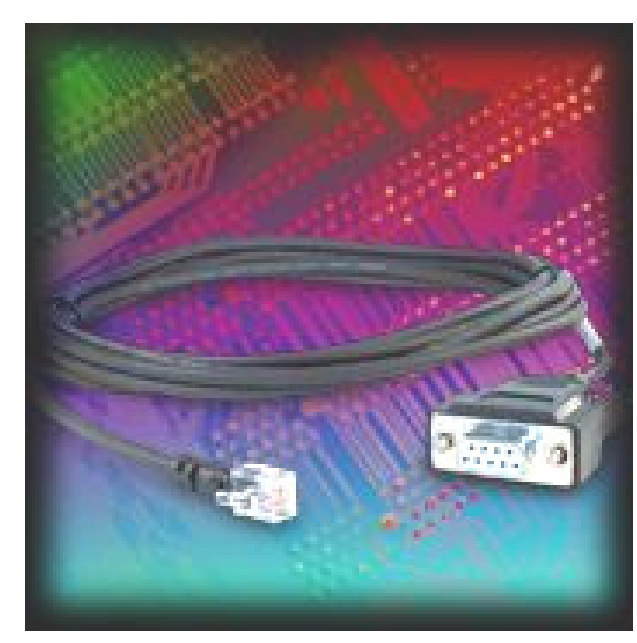

Figure 4.9: D2-DSCBL Programming Cable for the D0-06DD2 PLC [41]

Finally, the PLC cannot be programmed without the programming software itself.

Of course, there is specific programming software for the particular Version 4.0 DL06 CPU that controls the D0-06DD2 PLC. This programming software is called DirectSoft $32^{\odot}$, and it is part number PC-PGM-BRICK, available from Automation Direct. As is the case with most PLCs, this programming software is based on ladder logic. The ladder rungs are illustrated in the software; the inputs that make the rung "true" are placed on the rungs and the resulting output(s) are placed at the end of the rung. The software provides the user with instant programming error-checking, the ability to add element names and documentation, and full printing features. It also manages the connection between the PC and the PLC. DirectSoft $32^{\odot}$ is compatible with Windows 98/2000/NT 4.0 or later, and all Windows XP versions. There are no UNIX, LINUX, Macintosh, or DOS versions of this product available. The minimum system requirements for running this software are a Pentium/Celeron CPU running at $333 \mathrm{MHz}$ clock speed, CD-ROM for loading the software, 32MB of free memory, $11 \mathrm{MB}$ free hard 
drive disk space, at least one unused serial communication port, and a color SVGA monitor [42].

\subsubsection{PLC Optional Modules}

The D0-06DD2 PLC gives the user the ability to add up to four optional modules; Project Oculus will require the use of two of these expansion slots. The CLN-50 halleffect current sensor has an analog output that the PLC must be able to receive. However, the standard inputs on the unit are 12-24 VDC inputs. Therefore, an optional module that will enable the D0-06DD2 PLC to accept an analog input must be added. The F0-04AD-1 4-channel analog input module, available from Automation Direct, will be installed in the first expansion slot. This input module has a range of $4-20 \mathrm{~mA}$ or 0 20mA and a 12 bit resolution. The F0-04AD-1 input module is shown in Figure 4.10.

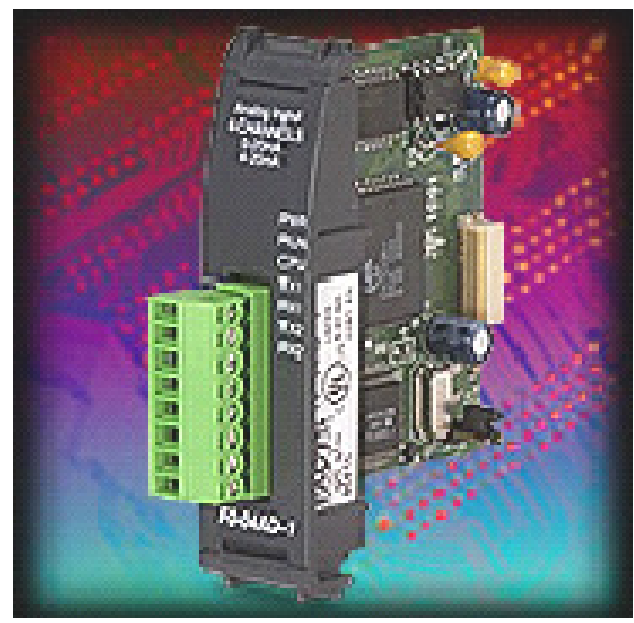

Figure 4.10: F0-04AD-1 Analog Input Module [43]

All specifications and user manual information about the F0-04AD-1 analog input module supplied from Automation Direct are shown in Appendix 14. It is important that the module is placed in the first expansion slot, the one that is located to the far left of the 
expansion slots. The reason for this is software based; when writing the program to control the PLC, code is written to configure the F0-04AD-1 analog input module and refer to memory locations associated with the first expansion slot.

For the F0-04AD-1 analog input module to accept the signal from the CLN-50 current sensor, the $\mathrm{O} / \mathrm{P}$ signal needs to be rectified into a $+/$ - signal. To do this, the $\mathrm{O} / \mathrm{P}$ signal is ran through a bridge rectifier. The circuit to perform this operation is shown below in Figure 4.11.

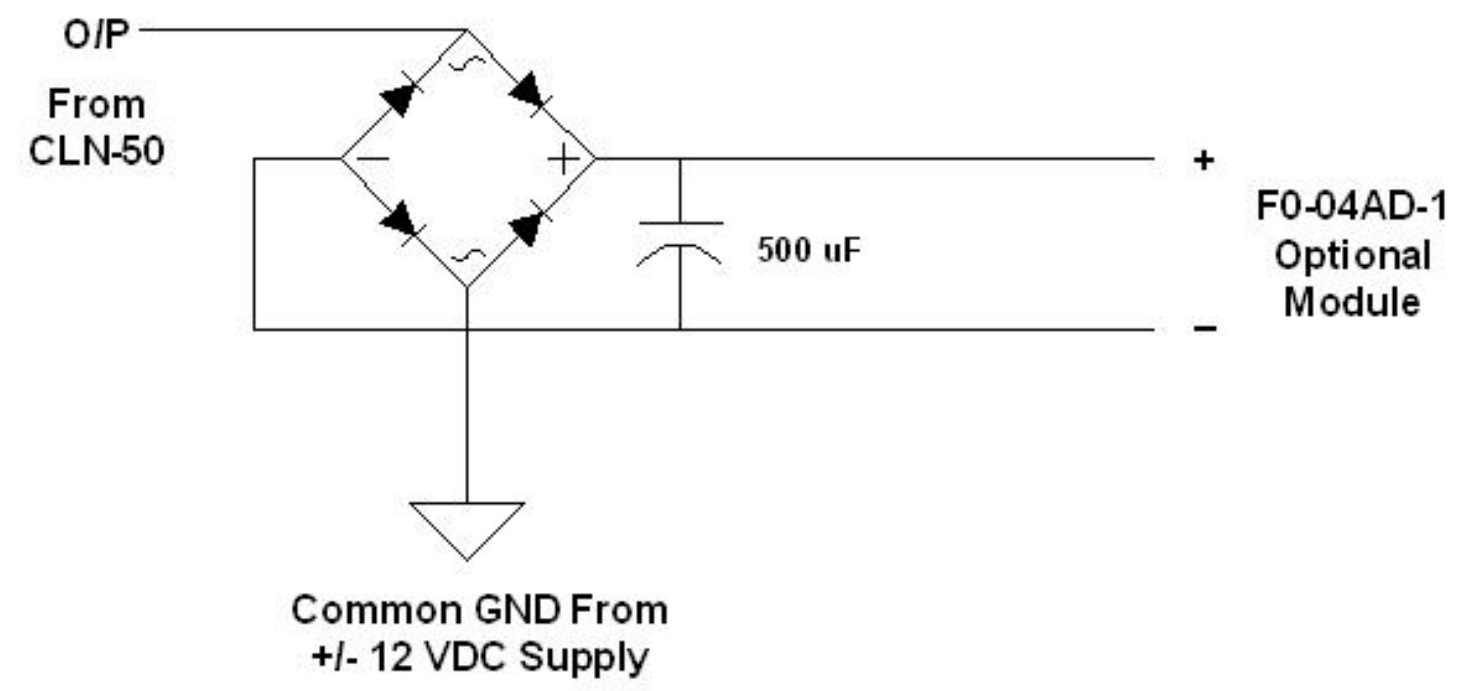

Figure 4.11: Current Sensor to F0-04AD-1 Analog Input Module Circuit

Studying the specifications for the D0-06DD2 PLC, one will find that the outputs source current. The source current here is needed to energize the relays for the translation motor and drive the LED indicators, but this type of output will not operate the digital inputs on the GS2-22P0 motor controller. Therefore, the second optional module that is needed for the system is a digital output module that will sink current rather than source current. The optional module chosen for this operation is the D008CDD1 available from Automation Direct. This module is actually a combination of 
four digital inputs and four digital outputs; however, only the digital outputs are important here. This module is pictured in Figure 4.12 shown below.

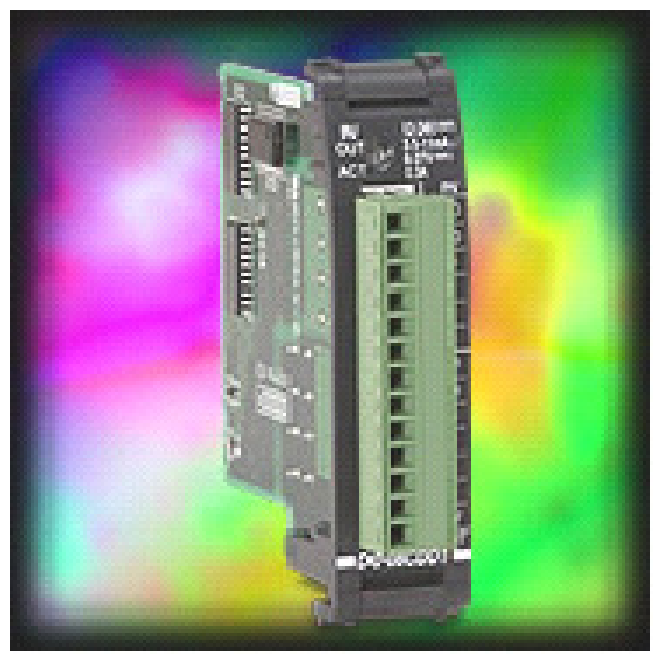

Figure 4.12: D0-08CDD1 Digital Output Module [44]

The outputs' operating voltage range is 6-27 VDC, and the maximum output current is $0.3 \mathrm{~A}$ per point and $1.2 \mathrm{~A}$ per common [44]. All specifications supplied by Automation Direct for the D0-08CDD1 digital output module are shown in Appendix 15. Also, the equivalent circuit for the digital output is shown in Figure 4.13 below.

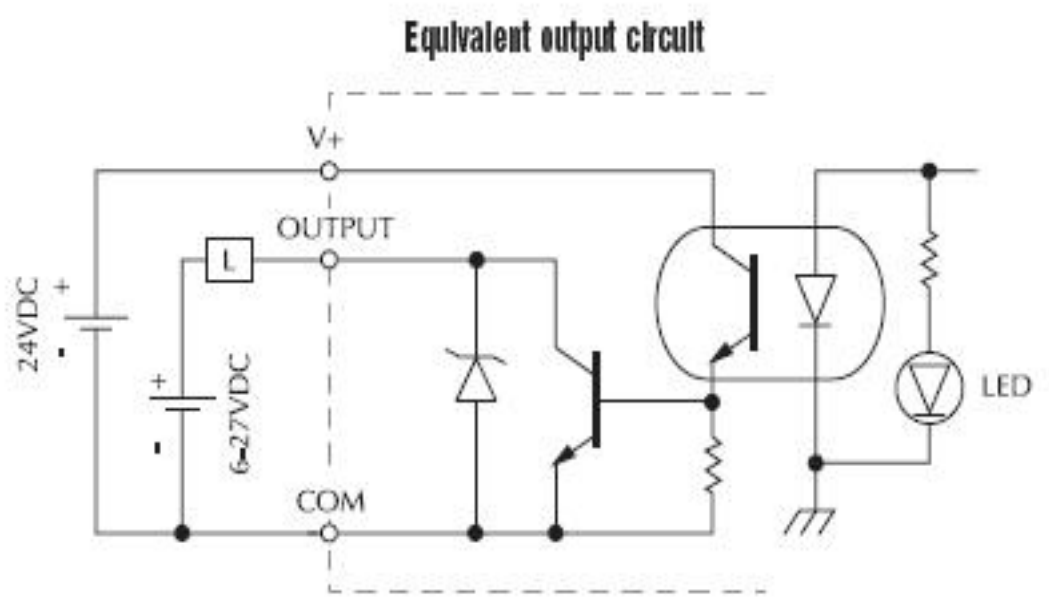

Figure 4.13: Equivalent Output Circuit for the D0-08CDD1 [45] 
This concludes the hardware specifications for automatic mode. Now that the hardware has chosen and the placement for proximity sensors has been set, the program to run automatic mode must be designed and written. Chapter 5 will detail the design and coding of the automatic mode ladder program. 


\section{Chapter 5: Automatic Mode Software Design}

Now that the Programmable Logic Controller (PLC) has been chosen to be the D0-06DD2 available from Automation Direct, the WVU-CIRA computer engineer had to program it to carry out the automatic mode deployment of the sensor arm/pod system. To program the PLC, the engineer needed to use the special programming software designed especially for the DL06 PLC processor, which is the DirectSoft32 ${ }^{\odot}$ programming software that was described in Chapter 2. This chapter will detail the process followed in designing the program and programming the PLC.

First, the inputs to and outputs from the PLC need to be defined. Once the inputs and outputs have been determined, a program must be created that responds to certain groups of inputs and generates the correct corresponding outputs. Finally, certain error states that could occur during operation should be determined and prepared for in the program itself.

\subsection{Definition of PLC Inputs and Outputs}

The PLC inputs and outputs were first defined and then mapped to input and output points on the PLC itself. The inputs have been basically defined in previous chapters. There are four proximity sensors, defined in Chapter 4 as "T-Stow Sensor", "TExtend Sensor", "R-Stow Sensor", and "R-Extend Sensor", as well as two operator pushbuttons on the pendant, the Extend and Stow buttons, that need to be inputs accepted by the PLC. These six inputs take the form of 24VDC signals. Also, there is an analog signal generated by the CLN-50 current sensor that the PLC must see as an input. This input is received by the optional F0-04AD-1 analog input module discussed in Chapter 4. For the D0-06DD2 PLC to accept inputs from this optional module, the optional module 
and the expansion slot that it is mounted in needs to be "configured" in the program itself, which was covered in Chapter 2.

The outputs have changed during the course of the design and now have been finalized at five standard outputs and two outputs from the D0-08CDD1 digital output module. The standard outputs are of course two signals to turn on the R-TCW and RTCCW relays, an output to turn on the green Automatic Mode LED indicator, and two outputs to turn on the Translation and Rotation Operating LED indicators. The other LED indicators that are present in the system will be driven by their respective proximity sensors.

The two outputs from the D0-08CDD1 digital output module control the digital inputs of the GS2-22P0 motor controller. When using the D0-08CDD1 module, the D006DD2 PLC reserves certain output reference names for the four outputs present on the module. D0-08CDD1 module outputs 0-3 directly map to D0-06DD2 PLC outputs Y100-Y103 that can be controlled through the DirectSoft $32^{\odot}$ programming software. The D0-08CDD1 module does not need to be configured for use in the program like the F0-04AD-1 module; it is strictly plug-and-play.

These inputs and outputs described above were mapped to the D0-06DD2 PLC input/output points, which are illustrated in Figure 5.1 shown below. All the commons on the input side of the PLC, points C0-C4, were tied together to the PS24-075D 24VDC power supply common. The voltage input points on the output side were tied together to the PS24-075D + 24VDC power supply, and the single common point C0 was wired to the PS24-075D power supply common. 


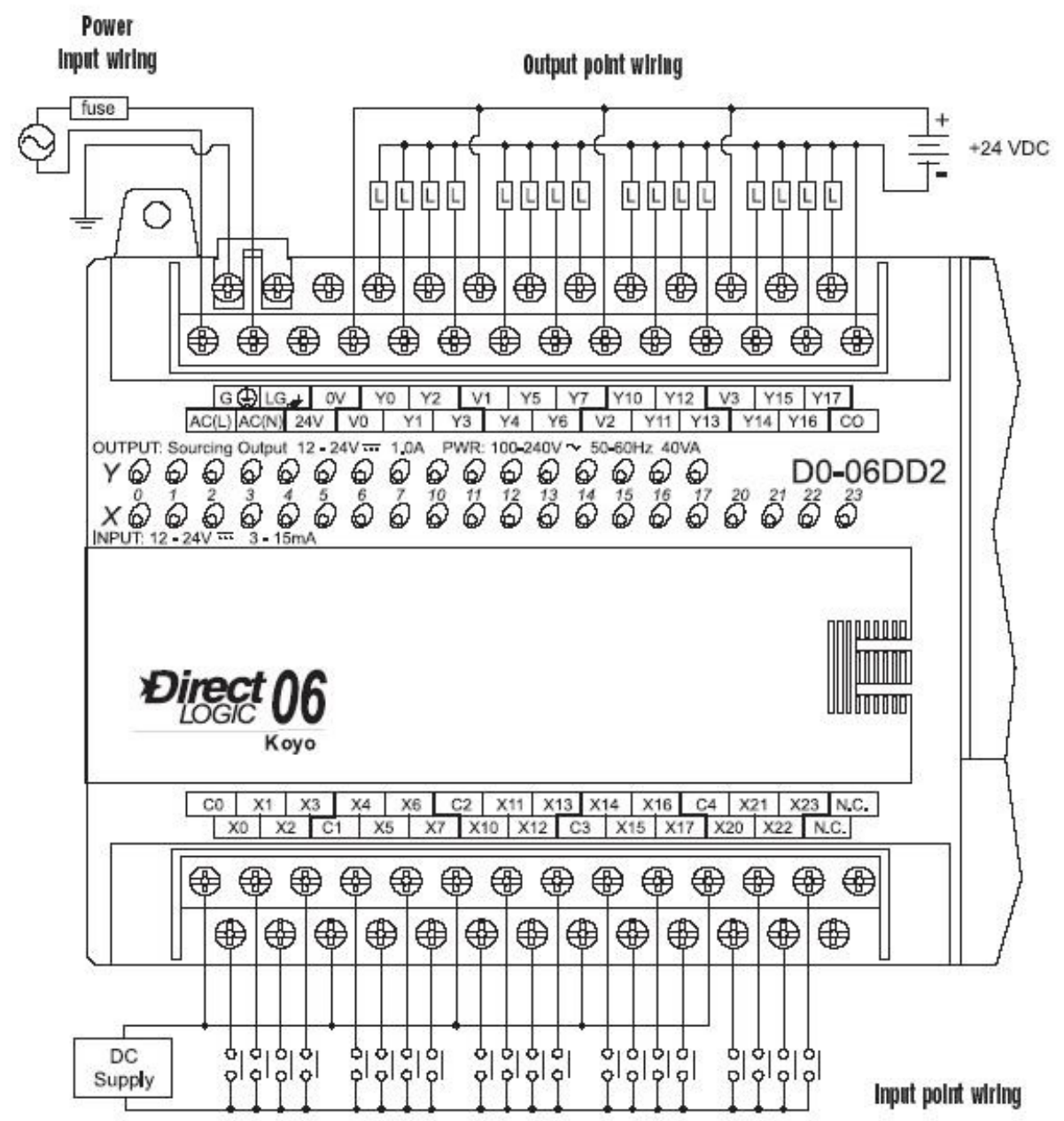

Figure 5.1: D0-06DD2 PLC General Wiring Diagram [39]

This figure provides a general wiring diagram for the D0-06DD2 PLC; for the specific wiring diagram created for the Project Oculus system, please see the drawing " $\mathrm{C}$ 130 PLC Circuit Diagram" shown in Appendix 6 "Sensor Pallet Control Circuit Diagrams.”

Table 5.1 shown below illustrates the way the inputs and outputs were mapped to the input/output points on the PLC. Inputs $\mathrm{X} 0-\mathrm{X} 3$ were not used because they are highspeed inputs; likewise, outputs Y0-Y1 were not used because they generate pulse outputs. Since outputs Y2-Y3 were in the same bank as Y0-Y1, they were also skipped. 
Table 5.1: D0-06DD2 PLC Input/Output Map

\begin{tabular}{|c|c|c|c|}
\hline \multicolumn{2}{|c|}{ Inputs } & \multicolumn{2}{|c|}{ Outputs } \\
\hline Input Point & Status & Output Point & Status \\
\hline $\mathrm{X} 0$ & $\begin{array}{l}\text { Not Used - High } \\
\text { Speed Input }\end{array}$ & Y0 & $\begin{array}{c}\text { Not Used - Pulse } \\
\text { Output }\end{array}$ \\
\hline $\mathrm{X} 1$ & $\begin{array}{l}\text { Not Used - High } \\
\text { Speed Input }\end{array}$ & Y1 & $\begin{array}{l}\text { Not Used - Pulse } \\
\text { Output }\end{array}$ \\
\hline $\mathrm{X} 2$ & $\begin{array}{l}\text { Not Used - High } \\
\text { Speed Input }\end{array}$ & $\mathrm{Y} 2$ & Not Used \\
\hline $\mathrm{X} 3$ & $\begin{array}{l}\text { Not Used - High } \\
\text { Speed Input }\end{array}$ & Y3 & Not Used \\
\hline $\mathrm{X} 4$ & Extend Button & Y4 & Not Used \\
\hline $\mathrm{X} 5$ & Stow Button & Y5 & Not Used \\
\hline $\mathrm{X} 6$ & $\begin{array}{l}\text { Rotation Extend } \\
\text { Sensor }\end{array}$ & Y6 & $\begin{array}{l}\text { Translate Operate } \\
\text { LED Indicator }\end{array}$ \\
\hline $\mathrm{X} 7$ & $\begin{array}{l}\text { Rotation Stow } \\
\text { Sensor }\end{array}$ & Y7 & Not Used \\
\hline $\mathrm{X} 10$ & $\begin{array}{c}\text { Translation Extend } \\
\text { Sensor }\end{array}$ & Y10 & Not Used \\
\hline $\mathrm{X} 11$ & $\begin{array}{c}\text { Translation Stow } \\
\text { Sensor }\end{array}$ & Y11 & $\begin{array}{l}\text { Rotate Operate } \\
\text { LED Indicator }\end{array}$ \\
\hline $\mathrm{X} 12$ & Not Used & Y12 & Not Used \\
\hline $\mathrm{X} 13$ & Not Used & $\mathrm{Y} 13$ & Not Used \\
\hline $\mathrm{X} 14$ & Not Used & Y14 & Not Used \\
\hline $\mathrm{X} 15$ & Not Used & Y15 & Not Used \\
\hline $\mathrm{X} 16$ & Not Used & Y16 & R-TCCW Relay \\
\hline $\mathrm{X} 17$ & Not Used & Y17 & R-TCW Relay \\
\hline $\mathrm{X} 20$ & Not Used & Y100 & GS2-22P0 DI2 \\
\hline $\mathrm{X} 21$ & Not Used & Y101 & GS2-22P0 DI1 \\
\hline $\mathrm{X} 22$ & Not Used & Y102 & Not Used \\
\hline $\mathrm{X} 23$ & Not Used & Y103 & Not Used \\
\hline
\end{tabular}

\subsection{Automatic Mode Program Design}

When determining the design of the PLC program that will operate Automatic mode, a state diagram is a good way to illustrate what needs to happen. The state diagram can show all the stages that the system can be in and the inputs that need to be present to cause a change of state. The state diagram is shown in Figure 5.2 below. 


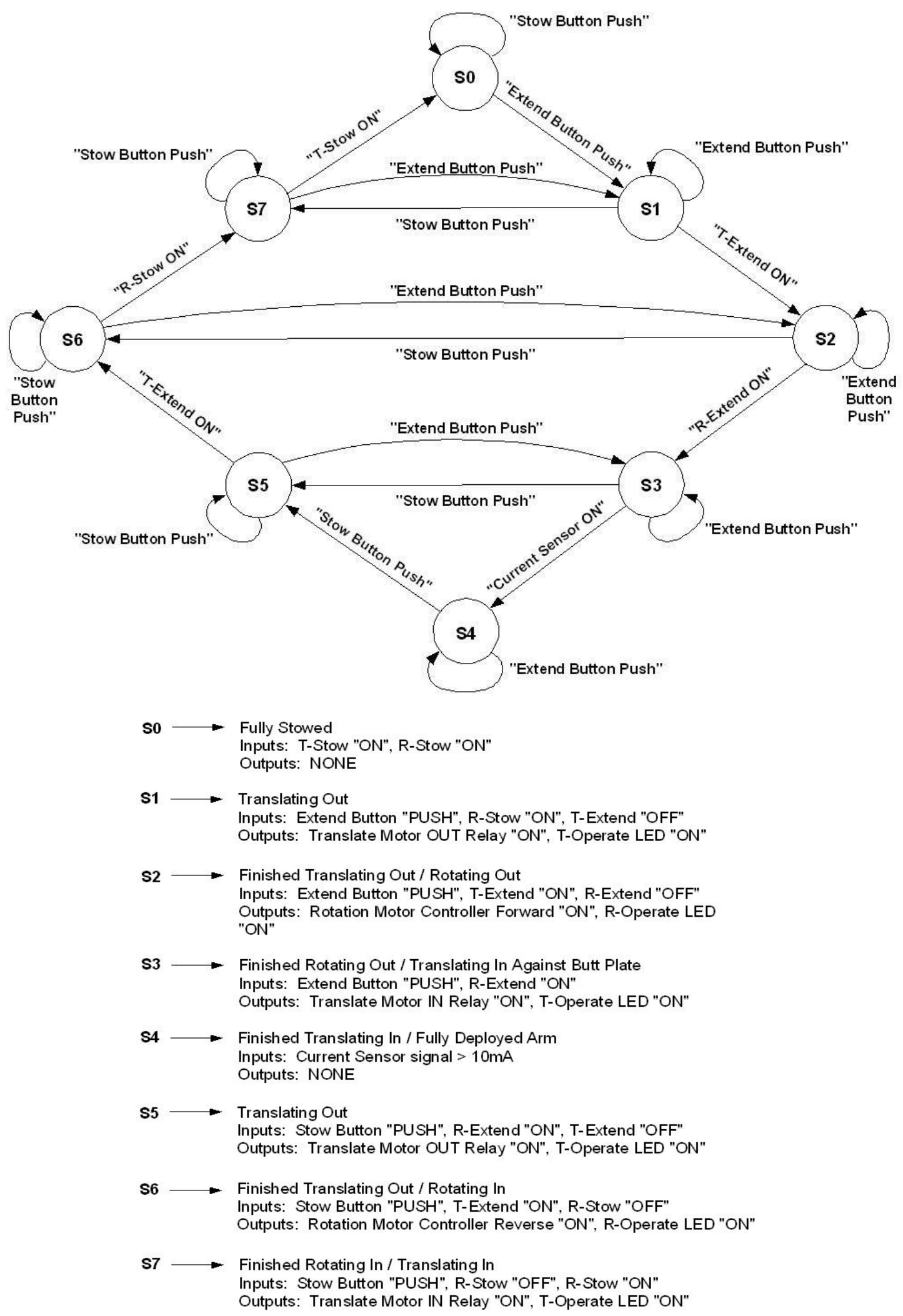

Figure 5.2: PLC Program State Diagram 


\subsubsection{Discussion of the State Diagram}

Recall from Chapter 1 that there are three steps or stages to both of the extending and stowing procedures. When the system is extending, first the translating plate moves outward 19", then the rotating arm rotates $206^{\circ}$, and finally the translating plate moves backward till the Sensor Pod has fit tightly up against the C-130 door. When the system is stowing, first the translating plate moves outward to its 19" fully extended position, then the rotating arm rotates back to its resting position, and then the translating plate moves backward to its fully stowed position.

The state diagram shown in Figure 5.2 above shows each of these states, as well as the stimuli that must be present to jump from state-to-state. The fully stowed position, where the translating plate and rotating arm are in their initial resting positions, is represented by state $\mathrm{S}_{0}$. The fully deployed state, where the arm has rotated completely and the Sensor Pod has been pulled back against the butt plate underneath the door, is represented by state $\mathrm{S}_{4}$.

\subsubsection{State Diagram - System Deployment Procedure}

The three stages of the extending (deployment) procedure are illustrated by states $\mathrm{S}_{1}, \mathrm{~S}_{2}$, and $\mathrm{S}_{3}$. To leave the stowed state $\mathrm{S}_{0}$ and enter the deployment procedure at state $\mathrm{S}_{1}$, the user must press the Extend Button on the operator pendant. This sets the translating plate into motion outward. To do this, the R-TCCW relay must be energized (output Y16 must be turned "ON"). This puts 110VAC on the red wire of the translation motor and turns the motor in the counterclockwise direction, moving the translating plate outward. Also, the Translation Operate LED indicator (output Y6) will be turned on at this time. 
Once the plate has moved 19" outward, it reaches the "T-Extend" proximity sensor. When this sensor is tripped, the system moves to state $S_{2}$, where the rotating arm rotates $206^{\circ}$ to its final position underneath the plane's door. This is done by sending a signal to the GS2-22P0 motor controller digital input DI1, which is done by turning on output Y101. In this stage, the Rotation Operation LED indicator (output Y11) will be turned on as well.

When the rotating arm has completed its motion, it reaches the "R-Extend" proximity sensor. By tripping this sensor, the system is put into state $S_{3}$, where the translating plate pulls the Sensor Pod back against the butt plate underneath the C-130 door. To perform this stage, the PLC must energize the R-TCW relay (output Y17). This puts 110VAC on the blue wire to the translation motor and turns the motor in the clockwise direction, moving the translating plate inward. Again, the Translation Operate LED indicator (output Y6) will be turned on at this time.

Once the Sensor Pod makes contact with the butt plate and pulls up tight, the translation motor pulls more and more current, causing a current spike of up to $11 \mathrm{~A}$ or more. When this happens, the CLN-50 current sensor registers the current spike; the analog output on the $\mathrm{O} / \mathrm{P}$ pin on the $\mathrm{CLN}-50$ sensor will go over $10 \mathrm{~mA}$ at this point. The F0-04AD-1 analog input module is continually taking the value from the $\mathrm{O} / \mathrm{P}$ pin and storing the value in PLC memory location V2000 (directly maps to Channel 1 on the F004AD-1 when mounted in expansion slot 1). A comparison is made during each PLC sweep comparing the value stored in V2000 to V2004, which stores the value $10 \mathrm{~mA}$ in BCD format (1536); at the point that the current spike occurs, the value in V2000 goes 
over $10 \mathrm{~mA}$ and the translation motor is shut off. The system is now in state $\mathrm{S}_{4}$, which is the fully deployed system state.

At any point during this deployment process, the user may be able to push the Extend or Stow buttons on the user pendant. In any of the states $\mathrm{S}_{1}-\mathrm{S}_{4}$, if the Extend button is pushed, the system should remain in its current state. However, if the Stow button is pressed, the system should stop and jump to a different state to begin the stow procedure. If the system is in state $S_{1}$, the system will jump to state $S_{7}$; if the system is in state $S_{2}$, the system will jump to state $S_{6}$; and if the system is in state $S_{3}$, the system will jump to state $\mathrm{S}_{5}$.

\subsubsection{State Diagram - System Stowing Procedure}

The three stages of the stowing (retracting) procedure are illustrated by states $\mathrm{S}_{5}$, $\mathrm{S}_{6}$, and $\mathrm{S}_{7}$. To leave the fully deployed state $\mathrm{S}_{4}$ and enter the retracting procedure at state $\mathrm{S}_{5}$, the user must press the Stow Button on the operator pendant. This sets the translating plate into motion outward. To do this, the R-TCCW relay must be energized (output Y16 must be turned "ON"). This puts $110 \mathrm{VAC}$ on the red wire of the translation motor and turns the motor in the counterclockwise direction, moving the translating plate outward. Also, the Translation Operate LED indicator (output Y6) will be turned on at this time.

Once the plate has moved outward as far as it will go, it reaches the "T-Extend" proximity sensor. When this sensor is tripped, the system moves to state $S_{6}$, where the rotating arm rotates back to its resting position on the arm supports mounted on the translating plate. This is done by sending a signal to the GS2-22P0 motor controller digital input DI2, which is done by turning on output Y100. In this stage, the Rotation Operation LED indicator (output Y11) will be turned on as well. 
When the rotating arm has completed its motion, it reaches the "R-Stow" proximity sensor. By tripping this sensor, the system is put into state $S_{7}$, where the translating plate translates back to its initial, resting, position. To perform this stage, the PLC must energize the R-TCW relay (output Y17). This puts 110VAC on the blue wire to the translation motor and turns the motor in the clockwise direction, moving the translating plate inward. Again, the Translation Operate LED indicator (output Y6) will be turned on at this time.

When the translating plate reaches its initial stowed position, the "T-Stow" proximity sensor is tripped, and the system has completely returned to its fully stowed state, represented by state $S_{0}$. All motors are turned off and the system returns to waiting for any user input in the form of button presses on the pendant.

At any point during this deployment process, the user may be able to push the Extend or Stow buttons on the user pendant. In any of the states $\mathrm{S}_{5}-\mathrm{S}_{7}$, if the Stow button is pushed, the system should remain in its current state. However, if the Extend button is pressed, the system should stop and jump to a different state to begin the extend procedure. If the system is in state $S_{5}$, the system will jump to state $S_{3}$; if the system is in state $\mathrm{S}_{6}$, the system will jump to state $\mathrm{S}_{2}$; and if the system is in state $\mathrm{S}_{7}$, the system will jump to state $\mathrm{S}_{1}$.

\subsubsection{PLC Program Specifications}

Besides performing the steps illustrated in the State Diagram, there are other specifications that the program should have. The WVU-CIRA engineers decided that there should be a timed delay whenever the system goes from state-to-state. There will 
also be status messages displayed on the PLC's LCD screen so that the operator will be able to determine the PLC state in case of an error.

\subsubsection{Timed Delays in the Program}

Timed delays are important for safety reasons; if either the Extend or Stow button is pressed with anyone in the way of the system, that person will be able to clear the area before the system is set in motion. Otherwise, the person may be injured by the translating plate or the heavy Sensor Pod. Also, after the system has already been set into motion, there should be a delay from state-to-state to protect the components in the system. Quickly changing outputs and turning on different motors could cause damage to the system components.

Whenever the Extend or Stow button is pressed, there will be a five second delay before any motion takes place, regardless of where the translating plate or rotating arm is positioned at the time. Between states, there will only be a three second delay before the next stage of motion takes place. Programming with timers in the DirectSoft $32^{\odot}$ software was discussed in Chapter 2. When programming, there was a different timer used for each change of state. The timers that are used in the PLC program are illustrated below in Table 5.2.

Table 5.2: Timers in the PLC Program

\begin{tabular}{|c|l|}
\hline PLC Timer & \multicolumn{1}{|c|}{ Timer Use } \\
\hline T0 & 5-sec. Extend Button Timer \\
\hline T1 & 5-sec. Stow Button Timer \\
\hline T2 & 3-sec. Translating Out to Rotating Out Timer (Extend Process) \\
\hline T3 & 3-sec. Rotating Out to Translating Back Timer (Extend Process) \\
\hline T4 & 3-sec. Translating Out to Rotating In Timer (Stow Process) \\
\hline T5 & 3-sec. Rotating In to Translating Back Timer (Stow Process) \\
\hline
\end{tabular}




\subsubsection{LCD Screen Messages}

The program utilizes LCD screen messages so that the user will know what state the program is in (or going to be in once the respective timer completes its countdown) and for the purpose of error diagnosis. Writing messages to the LCD screen in the program is detailed in Chapter 2 .

Whenever the PLC receives a new input, a new message appears on the LCD screen. The LCD has two lines on which a message can be displayed. The top line should always read "Automatic Mode"; this is an unconditional output to the LCD screen in the program and cannot be changed as long as the program is functioning correctly. The second line will display the state of the program. Table 5.3 shown below outlines the possible LCD messages and what they mean.

Table 5.3: LCD Messages

\begin{tabular}{|l|l|}
\hline \multicolumn{1}{|c|}{ LCD Message } & \multicolumn{1}{c|}{ Meaning } \\
\hline "Fully Stowed" & $\begin{array}{l}\text { Translating plate and rotating arm are in } \\
\text { their resting positions }\end{array}$ \\
\hline "E: Button Push" & $\begin{array}{l}\text { Error: Extend and Stow button have been } \\
\text { pushed simultaneously, which should not } \\
\text { occur }\end{array}$ \\
\hline "Extend Button" & Extend Button has been pressed \\
\hline "Translating Out" & The translating plate is translating outward \\
\hline "Rotating Out" & The rotating arm is rotating outward \\
\hline "Translating Back" & The translating plate is translating backward \\
\hline "Fully Extended" & $\begin{array}{l}\text { Current Sensor has been tripped, should } \\
\text { mean that the Sensor Pod has been pulled up } \\
\text { tightly against the butt plate on the door }\end{array}$ \\
\hline "Stow Button" & Stow Button has been pressed \\
\hline "Rotating In" & The rotating arm is rotating inward \\
\hline &
\end{tabular}




\subsubsection{Error States}

With every system, errors can occur. The user may input erroneous stimuli, sensors may be accidentally tripped or could fail completely, or any other unforeseen problem could occur. One of the error states that can clearly occur in this system is the user pressing both the Extend and Stow buttons on the pendant simultaneously. At that point, the PLC will be confused as to how to proceed, most likely beginning motion in one direction and then the other. This could somehow cause damage to components as well, jumping from state to state in such a manner.

Therefore, to prevent an occurrence of such a nature from harming components, an error state is introduced to the program. Whenever the PLC receives input from both the Extend and Stow buttons at the same time, all motion is halted and all timers and memory locations are reset. Once a single button is pushed, whether it is the Extend or Stow button, the error state is cleared and normal operation of the system can continue.

Other error states may exist, such as the ones alluded to before where sensors may fail, but the PLC program does not account for these error states. Future work in this area may be needed to be done for the system to become more fully functional.

\subsubsection{PLC Memory Locations Used in Program}

PLC's are constantly scanning their inputs and reacting accordingly, as well as checking their timers. Their outputs are based on the inputs and timer countdowns that occurred during that "sweep"; therefore, if a button is pressed for a moment and then released, that input is only seen for that moment. Likewise for a timer; when the timer finishes counting down, the PLC only sees that it finished its countdown for a single "sweep". Though this makes the PLC dynamic and allows it to react to a series of inputs 
without making the programmer write a series of loops, it does cause other programming problems. How might the PLC "remember" that a certain input has occurred? In the PLC program, this is an important question; stages in the program that last for several "sweeps" in a row depend on whether the Extend or Stow button has been pressed or whether a timer has finished its countdown. The answer is to use PLC memory locations to store when a button press has occurred or a timer has finished its countdown. The memory locations used in the programs and what is stored there are shown below in Table 5.4.

Table 5.4: Memory Location Definition

\begin{tabular}{|c|l|}
\hline Memory Location & \multicolumn{1}{c|}{ Data Stored } \\
\hline X50 & Extend Button Memory \\
\hline X51 & Stow Button Memory \\
\hline X52 & Extend Timer Memory (5-sec.) \\
\hline X53 & Stow Timer Memory (5-sec.) \\
\hline X55 & $\begin{array}{l}\text { Current Sensor Comparison Memory } \\
\text { (V2000 } \geq \text { V2004) }\end{array}$ \\
\hline X56 & Extend/Stow Button Press Error Memory \\
\hline X57 & $\begin{array}{l}\text { Translating Out to Rotating Out Timer } \\
\text { Memory (3-sec.) }\end{array}$ \\
\hline X60 & $\begin{array}{l}\text { Rotating Out to Translating Back Timer } \\
\text { Memory (3-sec.) }\end{array}$ \\
\hline X61 & $\begin{array}{l}\text { Translating Out to Rotating In Timer } \\
\text { Memory (3-sec.) }\end{array}$ \\
\hline & $\begin{array}{l}\text { Rotating In to Translating Back Timer } \\
\text { Memory (3-sec.) }\end{array}$ \\
\hline
\end{tabular}

This concludes the description of the PLC program development. To see the PLC program as it was coded, please see Appendix 5. The program is shown there fully commented to ease in reading. 


\section{Chapter 6: Project Results}

Over the last few months, the electrical design for the Operator Station and the Sensor Pallet, as well as the Automatic mode program, were implemented in the system assembled by the Project Oculus team of engineers. Once everything was assembled, the testing process began.

\subsection{Testing the Operator Station Circuit}

After the Operator Station had been wired, the system had to be tested. The first test for the system was to power it up using a 28VDC 200A "generator set" that simulated the power supply aboard the C-130. This power source was equipped with an AN2551 female plug to fit into the AN2552-3A male socket on the power input side of the Operator Station. A red LED located inside the operator station in the top left rack indicates that a $28 \mathrm{VDC}$ power source is available. Upon the flip of the "ON" switch, the green LED came on to indicate that DC power was powering the system. A look at the TSC24-4500D inverter remote controller showed that the inverter was converting the DC power to $220 \mathrm{VAC} 60 \mathrm{~Hz}$ split-phase, indicating that it was working properly. All 30 power outlets (ten outlets on three power outlet strips located on the back of the racks inside the operator station) were tested to ensure that they were supplying $110 \mathrm{VAC} 60 \mathrm{~Hz}$ for the devices that would reside in the racks inside the Operator Station. The circuit breakers were also tested to ensure that they would manually open the circuit.

The next test for the Operator Station circuit was to make certain that it could be powered from a standard 220VAC $60 \mathrm{~Hz}$ power source. A cable equipped with a 220VAC 30Amp plug on one end to fit the 220VAC wall outlet located in the WVU hanger wall, and a HBL430C12W on the other end was plugged into the power input side 
of the Operator Station. Again, the red LED indicators corresponding to Line 1 and Line 2 of the 220VAC input came on, signifying that $60 \mathrm{~Hz}$ AC power was directly available for the system. Flipping the switch powered on the system, just as the DC power had before.

The final test for the Operator Station power input circuit was to make sure that the interlocking between the two possible power sources would work. If the DC power source is available and turned on, the interlocking circuit should not allow the user to apply an available $60 \mathrm{~Hz} \mathrm{AC}$ power to the system, and vice versa. To perform this test, both $60 \mathrm{~Hz} \mathrm{AC}$ and $\mathrm{DC}$ power sources were connected as in the previous tests. First, the $60 \mathrm{~Hz}$ AC power source was turned on with the switch, supplying power to the system. Then, the DC power switch was flipped to the "on" position; the system remained powered by the $60 \mathrm{~Hz} \mathrm{AC}$ power, and the green LED indicator showing that the system was powered from DC remained off. Next, the system was powered from the DC power source, and the $60 \mathrm{~Hz} \mathrm{AC}$ power was turned on; the system remained powered from $\mathrm{DC}$ and did not allow the $60 \mathrm{~Hz}$ AC power to be available. Having completed all these tests, the Operator Station power input circuit design was deemed a success.

\subsection{Testing the Sensor Pallet Circuit and Program}

Next, the electrical engineers had to test the Sensor Pallet to ensure it was in good working order. The Sensor Pallet had three general areas to test: (1) would the sensor pallet electronics power up when its power cord was plugged into the Operator Station, (2) manual mode operation with the operator pendant, and (3) Automatic mode, including all electronics and software associated with Automatic mode. 


\subsubsection{Testing the Sensor Pallet Power}

To test the Sensor Pallet, the jumper cable located on the Sensor Pallet must be connected into the Operator Station power. The HBL430P12W plug on the jumper cable needs to be plugged into the matching HBL430R12W receptacle on the exterior of the Operator Station facing the Sensor Pallet. Then, the power in the Operator Station needs to be turned on to supply power to the Sensor Pallet. Upon doing this, visual inspection of the Sensor Pallet shows that the GS2-22P0 motor controller inside the motor control panel and the 24VDC power supply power are on. The red Manual mode LED indicator located on the motor control panel comes on if the Automatic/Manual switch on the operator pendant is switched to "Manual." Switching the Automatic/Manual switch to "Automatic" turns off the red Manual mode LED indicator and powers on the D0-06DD2 Programmable Logic Controller (PLC). Seeing that all the Sensor Pallet electronics are powering on, this test is successful.

\subsubsection{Testing the Sensor Pallet in Manual Mode}

Now that the Sensor Pallet is powered, the two different modes of operation of the Sensor Pallet can be tested. First, the engineers will test Manual mode. The testing procedure is illustrated in the flow chart shown in Figure 6.1 below. 


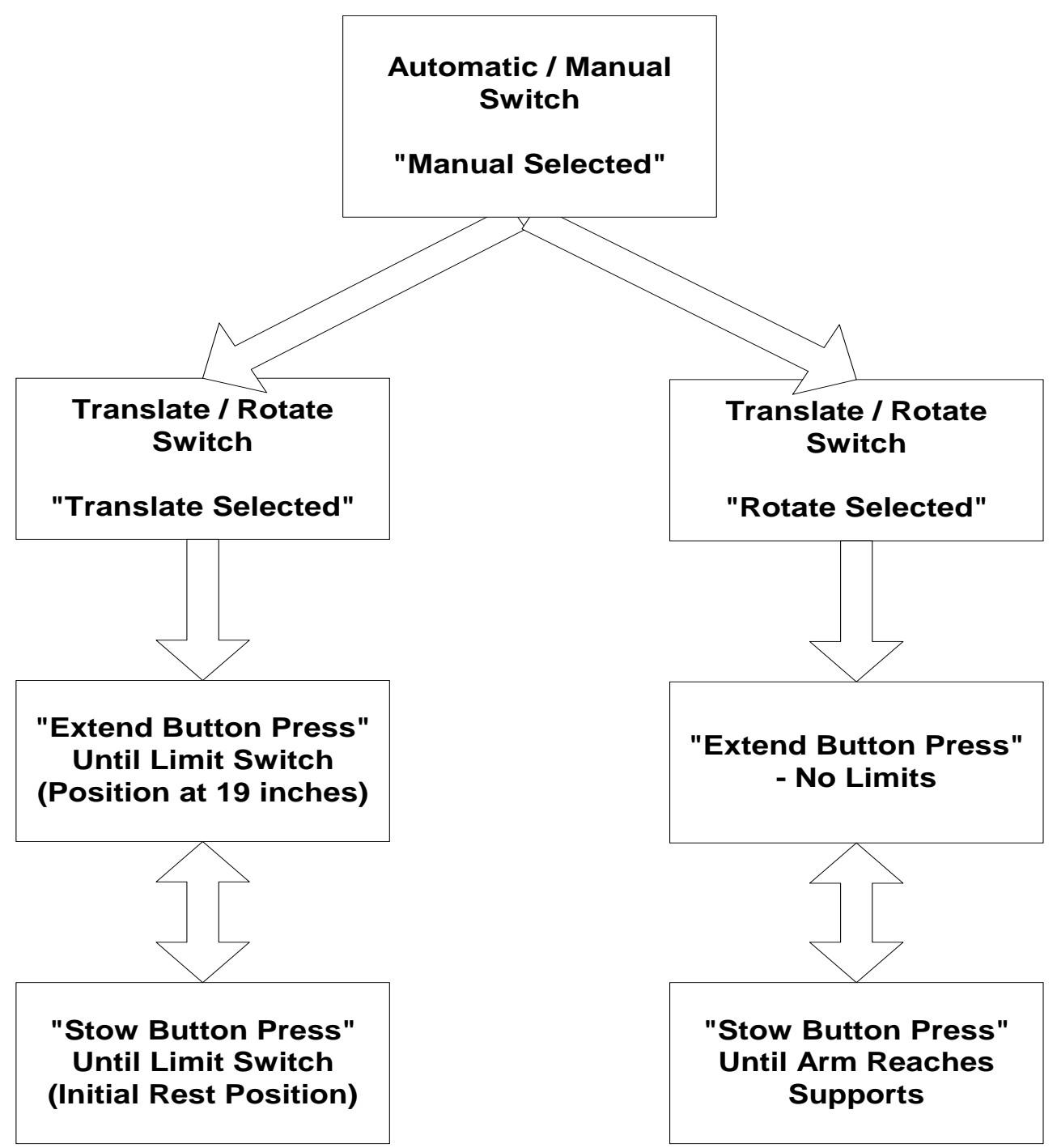

Figure 6.1: Manual Mode Testing Procedure

To run the pallet in Manual mode, the Automatic/Manual switch should be set to "Manual." In manual mode, the operator designates which motor he wants to run by using the Translate/Rotate switch, also on the operator pendant. Flipping this switch to "Translate", the engineers first tested Manual mode for the translation process. When pressing the Extend button, the translating plate moved from its initial resting position to its fully extended position 19" inches outward before the limit switch mounted there was triggered and stopped the translation. Pressing the Stow button moved the translating 
plate back to its initial resting position; again the process was ended by triggering the other limit switch. All components of that process, which included powering the translation motor, wiring of the buttons and switches, and the use of the limit switches, were deemed a success.

Flipping the Translate/Rotate switch to "Rotate", the engineers may now test Manual mode for the rotation process. For this test to be successful, the GS2-22P0 motor controller digital inputs must be wired correctly and supply sufficient power to the rotation motor. When pressing the Extend button, the rotating arm rotated outward, going as far as the user wants it to go, considering there are no limiting factors on its manual motion as there is on the translational process. Pressing the Stow button moved the rotating arm back to its initial resting position on the supports mounted on the translating plate. All components of this process, which included sending the correct signals to the motor controller, powering on the rotation motor, and the wiring of the buttons and switches, were deemed a success.

\subsubsection{Testing the Sensor Pallet in Automatic Mode}

To test the Sensor Pallet, the Automatic/Manual switch needs to be on "Automatic" and the D0-06DD2 needs to be set on "Run", which means it is running the program that is stored in the PLC's memory. No motion should occur right away; the system is waiting on input from the user pendant pushbuttons. Also, the Translate/Rotate switch is nonfunctional in Automatic mode.

The engineers tried to test a full cycle of the automated process. Upon pushing the Extend button, the deployment procedure began. The translating plate moved from its initial position to its fully extended position 19" outward, and then the system began to 
try to rotate the arm out. However, a problem occurred at this point. The PLC was receiving conflicting inputs from the rotation stowed and extended proximity sensors, sending the system into two different states at the same time. Therefore, the system was not functional at that time.

This was the major bug that had to be fixed in the system. The problem was hypothesized to be electrical noise interference generated by the power cord to the rotational motor being picked up by the proximity sensor cables. This noise would cause a false triggering signal on the sensing lines of these sensors. Indeed, the test prototype ran both the power cable to the rotational motor and the proximity sensor cables together through the same conduit.

The first solution to the problem was to run shielded cable to the proximity sensors rather than the unshielded cable that the sensors were purchased with. The shield was grounded to the box housing the electronic equipment, and the shielded cable was run all the way from the sensor to the PLC inputs. But when the test was run again, the same problem still occurred. Though this was a good idea that normally fixes problems such as these, another approach was needed.

After other failed attempts at solving the problem, which included increasing the sourcing current from the proximity sensors, it was decided that physical separation of the cables was required to make the system work. The rotation stowed and rotation extended proximity sensors were moved to the opposite side of the pallet but remained connected with shielded cable. The testing procedure was repeated, again pressing the Extend button to begin the deployment procedure. When the translating plate finished its motion, the rotating arm began rotating with no problem. A full cycle of both the 
deployment and stowing procedures were completed to ensure that Automatic mode was in full working order. Finally, Automatic mode was deemed a success.

\subsection{Project Oculus Tested on the C-130}

In February, 2004, the WVU-CIRA team of engineers accompanied the Project Oculus system to the Air National Guard base in Charleston, WV, to load the pallets onto the plane for testing purposes and for a show-and-tell session. The Operator Station was plugged into the plane's 28VDC power source, just as it was designed to do, and was powered up with no problems. The Sensor Pallet was placed on the C-130 rear door, where the mechanical arm was completely deployed using only Manual mode. Automatic mode was not tested at this time; though it had been proven to work, the engineers feared they may damage the plane in some way. The visit and test session in Charleston was a success; Figure 6.2 below shows the Sensor Pallet on the C-130 door. 

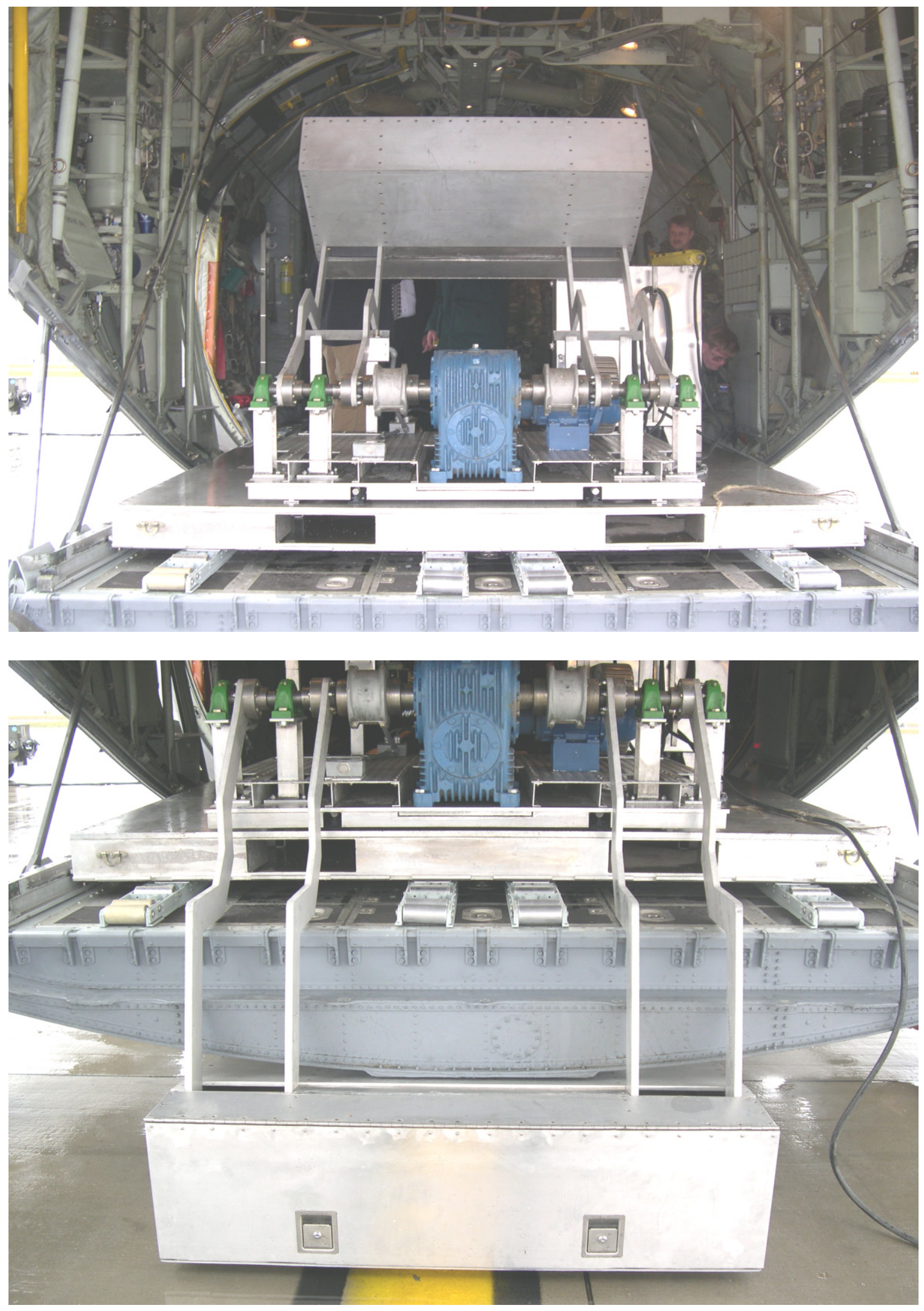

Figure 6.2: Sensor Pallet in Operation on C-130 in Charleston, WV 


\section{Chapter 7: Conclusion}

First, in these concluding remarks, it must be said that one of the overriding goals of this thesis was to be a complete summary of all the work performed by the electrical engineers on Project Oculus. It should be a fully inclusive manual providing all the design criteria, circuit diagrams, program design, and specifications of the hardware that was put into this project.

\subsection{Project Conclusions}

This project has been completely designed, built, programmed, and tested. It seems that every aspect of the project has passed all testing configurations. The Operator Station power distribution circuit design is a success; it works, providing all devices with their required power. After working out a few bugs, the Sensor Pallet control circuit, operating in both Automatic and Manual modes, is also in working order.

One main issue of concern, however, in this design is the amount of power that is needed to run all components involved and the sensors that will be deployed in the Sensor Pod on the Sensor Pallet. This study is shown in Appendix 2, which is a Power Budget prepared by team member Jonathan Byrd. The team of electrical engineers perhaps should make decisions on supplemental forms of power for the system.

\subsection{Recommendations for Future Work}

Because no design is ever finished or completely optimized with every known feature, recommendations for future work are offered here. There are a few areas of the project that can be improved or modified in the future. First, plans for additional power need to be addressed in the near future. 
The second area that needs improved is "system protection" in Manual mode. The electrical engineers did install mechanical limit switches to protect system components when the system is running in Manual Translate mode; however, there is no analogous feature for Manual Rotate mode. The operator can extend the mechanical arm as far as he wants to, which could allow the arm to strike and damage the "R-Extend" proximity sensor.

And the final area that needs improved is the Automatic mode ladder program. Through this study, error states had already begun to be defined, but only one error state was really handled in the code itself. Future work on the project could revolve around making the Automatic mode program better by handling more errors, such as defining the process to follow if the proximity sensors should fail. Other unforeseen features could most likely be added to the program as well; the system should stay up-to-date with the future requirements of the system. 


\section{Works Cited}

[1]. Design of a Standardized Sensor Platform for a C-130 Aircraft. Zenovy Wowczuk, August 2004.

[2]. Concept Paper for Review: C-130 Reconnaissance Pallet Standardization for Counterdrug Operations.

$<$ dms2.gtri.gatech.edu/maps/cmaps/130\%20RORO/Concept_paper_idea.doc $>$

[3]. Overview of WVU Sensor Pallet Design.

$<$ dms2.gtri.gatech.edu/maps/cmaps/130\%20RORO/Sensor\%20Pallet\%20Deployment\&T est.doc $>$

[4]. "Hairy Buffalo May Ro-Ro Roam onto C-130".

<www.dcmilitary.com/navy/tester/8_29/national_news/24296-1.html>

[5]. Drawing by Lawrence A. Feragotti, West Virginia University, C-130 Project Oculus Team.

[6]. Drawing by Adam Naternicola, West Virginia University, C-130 Project Oculus Team.

[7]. Duval, Brian and Thomas A. Kinney, "Sensors 101: Baumer Electric Basics," $<$ http://www.clickautomation.com/PDF/categories/Click\%20Auto\%20Sensor\%20primer. pdf $>$

[8]. DL05/06 Option Modules User Manual, Automationdirect.com, Inc., p. 3-10, 3-12, 2004, <http://web1.automationdirect.com/static/manuals/d0optionsm/ch3.pdf>

[9]. External Power Connector.

$<$ http://www.aircraftspruce.com/catalog/elpages/extpowerrect.php>

[10]. HBL430C12W - Watertight IEC Pin and Sleeve Connector Product Datasheet.

$<$ http://www.hubbellcatalog.com/wiring/explorercat/pin\%20sleeve/Product\%20Datasheet \%20--\%20hbl430c12w.htm>

[11]. HBL430B12W - Watertight IEC Pin and Sleeve Inlet Product Datasheet. $<$ http://www.hubbellcatalog.com/wiring/section-edatasheet.asp?PN=HBL430B12W\&FAM=PS\&P=15676,13082,1102,1590>

[12]. Vanner, Inc. DuraSine TSC Details Page.

$<$ http://www.vanner.com/htm/pro_01.htm?series_sku=3195300985138312\&a=a\&pt=3>

[13]. TruSine 4500 Owner's Manual, Vanner Power Group, D98771 Rev. B, p. 5-6, 18. $<$ http://www.vanner.com/pdf/man-0007.pdf $>$ 
[14]. Honeywell Control Toggle Switch.

$<$ http://www.newark.com/NewarkWebCommerce/newark/en_US/support/catalog/product Detail.jsp?id=23F1895>

[15]. Chicago Miniature Lamp, Inc. M14 LED Indicators. $<$ http://www.newark.com/product-details/text/CD121/72967.html $>$

[16]. Chicago Miniature Lamp, Inc. Sunlight Visible M14 LED Indicators. $<$ http://www.newark.com/product-details/text/CD121/72968.html>

[17]. Albright 150 to 400 Amp DC Contactors. $<$ http://www.tecknowledgey.com/catalog/product_info.php?cPath=57_60\&products_id= $528>$

[18]. GH15FT-3-00A Contactor Products. $<$ http://web1.automationdirect.com/adc/Shopping/Catalog/Motor_Controls/Centsable_Co ntactors_-z-_Starters_-z-_Overloads/45mm_Contactors_-z-_Overloads./GH15FT-3$00 \mathrm{~A}>$

[19]. GH15S11 Auxiliary Contact Products. $<$ http://web1.automationdirect.com/adc/Shopping/Catalog/Motor_Controls/Centsable_Co ntactors_-z-_Starters_-z-_Overloads/45mm_Contactors_-z-_Overloads./GH15S11>

[20]. 7274 Series Klixon Circuit Breakers.

$<$ http://www.ti.com/mc/docs/precprod/docs/7274.htm>

[21]. HBL430R12W - Watertight IEC Pin and Sleeve Receptacle Product Datasheet. $<$ http://www.hubbellcatalog.com/wiring/section-edatasheet.asp?PN=HBL430R12W\&FAM=PS\&P=15676,13080,13025,1102,1590>

[22]. HBL430P12W - Watertight IEC Pin and Sleeve Plug Product Datasheet. $<$ http://www.hubbellcatalog.com/wiring/section-edatasheet.asp?PN=HBL430P12W\&FAM=PS\&P=15676,12999,13080,13081,13001,1102 ,1590>

[23]. GS2-22P0 Motor Controller Products. $<$ http://web1.automationdirect.com/adc/Shopping/Catalog/AC_Drives_-z_Motors/GS2_(230_-z-_460_VAC_V-z-Hz_Control)/GS2-22P0>

[24]. GS2 Series Motor Controller Specifications.

$<$ http://web1.automationdirect.com/static/specs/gs2drive.pdf $>$

[25]. GS2 Series Drives User Manual, Automationdirect.com, Inc., First Edition, Rev. A, 2003, <http://web1.automationdirect.com/static/manuals/gs2m/gs2m.pdf> 
[26]. Red 30mm Pushbutton Product Datasheet.

$<$ http://www.grainger.com/Grainger/searchresults=2EN49.jsp $>$

[27]. Black 30mm Selector Switch Product Datasheet.

$<$ http://www.grainger.com/Grainger/searchresults=5B445.jsp $>$

[28]. Universal 30mm Pushbutton Product Datasheet.

$<$ http://www.grainger.com/Grainger/searchresults=5B517.jsp $>$

[29]. Pendant Enclosure Product Datasheet.

$<$ http://www.grainger.com/Grainger/searchresults=2ER81.jsp $>$

[30]. PS24-075D Power Supply Products.

http://web1.automationdirect.com/ade/Shopping/Catalog/Electrical_Power_Products/DC _Power_Supplies/Standard_Case/PS24-075D

[31]. Switching Power Supplies Specifications.

$<$ http://web1.automationdirect.com/static/specs/powersuppliesps.pdf $>$

[32]. QL2X1-D24 Relay Products.

$<$ http://web1.automationdirect.com/adc/Shopping/Catalog/Relays_-z-

_Timers/10A_Electro-Mechanical_Cube_Relays/QL2X1-D24>

[33]. Electro Mechanical Relay Selection Guide.

$<$ http://web1.automationdirect.com/static/specs/qlrelays.pdf $>$

[34]. ABM6E42Z11 Limit Switch Products.

$<$ http://web1.automationdirect.com/adc/Shopping/Catalog/Sensors_-z-_Encoders/Heavy-

Duty_IEC_Limit_Switches/Lever_with_Stainless_Steel_Roller_Actuator/ABM6E42Z11>

[35]. CT1-AP-1A Proximity Sensor Products.

$<$ http://web1.automationdirect.com/ade/Shopping/Catalog/Sensors_z-

_Encoders/Capacitive_Proximity_Sensors/30mm_DC_Powered_(CT1_Series)/CT1-AP-1A>

[36]. CT Series Capacitive Proximity Sensors.

$<$ http://web1.automationdirect.com/static/specs/prox30mmcapct.pdf $>$

[37]. Model CLN-50/100 Closed Loop Hall Effect Current Sensors.

$<$ http://www.sypris.com/library/documents/CLN-50-100-Datasheet.pdf $>$

[38]. D0-06DD2 Programmable Logic Controller Products.

$<$ http://web1.automationdirect.com/ade/Shopping/Catalog/PLC_Hardware/DirectLogic_0

6/PLC_Units/D0-06DD2>

[39]. DL06 I/O Specifications: D0-06DD2.

$<$ http://web1.automationdirect.com/static/specs/d006dd2.pdf $>$ 
[40]. D0-06LCD LCD Screen Products.

$<$ http://web1.automationdirect.com/adc/Shopping/Catalog/PLC_Hardware/DirectLogic_0

6/PLC_Units/D0-06LCD>

[41]. D2-DSCBL Cable Products.

$<$ http://web1.automationdirect.com/adc/Shopping/Catalog/Software_Products/Directsoft -a-_DSData_Pgming_-a-_Comm_Cables/D2-DSCBL>

[42]. DirectSoft $32^{\odot}$ PLC Programming Software.

$<$ http://web1.automationdirect.com/static/specs/directsoftspecs.pdf $>$

[43]. F0-04AD-1 Analog Input Module Products.

$<$ http://web1.automationdirect.com/adc/Shopping/Catalog/PLC_Hardware/DirectLogic_0 6/PLC_Units>

[44]. D0-08CDD1 Digital Input/Output Module Products.

$<$ http://web1.automationdirect.com/adc/Shopping/Catalog/PLC_Hardware/DirectLogic_0

6/PLC_Units>

[45]. DL05/06 I/O Option Modules: D0-08CDD1.

$<$ http://web1.automationdirect.com/static/specs/d008cdd1.pdf $>$

[46]. DuraSine TSC AC Power Inverter/Charger. $<$ http://www.vanner.com/pdf/bul0042.pdf $>$

[47]. Centsable ${ }^{\mathrm{TM}}$ IEC Limit Switches Specifications.

$<$ http://web1.automationdirect.com/static/specs/limitabm.pdf>

[48]. DL05/06 Option Modules: F0-04AD-1.

$<$ http://web1.automationdirect.com/static/specs/f004ad1.pdf> 


\section{Appendix 1: Vanner TSC24-4500D Inverter Specifications}

This appendix contains data sheets and general information regarding the Vanner TSC244500D power inverter and the optional TSR remote control [46]. 


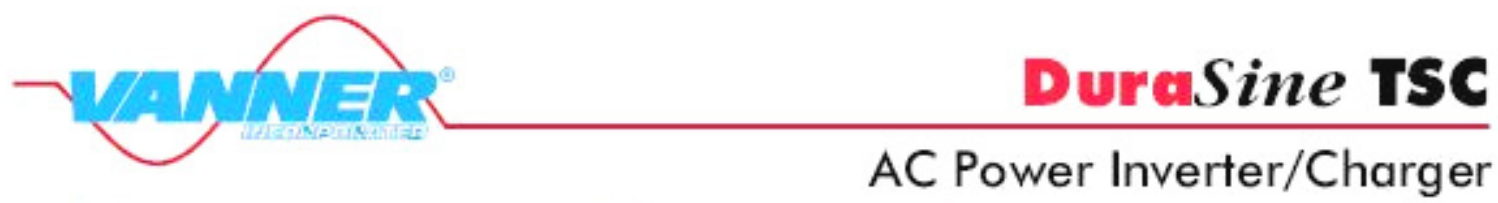

Your AC solution for display vans, mobile offices, communications backup, sensitive test equipment, traffic signal backup, and more!

\section{Introduction}

The TruSine $4.5 \mathrm{~kW}$ system consists of a high-performance 4500 watt sine-wave inverter, four. stage battery charger/conditioner, and an automatic $A C$ transfer switch. The system offers you unparalleled capabilifies for the most demanding applications. For example, a high efficiency, low power sine-wave inverter saves energy by operating when only small $\mathrm{AC}$ bods such as battery

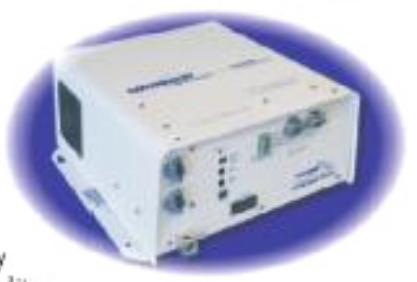
rechargers are present. Because the test equipment and toals you use may be sensifive to the quality of $\mathrm{AC}$ power, we have designed the TruSine inverter/charger to supply high quality, low btal Harmonic Distortion sine-wave power while also maintaining high operating efficiencies over the power range.

Recognizing that installation configurations and requirements wary, we have designed maximum flexibility into the TruSine* imverter/charger system. We have separated the operator's cansole/remote control from the inverter enclosure, allowing you to contral and monitor the system from whe rever you want. Our data cammunications network allows you to install mulfiple operator's consoles near the imverter, or at remote locations. Installation is simplified with the consalidation of all wiring on the bottom panel of the unit (the bottom surface on the wall mounted unit). This panel contains an isolated AC wiring compantment, complete with cable clamps for the external AC cables, and a unique DC wiring compartment is provided for the battery cables with two screw-type terminals to accommodate the DC cables.

Underwriters Laboratories Listed TruSine models TSC24-4500 and TSC24-4500D are UL and C.ULL Listed as a Power inverter for Land/Recreational vehicles.

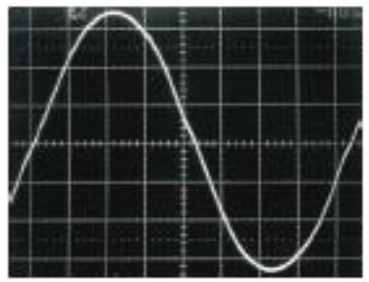

Actual photo of Trusine* waveform at 4500 watts

\section{Power Inverter}

Vanner's advanced TruSine* fechnology inverter design produces a smooth, extremely high quality sinusoidal waveform that has no visible steps. This produces less than $1.75 \%$ Total Harmonic Distortion (THD), enabling loads such as motors and electronic equipment to operate more efficiently than with stepped sine-wave or modifed sinewave imverters. Output AC voltage is regulated to $+/ .3 \%$ and frequency regulation is maintained to within $+1.0 .1 \mathrm{~Hz}$. The inverter produces 4500 watts of continuous power and 10,000 wats of surge power, enabling it to run the most demanding loads. In order to meet your installation needs, we offer two $A C$ power configurations:

- TSC24-4500D: 120/240 wolt/60 Hz 3-wire "split-phase" input and output

- TSC24-4500: 120 valv $60 \mathrm{~Hz}$ single phase input and output

\section{Battery Charger/Conditioner}

Battery charging is accomplished efficiently with the TruSine system's $100 \mathrm{amp}$,24 wolt), four-stage charging sequence. This approach quickly charges the battery bank, then applies a float charge to maintain the charge. For flooded lead acid batteries, the operator may call for an equalize charge ocle through the remote operator's console.

\section{Automatic AC Transfer Switch}

The systems' automatic $A C$ transfer switch connects the $A C$ input to both the $A C$ output and to the battery charger when $A C$ output power is present. The transfer will occur after an adjustable time delay which allows for generator stabilization. Upon loss of $A C$ input power, the transfer back to the inverter will occur instantly (within 40 milliseconds) to minimae power interruption to the AC loads.

\section{Operator Controls}

When complete function control and moniforing is required, we recommend installing the optional TSR Operator's Cansole. The TSR allows you to operate the TruSine" inverter system from multiple locations. You can bcate a TSR near the inverter and others at remate bcations. The TSR remote cantrol panel is a compad but powerful terminal cansisting of a backlit LCD display, function keypad and alarm LED indicator. The TSR functions provide system status displas fault monitoring and alarm display, password protected data parameter programming, display of data values, and system operating mode control.

To simplify operation, a main menu is provided along with an advanced function menu for the more complex functions. The TSR is easily installed with four screws in a panel cutout.

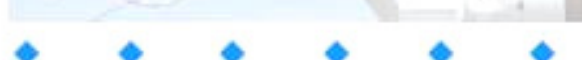

EXPERIENCE THE POWER. 


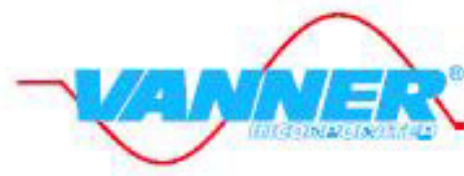

\section{DuraSine TSC}

AC Power Inverter/Charger

\begin{tabular}{|c|c|c|c|}
\hline Model & TSC $24-4500$ & TSC24-4500D & TSC-4500EX' \\
\hline \multicolumn{4}{|l|}{ Inverter: } \\
\hline AC Oulput Voltage & $120 \mathrm{Voc}+/ .3 \%$ & $120 / 240 V o c+/ .3 \%$ & $230 \mathrm{Vac}+1.3 \%$ \\
\hline Continuous Power at $25 \mathrm{C}$ & 4500 Wotts (37.50 Amps) & 4500 Watts (18.75 Amps per Leg) & 4500 Wotts (18.75 Amps) \\
\hline Surge Power & 10,000 Wats & 10,000 Wats & 10,000 Wotts \\
\hline Frequency & $60 \mathrm{~Hz}+/=0.1 \mathrm{~Hz}$ & $60 \mathrm{~Hz}_{2}+/ .0 .1 \mathrm{~Hz}$ & $50 \mathrm{~Hz}+/-0.1 \mathrm{~Hz}$ \\
\hline AC Waveform & Pure Sine-wave & Pure Sine-wave & Pure Sine-wave \\
\hline Total Hamanic Distortion (THD) & $<1.75 \%$ & $<1.75 \%$ & $<1.75 \%$ \\
\hline Power Factor Allowed & $=0$ to 1 to +0 & $-010110+0$ & $-010110+0$ \\
\hline \multicolumn{4}{|l|}{ DC Input } \\
\hline Nominal & 24 Vols & 24 Volts & 24 Volts \\
\hline Operafing Range & 12 to 34 Volts & 12 to 34 Volts & 12 to 34 Vols \\
\hline No Lood, Inverter On & 0.5 Amps (13 Wotts) & 0.5 Amps (13 Wotts) & 0.5 Amps (13 Wats) \\
\hline No Load, Inverter Standby & 0.2 Anps (5.2 Wotts) & 0.2 Anps (5.2 Wots) & 0.2 Amps (5.2 Watts) \\
\hline Full Power & $225 \mathrm{Amps}$ & 225 Amps & 225 Amps \\
\hline \multicolumn{4}{|l|}{ Battery Charger: } \\
\hline Maximum Charger Power & 100 Amps DC & 100 Amps DC & 100 Amps DC \\
\hline Input Voltage & $120 V a c+/ .10 \%$ & $120 / 240$ Voc $(4-$ wire $)+/ .10 \%$ & $230 \mathrm{Vac}+/ \cdot 10 \%$ \\
\hline Input Current Waveform & Sinusoidol & Sinusaidal & Sinusaidal \\
\hline Input Current Rating & 32 Amps & $16 \mathrm{Amps}$ per Leg & $16 \mathrm{Amps}$ \\
\hline Input Frequency & $60 \mathrm{~Hz}_{2}+/ .12 \%$ & $60 \mathrm{~Hz}+/ .12 \%$ & $50 \mathrm{~Hz}+/ .12 \%$ \\
\hline \multicolumn{4}{|l|}{ AC Transfer Switch: } \\
\hline Power Rafing & 30 Amps of $120 \mathrm{Voc}$ & 30 Amps of $120 / 240 \mathrm{Vac}$ & 30 Amps at $230 \mathrm{Vec}$ \\
\hline Transfer Speed & $<40$ milliseconds & $<40$ milliseconds & $<40$ milliseconds \\
\hline \multicolumn{4}{|l|}{ System: } \\
\hline Operating Ambient Temp. & & $-40 \mathrm{C}(40 \mathrm{~F})$ to $+40 \mathrm{C}(104 \mathrm{~F})$ & \\
\hline Cooling & & hermostafically controlled exhoust fan & \\
\hline Mounting & & Wall or shelf & \\
\hline Weight & & 83 Lbs. (37.7 kg.) & \\
\hline Dimensions & & $17.5^{\circ} \mathrm{H} \times 19.0^{\circ} \mathrm{W} \times 8.5^{\mathrm{N}} \mathrm{D}$ & \\
\hline
\end{tabular}

Your authorized Vanner distributor is:

\section{Corporate Office:}

Vanner, Inc.

4282 Reynolds Drive

Hilliard, Ohio 43026

Tel: $614-771-2718$

Fax: $614-771-4904$

Copynight 2001, Vome, inc.

Printed tuly 2001

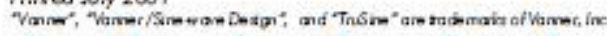

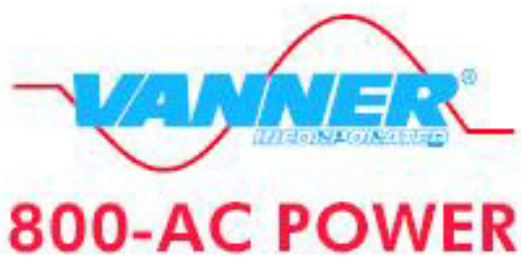

www.vanner.com e-mail: pwrsales@vanner.com 


\section{Appendix 2: Project Oculus Power Budget}

This appendix contains the Project Oculus Power Budget, created as an Excel spreadsheet by $\mathrm{C}-130$ project team member Jonathan Byrd. This budget consists of all components that exist in the system and the power that these components consume. Not all components will be drawing power at the same time; therefore, an "In Use" column was added so that the user may determine the available power when only certain components are being used. The power budget is shown below with all components in use. 


\begin{tabular}{|c|c|c|c|c|c|c|}
\hline \multirow{3}{*}{$\begin{array}{l}\text { Project Oculus Power Budget } \\
\text { Developed by Jonathan Byrd } \\
\text { Created: March 8, } 2004 \\
\end{array}$} & \multicolumn{3}{|c|}{ There are $5040 \mathrm{~W}$ available as total power, } & & \multicolumn{2}{|c|}{ Remaining DC power on SP (W) } \\
\hline & \multicolumn{3}{|c|}{$4158 \mathrm{~W}$ of that can be used as $A C$ power. } & & -730.4 & \\
\hline & & & & & \multicolumn{2}{|c|}{ Remaining $\mathrm{AC}$ power (W) } \\
\hline \multirow[t]{2}{*}{ Last Revised: April 12, 2004} & & & & & -112.67 & \\
\hline & & & & & \multicolumn{2}{|c|}{ Total Remaining Power (W) } \\
\hline Power Available: & & & & & $\underline{769.33}$ & \\
\hline Description: & Max Voltage $(M)$ & Max Current (A) & Efficiency & Total Input Power (W) & & \\
\hline 28 Volt DC Input from bulkhead & 28 & 180 & N/A & 5040 & & \\
\hline Wanner inverter DC - AC eff@4500W 82.5\% & 120 & 34.65 & 0.825 & 4158 & & \\
\hline DC power available on sensor pallet & 24 & 3 & N/A & 72 & & \\
\hline \multicolumn{7}{|l|}{ SENSOR PALLET } \\
\hline \multicolumn{7}{|l|}{ Power Used: } \\
\hline Item Description & Quantity & $A C$ or $D C$ & Voltage $(\mathrm{M})$ & Current (A) & Power Used (W) & In Use (1 or 0$)$ \\
\hline Proximity Sensors & 4 & DC & 28 & 0.2 & 22.4 & 1 \\
\hline Rotational Motor 2HP & 1 & & & & 1492 & 1 \\
\hline Translational Motor $1 / 3 \mathrm{HP}$ & 1 & & & & 248.67 & 1 \\
\hline Camera and Sensor & 1 & DC & 28 & 10.714285 & 300 & 1 \\
\hline Flir System & 1 & DC & 28 & 17.142857 & 480 & 1 \\
\hline Cooling Fans & 2 & $A C$ & 110 & 0.338181818 & 74.4 & 1 \\
\hline \multicolumn{7}{|l|}{ OPERATOR STATION } \\
\hline \multicolumn{7}{|l|}{ Power Used: } \\
\hline Item Description & Quantity & $A C$ or $D C$ & Voltage $(\mathrm{V})$ & Current $(A)$ & Power Used (W) & \\
\hline KMM Switch CS-228 & 1 & $\mathrm{AC}$ & 120 & 0.06 & 7.2 & 1 \\
\hline Little Lite Rack Mount Light & 3 & $A C$ & 120 & 0.2 & 72 & 1 \\
\hline Communications Reciever IC.R9O0OL & 1 & $A C$ & 120 & 0.45 & 54 & 1 \\
\hline VCR Sony SV0-1630 & 1 & $A C$ & 120 & 0.133333333 & 16 & 1 \\
\hline STC Leicus Dehumidifier & 1 & $A C$ & 120 & 1.5 & 180 & 1 \\
\hline Overhead Florescent Lights & 2 & $A C$ & 120 & 0.283333333 & 68 & 1 \\
\hline Exhaust $F$ an & 2 & $A C$ & 120 & 1.4 & 336 & 1 \\
\hline Florescent Lighting (behind rack) & 2 & $A C$ & 120 & 0.333333333 & 80 & 1 \\
\hline LCD Flat Panel Monitors & 2 & $A C$ & 120 & 0.583333333 & 140 & 1 \\
\hline Computer Power Supplies & 2 & $A C$ & 120 & 2.916666667 & 700 & 1 \\
\hline
\end{tabular}




\section{Appendix 3: Klixon Aircraft Circuit Breakers, 7274 Series}

This appendix consists of specifications and general information for the 7274 series of Klixon aircraft circuit breakers, made by Texas Instruments. Specifically, the Project Oculus system uses Klixon series 7274-11 circuit breakers, with current ratings of 10 Amps and 20 Amps. Circuit breakers used in the system are highlighted where appropriate [20]. 


\section{Series}

\section{Single Phase, Non-Compensated}

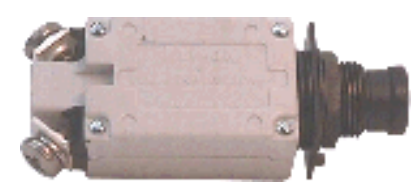

\section{Features}

- Uses Minimum Space

- Light Weight

- Current Rating ( $1 \frac{1}{2}$ to 20 Amps)

- MIL-C-5809 Qualified

- High Vibration Resistance

\section{Overview}

The Klixon ${ }^{\circledR} 7274$ series are small, lightweight, low amperage devices that are specifically designed to protect aircraft/aerospace cable and components in airborne vehicles and equipment.

The 7274 series features a trip-free, indicating-type reset button. They are available in standard ratings from $1 / 2$ to 20 amps.

\section{Options}

- Long Pushbuttons

- Auxiliary Switch

- Dust Boot ${ }^{1}$

${ }^{1}$ Part number $14500-1$ fits $15 / 32$ bushing Part number $14500-5$ fits $7 / 16$ bushing

Calibration: 1-20 Amps (Typical*)

\begin{tabular}{|c|c|c|c|c|c|}
\hline \multirow{2}{*}{$\begin{array}{c}\text { Temp } \\
{ }^{\circ} \mathbf{C}\end{array}$} & Min. Ult. & Max. Ult. & \multicolumn{3}{|c|}{ Trip Time - Seconds } \\
\cline { 4 - 6 } & Trip & Trip & $\mathbf{2 0 0 \%}$ & $\mathbf{5 0 0 \%}$ & $\mathbf{1 0 0 0 \%}$ \\
\hline+25 & $115 \%$ & $150 \%$ & $2-20$ & $.16-1.2$ & $.046-.80$ \\
\hline-55 & $135 \%$ & $180 \%$ & - & - & - \\
\hline+71 & $90 \%$ & $130 \%$ & - & - & - \\
\hline
\end{tabular}

*The above calibration chart is representative of a standard commercial device. TI offers specific variants with similar performance dependant on military or customer specifications. 


\section{Performance}

Vibration*.............. $10 \mathrm{G}$ minimum, $50-500 \mathrm{~Hz}$

Mechanical Shock.....35 G

Acceleration............. $10 \mathrm{G}$

Weight

7274-2 - 28 grams

7274-2-5 - 19.8 grams

7274-4 - 28 grams

7274-11 - 33 grams

7274-11-5 - 24.7 grams

7274-69 - 33 grams

7274-70 - 33 grams

*Other vibration levels available

\section{Interrupting Capacity}

$1 / 2-5$ amps

$71 / 2-15$ amps

$1 / 2-1 \frac{1}{2}$ amps

$2-5$ amps

Unlimited amps at $28 \mathrm{VDC}$

2000 amps at $28 \mathrm{VDC}$

Unlimited amps at $120 \mathrm{VAC}, 400 \mathrm{~Hz}$

800 amps at $120 \mathrm{VAC}, 400 \mathrm{~Hz}$

$71 / 2-20 \mathrm{amps} \quad 500 \mathrm{amps}$ at $120 \mathrm{VAC} .400 \mathrm{~Hz}$
Endurance

2500 cycles 120 VAC. $400 \mathrm{~Hz}$, Inductive 5000 cycles 120 VAC. $400 \mathrm{~Hz}$, Resistive 2500 cycles $30 \mathrm{VDC}$, Inductive 5000 cycles 30 VDC, Resistive 10,000 cycles Mechanical, No Load

$\begin{array}{cccc}\begin{array}{c}\text { Amp } \\ \text { Rating }\end{array} & \begin{array}{c}\text { Voltage } \\ \text { Drop (max)* }\end{array} & \begin{array}{c}\text { Amp } \\ \text { Rating }\end{array} & \begin{array}{c}\text { Voltage } \\ \text { Drop (max)* }\end{array} \\ \frac{1}{2} 2 & 2.00 & 4 & 0.45 \\ 1 & 1.45 & 5 & 0.35 \\ 11 / 2 & 1.10 & 71 / 2 & 0.30 \\ 2 & 0.75 & 10 & 0.28 \\ 21 / 2 & 0.75 & 15 & 0.25 \\ 3 & 0.70 & 20 & 0.25\end{array}$

*Max voltage drop at nominal rated current.

\section{Qualifications}

TI Number MS Number

7274-2- $1 / 2$ MS 26574- $1 / 2$

7274-2-3/4 MS 26574-3/4

7274-2-1 MS 26574-1

$7274-2-1 \frac{1}{2}$ MS 26574-1 1/2

7274-2-2 MS 26574-2

$7274-2-2 \frac{1}{2}$ MS 26574-21/2

7274-2-3 MS 26574-3

7274-2-4 MS 26574-4
TI Number MS Number

$\begin{array}{ll}7274-4-1 / 2 & \text { MS 26574- } 1 / 2 \mathrm{~A} \\ 7274-4-3 / 4 & \text { MS 26574-3/4A } \\ 7274-4-1 & \text { MS 26574-1A } \\ 7274-4-11 \frac{1}{2} & \text { MS 26574-1 } 1 \frac{2}{A} \mathrm{~A} \\ 7274-4-2 & \text { MS 26574-2A } \\ 7274-4-21 \frac{1}{2} & \text { MS 26574-21/2A } \\ 7274-4-3 & \text { MS 26574-3A } \\ 7274-4-4 & \text { MS 26574-4A }\end{array}$




$\begin{array}{llll}7274-2-5 & \text { MS 26574-5 } & 7274-4-5 & \text { MS 26574-5A } \\ 7274-2-71 / 2 & \text { MS 26574-71/2 } & 7274-4-7 \text { 1/2 } & \text { MS 26574-71/2A } \\ 7274-2-10 & \text { MS 26574-10 } & 7274-4-10 & \text { MS 26574-10A } \\ 7274-2-15 & \text { n/a } & 7274-4-15 & \text { n/a } \\ 7274-2-20 & \text { n/a } & 7274-4-20 & \text { n/a }\end{array}$

\begin{tabular}{|c|c|c|c|c|c|}
\hline TI Number & MS Number & TI Number & MS Number & TI Number & MS Number \\
\hline $7274-11-1 / 2$ & MS $22073-1 / 2$ & $7274-69-1 / 2$ & MS $22073-1 / 2 \mathrm{~V}$ & $7274-70-1 / 2$ & MS $26574-1 / 2 \mathrm{~L}$ \\
\hline $7274-11-3 / 4$ & MS $22073-3 / 4$ & $7274-69-3 / 4$ & MS $22073-3 / 4 \mathrm{~V}$ & $7274-70-3 / 4$ & MS 26574-3/4L \\
\hline $7274-11-1$ & MS 22073-1 & $7274-69-1$ & MS 22073-1V & $7274-70-1$ & MS 26574-1L \\
\hline $7274-11-1 \frac{1}{2}$ & MS $22073-1 \frac{1}{2}$ & $7274-69-1 \frac{1}{2}$ & MS $22073-1 \frac{1 / 2 V}{}$ & $7274-70-1 \frac{1}{2}$ & MS $26574-1 \frac{1}{2} \mathrm{~L}$ \\
\hline $7274-11-2$ & MS 22073-2 & $7274-69-2$ & MS 22073-2V & $7274-70-2$ & MS 26574-2L \\
\hline $7274-11-2^{1 / 2}$ & MS $22073-2^{1 / 2}$ & $7274-69-2 \frac{1}{2}$ & MS $22073-2^{1 / 2} \mathrm{~V}$ & $7274-70-2^{1 / 2}$ & MS $26574-2^{1 / 2}$ L \\
\hline $7274-11-3$ & MS 22073-3 & $7274-69-3$ & MS 22073-3V & $7274-70-3$ & MS 26574-3L \\
\hline $7274-11-4$ & MS 22073-4 & $7274-69-4$ & MS 22073-4V & $7274-70-4$ & MS 26574-4L \\
\hline $7274-11-5$ & MS 22073-5 & $7274-69-5$ & MS $22073-5 \mathrm{~V}$ & $7274-70-5$ & MS 26574-5L \\
\hline $7274-11-71 / 2$ & MS $22073-71 / 2$ & $7274-69-71 / 2$ & MS $22073-71 / 2 \mathrm{~V}$ & $7274-70-7 \quad 1 / 2$ & MS $26574-71 / 2 \mathrm{~L}$ \\
\hline 7274-11-10 & MS 22073-10 & 7274-69-10 & MS 22073-10V & 7274-70-10 & MS 26574-10L \\
\hline $7274-11-15$ & $\mathrm{n} / \mathrm{a}$ & $7274-69-15$ & $\mathrm{n} / \mathrm{a}$ & $7274-70-15$ & $\mathrm{n} / \mathrm{a}$ \\
\hline 7274-11-20 & $\mathrm{n} / \mathrm{a}$ & $7274-69-20$ & $\mathrm{n} / \mathrm{a}$ & $7274-70-20$ & $\mathrm{n} / \mathrm{a}$ \\
\hline
\end{tabular}

\section{4-11 and 7274-69}

\section{Top View}
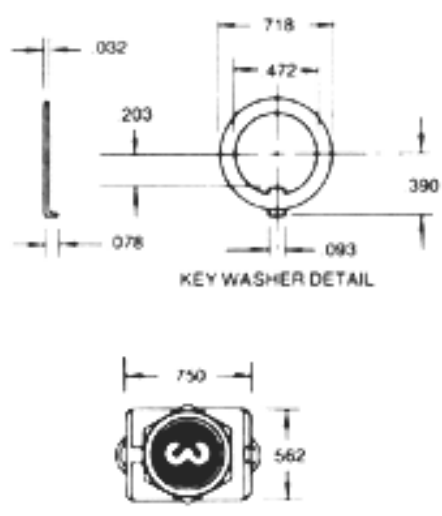

\section{Side View}

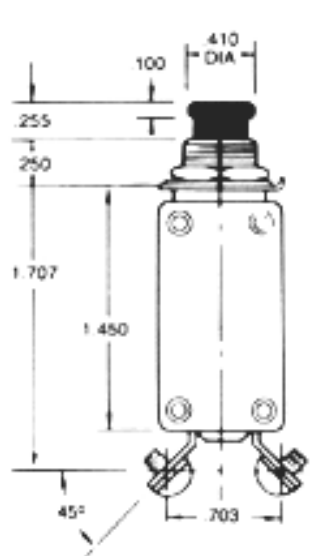

PUSA PULL BUTTON POSITION WITH CIACUIT GREAKEA TAIPPED IOFA

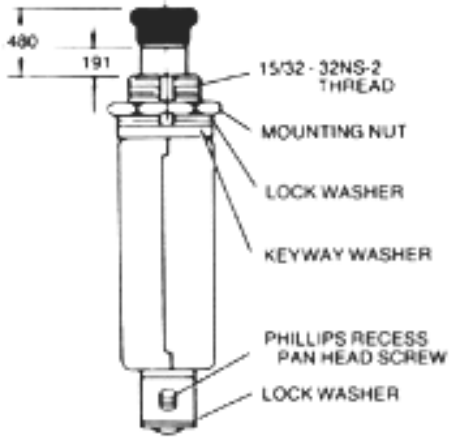

Nominal dimensions provided for reference purposes. 


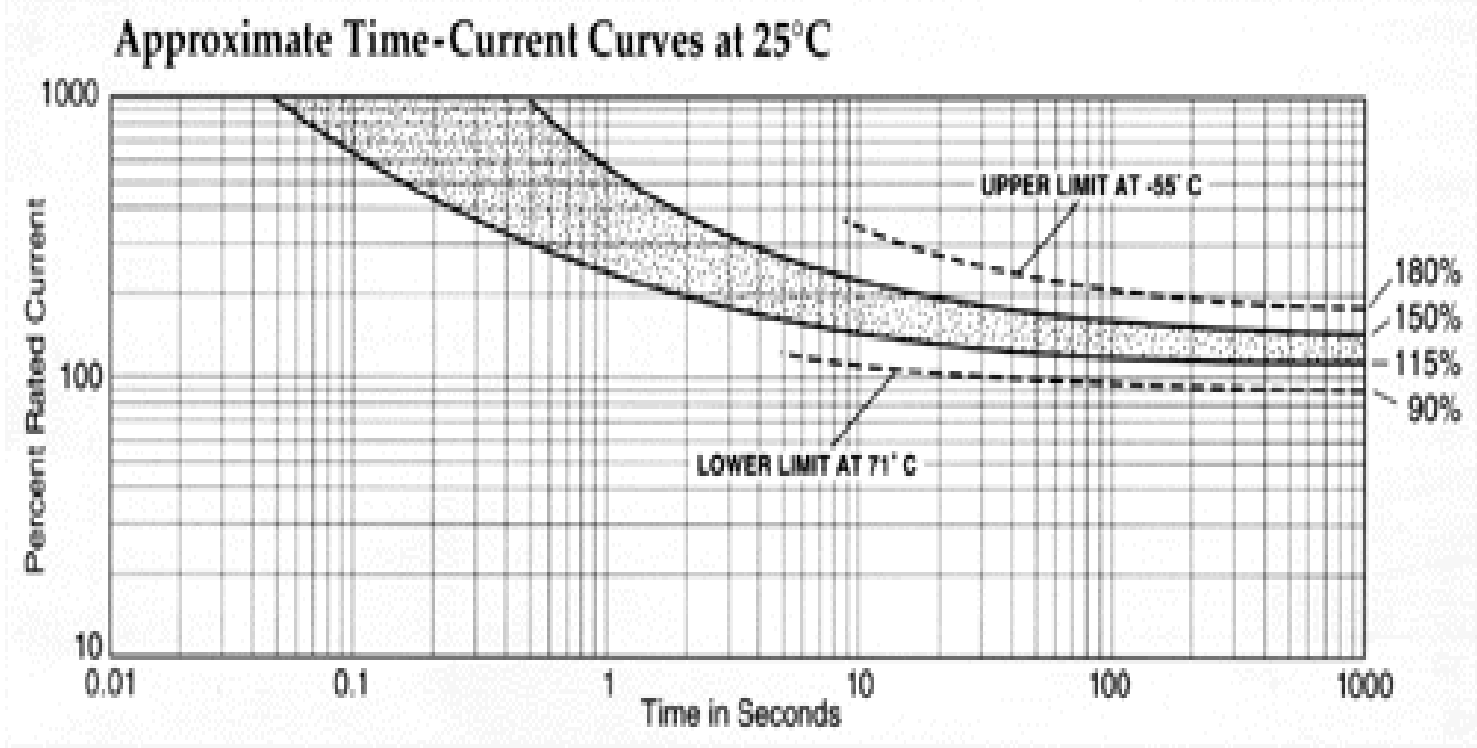




\section{Appendix 4: Operator Station Circuit Diagrams}

This appendix consists of the Operator Station input power circuit diagrams. The diagrams shown are

(1) C-130 Operator Station Power In/Out: An illustration of input power available to the system and output power for the Sensor Pallet.

(2) C-130 Operator Station Power Schematic: Circuit diagram for DC and $60 \mathrm{~Hz}$ AC input power, Vanner inverter, and AC and DC circuit breakers.

(3) C-130 Operator Station Power In Control: Close-up version of the power input control interlocking circuit shown in diagram (2).

The circuits were originally designed by Dr. Roy S. Nutter; these diagrams were drawn by Robert P. Hayes. 


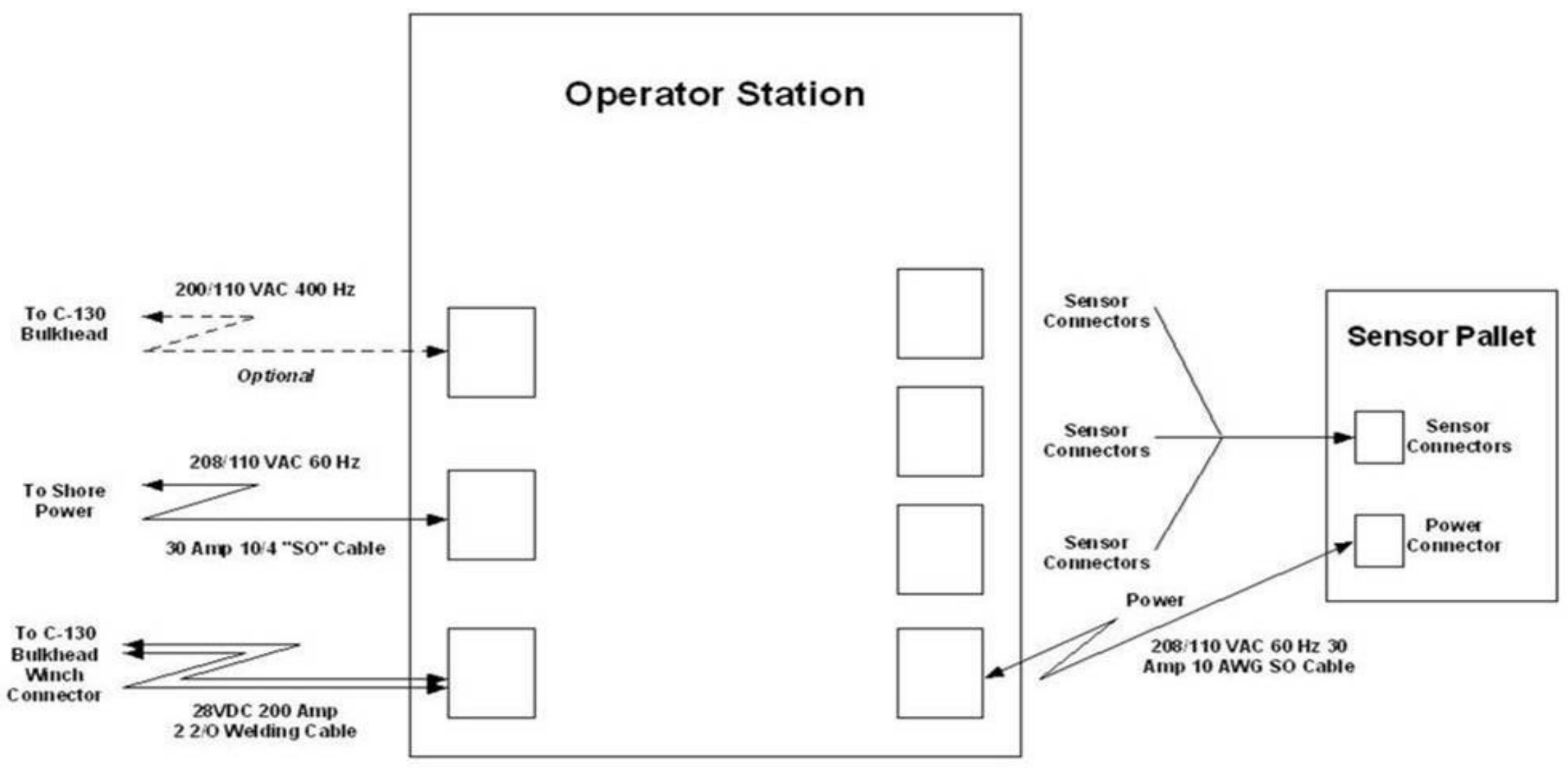

Title: C-130 Operator Station Power In/Out

Created by: Dr. Roy S. Nutter

Drawn by: Robert P. Hayes

Version No.: 1.0

Date: November 10, 2003 


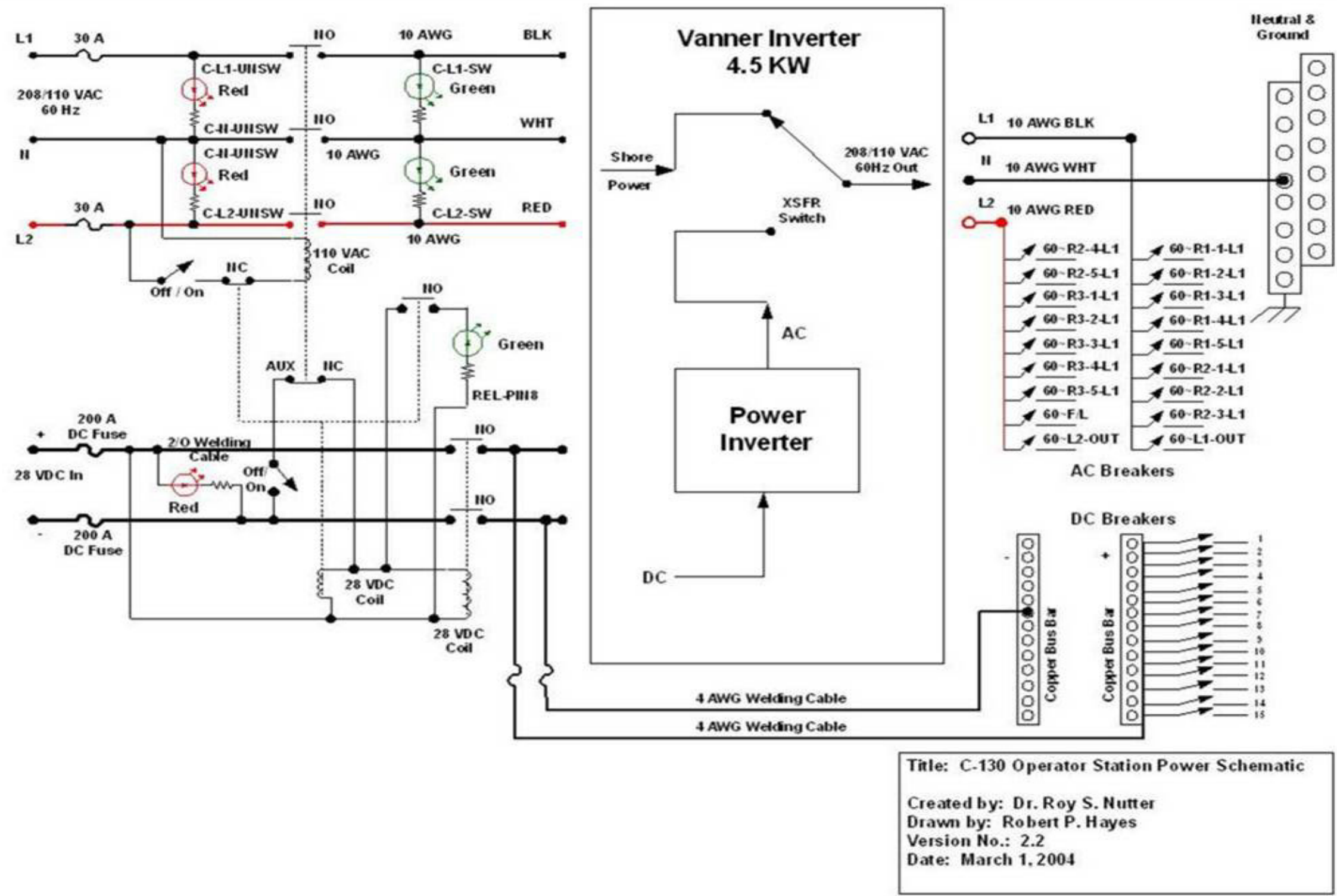




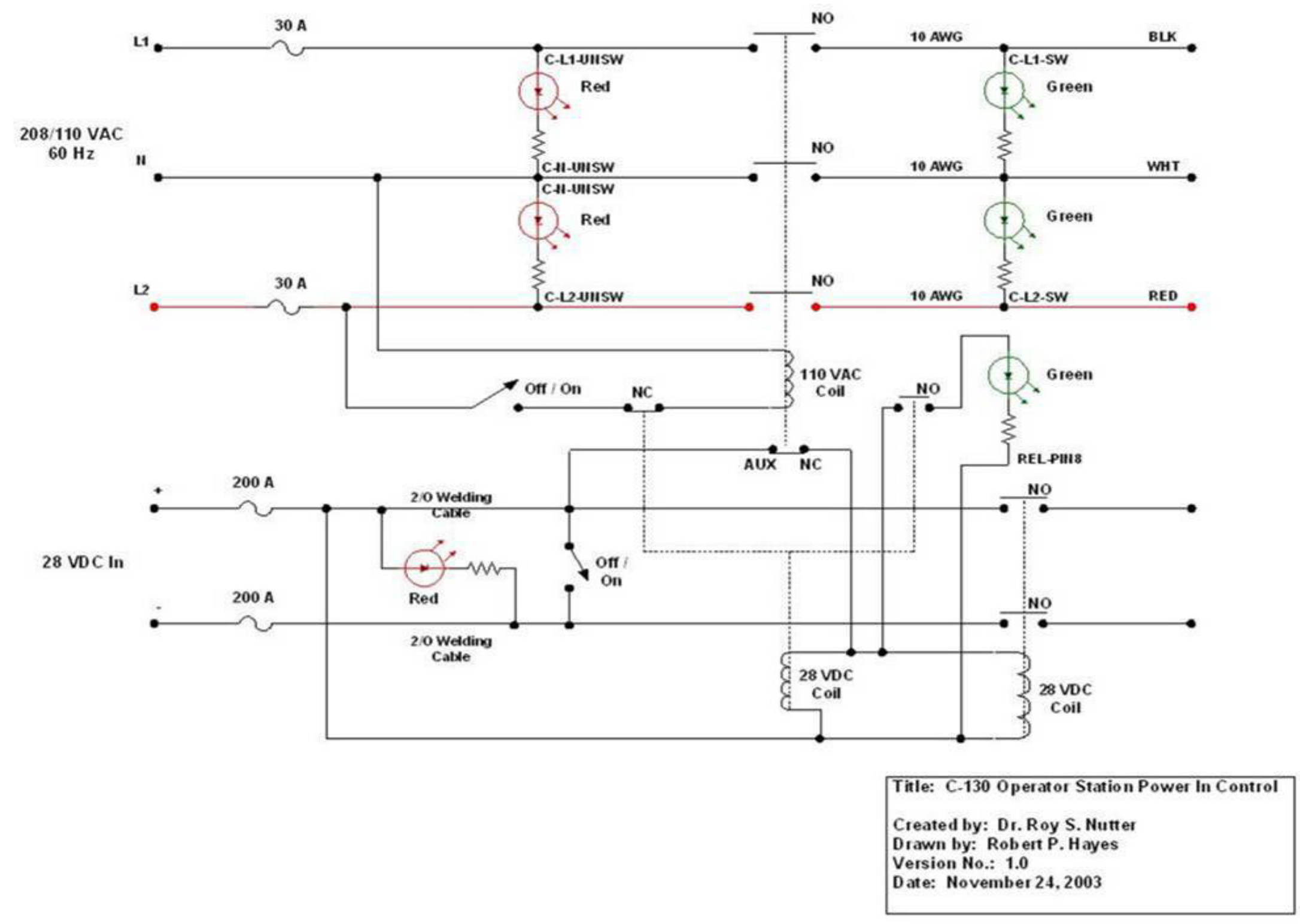




\section{Appendix 5: Automatic Mode Ladder Program}

This appendix contains the ladder program written to control the Automatic mode deployment of the Sensor Pallet, written using the DirectSoft $32^{\odot}$ programming software. Every rung of the program is commented to explain the purpose of each rung. The program was written by Robert P. Hayes. 
Rung 1: Here are the unconditional outputs for the program. Several status outputs are present, as well as initialization parameters to use the F0-04AD-1 AVD input board. The AuD board is set up to keep ite data in BCD format, and it 4 channel input is mapped to $V$-memery lecations $w / 2000-2003$. The censtant $10 \mathrm{~mA}$, the amperage that we should see from the current senswr when the motor has finished translating, is loaded into $U$-memony location Vz004. Here are the outputs:

01.) Message on the LCD should read "Automatic Mode"

\begin{tabular}{|l|l|}
\hline LCD \\
Line Number : \\
"Automatio Mod e"
\end{tabular}


final program $v 10$

Rung 2: On the first scan through the program, the memory locations used to store button pushes and timers should be cleared. Here, this is done. Memory locations $\times 50, \times 51$, $\times 52, \times 53, \times 54, \times 55, \times 50, \times 57, \times 60$, and $\times 61$ are cleared.

2

Firstsoan SPO

Extend Button Memory Location E. Button Memory $\times 50$
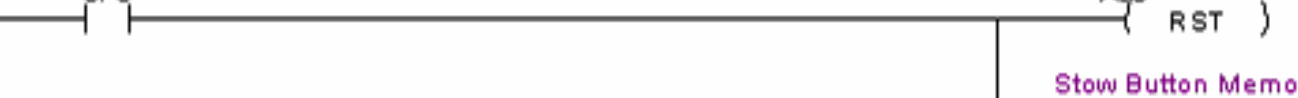

Stow Button Memory Location S-Button Memony $\times 51$

RST )

Extend Timer Memony Location E-Timer Memony $\times 52$ RST )

Stow Timer Memory Location S-Timer Memory $\times 53$ RST )

Current Sensor

Comparison Memory

Location

C.Sensor Memony $\times 54$ RST )

Extend/Stow Button Error Memony Location B-Error Memons X56 RST )

Translating Dut to Rotating Out Timer Memony Location TO-to-RO Memory $x+8$

RST

Rotating Out to Translating $\mathrm{Back}$ Timer Memory Looation RO- to. PB Memory $\times 57$

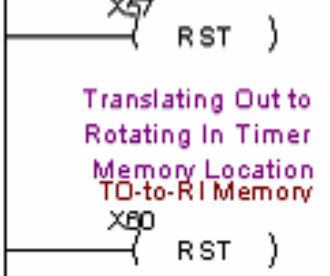

Rotating In to

Translating Back Timer Memary Location RI-to-To Memorv X01

RST ) 
Rung 3: This rung only controls the LCD monitor. If the PLC inputs are:

11.) Translation Stow Sensor is on

12.) Extend Button has not been pushed

the PLC output should be:

01.) The LCD display should read "Fully Stowed"

Translation Stow Sensor

$$
\text { Extend Button Memory }
$$

T-Stow Sensor

Location

3 $\times 11$

LCD

Line Number :

"Fully Stowed" 
Rung 4: This is the ladder rung that handles the error state of pushing both the Extend Button and Stow Button at once. If the PLC inputs are:

11.) Extend Button is pushed

12.) Stow Button is pushed

the PLC outputs are:

01.) The LCD display should read "E: Button Push"

02.) The Extend Button memony location is cleared.

03.) The Stow Button memony location is cleared.

04.) The Extend Timer memony location is cleared.

05.) The Stow Timer memony location is cleared.

06.) The Extend/Stow Button Error memony location is set.

07.) The TO-to-RO Timer memony location is cleared.

08.) The RO-to-TB Timer memory location is cleared.

09.) The TO-to-RI Timer memony location is cleared.

4

Extend Button
Extend Button

CD

Line Number:

K2

"E: Button Push"

Extend Button Memony Location

E-Button Memon $\times 50$

RST )

Stow Button Memory Location S-Button Memony $\times 51$

RST

Extend Timer Memony

Location

E-Timer luemory

$\times 52$

RST

Stow Timer Memon

Location

S-Timer Mlemory

$\times 5_{3}$

RST )

Extend/Stow Button Error

Memony Location

B-Error Memony

X⿸厂万⿺乚一

SET )

Translating Out to

Rotating Dut Time

Memony Location

X65

RST ,

Rotating Dut to

Translating Back Time

Memony Location
RO- to-T'B Memony

$\times 5 \%$

RST )

Translating Out to

Rotating In Timer

Memon Location

$x \in 0$

RST

Rotating In to

Translating Back Time

Memong Location

Xo1

RST ) 
Rung 5: This is another error handling ladder rung. If the Button Error memory location is set, and only the Extend Button is pushed, the Button Error memony location should be reset.

Extend Button

Stow Button

Stown Button
Extend/Stow Button Error

Memony Location

B-Error Memony
Extend/Stow Button Error

Memony Location

B-Errór Memony

X55 X56

Rung 6: This is another error handling ladder rung. If the Button Error memony location is set, and only the Stow Button is pushed, the Button Error memony location should be reset.

6

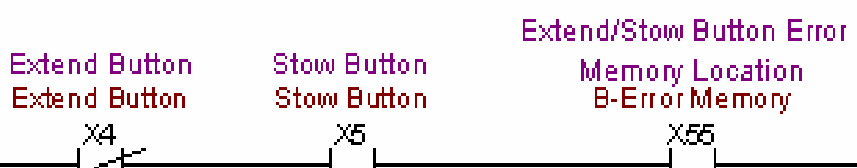

Extend Button Stow Button

Extend Button Stow Button $x^{5}$

Extend/Stow Button Error Memory Location B-Error Memony XE5

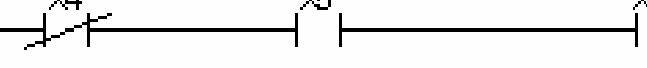

Extend/Stow Button Error

Memony Location

B-Error Memony

$X 5^{\circ}$

RST )

Rung 7: This rung sets the extend process into motion. When the Extend Button is pushed, the Extend Button memory location is set. The PLC inputs are:

11.) The Extend Button is pushed.

12.) The ExtendiStow Button Error memony location is not set.

The PLC outputs are:

01.) The Extend Button memony location is set.

02.) The LCD display should read "Extend Button".

Extend Button

Extend Button

7

Extend/Stow Button Error

Memony Location

B-Error Memony

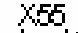

Extend Button Memony

Location

E- Button Memory

$\times 50$

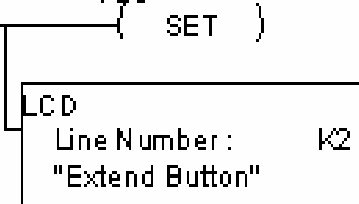


Rung 8: This rung is to handle the memony locations. If the Stow Button memony location is set when the Extend Button is pushed, the memony locations associated with the stow process should be reset. The PLC inputs are:

11.) The Extend Button is pushed.

12.) The Stow Button memony location is set.

The PLC outputs are:

01.) The Stow Button memony location is reset.

02.) The Stow Timer memony location is reset.

03.) The TO-to-RI Timer memony location is reset.

04.) The RI-to-TB Timer memony location is reset.

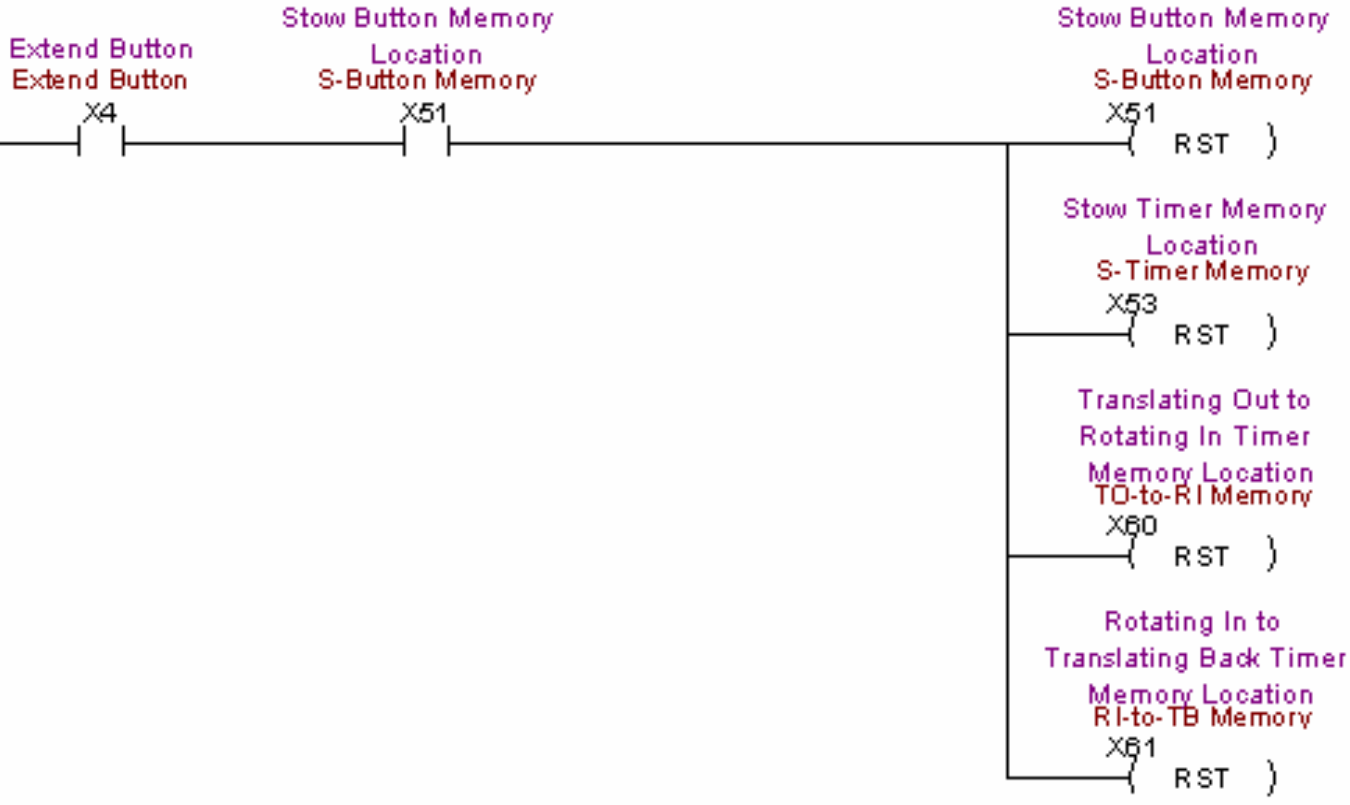

Rung 9: When the Extend Button is pushed, it sets a 5.0 second timer that must finish its countdown before the extend process begins. Here, the Extend Button Timer is set to 5.0 seconds.

9

\section{Extend Button Memory}

Location

E-Button Memony

$\times 50$

\section{TMR} Extend Button Timer Extend Timer

TO

K50

Rung 10: The PLC must remember that the Extend Button Timer finished its countdown. so at this rung, when the Extend Button Timer finishes, the Extend Timer memony location is set.

Extend Button Timer

Extend Timer Memony Extend Timer

Location

TO

E-Timer Memory

10

$\times 52$ 
Rung 11: This rung only controls the LCD display. If the PLC inputs are:

11.) The Extend Button memony location is set.

12.) The Extend Timer memory location is set.

13.) The Rotation Extend Sensor is not on.

14.) The Rotation Stow Sensor is on.

15.) The Translation Extend Sensor is not on. - $\mathrm{DR}$ -

11.) The Extend Button memony location is set.

12.) The Extend Timer memory location is set.

13-6.) All Sensors are not on. -OR.

11.) The Stow Button memony location is set.

12.) The Stow Button memony location is set.

13-6.) All Sensors are not on.

Extend Button Memony Location

E-Button Memory

Extend Button Memony

Location

E-Button luemony

.

Stow Button Memony

Location

S-Button Memony $\times 51$

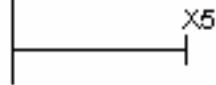

Rotation Stow Sensor

R-Stow Sensor

A.

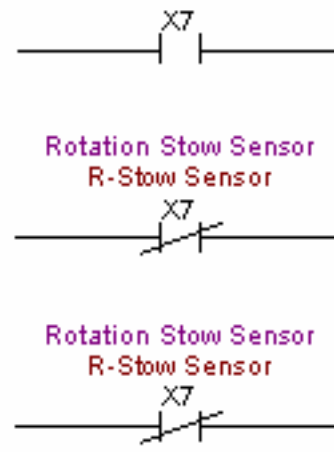

Extend Timer Memony Location

E-Timer Memony $\times 52$

Extend Timer Memony

Location

E-Timer Memony

$\times 52$

Stow Timer Memony

Location

S-Timer Memony $x_{53}$

Translation Extend Sensor

T-Extend Sensor

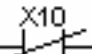

Translation Extend Sensor

T-Extend Sensor $\times 10$.

Translation Stow Sensor

T-Stow Sensor R-Extend Sensor

otation Extend Sensor

R-Extend Sensor

A

Translation Extend

Sensor

T-Extend Sensor

$\times 10$

Translation Stow Sensor

T-Stow Sensor $\times 11$ 
Rung 12: This rung controls the LCD display as well as sets the Translating Out to

Rotating Dut Timer to 3.0 seconds. If the PLC inputs are:

11.) The Extend Button memony location is set.

12.) The Extend Timer memony location is set.

13.) The Rotation Extend Sensor is not on.

14.) The Translation Extend Sensor is on.

the PLC outputs are:

01.) The LCD display should read "Rotating Dut".

02.) The TO-to-RO Timer is set to 3.0 seconds.

Extend Button Memony
Location
E-Button Memony

Rung 13: When the TO-to-RO Timer finishes it 3.0 second countdown, the PLC needs

to remember that the timer has finished. Here, the TO-to-RO memony location is set when

the timer finishes its countdown.

Translating Out to

Rotating Dut Timer

TO-to-RO Timer

13

$\left.\right|^{T 2}$

Translating Dut to

Rotating Dut Timer

Memony Location

$\times 56$ SET 
Rung 14: This rung controls the LCD display and sets the Rotating Dut to Translating

Back Timer to 3.0 seconds. If the PLC inputs are:

11.) The Extend Button memony location is set.

12.) The Extend Timer memory location is set.

13.) The Rotation Extend Sensor is on.

the PLC outputs are:

01.) The LCD display should read "Translating Back".

02.) The RO-to-TB Timer is set to 3.0 seconds.

Extend Button Memony Extend Timer Memony
Location
E-Button Memony

Rung 15: When the RO-to-TB Timer finishes its 3.0 second countdown, the PLC needs to remember that the timer has finished. Here, the RO-to-TB memony location is set when the timer finishes its countdown.

Rotating Dut to

Translating Back Timer

RO-to-TB Timer

15
Rotating Out to

Translating Back Timer

Memon Location

RO-to-TB Memony

$\times 57$ 
Rung 16: In this stage, the plate finishes translating inward and is in its fully extended position. This is initiated by the platelarm jamming up against the C-130 door, causing a current spike seen by the current sensor CLN-50 and captured by the F0-04AD-1 AJD

input board. When this occurs, the current spike should rise above $10 \mathrm{~mA}$, and this is reflected by setting the Current Sensor Comparison memony location. The PLC inputs are:

11.) Channel 1 of the $A / D$ input board (stored at V2000) is greater than or equal to $10 \mathrm{~mA}$ (stored in v2004)

The PLC should output:

01.) The Current Sensor Comparison memory location is set.

02.) The Extend Button memony location is reset.

03.) The Extend Timer memony location is reset.

04.) The Stow Button memony location is reset.

05.) The Stow Timer memony location is reset.

06.) The TO-to-RO Timer memony location is reset.

07.) The RO-to-TB Timer memony location is reset.

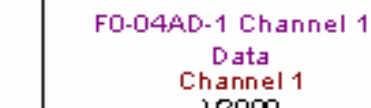

16
Channel 1 is compared

to this value

Comparison Value v2004
Current Sensor

Comparison Memony

Location

$\times 54$

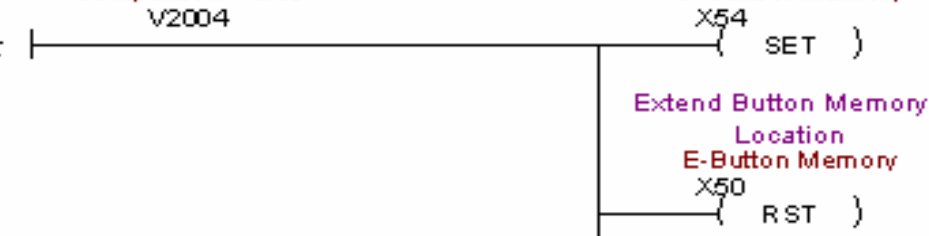

Extend Timer Memony Location

E-Timer Mlemory

$\times 52$

RST )

Stow Button Memony

Location

S-Button Memon

$\times 51$

RST

Stow Timer Memony

$$
\text { Location }
$$

S-Timer hemory

$\times 53$

RST

Translating Dut to

Rotating Dut Timer

Memony Location

TO-to-RO hiemory

$\times 56$

RST )

Rotating Dut to

Translating Back Timer

Memon Location

$\times 57$

RST

Translating Dut to

Rotating In Timer

Memon Location

TO-to-RIMemony

X⿸厂二

RST

Rotating In to

Translating Back Timer

Memony Location

ri-to-

$\times 01$

RST ) 
Rung 17: This rung only controls the LCD display. When the Current Sensor Comparison memony location is set, the LCD display should read "Fully Extended".

Current Sensor

Comparison Memony

Location

C-Sensor wemon

$\times 54$

17 1

Rung 18: This rung takes care of setting the memony locations. Wuhen the Extend Button memony location has been set, but now the Stow Button has been pushed, the memony locations related to the extend process should be reset. If the PLC inputs are:

11.) The Extend Button memory location is set.

12.) The Stow Button has been pushed.

the PLC outputs are:

01.) The Extend Button memory location is reset.

02.) The Extend Timer memony location is reset.

03.) The TO-to-RO Timer memony location is reset.

04.) The RO-to-TB Timer memony location is reset.

Extend Button Memony

$$
\text { Location }
$$

E-Button Memony

18 $\times 50$

Stow Button

Stow Button $\times 5$

Extend Button Memory

$$
\text { Location }
$$

E-Button Memory $\times 50$

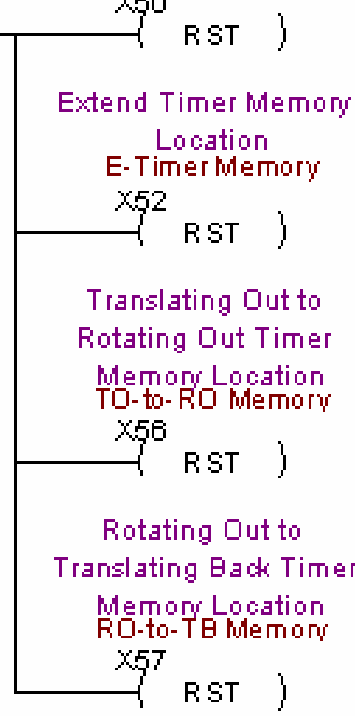


Rung 19: In this rung, the stow process is set into effect. It begins by setting the Stow Button memony location when the Stow Button is pushed. If the PLC inputs are:

11.) The Stow Button is pushed.

12.) The Extend/Stow Button Error memony location is not set.

the PLC outputs are:

01.) The Stow Button memony location is set.

02.) The Current Sensor Comparison memony location is reset.

03.) The LCD display should read "Stow Button".

Extend/Stow Button Error

Stow Button

Memony Location

B-Error lulemory

Stow Button Memony

Location

S- Button Memony

19

$\times 5$ X55

$\times 51$

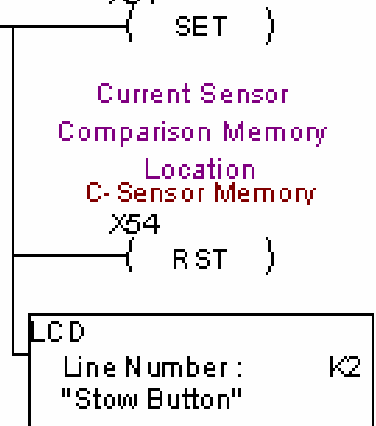

Rung 20: Woinen the Stow Button is pushed, it sets a 5.0 second timer that must finish it: countdown before the stow process begins. Here, the Stow Button Timer is set to 5.0 seconds.

Stow Button Memory

Location

S-Button Memony

$\times 51$

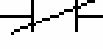

ThR
Stow Button Timer
Stow Timer
T1
K50

Rung 21: The PLC must remember that the Stow Button Timer finished its countdown, so at this rung, when the Stow Button Timer finishes, the Stow Timer memony location is set.

Stow Button Timer

Stown Timer

Stow Timer Memony

Location

T1

S-Timer Memony

21 $\times 53$

1

SET ) 


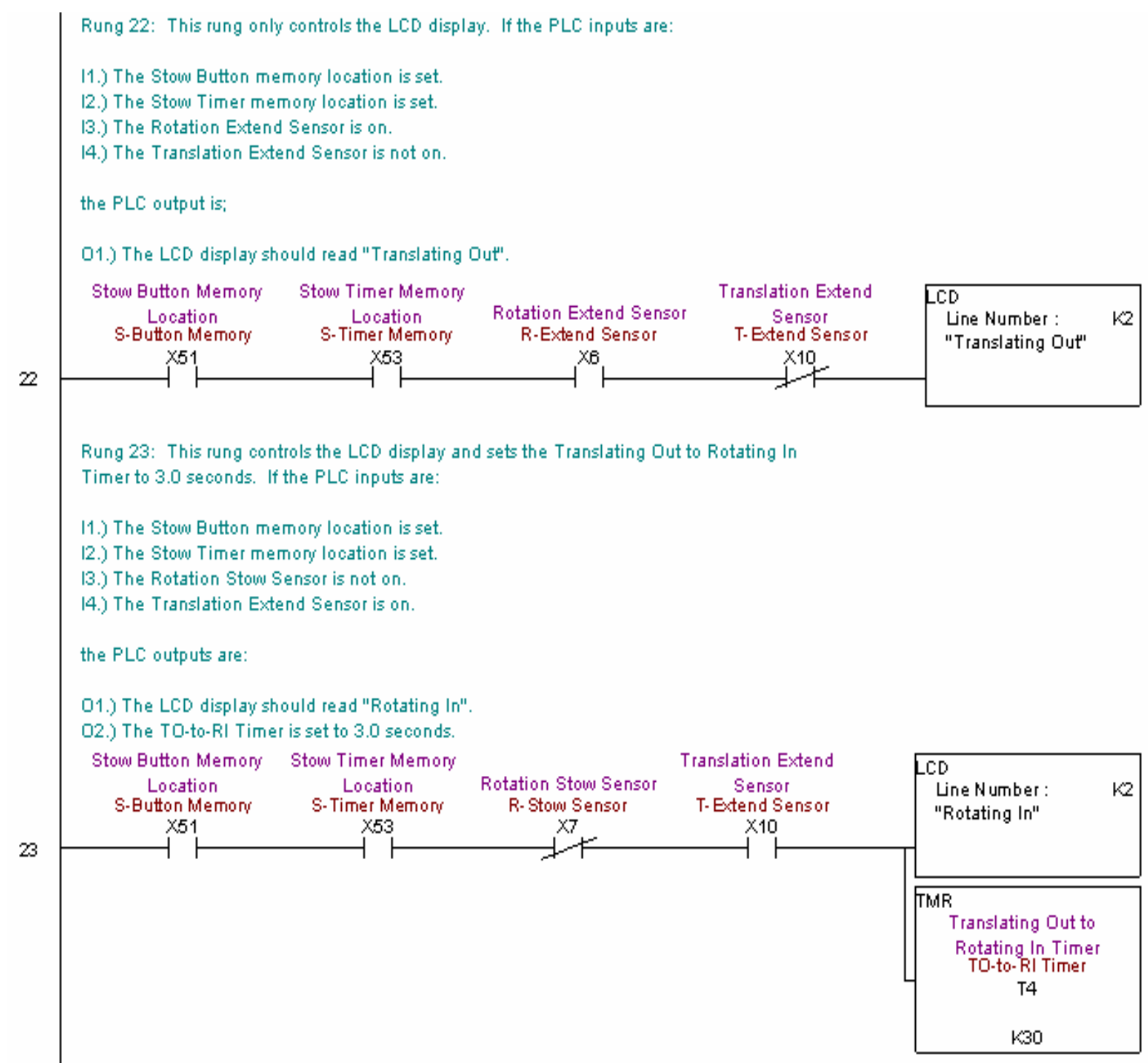

Rung 24: When the TO-to-RI Timer finishes its 3.0 second countdown, the PLC needs to remember that the timer has finished. Here, the TO-to-RI memony location is set when the timer finishes its countdown.

Translating Out to

Rotating In Timer

TO-to-RI Timer

Translating Out to

Rotating In Timer T4

24

Memony Location
TO-to-RI Memony $\times 60$ 
Rung 25: This rung controls the LCD display and sets the Rotating In to Translating Back

Timer to 3.0 seconds. If the PLC inputs are:

11.) The Stow Button memory location is set.

12.) The Stow Timer memony location is set.

13.) The Rotation Stow Sensor is on.

14.) The Translation Stow Sensor is not on.

the PLC outputs are:

01.) The LCD display should read "Translating Back".

02.) The RI-to-TB Timer is set to 3.0 seconds.

Stow Button Memony Stow Timer Memony$$
\text { Location }
$$$$
\text { Location }
$$

Rotation Stow Sensor R-Stow Sensor

Translation Stow Sensor T-Stow Sensor

LCD

Line Number:

"Translating Back"

25 S-Timer Memon $\times 53$ $\times 7$ X11

\begin{tabular}{c} 
TMR Rotating In to \\
Translating Back Timer \\
Ri-to-T日 Timer \\
T5 \\
$k 30$ \\
\hline
\end{tabular}

Rung 26: When the RI-to-TB Timer finishes its 3.0 second countdown, the PLC needs to remember that the timer has finished. Here, the RI-to-TB memony location is set when the timer finishes its countdown.

Rotating In to

Rotating In to

Translating Back Timer

RI-to-T日 Timer

Rung 27: This rung takes care of setting /resetting memony locations. If the Translation

Stow Sensor turns on after the Stow Button has been pushed, the memony locations

related to the stow process should be reset. If the PLC inputs are:

11.) The Translation Stow Sensor is on.

12.) The Stow Button memory location is set.

the PLC outputs are:

01.) The Stow Button memony location is reset.

02.) The Stow Timer memory location is reset.

03.) The TO-to-RI Timer memony location is reset

04.) The Rl-to-TB Timer memony location is reset.

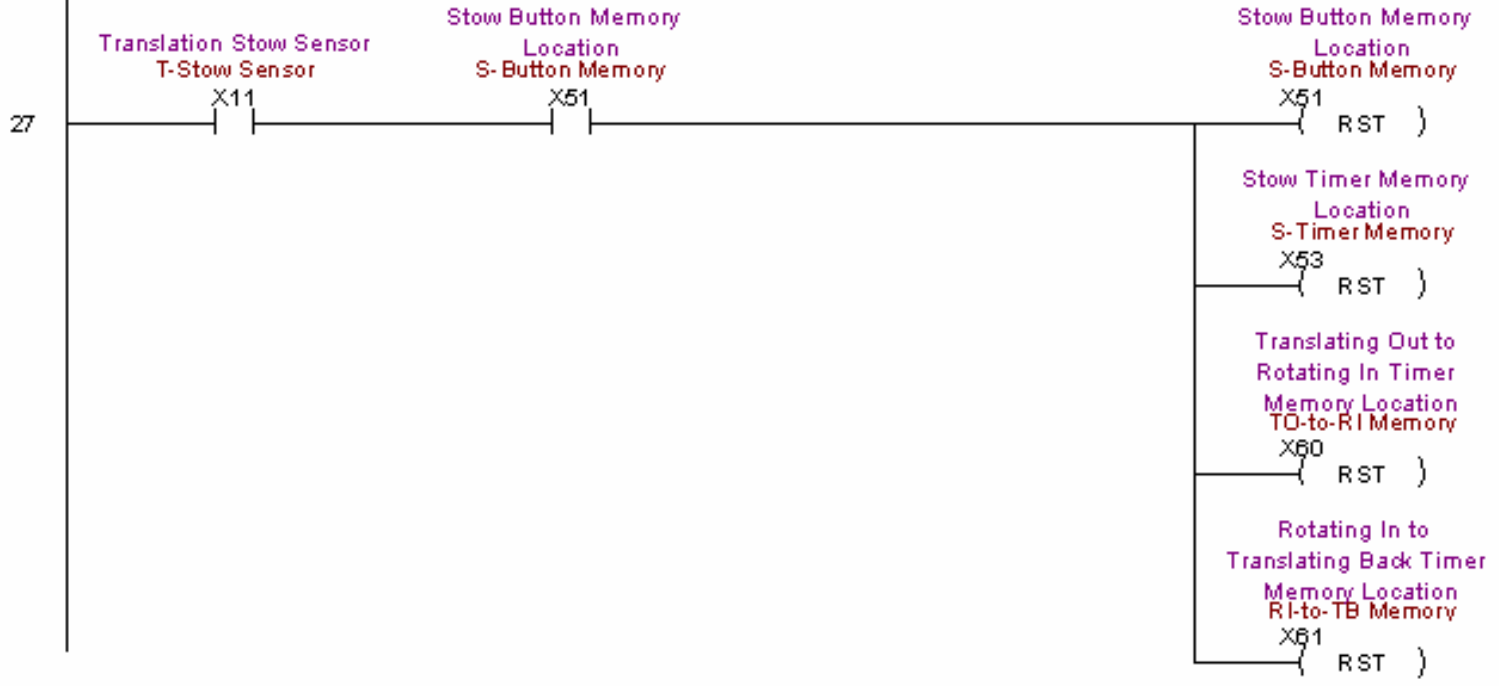


Rung 28: Output $Y 17$ (Translation Clodowise - In) is turned on when the PLC inputs are:

11.) The Extend Button memony location is set.

12.) The Extend Timer memony location is set.

13.) The RO-to-TB Timer memory location is set.

14.) The Rotation Extend Sensor is on.

$$
\text { -OR. }
$$

11.) The Stow Button memony location is set.

12.) The Stow Timer memony location is set.

13.) The RI-to-TQ Timer memory location is set.

14.) The Rotation Stow Sensor is on.

15.) The Translation Stow Sensor is not on.

Extend Button Memony Extend Timer Memony Translating Back Timer

Location
$\begin{array}{ll}\text { E-Button Memony } & \text { E-Timer Memony } \\ \text { RO-to-TBMemony }\end{array}$

Rotating In to

Stow Button Memony Stow Timer Memony Translating Back Timer

Location

S-Button Memony

$\times 51$
Location

S.Timer Memony

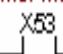

Memony Location

Ri-to-T⿱㇒日勺 Memory

$x^{x 1}$
Rotation Stow Sensor Translation Stow Sensor

R.Stow Sensol

$\mathrm{X} 7$
T.Stow Sensor

$\times 11$ 
Rung 29: Dutput $Y 16$ (Translation Counter-Clockowise - Dut) is on when PLC inputs are:

11.) The Extend Button memory location is set.

12.) The Extend Timer memony location is set.

13.) The Rotation Extend Sensor is not on.

14.) The Rotation Stow Sensor is on.

15.) The Translation Extend Sensor is not on. -OR-

11.) The Stow Button memony location is set.

12.) The Stow Timer memory location is set.

13.) The Rotation Extend Sensor is on.

14.) The Translation Extend Sensor is not on. -OR-

11.) The Extend Button memony location is set.

12.) The Extend Timer memony location is set.

13-6.) All Sensors are not on. -OR-

11.) The Stow Button memory location is set.

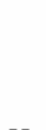

29

\section{Extend Button Memony}

Location

E-Button Memony

$\times 50$

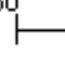

Stow Button Memony

$$
\text { Location }
$$

S-Button Memony

Extend Button Memony

Location

E-Button Memony

$\times 50$

.

Stow Button Memony

Location

S-Button Mlemony

$\times 51$

.

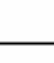

Rotation Extend Sensor

R-Extend Sensor

E-Timer Memony

$\times 52$

Stow Timer Memony

Location

S-Timer Mlemon

$\times 53$

Extend Timer Memony

Location

E-Timer Memony

$\times 52$

Stow Timer Memony

Location

S-Timer Mlemony $\times 53$

Rotation Extend Sensor

R-Extend Sensor x
A

Rotation Extend Sensor

R-Extend Sensor $\left.\right|^{x /}$

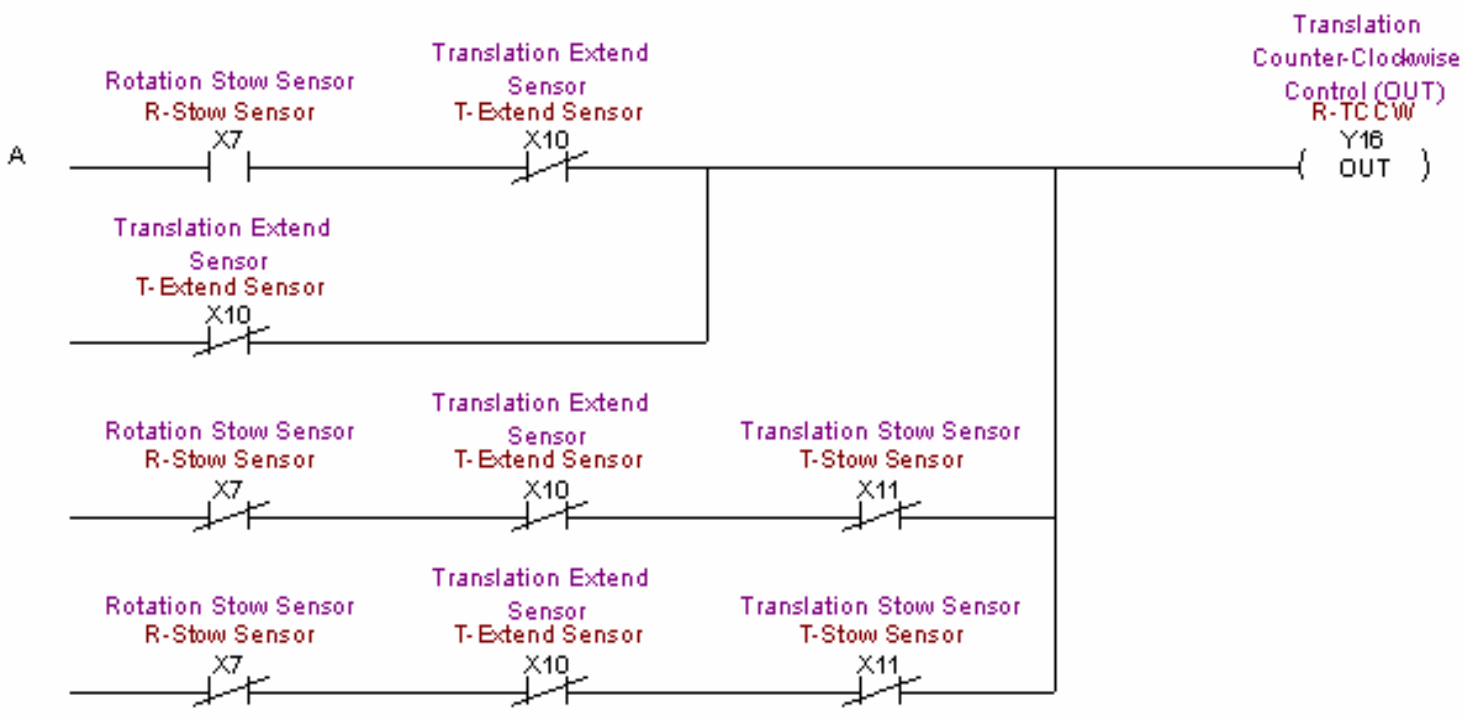


Rung 30: Dutput Y6 (Translation Operate LED Indicator) is on when the PLC inputs are:

11-2.) The Extend Button and Extend Timer memony locations are set.

13.) The Rotation Extend Sensor is not on.

14.) The Rotation Stow Sensor is on.

15.) The Translation Extend Sensor is not on. -OR-

11-2.) The Extend Button and Extend Timer memony locations are set.

13.) The RO-to-TB memony location is set.

14.) The Rotation Extend Sensor is on. -OR-

11-2.) The Stow Button and Stow Timer memony locations are set.

13.) The Rotation Extend Sensor is on.

14.) The Translation Extend Sensor is not on. -OR.

11-2.) The Stow Button and Stow Timer memony locations are set.

13.) The Rl-to-TB memony location is set.

14.) The Rotation Stow Sensor is on.

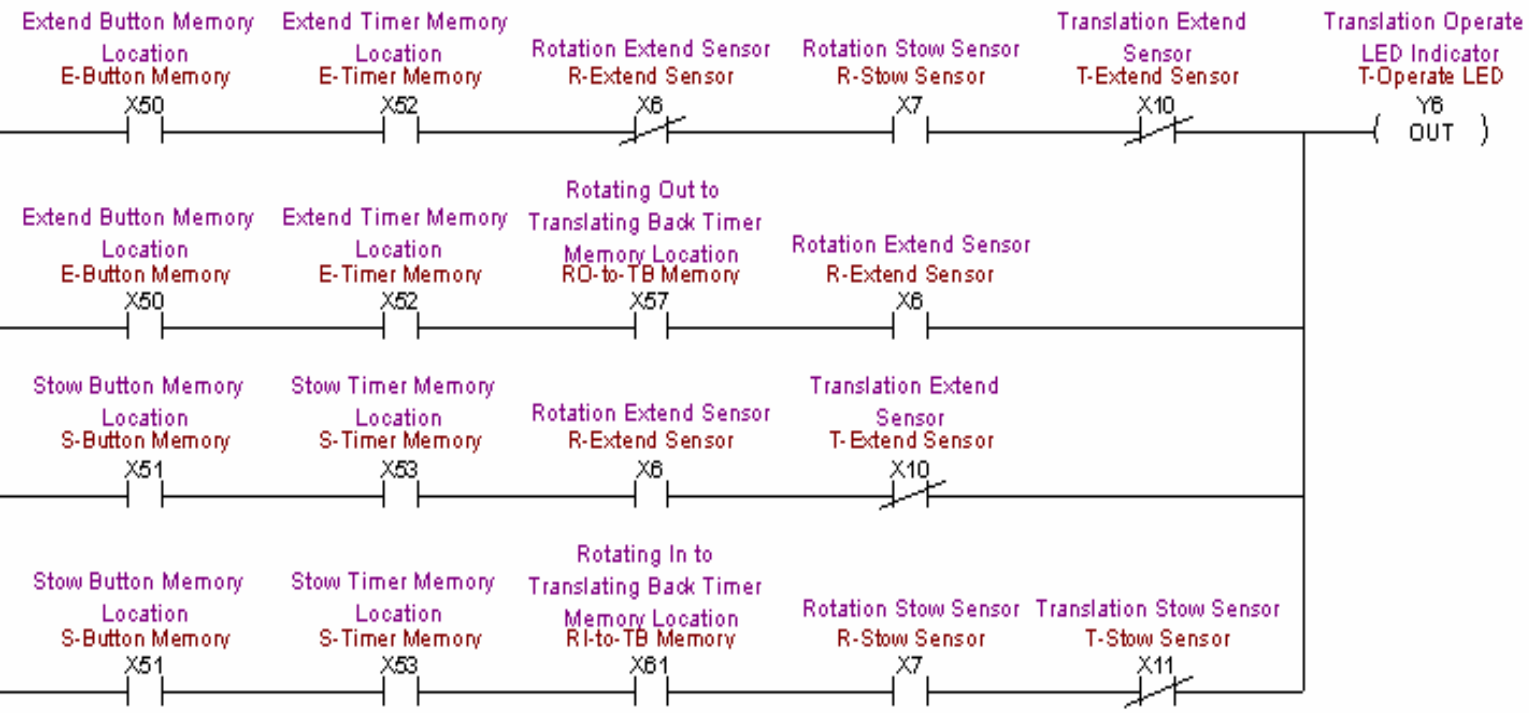

Rung 31: Dutput Y11 (Rotation Operate LED Indicator) is turned on when the PLC inputs

are:

11.) The Extend Button memony location is set.

12.) The Extend Timer memory location is set.

13.) The TO-to-RO Timer memony location is set.

14.) The Rotation Extend Sensor is not on.

15.) The Translation Extend Sensor is on.

-OR.

11.) The Stow Button memony location is set.

12.) The Stow Timer memony location is set.

13.) The TO-to-RI memory location is set.

14.) The Rotation Stow Sensor is not on.

15.) The Translation Extend Sensor is on

Translating Out to

Extend Button Memory Extend Timer Memony Rotating Out Timer
Location
Location
Memony Location

E-Button Memony E-Timer Memons

To-to-Ro Memon

Rotation Extend Sensor Translation Extend

R-Extend Sensor T-Extend Sensor

$\times 50$

$\times 52$

$\times 56$

$\times 6$

$\times 10$

Indicator

R. Operate LED

31

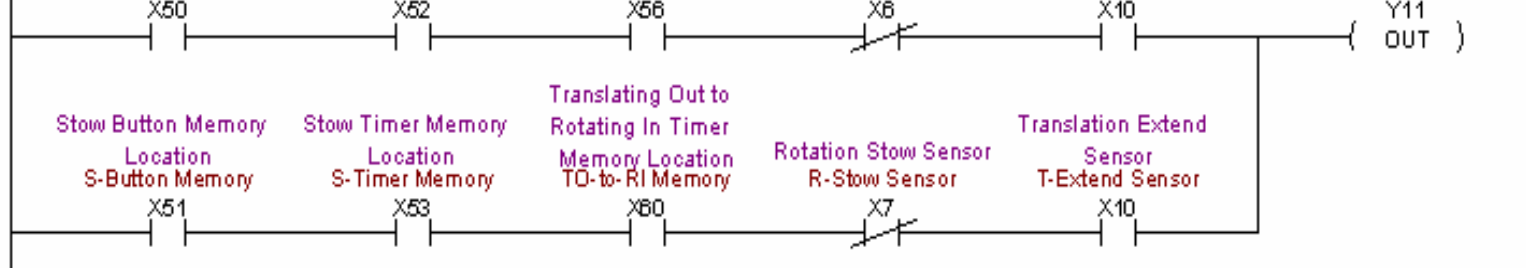


Rung 32: Dutput Y101 (Rotation Motor Fonward Controller) is turned on when the PLC

inputs are:

11.) The Extend Button memony location is set.

12.) The Extend Timer memory location is set.

13.) The TO-to-RO Timer memony location is set.

14.) The Rotation Extend Sensor is not on.

15.) The Translation Extend Sensor is on,

Translating Dut to

Extend Button Memony Extend Timer Memony Rotating Dut Time

Location

E-Button Memony

-Timer Memon

$\times 52$

32

$\times 50$ Memory Location
TO-to-Ro Memony
Rotation Extend Sensor
R-Extend Sensor
Translation Extend

Sensor

T-Extend Sensor
Rotation Motor Fonward

Control R-Motor Fonward

Rung 33: Dutput Y100 (Rotation Motor Reverse Controller) is turned on when the PLC inputs are:

11.) The Stow Button memony location is set.

12.) The Stow Timer memony location is set.

13.) The TO-to-RI Timer memony location is set.

14.) The Rotation Stow Sensor is not on.

15.) The Translation Extend Sensor is on.

Translating Dut to

Stow Button Memony Stow Timer Memony Rotating In Timer

Location Location Memon Location

S-Button Memony S-Timer Memons To-to-Rl Memon

$\times 60$

$\begin{array}{cc}\text { Rotation Stow Sensor } & \text { Translation Extend } \\ \text { R.Stow Sensor } & \text { T-Extend Sensor }\end{array}$

Rotation Motor Reverse

$\times 10$

Control

R-Motor Reverse

Y100

DUT )

Rung 34: This is the END rung, the end of the program.

34

END ) 


\section{Appendix 6: Sensor Pallet Control Circuit Diagrams}

This appendix contains the circuit diagrams used to implement Automatic and Manual mode deployment of the Sensor Pallet. The diagrams shown here are:

(1) C-130 Pendant Schematic: Diagram of how the Emergency Stop, Extend, and Stow pushbuttons and Automatic/Manual and Translate/Rotate switches are wired in the operator pendant.

(2) C-130 Motors Circuit Diagram: Control circuit for the translation and rotation motors used on the Sensor Pallet.

(3) C-130 PLC Circuit Diagram: Diagram showing how the Programmable Logic Controller was wired up, including the inputs and outputs, and the proximity sensors.

The circuits were originally designed by Dr. Roy S. Nutter; these diagrams were drawn by Robert P. Hayes. 


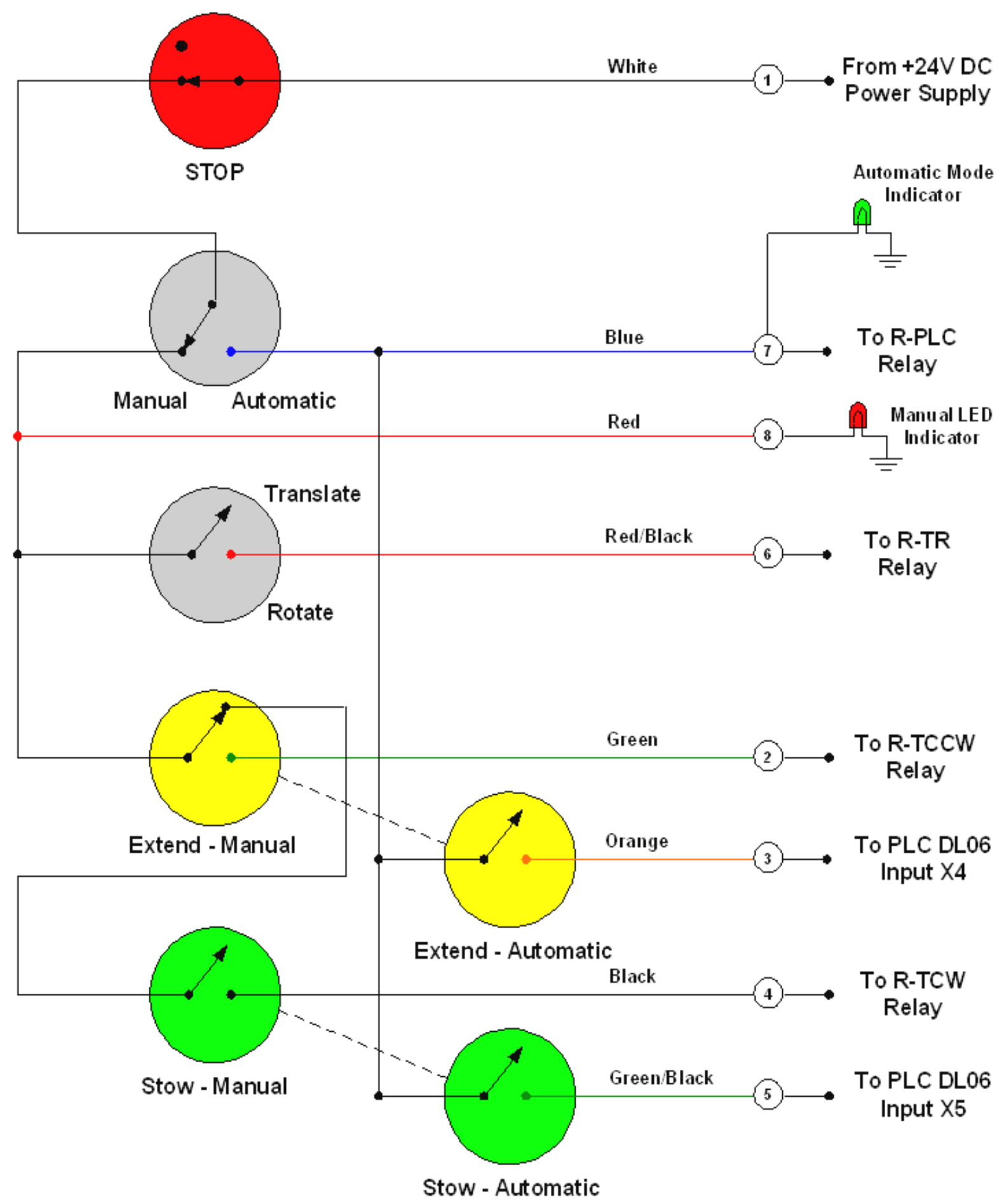

Note: Circled Numbers Are Contact Blocks

Title: C-130 Pendant Schematic

Created by: Dr. Roy S. Nutter

Drawn by: Robert P. Hayes

Version No:: 1.0

Date: May 5, 2004 


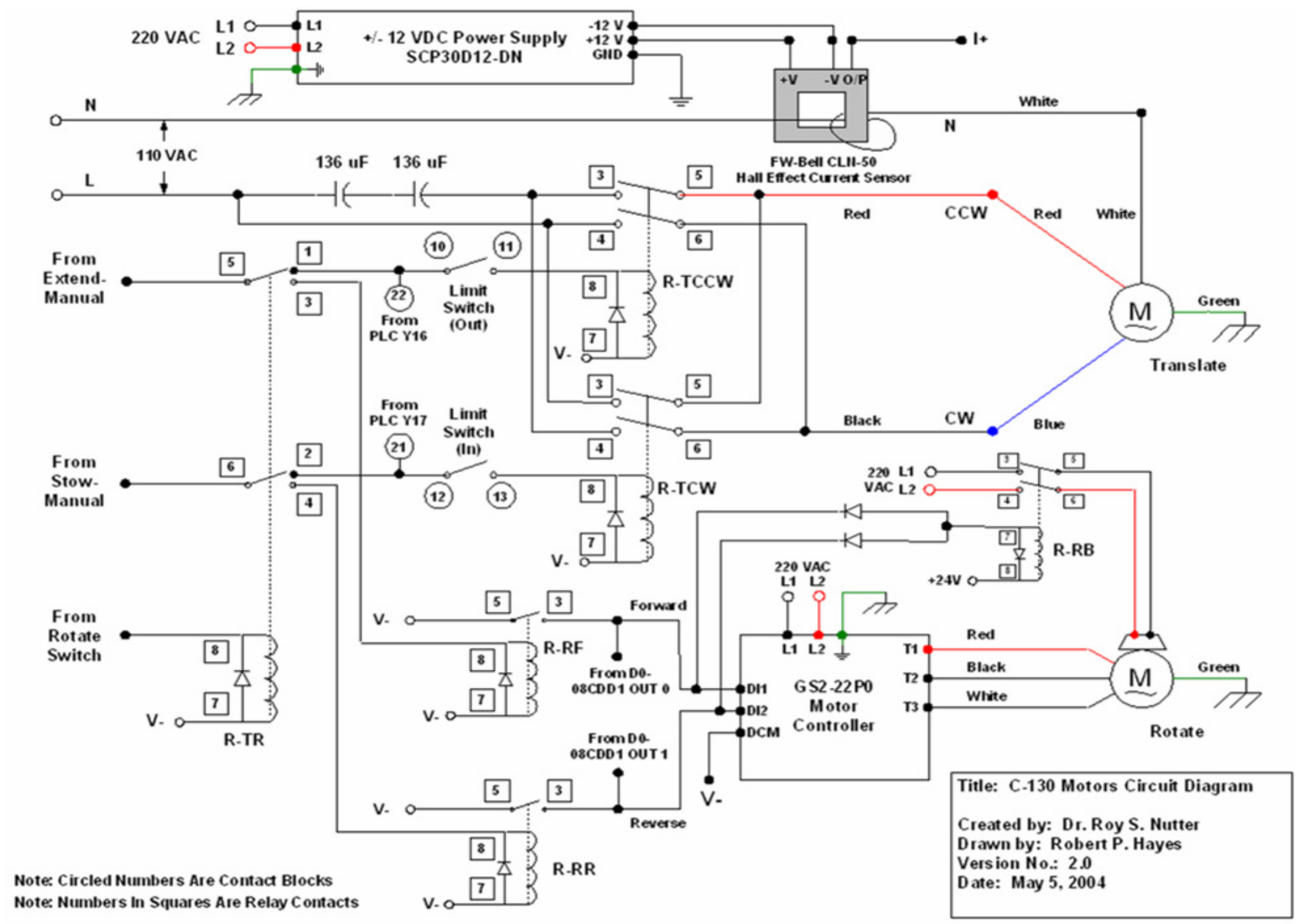




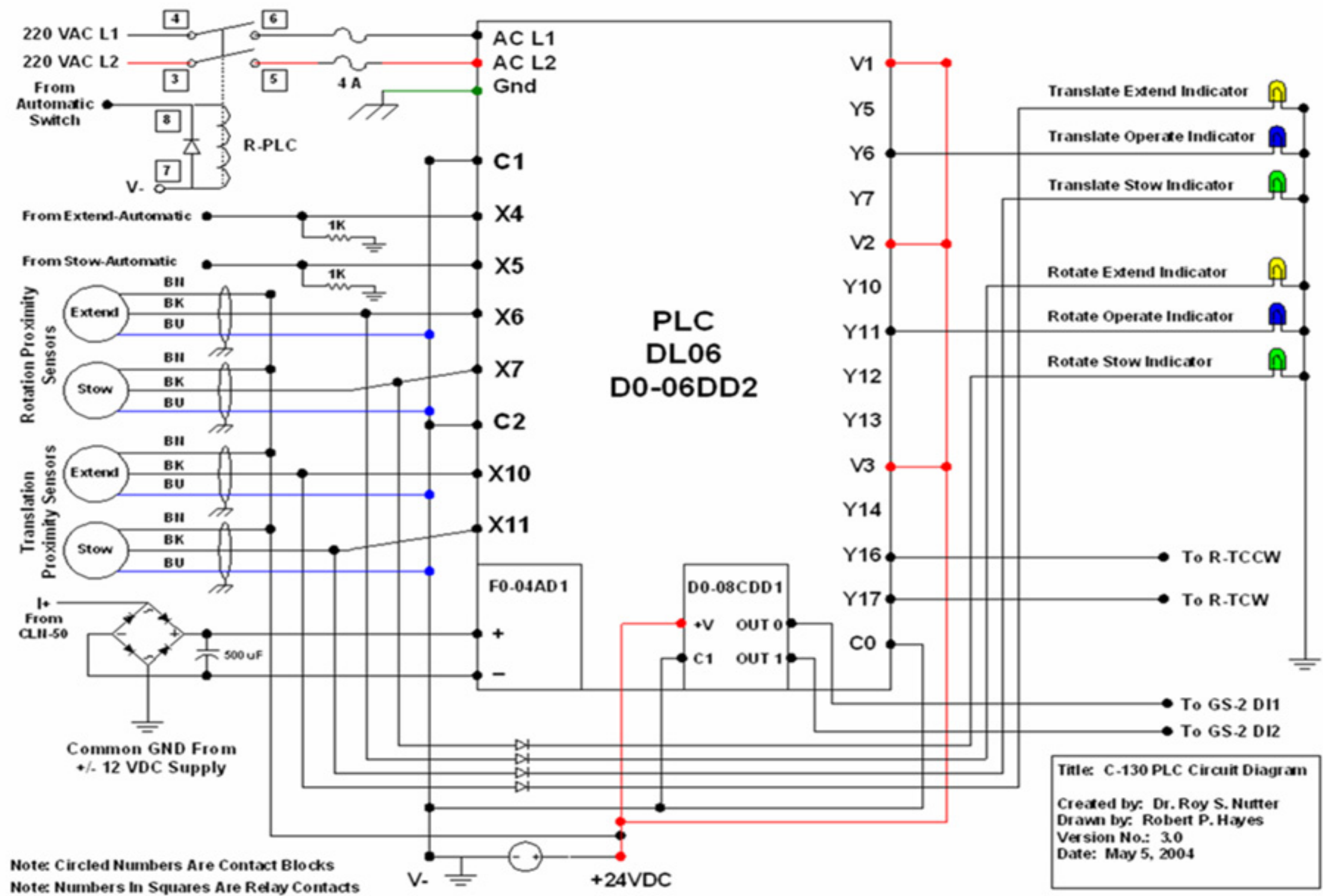




\section{Appendix 7: GS2-22P0 Motor Controller Specifications}

This appendix contains information for the GS2-22P0 2.0HP motor controller used to operate the rotation motor on the Sensor Pallet. This includes specifications, installation, wiring diagrams, and diagrams for the device. This device and further information is available from Automation Direct [24]. 


\section{GS2 Series - InTRODUCtION}

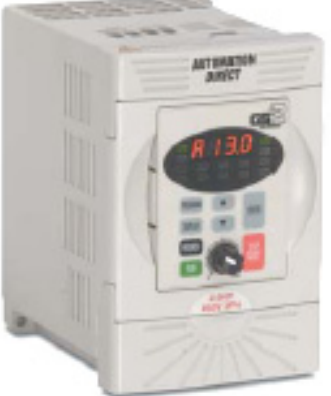

\section{Overview}

The GS2 series of AC drives offers all of the features of our GS1 drive plus dynamic braking. PID and a removable keypad. The drive can be configured using the built-in digital keypad or with the standard RS-485 serial communications port. The standard keypad allows you to configure the drive, set the speed. start and stop the drive, and monitor specific parameters during operation. Each GS2 features one analog and six programmable digital inpurs, and one analog and rwo programmable relay outputs.

\begin{tabular}{|l|l|c|c|c|c|c|c|c|}
\hline \multicolumn{2}{|c|}{ GS Soiles Dives } \\
\hline \multirow{2}{*}{ Motor Rating } & Hp & .5 & 1 & 2 & 3 & 5 & 7.5 & 10 \\
\hline & $k W$ & 0.4 & 0.75 & 1.5 & 2.2 & 3.7 & 5.5 & 7.5 \\
\hline Single/Three Phase 200 Volt Class & $\checkmark$ & $\checkmark$ & $\checkmark$ & $\checkmark$ & & & \\
\hline Three Phase 200 Volt Class & & & & $\checkmark$ & $\checkmark$ & $\checkmark$ & \\
\hline Three-Phase 400 Volt Class & & $\checkmark$ & $\checkmark$ & $\checkmark$ & $\checkmark$ & $\checkmark$ & $\checkmark$ \\
\hline
\end{tabular}

\section{Features}

- Simple Volits/Heriz control

- Sinusoidal PulseWidth Modulation (PWM

-1-12KHz carrier frequency

- IGBT technolog

- 175\% starling torque

- 150\% rated current for one minute

- Bectronic overload protection

-Stall prevention

- Adjustable accel and decel ramps

-S-curve settings for acceleration and deceleration

- Automatk torque compensation

- Automatk slip compensation

- Dynamk braking circuit

- DC brakine

- Three skip frequencies

- Trip history

- Programmable jog speed

- Integral PID control

- Removable keyped with speed potentiometer

- Programmable analog input

- Programmable analog output

- Sox progammable digital inputs

- Two programmable relay outputs

- RS-232/485 MODBUS communkations $\$ 384 \mathrm{~K}$
- Optional Ethernet communications - UL/CE listed

\section{Accessories}

Ac linere

- EMI filters

- Braking res istors

- Fuse kils and replacement fuses

- Ethernet interface

- Replacement keypads

- Keypad cables in 1, 3 and 5 meter lengths - Four and eight portcommunication boaros DG alied descriptions and specincations for the GS2 accessories are avaliabie later in timis section.

\section{GS2 series part numbering system}

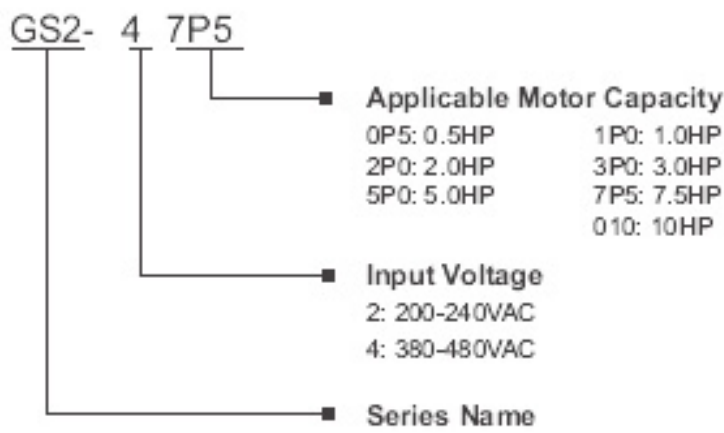




\section{GS2 Series Specifications}

\begin{tabular}{|c|c|c|c|c|c|c|c|}
\hline \multicolumn{8}{|c|}{$20 Y$ BISS AS2 SE:IIS } \\
\hline \multicolumn{2}{|l|}{ Model } & GS2-20F5 & GS2-21P0 & $\operatorname{GS} 2-22 \mathrm{PO}$ & GS2-23P0 & $\operatorname{CS} 2-25 \mathrm{PO}$ & GS2-27PS \\
\hline \multicolumn{2}{|l|}{ Price } & $\$ 18200$ & $\$ 20900$ & $\$ 27900$ & $\$ 20900$ & $\$ 6400$ & $\$ 99700$ \\
\hline \multirow{2}{*}{ Motor Rating } & $H P$ & $1 / 2 \mathrm{HP}$ & $1 \mathbf{P}$ & $2 \mathrm{HP}$ & $3 \mathbf{P}$ & SHP & 7SHP \\
\hline & $k W$ & $0.4 k W$ & $0.75 W W$ & $1.5 W W$ & $22 X N$ & $37 W$ & $5.5 K N$ \\
\hline \multicolumn{2}{|c|}{ Rated Ouqut Capacily (200V) kVA } & 1.0 & 1.9 & 2.7 & 3.8 & 6.5 & 9.5 \\
\hline \multicolumn{2}{|c|}{ Rated Input Vollage } & \multicolumn{4}{|c|}{ 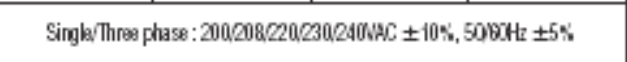 } & \multicolumn{2}{|c|}{ 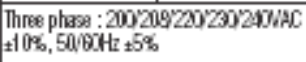 } \\
\hline \multicolumn{2}{|c|}{ Rated Ouqut Voltage } & \multicolumn{6}{|c|}{ Corresponds to inpet vilags } \\
\hline \multicolumn{2}{|c|}{ Rated Input Current (A) } & $6.3 / 29$ & 11563 & $15.7 / 8.8$ & $270^{\prime} 125$ & 19.6 & 28 \\
\hline \multicolumn{2}{|c|}{ Rated Ouqut Current (A) } & 25 & 50 & 70 & 10 & 17 & 25 \\
\hline \multicolumn{2}{|l|}{ DC Braking } & \multicolumn{6}{|c|}{ Frequancy $60-0 \mathrm{Ht}$, 0-100\% ralod cument, stat lime $0.0-5.0$ seconds, Sbp Time $0.0-25.0$ seoconds } \\
\hline \multicolumn{2}{|c|}{ Protective Structure } & \multicolumn{6}{|c|}{ Probchd chassis IP20 } \\
\hline \multicolumn{2}{|c|}{ Ambient Operating Temperature } & \multicolumn{5}{|c|}{$-10^{\circ} \mathrm{C}$ to $50^{\circ} \mathrm{C}\left(14^{\circ} \mathrm{F}\right.$ to $\left.122^{\circ} \mathrm{F}\right)$ wihot daraing } & $\begin{array}{l}-10^{\circ} \mathrm{C} \text { b } 49^{\circ} \mathrm{C} \\
\left(14^{\circ} \mathrm{F} \text { b } 10 \mathrm{~A}^{\circ} \mathrm{F}\right) \\
\text { wiltout darding }\end{array}$ \\
\hline \multicolumn{2}{|c|}{ Storage Temperature } & \multicolumn{6}{|c|}{$-25^{\circ}$ to $60^{\circ} \mathrm{C}\left(-4^{\circ}\right.$ to $\left.145 \mathrm{~F}\right)$ dring short tam lanspatalizn perizd } \\
\hline \multicolumn{2}{|l|}{ Humidity } & \multicolumn{6}{|c|}{20 b $90 \%$ Huridhy (no ondansation) } \\
\hline \multicolumn{2}{|l|}{ VWration } & \multicolumn{6}{|c|}{$9.8 \mathrm{~m}^{\prime} \mathrm{s}^{1}(1 \mathrm{G})$ at loss han $10 \mathrm{H}, 5.9 \mathrm{~m} / \mathrm{s}^{2}(0.6 \mathrm{G}) 10$ to $\theta 0 \mathrm{Ht}$} \\
\hline \multicolumn{2}{|l|}{ Location } & \multicolumn{6}{|c|}{ Aliude $1,00 \mathrm{~m}$ ar less, Keep tom car rosine gases liqids or dust } \\
\hline \multicolumn{2}{|c|}{ Watt Loss $100 \%$ (I) } & 34 & 57 & 77 & 111 & 185 & 255 \\
\hline \multicolumn{2}{|l|}{ Weight: (Ib) } & 35 & 36 & 3.7 & 85 & 8.5 & 8.5 \\
\hline Dimensions $(H$ & & & $151,0 \mathrm{~mm} \times 100$ & $\mathrm{~mm} \times 140.5 \mathrm{~mm}$ & & $2000 \mathrm{~mm} \times 25$ & $\mathrm{~mm} \times 189.5 \mathrm{~mm}$ \\
\hline & & & ceassorias & & & & \\
\hline Line Beactor & Single Phase & GS-20P5-LP-1PH & GS-21PO-LA1PH & GS-2ZPOLR-1PH & GS-23PO-LA-1PH & N/A & $\mathrm{kQh}$ \\
\hline LWE Rеdст & Three Phase & GS-20FS-LP-3PH & GS-21PO-LA-3PH & GS-2ZFOLPR3PH & 6S-23PO-LA-3PH & 6S-25PO-LR & GS-2TFS-LA \\
\hline Braking Resist & & GS-2OPS-ER & GS-21PO-BR & GS-22P0-ER & GS-2ZPO-BR & GS-2SPO-ER & GS-27P5-BR \\
\hline EMI FNter & & & 2OORTIW3S & & 3XRT1W3C & $40 \pi$ & INAB \\
\hline Fune vat & Single Phase & GS-2UPSFKIT-1P & GS-21PU-FMF-1P & GS-ZZPOFNIT-1P & GS-23PO-FMF1P & N/A & $\mathrm{NQh}$ \\
\hline Fuse Kut & Three Phase & GS-2UFSFKII-3P & GS-21PO-FMF $3 P$ & GS-Z2F0+NUI-3P & GS-23PO-FAT $3 P$ & GS-2XPS-ANT & GS-27P5-FKI \\
\hline Benlacement & Single Phase & GS-2UFS-RLEE-1P & GS-21P0FUSE-1P & GS-22PO-FUSE-1P & GS-ZSPOFUSE-1P & N/A & $\mathrm{NQR}$ \\
\hline 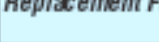 & Three Phase & GS-2CF5-FUCE-3P & GS-21POFLUSE-3P & GS-22PU-FUSE-SP & GS-2SPOFUSE-SP & GS-2SFOAUSE & GS-27F5-FUSE \\
\hline Spare Keypad, & & & & GS2- & $\mathrm{FPD}$ & & \\
\hline Keypad Cable, & & & & GS-DE & $2-1 \mathrm{~L}$ & & \\
\hline Keypad Cable, & & & & GS-CB & $2-3 \mathrm{~L}$ & & \\
\hline Keypad Cable, & & & & GS-CB & $2-5 \mathrm{~L}$ & & \\
\hline $\begin{array}{l}\text { Ethernet Comwn } \\
\text { Drives (DIN rai }\end{array}$ & for GS2 Series & & & GSE & DRN & & \\
\hline
\end{tabular}




\section{GS2 SPECIFICATIONS - INSTALLATION}

Understanding the installation requirements for your GS2 drive will help to ensure that it operates within its environmental and dectrical limits.

Note: Never use onily this dest r rerence for Installition instuctions or operation of equipment.

\begin{tabular}{|c|c|}
\hline \multicolumn{2}{|c|}{ Evironmental Specifications } \\
\hline Protective Structure & $\mathbf{P} 20$ \\
\hline $\begin{array}{l}\text { Ambient Operating } \\
\text { Temperature? }\end{array}$ & 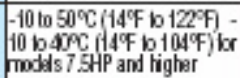 \\
\hline $\begin{array}{l}\text { Storage } \\
\text { Temperatures }\end{array}$ & -20 to $60^{\circ} \mathrm{C}\left(-4{ }^{\circ} \mathrm{F}\right.$ b $\left.140^{\circ} \mathrm{F}\right)$ \\
\hline Humidity & $\begin{array}{l}\mathrm{b} 90 \% \\
\text { mo condersation) }\end{array}$ \\
\hline Vibration 4 & $\begin{array}{l}5.9 \mathrm{~m} / \mathrm{Sg}(0.6 \mathrm{G}) \\
10 \mathrm{~b} 55 \mathrm{~Hz}\end{array}$ \\
\hline Location & $\begin{array}{l}\text { alituda } 1,000 \text { m or lass, } \\
\text { indoors (no ocrocive } \\
\text { gases or dust) }\end{array}$ \\
\hline
\end{tabular}

1: Protective stuchure is based upon EN60529

2: The ambient fempersture must be in the range of $-10^{\circ}$ to $40^{\circ} \mathrm{C}$. If the range wil be up to $50^{\circ} \mathrm{C}$, you WWil need to set the carrier firequency to 21 kfy o less and derate the output current to $\mathbf{0 0 \%}$ or less. See our Web ate for derating curves.

3: The storgge temperature refers to the stort-fem temperafure during transport.

4: Confomis to the test method spearied in Jis cost1 (1964)

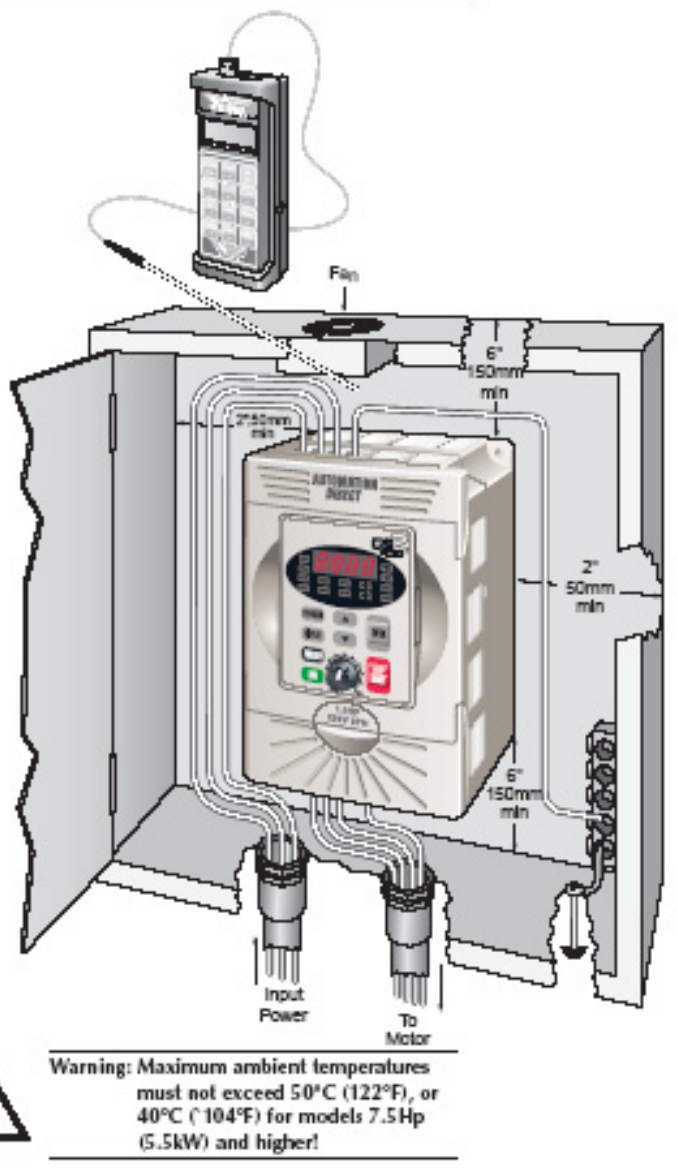

\begin{tabular}{|c|c|}
\hline \multicolumn{2}{|c|}{ Watt-loss Bhait } \\
\hline GS2 Drive Model & $100 \% \mathrm{~m}^{*}$ \\
\hline GS2-20P5 & 34 \\
\hline GS2-21P0 & 57 \\
\hline GS2-22P0 & 77 \\
\hline GS2-23PO & 111 \\
\hline GS2-25PO & 185 \\
\hline GS2-27P5 & 255 \\
\hline GS2-41P0 & 73 \\
\hline GS2-42P0 & 86 \\
\hline GS2-43P0 & 102 \\
\hline GS2-45PO & 170 \\
\hline GS2-47P5 & 240 \\
\hline GS2-4010 & 255 \\
\hline
\end{tabular}
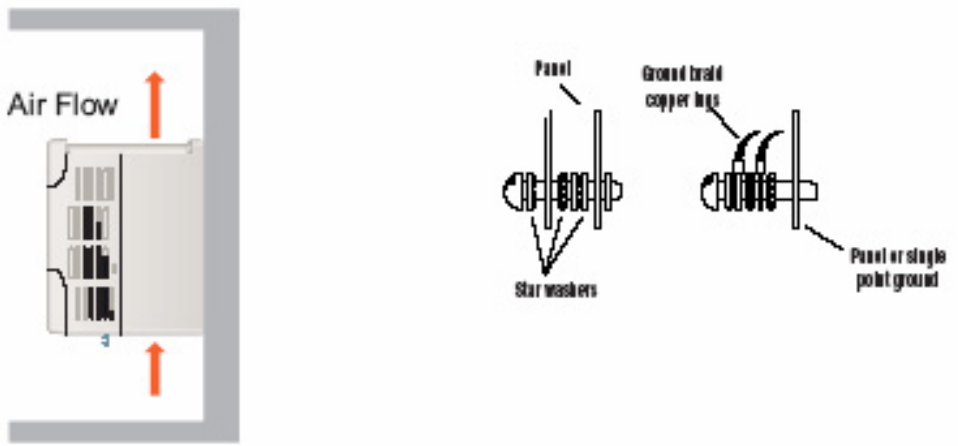

Warning: $\mathrm{AC}$ drives generate a large

amount of heat which may doms

the $\mathrm{AC}$ drive. Auxilian cooling meth.

ods are typically required in order not

to exceed maximum ambient tempera-

tures. 


\section{GS2 SPECIFICATIONS - TERMINALS}

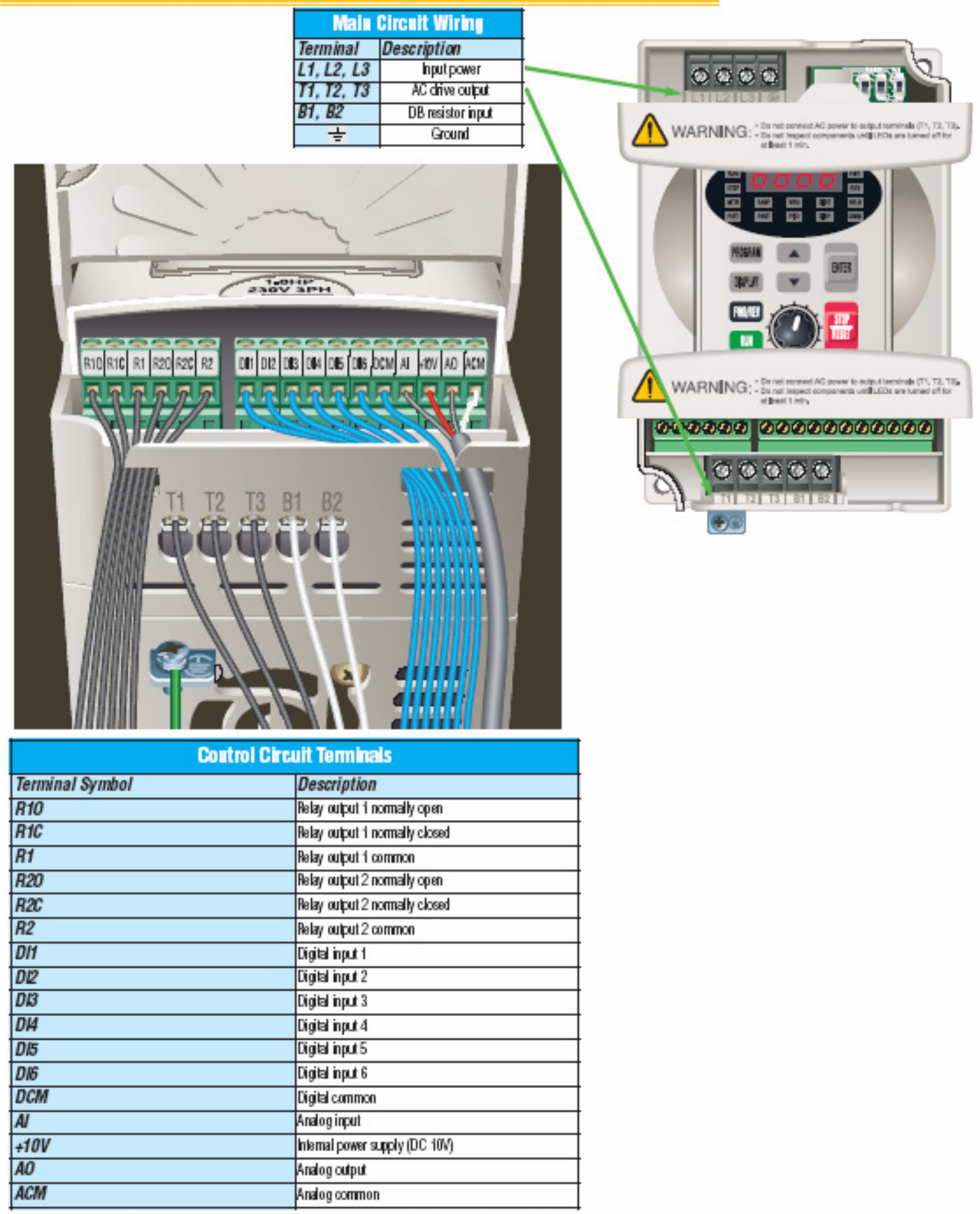

Note: Use hwisted-shieided, hwisted-pair or sticided-iead wires for the control signal wiring. It is recommended to run all signal wiring in a separate steel conduit. The shieid wire should on y be connected at the drive. Do not connect shieid wire on both ends. 


\section{GS2 Specifications - Basic Wiring Diagram}

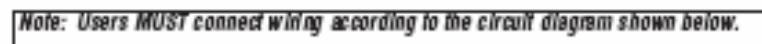

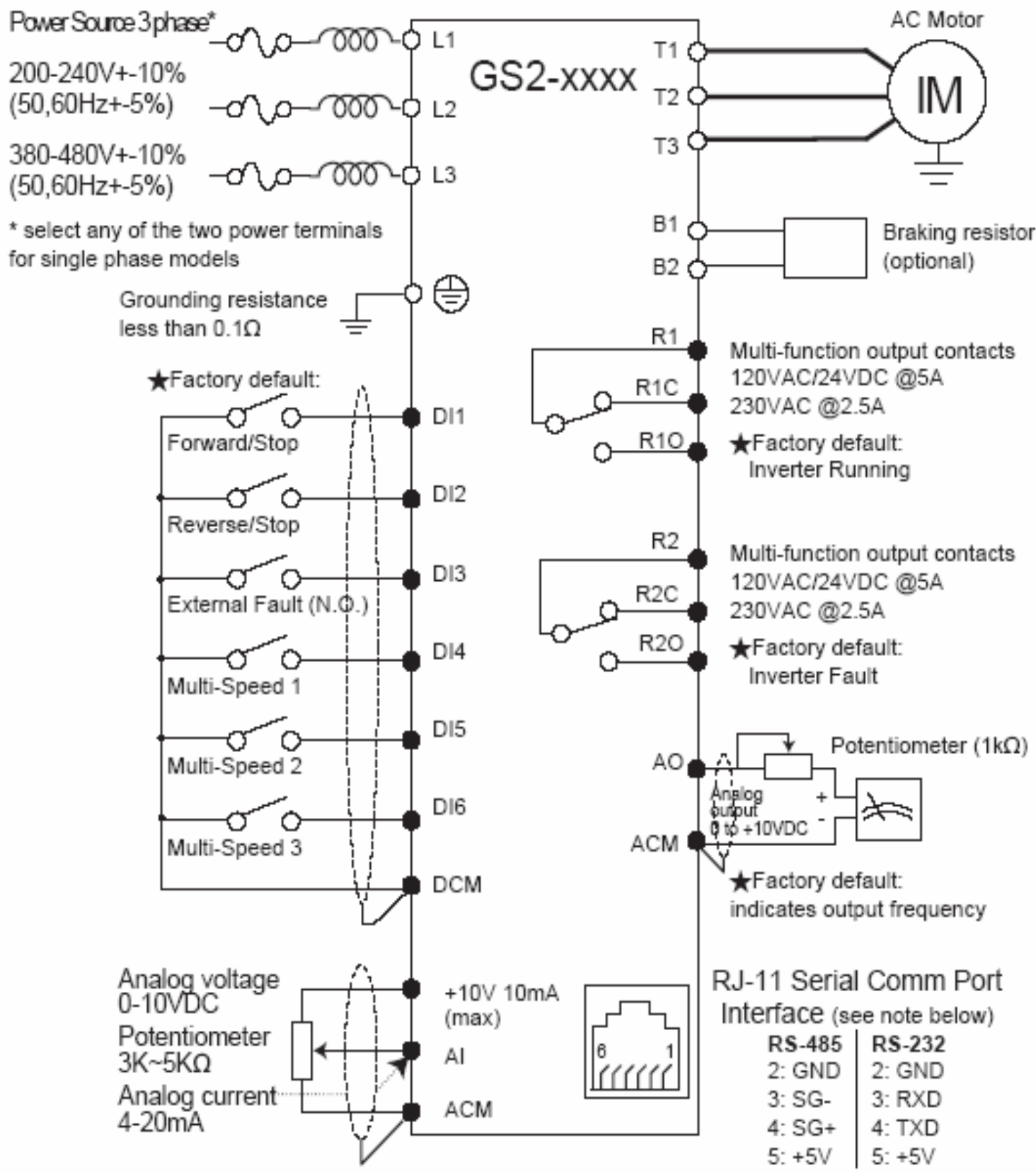

$\star$ Factory default: output frequency determined by the potentiometer on the keypad.

Main circuit (power) terminals Control circuit terminal Shielded leads 


\section{GS2 SPECIFICATIONS - DimeNSIONS}

GS2-20P5, GS2-21P0, GS2-22P0, GS2-23P0, GS2-41P0, GS2-42P0, GS2-43P0
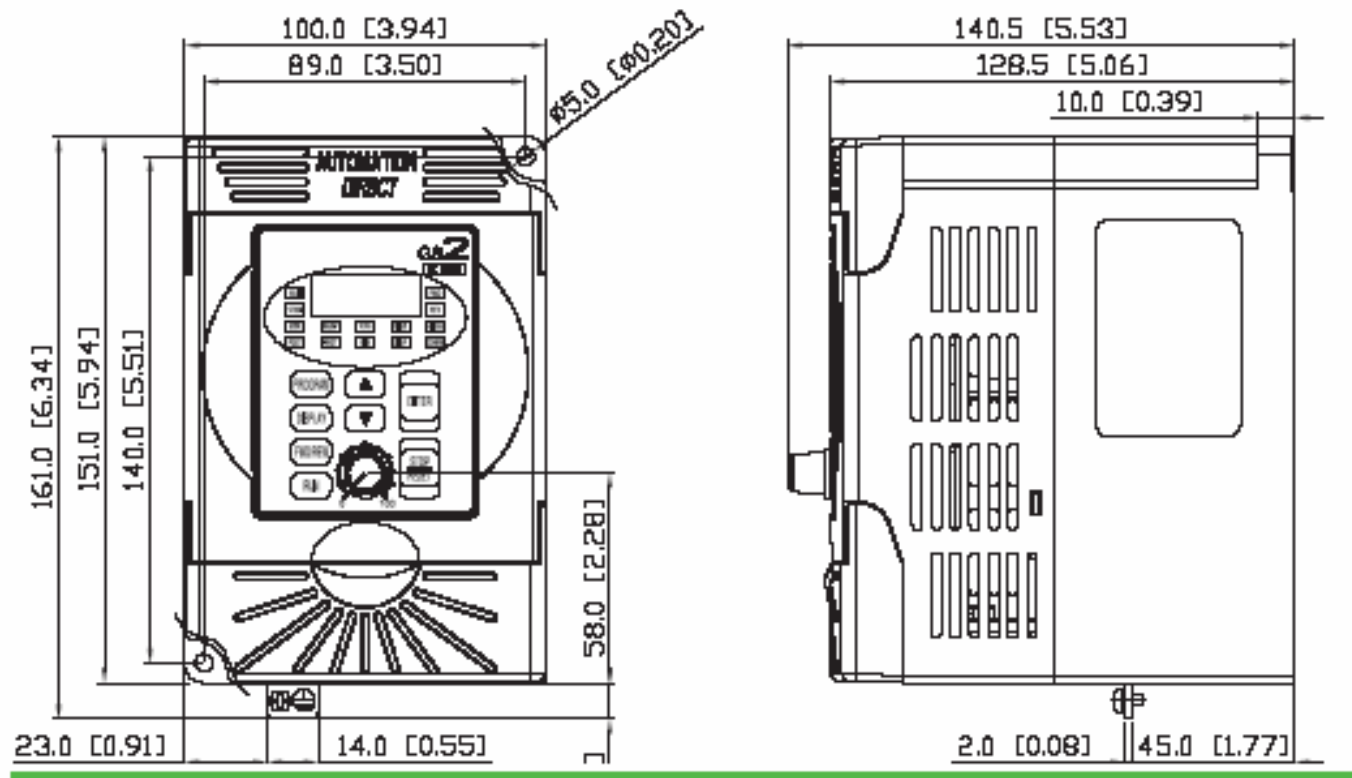

GS2-25P0, GS2-27P5, GS2-45P0, GS2-47P5, GS2-4010 


\section{Appendix 8: PS24-075D 24VDC Power Supply Specifications}

This appendix contains the specifications and dimensions of the PS24-075D +24VDC power supply used on the Sensor Pallet to power up the proximity sensors and as the operator pendant input signal. This device and further information is available from Automation Direct [31]. 


\section{PS Series Power Supplies Specifications}

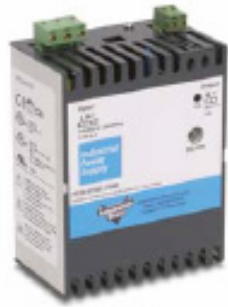

PS24-075D

Note: All \$ \$ecifieations are valid at nomiaal inpot voit age, foll load and $+25^{\circ} \mathrm{C}$ after wa mup time, unless ot herwise statgd.

\begin{tabular}{|c|c|c|c|c|c|c|c|}
\hline \multicolumn{8}{|c|}{ Input Specifleatlons } \\
\hline \multirow{2}{*}{$\begin{array}{l}\text { Part } \\
\text { Number }\end{array}$} & \multirow{2}{*}{$\begin{array}{l}\text { hput Voltage } \\
\text { Range }\end{array}$} & \multirow{2}{*}{$\begin{array}{l}\text { Input } \\
\text { Frequency } \\
\text { Range }\end{array}$} & \multicolumn{2}{|c|}{$\begin{array}{l}\text { Input Current } \\
\text { (Typical) }\end{array}$} & \multicolumn{2}{|c|}{$\begin{array}{l}\text { Inrush Current } \\
(<2 m s)\end{array}$} & \multirow{2}{*}{$\begin{array}{l}\text { Effi- } \\
\text { ciency } \\
\text { (Typ.) }\end{array}$} \\
\hline & & & 115VAC & 230VAC & $115 \mathrm{VAC}$ & $230 \mathrm{VAC}$ & \\
\hline PS24-075D & 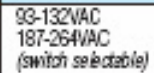 & $47-63 \mathrm{H}$ & $1.7 \mathrm{~A}$ & 0.98 & $<6.54$ & $\angle 3 A$ & \\
\hline
\end{tabular}

\begin{tabular}{|c|c|c|c|c|c|c|c|c|c|}
\hline \multicolumn{10}{|c|}{ Output Spedfilcations } \\
\hline \multirow{2}{*}{ Part Number } & \multirow{2}{*}{ Price } & \multirow{2}{*}{$\begin{array}{l}\text { Output } \\
\text { Voltage }\end{array}$} & \multirow{2}{*}{$\begin{array}{l}\text { Output } \\
\text { Voltage } \\
\text { Adj. Range }\end{array}$} & \multirow{2}{*}{$\begin{array}{l}\text { Outout } \\
\text { Current } \\
\text { (Max.) }\end{array}$} & \multirow{2}{*}{$\begin{array}{l}\text { Output } \\
\text { Power } \\
\text { (Max.) }\end{array}$} & \multirow{2}{*}{$\begin{array}{l}\text { Output } \\
\text { Voltage } \\
\text { Regulation * }\end{array}$} & \multicolumn{2}{|c|}{ Hold-Up Time } & \multirow{2}{*}{$\begin{array}{l}\text { MTBF } \\
\text { (IEC 1709 } \\
\left.@ 25^{\circ} \mathrm{C}\right)\end{array}$} \\
\hline & & & & & & & $115 V A C$ & 230VAC & \\
\hline PS24-075D & $\$ 9000$ & $24 \mathrm{VDC}$ & $24-28 \mathrm{VDC}$ & 3.94 & $75 W$ & $1 \%$ & $25 m 5$ & $30 \mathrm{~ms}$ & $1,200,000$ hours \\
\hline \multicolumn{4}{|c|}{ "Losd nniation (10-90x) } & \multicolumn{6}{|c|}{$\begin{array}{l}\text { Wotes: Output current diara cterisfic suifabie for battery charging applica- } \\
\text { tions. Not recommend ed for redundancy or parallel operation. }\end{array}$} \\
\hline
\end{tabular}

\begin{tabular}{|c|c|}
\hline \multicolumn{2}{|c|}{ Penera' Spedfileatbons } \\
\hline Temperature & 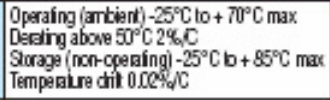 \\
\hline Humidity & $96 \%$ (ncr-oxndensing) ralative humidity max \\
\hline $\begin{array}{l}\text { Output } \\
\text { Regulation }\end{array}$ & $\begin{array}{l}\text { Input variation: } \pm 0.2 \% \text { max } \\
\text { Load varialior } \\
50 N, 75 \mathrm{~W}, 150 \mathrm{~W} \text { modals: } \pm 1 \% \text { max } \\
309 \mathrm{~W}, 509 \mathrm{~W}, 00 \mathrm{~W} \text { models: } \pm 0.3 \% \text { max }\end{array}$ \\
\hline $\begin{array}{l}\text { Output } \\
\text { Voltage } \\
\text { Ripple }\end{array}$ & $60 \mathrm{mV}$ padk-peak (20 MHt bandwith) \\
\hline $\begin{array}{l}\text { Output } \\
\text { Protection }\end{array}$ & $\begin{array}{l}\text { Current limit } 110 \% \text { maximum oulput rating } \\
\text { Vollage limi: } 140 \% \text { Vout nom }\end{array}$ \\
\hline Vibration & $\operatorname{lgn} 20$ sweeps each axis \\
\hline Shock & $15 \mathrm{gn}, 11 \mathrm{mS}$ each axis \\
\hline $\begin{array}{l}\text { Enclosure } \\
\text { Rating }\end{array}$ & IP 20 \\
\hline $\begin{array}{l}\text { Enclosure } \\
\text { Material }\end{array}$ & Aluminum (chassis) / stainlass slad (Cover) \\
\hline Mounting & $\begin{array}{l}\text { Snep-cn with salflocking spring for } 35 \mathrm{~mm} \\
\text { Dill rails }\end{array}$ \\
\hline Connection & Pemonable screw terminds br 22-10 AWG \\
\hline $\begin{array}{l}\text { Agency } \\
\text { Approvals }\end{array}$ & 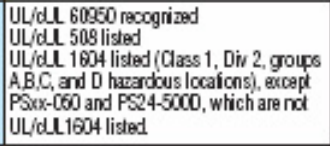 \\
\hline $\begin{array}{l}\text { Not: All specifica } \\
\text { ful load and }+25 \\
\text { stated. }\end{array}$ & ations are valid at nominal inputvoltage, \\
\hline
\end{tabular}

\section{Part numbering system}

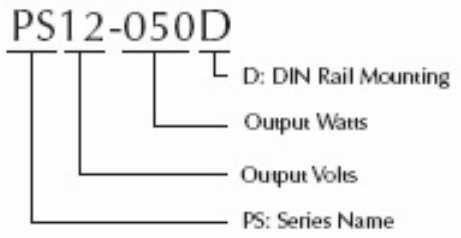

\section{PS Series Power Supplies Dimensions}

\section{PS12-075D, PS24-075D}
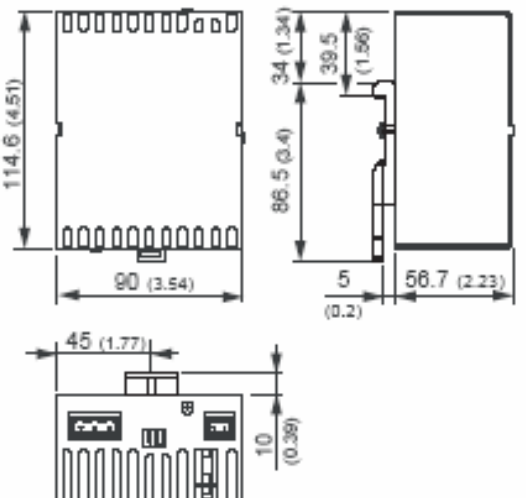

Note: All dimensions are in millimeters (inches) 


\section{Appendix 9: QL2X1-D24 Series Relays Specifications}

This appendix contains information for the QL2X1-D24 relay used in the implementation of the control circuit on the Sensor Pallet. This includes coil and contact specifications, wiring diagrams, derating curves, and dimensions of the device. This component and further information is available from Automation Direct [33]. 


\section{Electro Mechanical Relay Selection Guide}

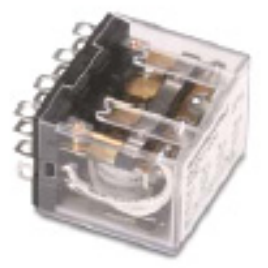

\begin{tabular}{|c|c|}
\hline Sperification & QL Series \\
\hline Coil Voltages & 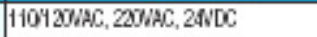 \\
\hline Configuration & 2PDT, $4 \mathrm{PDT}$ \\
\hline Contact Rating & $10 R$ \\
\hline Base Socket & 8 or 14 pin spade terminal \\
\hline Agency Approvals & 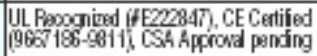 \\
\hline Pricing & Sating a $\$ 7.00$ \\
\hline
\end{tabular}

\section{QL Series Electro Mechanical Relay Selection Guide}

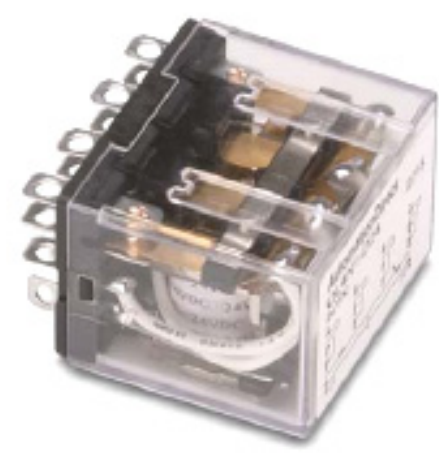

QL series relays are general purpose relays designed for a wide range of applications, from power to sequence controls in various factory machines and control panels. They are ideal for electric control panels requiring stable and reliable relays.

\section{Features}

- Small package design

- ARC Barrier equipped

- Silver Cadium Oxide contact

- High dielectric strength (1,200 VAC)

- High reliability and lone life

- Ultra-high sensitivity with quick

response time (25 ms max)

- High vilbration and shock resistance

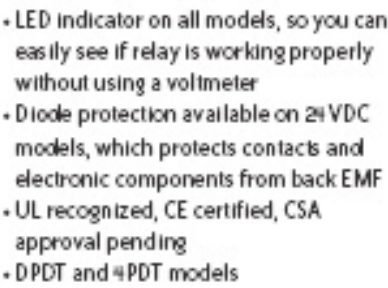

- LED indicator on all models, so you can easily see if relay is working properly without using a voltmeter

- Diode protection available on as VDC

models, which protects contacis and

electronic components from back EMF

- UL recognized, CE certified, CSA

approval pendine

-DPDT and 4 PDT models

- ORDER SOCKET SERIRITEW

\begin{tabular}{|c|c|c|c|c|c|c|c|c|}
\hline \multicolumn{9}{|c|}{ QLScries Selection Eulits } \\
\hline Part Number & Price & Coil Voltage & Configuration & Contact Rating & Dimensions & $\begin{array}{l}\text { Relay Socket } \\
\text { Part Number }\end{array}$ & Price & Dimensions \\
\hline OL2X1-D24 & $\$ 900$ & $2 N N D$ & 2PDT & 104 & Figure 1 & SOLOSD & $\$ 300$ & Figure 3 \\
\hline
\end{tabular}




\section{Ql Series Elegtro Meghanical Relay Specifications}

\begin{tabular}{|c|c|}
\hline Part Numbers & $a L 2 \times 1-D 24$ \\
\hline \multicolumn{2}{|c|}{ Contact Specifications } \\
\hline Cument Rating & 104 \\
\hline Contact Type & [FDT \\
\hline Terminal Type & Spada Plug-h Sockst \\
\hline Rated Max. Resistive Load & 10AEA10NRC/10AGQAVDC \\
\hline Rsted Max. Inductive Load & 7.5AG110NAC/ 5AEQAVDC \\
\hline Max. Switching Cap. (Resistive Load) & $1,100 \mathrm{k} ; 249 \mathrm{~N}$ \\
\hline Max. Switching Cap. (nductive Load) & 825/A, 120W \\
\hline Max. Contact Rating & $250 \mathrm{ACV} 125 \mathrm{VDC}$ \\
\hline \multicolumn{2}{|l|}{ Coil Specifications } \\
\hline Options & $\begin{array}{c}\text { LED } \\
\text { IndizakoDiode } \\
\text { Prodaction }\end{array}$ \\
\hline Coil hput Voltage & $24 V D C$ \\
\hline Rated Cument at $50 \mathrm{~Hz}$ & $36.9 m A$ \\
\hline Rated Cument at $60 \mathrm{~Hz}$ & $36.9 m A$ \\
\hline Coil Resistance & 6500 \\
\hline Power Consumption & Approx.0.9N \\
\hline $\begin{array}{l}\text { Dropaut Voltage } \\
\text { (\% of rated woltage) }\end{array}$ & I.ก. $10 \%$ \\
\hline $\begin{array}{l}\text { Pick-Up Voltage } \\
\text { (Must operate woltage) }\end{array}$ & $\begin{array}{l}\text { Max } 80 \% \text { of the rabd } \\
\text { ocil vdlage }\end{array}$ \\
\hline $\begin{array}{l}\text { Max. Voltage } \\
\text { ( } M \text { ax. conthuous woltage) }\end{array}$ & $110 \%$ of the rabs oxil wilag: \\
\hline Min. Operating Voltage & $92 \%$ of the rabd ocil voltage \\
\hline
\end{tabular}

\begin{tabular}{|c|c|}
\hline \multicolumn{2}{|r|}{ General Specifications } \\
\hline \multirow{2}{*}{ Service Life } & Macharicat AC: Mn. 50 milion cperdions, DC. Min 100 millisn cperdions (at cperding frequanzy of 18,000 operaicns/hour) \\
\hline & Bectizat DPDT: Min. 500k cpardizns, APD: Min 200k operations (ad operating frequency of 1,800 operdions/hour) \\
\hline Operste Time & $25 m s m a x$ \\
\hline Release Time & $25 m s$ max \\
\hline Ambient Temperature & $-25^{\circ} \mathrm{C}$ to $70^{\circ} \mathrm{C}\left(-13^{\circ} \mathrm{Fb} 158^{\circ} \mathrm{F}\right)$ \\
\hline Ambient Humidity & $45 \%$ RH to $8 \%$ FH \\
\hline Contact Material & Siver Cadum Oxide \\
\hline Contact Resistance & $50 \mathrm{~m} \Omega \max$. \\
\hline Opersting Frequency & Machanizal 18,000 opardiznshour, Elscrical 1,800 operatizns/hour \\
\hline Vibration Resistance & $10 \mathrm{H}$ t to $55 \mathrm{H} z$ a doubla amplìud of $1.0 \mathrm{~mm}$ \\
\hline Shock Resistance & $1,000 \mathrm{~m} / \mathrm{s}^{\mathrm{i}}$ (ағргок. 100G) \\
\hline Weight & $35 \mathrm{~g}(124 \mathrm{coc})$ \\
\hline Agency Approvak and Standards & UL Lisba (fE150950), CE Cerifiad (9667185-981), CSA Cortified \\
\hline
\end{tabular}




\section{QL Series Wiring Diagrams and Derating Curves}

Wiring Diagrams

QL2X1-D24

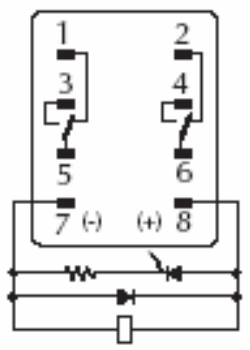

Derating Curves DPDT

Max. Switching capacity

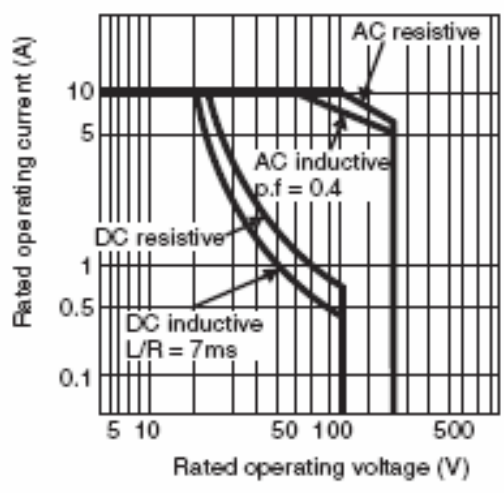

QL DPDT

\section{QL Series Dimensional Drawings}

\section{Mounting dimensions ( $\mathrm{mm} / \mathrm{in}$ )}

Figure 1

\section{QL2 Dimensions}

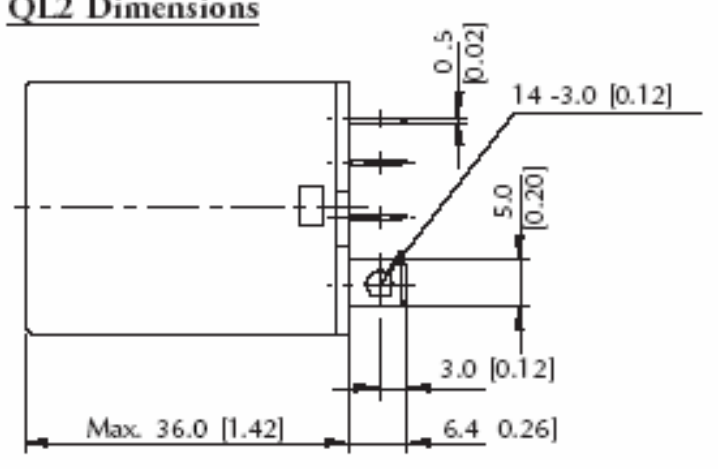

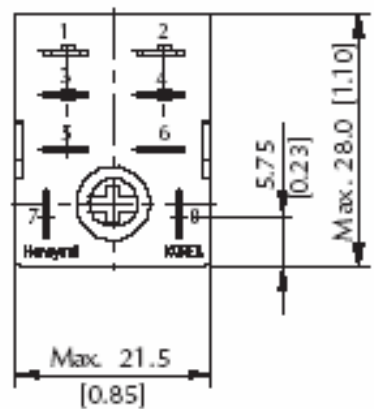




\section{Appendix 10: ABM6E42Z11 Mechanical Limit Switch Specifications}

This appendix contains information for the ABM6E42Z11 mechanical limit switches used in the implementation of the control circuit on the Sensor Pallet. This includes specifications of the switch and the contact blocks and how the actuator may be adjusted

for the user's needs. This device and further information is available from Automation Direct [47]. 


\section{GentSABIE ${ }^{\mathrm{Tm}}$ IEQ LIMIT SWItCheS}

ABM series heavy-duty IEC limit switches

- Feauring a da-cast aluminum boty for hasy-duty industria applicalizos

- Singls and multiple condut oporings to save wiring time and money when inbrocnnecing avera limit switchas

- Condut oparings in $1 / 2$ IPT or PG13.5

- Splined acualorshat allons very fire afusment of swich b fit al applicaions

- Choose from eight dilkrent achados induding roller lewers and plungars

- Choces from six inbrchangatle combinations of contact tbods

\begin{tabular}{|c|c|c|c|c|c|}
\hline \multicolumn{6}{|c|}{ ABM Series } \\
\hline Part Number & Price & Actuator Type & $\begin{array}{l}\text { Nomber of } \\
\text { Conduit } \\
\text { Openings }\end{array}$ & $\begin{array}{l}\text { Conduit } \\
\text { Threads }\end{array}$ & $\begin{array}{l}\text { Dimensions: } \\
\text { Bady / Head }\end{array}$ \\
\hline ABM6E42Z11 & $\$ 4400$ & 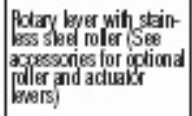 & Three catle hales & $1 / 2$ IPT threats & Figures 2, 8 \\
\hline
\end{tabular}

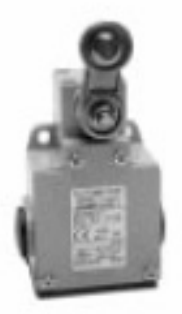

\section{CentSABIE" IEC LIMIT SWITCHES DIMENSIONS}

\section{Switch body dimensions}

Dimensions are in millimeters. $25.4 \mathrm{~mm}=1$ inch

For example, $30 \mathrm{~mm}$ to inches $=30 / 25.4=1.181$ inches .

Fig. 8: Side rotary with roller (ABM, ABP models)

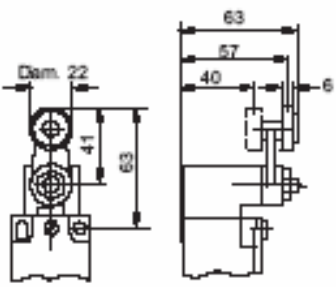




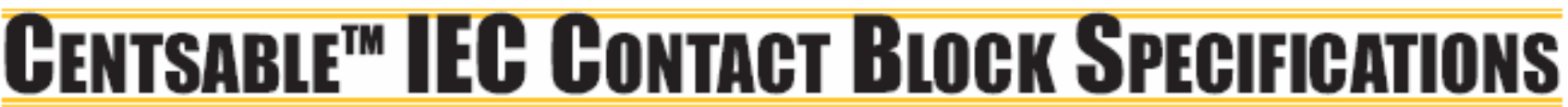

(4.) $\quad(\epsilon$

\begin{tabular}{|c|c|c|}
\hline \multicolumn{3}{|c|}{ 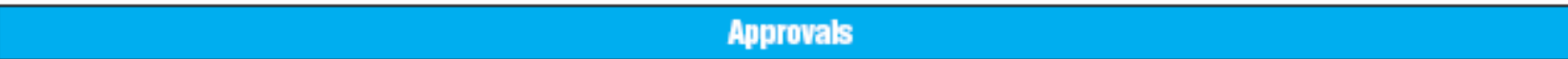 } \\
\hline \multicolumn{3}{|c|}{ All: CENELEC EN 50041, CEl ENl 60947-5-1 Phstic modsls: UL (508), CSA C222 Ho 14-1.91 } \\
\hline \multicolumn{3}{|r|}{ Environmental } \\
\hline \multicolumn{2}{|c|}{ Degree of Protection } & 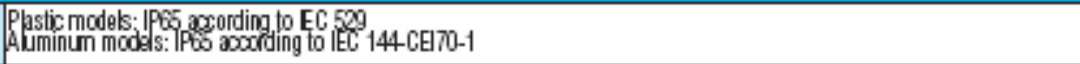 \\
\hline \multicolumn{2}{|c|}{ Temperature Range } & 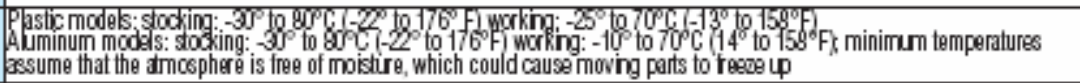 \\
\hline \multicolumn{2}{|c|}{ Pollution Degree } & 3 \\
\hline \multicolumn{3}{|c|}{ 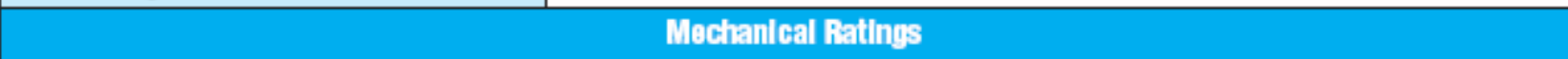 } \\
\hline \multicolumn{2}{|c|}{ Working Positions } & 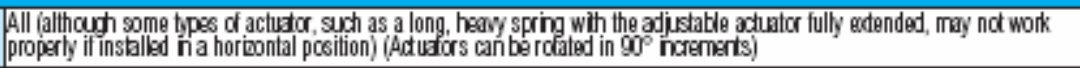 \\
\hline \multicolumn{2}{|c|}{ Mechanical Life } & $\begin{array}{l}\text { Sraight line working heads: } 30 \text { million cperations, side rotary heads: } 25 \text { million operations, multidrectional heads: } 10 \text { million } \\
\text { operalions }\end{array}$ \\
\hline & Phstic models: fiberglass-reinibroed plastic-V0 chss (UL94); aluminum models: dia cast aluminum \\
\hline \multicolumn{2}{|c|}{ 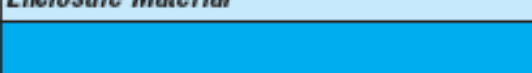 } & Fontaot Blocks Ratlng \\
\hline \multicolumn{2}{|c|}{ Positive Opening* } & Yes, all models \\
\hline \multicolumn{2}{|c|}{ Maximum Switching Frequency } & Cortact blocks: all two cycles per seoond \\
\hline \multicolumn{2}{|c|}{ Repeat Accuracy } & 0.01mm on the operating points at 1 million operations \\
\hline \multicolumn{2}{|c|}{ Short-Circuit Protection } & Cartridge fuses og 10A-500/ 10.3r381100KA \\
\hline \multicolumn{2}{|c|}{ Contact Resistance } & $\geq 25$ milli ohms \\
\hline \multicolumn{2}{|c|}{ Recommended Minimum Operating Speed } & $\begin{array}{l}\text { With snap-action cortads: } 20 \mathrm{~mm} \text { per minutata } \\
\text { With slow-adion contads: } 500 \mathrm{~mm} \text { per mirulata }\end{array}$ \\
\hline \multicolumn{2}{|c|}{ Rated Insulation Voltage } & $600 \mathrm{~N}$ \\
\hline \multicolumn{2}{|c|}{ Teminals Marking } & According to CENIELEC EN 500013 \\
\hline \multicolumn{2}{|c|}{ Wiring Connections } & $2 \times 25 \mathrm{~mm}^{2}$ (AWG14) to $2 \times 0.5 \mathrm{~mm}^{2}$ (AMG18) \\
\hline \multicolumn{2}{|c|}{ Wiring Terminal Type } & Captive screw with self-lifting presese plate \\
\hline \multicolumn{2}{|c|}{ Wiring Terminal Markings } & According to CEHELEC EREO013 \\
\hline & Dabla insulaticn (plastic modals only) \\
\hline \multicolumn{2}{|c|}{ 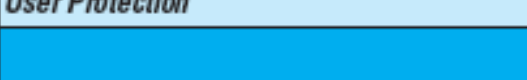 } & Bontaot Blocks Performancs \\
\hline \multicolumn{2}{|c|}{ Operation Frequency } & 3600 opsh \\
\hline \multicolumn{2}{|c|}{ Working Factor } & 0.5 \\
\hline \multirow{2}{*}{ Usage Class } & AC15 & 24VAC: 10A, 130NAC:6.5A, 230MAC: 4A, 400NAC: 25A \\
\hline & $D C 13$ & $24 V D C: 15 A, 110 V D C: 0.5 A$ \\
\hline \multicolumn{3}{|c|}{ 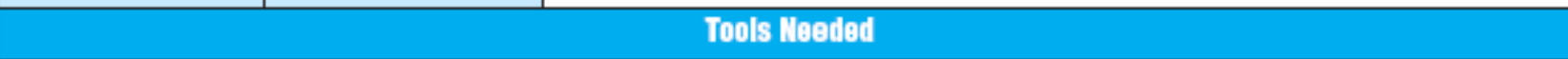 } \\
\hline \multicolumn{3}{|c|}{ Phillips screndriver, $¥ 1$ ₹2/Hax wrench, $10 \mathrm{~mm}$} \\
\hline \multicolumn{3}{|c|}{ 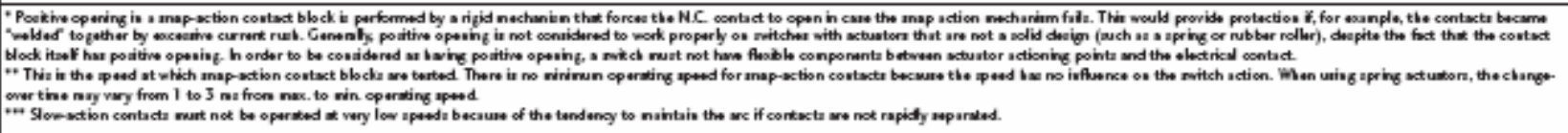 } \\
\hline
\end{tabular}




\section{Centsabiti" IEC Limit Switches Bar Gharts}

\section{Bar charts}

\section{Limit switch types}

Snap action contact: $A$ contact element in which the contact motion is independent of the speed of the actuator. This feature ensures reliable electrical performance even in applications involving very slow moving actuators.

Slow make - slow break contacts: A contact element in which the contact motion is dependent on the actuator speed.

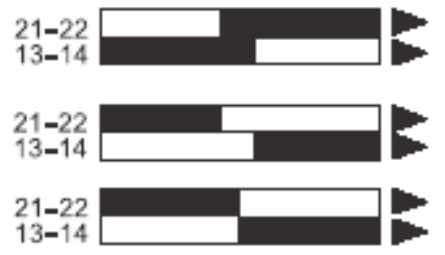

Terminal identification (IEC)

Each terminal is marked with two digits. The first digit indicates the pole (circuit). The second digit indicates the type of contact.

_- 1 - 2 is N.C., _3-_4 is N.O., so $\overline{1}-12,21-22$ are N.C., while $13-14$, 23-24 are N.O.
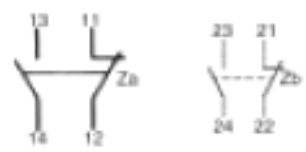

Make-before-break ionerlappine) SPDT: the N.O. connct cloos before the N.C contact opere.

Break-before-make (offse) SPDT: the N.C. connct opene before the N.O. contac closes.

Simultaneous make and break SPDT: the N.C. connet opere at the same time as the N.O. contact closes

\begin{tabular}{|c|c|}
\hline \multicolumn{2}{|c|}{ Teruinal Markings } \\
\hline \multicolumn{2}{|l|}{ European } \\
\hline Termina/ No. & Type \\
\hline $11-12$ & H.C. conbdt of pola mo. 1 \\
\hline $13-14$ & H. 0. conbet of pola m. $2^{1}$ \\
\hline $21-22$ & H.C. conbot of pola no. $2^{1}$ \\
\hline $13-14$ & H.O. conbd of pola mo. 1 \\
\hline With non-isolated ocnlads & "With isdated ocnlads \\
\hline
\end{tabular}

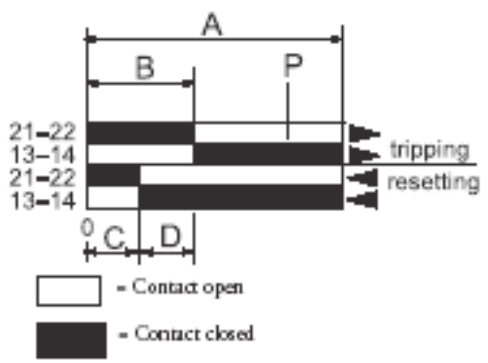

A - Max. tratd of the operator in mm or degrees

B - Tripping trand of the contact

C - Reserting traved of the connact

D - Differential travel (B - C)

$\mathrm{P}$ - Point from which poei tive opening is asured 


\section{Appendix 11: CT1-AP-1A Proximity Sensor Specification}

This appendix contains information for the CT1-AP-1A capacitive proximity sensors used in the implementation of Automatic mode on the Sensor Pallet. This includes general specifications, dimensions, and a wiring diagram for the device. This component and further information is available from Automation Direct [36]. 


\section{CT Series M30 Gapacitive Proximity Sensors}

\section{Capacitive proximity sensors:}

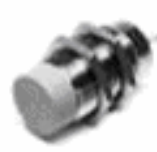

\section{M30 (30 mm) - DC}

.6 models avalable - Sensitivily adjustment with 20-turns trimmer

- Metal housing with axial cable

- Detects metalic and noo-meta lic objects

- Complete overload protection

- IP65 protection degree

- Dable LED status indicators

\begin{tabular}{|c|c|c|c|c|c|c|c|}
\hline \multicolumn{8}{|c|}{ HT Sarigs 30B Rapactiog Prox Sansor Salegtion Fiat } \\
\hline Part Number & Price & $\begin{array}{l}\text { Sensing } \\
\text { Range }\end{array}$ & \multicolumn{2}{|c|}{ Housing } & $\begin{array}{c}\text { Output } \\
\text { State }\end{array}$ & Logic & Connection \\
\hline CT1-AP-1A & $\$ \infty 4,00$ & \multirow{2}{*}{ 2015 } & \multirow{2}{*}{\multicolumn{2}{|c|}{ Shieddsd }} & \multirow{2}{*}{ no. } & PIIP & $2 \mathrm{~m}(5.5)$ axial catle \\
\hline & & & & & & & \\
\hline \multicolumn{8}{|c|}{ Spgetfontions: } \\
\hline \multicolumn{4}{|l|}{ Type } & \multicolumn{3}{|c|}{ काidded } & \\
\hline \multicolumn{4}{|c|}{ Operating Distance } & \multicolumn{3}{|c|}{$2-15 \pi m(0,090-0.50 h)$} & \\
\hline \multicolumn{4}{|c|}{ Differential Travel } & \multicolumn{4}{|c|}{$21020 \%$} \\
\hline \multicolumn{4}{|c|}{ Repeat Accuracy } & \multicolumn{4}{|c|}{$10 \%$} \\
\hline \multicolumn{4}{|c|}{ Operating Voltage } & \multicolumn{4}{|c|}{$10-39 \mathrm{DC}$} \\
\hline \multicolumn{4}{|l|}{ Ripple } & \multicolumn{4}{|c|}{$\leq 10 \%$} \\
\hline \multicolumn{4}{|c|}{ No-load Supply Current } & \multicolumn{4}{|c|}{$8 m \AA$} \\
\hline \multicolumn{4}{|c|}{ Losd Current } & \multicolumn{4}{|c|}{$\leq 200 \mathrm{ma}$} \\
\hline \multicolumn{4}{|c|}{ Leskage Cument } & \multicolumn{4}{|c|}{ ș̣̂̉ } \\
\hline \multicolumn{4}{|c|}{ Voltage Drop } & \multicolumn{4}{|c|}{$18 \mathrm{wls}$ majimum } \\
\hline \multicolumn{4}{|l|}{ Ouput Type } & \multicolumn{4}{|c|}{ MPH or Fie /N.0, a N.C./3 wire } \\
\hline \multicolumn{4}{|c|}{ Swiching Frequency } & \multicolumn{4}{|c|}{$10 \mathrm{~Hz}$} \\
\hline \multicolumn{4}{|c|}{ (tv) Time Delay Before Availabilky } & & & & \\
\hline hout Volage & ransient & Protection & & & Ys, contyil & mind pe & is fol anod 30. \\
\hline hout Power f & barity $R$ & versal Proted & & & & & \\
\hline Ouput Power & Short-Cit & uit Protection & & & Ysissutch & Jibesats & gerthod is remonedj \\
\hline Tempersture & ange & & & & & $10+200$ & (bis8) \\
\hline Tempersture & & & & & & & \\
\hline Protection De & ree $(D T)$ & 40050) & & & & & \\
\hline LED Indicator: & & & & & Gnest is & ipply Pad ! & oưpu energibadi \\
\hline Housing Mate & & & & & & Kidalp & bress \\
\hline Sensing Face & Aaterial & & & & & & \\
\hline Tightening To & pue & & & & & $1002 m$ & b.ril. \\
\hline Weight (cable & connects & & & & & $290 \mathrm{gi}$ & $80 x)$ \\
\hline
\end{tabular}

\section{Dimensions}

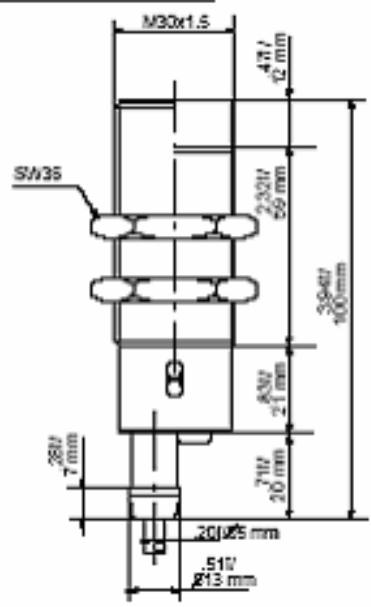

\section{Wiring diagrams}

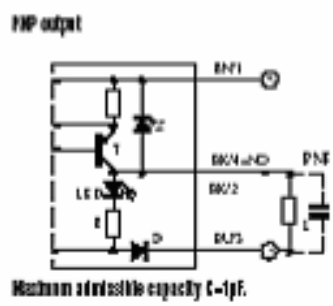




\section{Appendix 12: CLN-50 Current Sensor Specifications}

This appendix contains information about the CLN-50 Hall Effect current sensor used in the implementation circuit of Automatic mode on the Sensor Pallet. Though these data sheets shown here include the CLN-100, only the CLN-50 was used in the system. This device and further information is available from F.W. Bell [37]. 


\section{Description}

Models CLN-50 and CLN-100 are closed loop Hall effect current sensors that accurately measure DC and AC currents and provide electrical isolation between the current carrying conductor and the output of the sensor.

Features

- Noncontact measurement of high current

- Measures DC, AC and impulse currents

- Current sensing up to 400A peak

\section{Applications}

- Variable speed drives for motors

- Welding Equipment

- Power supply Equipment

- Measure and contra system

- Over current protection

- Protection of power semiconductors

\section{Electrical Specifications}

Nominal current $\left(\mathbf{l}_{\mathrm{N}}\right)$

Measuring range

Sense resistor. with $\pm 12 \mathrm{~V}$ at $=70 \mathrm{~A}$ peak at \pm 100 A peak at $\pm 150 \mathrm{~A}$ peak with $=15 \mathrm{~V}$ at $=90 \mathrm{~A}$ peak at $=100$ A peak at $\pm 150 \mathrm{~A}$ peak

Nominal analog output current

Turns ratio

Overall accuracyat $25 \mathrm{C}$ and $\pm 12 \mathrm{~V}$

Overall accuracyat $25 \mathrm{C}$ and $\pm 15 \mathrm{~V}$

Supplyvdtage(Vdc) .

Dielectric strength

(between the current carrying conductor and the output of the sensor)

\section{Accuracy-Dynamic Performance}

Zero current offset at $25^{\circ} \mathrm{C}$. Offeetcurrent temperature drift

between $0^{\circ} \mathrm{C}$ and $+70^{\circ} \mathrm{C}$

between $-25^{\circ} \mathrm{C}$ and $+85^{\circ} \mathrm{C}$

Linearity.....

Response time

didt accurately followed

Bandwidth

\section{General Information}

Operating temperature.

Storage temperature ......................................... Current drain (plus output current)

Coil resistance at $+70^{\circ} \mathrm{C}$

Package ...

Weight

Mounting

Aperture

Output reference
- Very fast response and high accuracy

- High overload capacity

- PC board mount

- Solid core with aperture
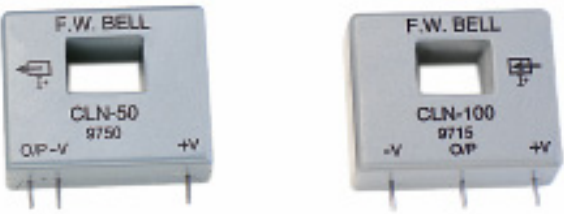

CLN-50

$50 \mathrm{~A}$ rms

0 to $\pm 90 \mathrm{~A}$

R. min. R. max.

50 ohms -90 ohms

na

$\mathrm{Na}-\mathrm{N} / \mathrm{a}$

$\mathrm{n} / \mathrm{a}-\mathrm{n} / \mathrm{a}$

70 ohms -100 ohms

nva na

na

$-n a-$

$50 \mathrm{ma}$

$-1: 1000$

$\pm 0.9 \%$ of $\mathrm{I}_{\mathrm{u}}$

$\pm 0.5 \%$ of $\mathrm{I}_{\mathrm{n}}$

$=12$ to $=15( \pm 5 \%)$

CLN-100

$100 \mathrm{~A}$ rms

0 to $\pm 150 \mathrm{~A}$

R. min. R. max

n/a - n/a

$30 \mathrm{ohms}-55 \mathrm{ohms}$

$-10 \mathrm{ohms}-25 \mathrm{ohms}$

na $n / a$

$30 \mathrm{ohms}-40 \mathrm{ohms}$

$-100 \mathrm{~mA}$

$\mathrm{kV} \mathrm{rms/50} \mathrm{Hz/1} \mathrm{min.}$

$\pm 0.2 \mathrm{~mA} \max$

\pm 0.3 mA typ., $\pm 0.5 \mathrm{~mA} \mathrm{max}$.

\pm 0.3 mAtyp., $\pm 0.8 \mathrm{~mA}$ max

better than $=0.1 \%$

less than $500 \mathrm{~ns}$

better than $100 \mathrm{~A} / \mathrm{us}$

0 to $150 \mathrm{kHz}(-1 \mathrm{~dB})$

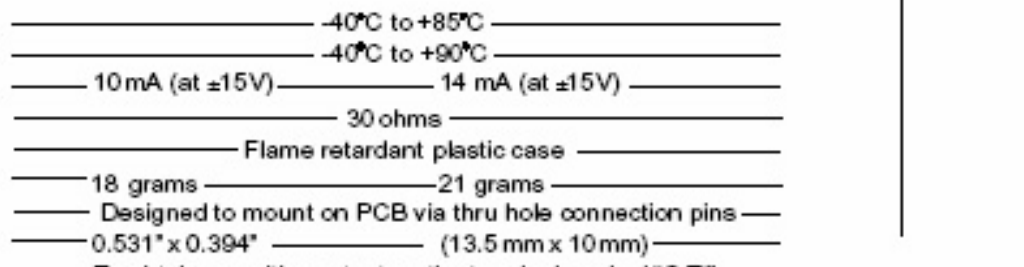

$0.531^{\prime} \times 0.394^{\circ}$

$(13.5 \mathrm{~mm} \times 10 \mathrm{~mm})$

- To obtain a positive cutput on the terminal marked "O/P". aperture current must flow in the direction of the arrow (conventional flow)

Noteax - The temperatse of the current carnying conductor stould not exceed $90^{\prime} \mathrm{C}$ - Cortact F.W. Bel br oher modets.

- Dus to cortinuare prooese inprovement spectisatione are autject to change without notios

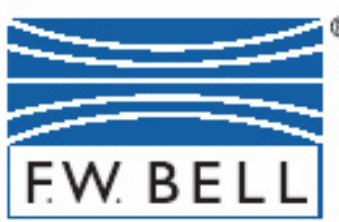

Rew. date 04/2003 


\section{Appendix 13: D0-06DD2 Programmable Logic Controller Specifications}

This appendix contains general information about the D0-06DD2 programmable logic controller used in the implementation of Automatic mode on the Sensor Pallet. This includes specifications and wiring diagrams for the device, as well as diagrams of the each input and output available on the device; programming specifications for this PLC is covered elsewhere. This component, accessories, and further information are available from Automation Direct [39]. 


\section{DLOG I/O SPECIFICATIONS}

\section{D0-06DD2 \$199.00}

Wiring diagram and specifications

\begin{tabular}{|c|c|c|c|}
\hline \multicolumn{4}{|c|}{ 01-08012 Specifications } \\
\hline \begin{tabular}{|l|} 
AC Power Supply \\
Specifications
\end{tabular} & Voltage Range & $(302)^{2}$ & \\
\hline \multirow{10}{*}{$\begin{array}{l}\text { DC Input } \\
\text { Specifications }\end{array}$} & Nomber of Input Ps. & \multicolumn{2}{|c|}{20 (sink/souros) } \\
\hline & Number of Commons & \multicolumn{2}{|c|}{2 (isolabd) } \\
\hline & input Vollage Range & \multicolumn{2}{|c|}{$12-2 A N D C$} \\
\hline & Input Impedance & \multicolumn{2}{|c|}{ 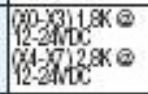 } \\
\hline & $\begin{array}{l}\text { On Cument/ } \\
\text { Voltage Level }\end{array}$ & \multicolumn{2}{|c|}{$25 \mathrm{~mL} / 10 \% \mathrm{DC}$} \\
\hline & $\begin{array}{l}\text { OFF Current/ } \\
\text { Voltage Level }\end{array}$ & \multicolumn{2}{|c|}{$40.5 \mathrm{~m} M \angle 2 \mathrm{DDC}$} \\
\hline & Response Time & $90-33$ & $x 4-x 23$ \\
\hline & $\begin{array}{l}\text { OFF to OW } \\
\text { Response }\end{array}$ & $<00 \mathrm{ps}$ & ams \\
\hline & $\begin{array}{l}\text { OW to OFF } \\
\text { Response }\end{array}$ & <100 ps & $9 \pi$ \\
\hline & Fuses & \multicolumn{2}{|l|}{ None } \\
\hline & $\begin{array}{l}\text { Number of Output } \\
\text { Points }\end{array}$ & \multicolumn{2}{|c|}{16 (sourcing) } \\
\hline & Number of Commons & \multicolumn{2}{|c|}{4 isolted } \\
\hline & Output Voltage Range & \multicolumn{2}{|c|}{$12-2 N D C$} \\
\hline & Peak Voltage & \multicolumn{2}{|l|}{$30 N D C$} \\
\hline & Max.Frequency (YO, Y1) & \multicolumn{2}{|l|}{$7 \mathrm{HHz}$} \\
\hline & ON Voltage Drop & \multicolumn{2}{|c|}{$0.3 \mathrm{NC} @ 1 \mathrm{~A}$} \\
\hline & Maximum Current & \multicolumn{2}{|c|}{ 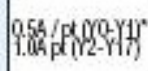 } \\
\hline $\begin{array}{l}\text { DC Output } \\
\text { Specifications }\end{array}$ & $\begin{array}{l}\text { Maximum } \\
\text { Leakage Cument }\end{array}$ & \multicolumn{2}{|c|}{$15 \mu @ 3900 \mathrm{DC}$} \\
\hline & $\begin{array}{l}\text { Maximum } \\
\text { hnush Cument }\end{array}$ & \multicolumn{2}{|c|}{$2 \mathrm{~A}$ for $100 \mathrm{~ms}$} \\
\hline & OFF to OW Response & \multicolumn{2}{|l|}{ LQpis } \\
\hline & ON to OFF Response & \multicolumn{2}{|c|}{$\begin{array}{l}\text { says (Yo-Y1 } \\
\text { disms (r2-Y7) }\end{array}$} \\
\hline & $\begin{array}{l}\text { Extemal DC Power } \\
\text { Requined }\end{array}$ & \multicolumn{2}{|c|}{ 2028yc. } \\
\hline & Status Indicators & \multicolumn{2}{|c|}{ Logic sida } \\
\hline & Fuses & \multicolumn{2}{|c|}{$\begin{array}{l}\text { Tone (axdaral } \\
\text { recomminded) }\end{array}$} \\
\hline
\end{tabular}
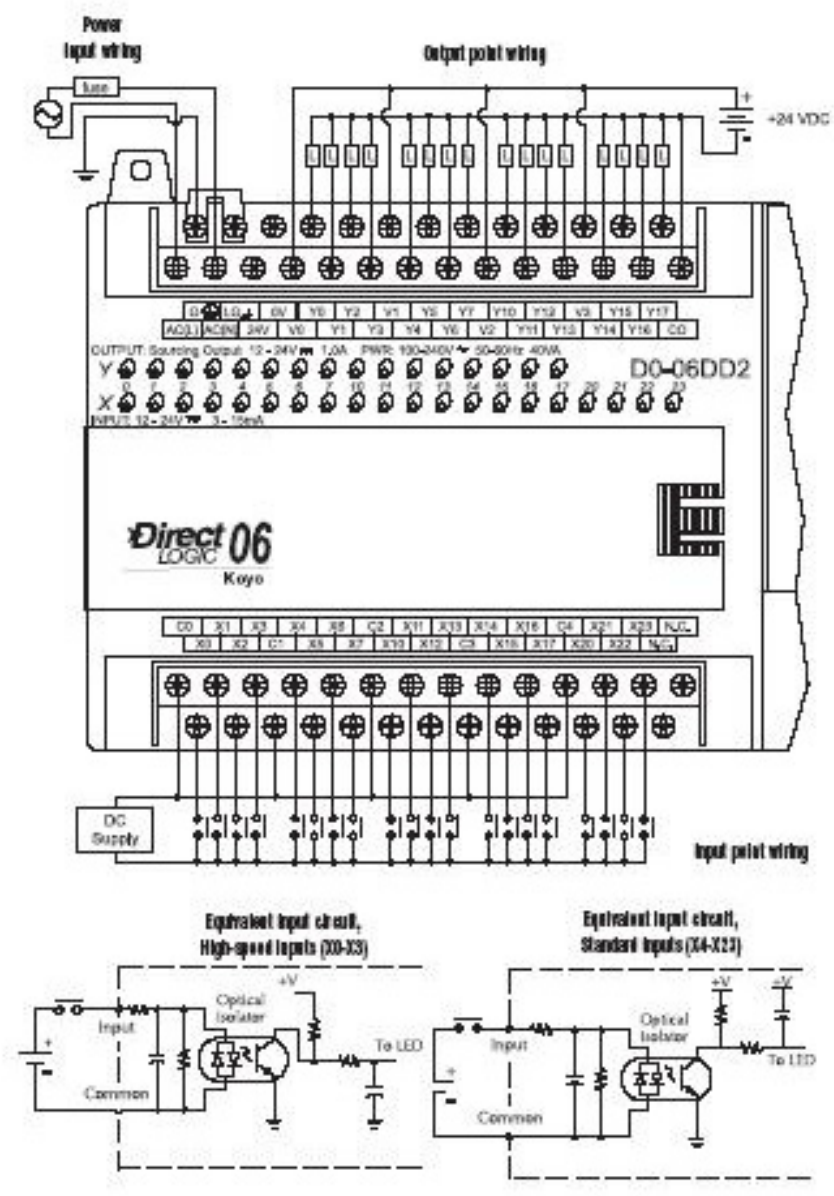

'Wu W-r1 are Id used fir plso abrits, nahun tumut output ls 1.00
Derally dat for oc atprats

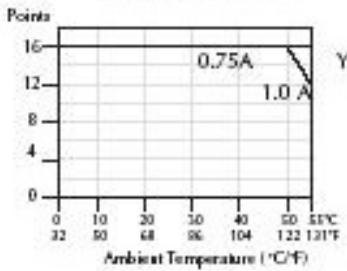

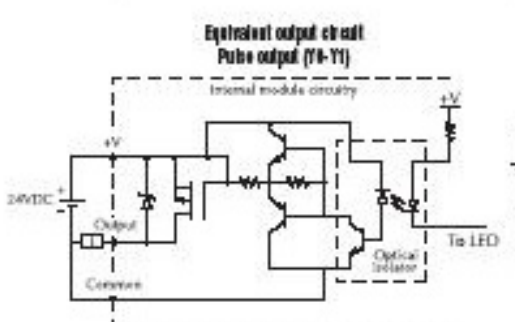

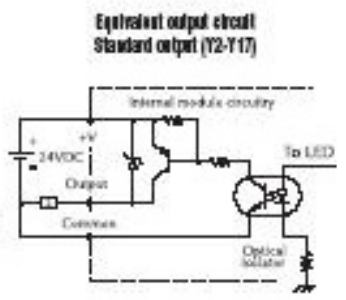

Yo- $Y_{17}$ 


\section{Appendix 14: F0-04AD-1 Analog Input Module Specifications}

This appendix contains information for the 4-channel F0-04AD-1 analog input module used in conjunction with the D0-06DD2 PLC. This includes input specifications and wiring diagrams for the device. This component and further documentation is available from Automation Direct [48]. 


\section{DL05/06 OPTION MODUIES}

\section{F0-04AD-1 \$79.00}

4-channel analog input module

\begin{tabular}{|c|c|}
\hline \multicolumn{2}{|c|}{ Input Spacifications } \\
\hline Nomber of Channels & $\begin{array}{l}\text { 4. sinde endyd } \\
\text { cone ormmoni }\end{array}$ \\
\hline mput Range & 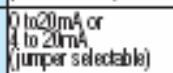 \\
\hline Resolution & 12 tit (1 in 4966$)$ \\
\hline Step Response & 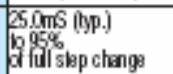 \\
\hline Crosstalk & $1 / 2 \cos )^{2} \max$ \\
\hline Active Low-pass Filtering & 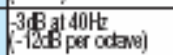 \\
\hline Input Impedance & $\begin{array}{l}125 \Omega \pm 0.1 \% \\
18 \mathrm{wat}\end{array}$ \\
\hline Absolute Max Ratings & $\begin{array}{l}-30 m A 10+33 m A \\
\text { carmentimput }\end{array}$ \\
\hline Converter Type & $\begin{array}{l}\text { Suscassive } \\
\text { Tprovimation }\end{array}$ \\
\hline Linearity Error (end to end) & \pm 2 counts \\
\hline Input Stabiliky & \pm 1 count $^{*}$ \\
\hline Full-scale Calirstion Error & $\begin{array}{l} \pm 1000 y n t s ~ m a x \\
0\end{array}$ \\
\hline Offset Calibration Error & $\begin{array}{l}\mathbf{t} 5 \text { cophits max. } \\
4 \mathrm{~m} h\end{array}$ \\
\hline Max Inaccuracy & $\begin{array}{l} \pm 04 \% \text { a } 25 \circ \mathrm{C} \\
70^{\circ} \mathrm{s} \text { a a } 0 \text { b } 60^{\circ} \mathrm{C} \\
\left.32 \mathrm{~b} 149^{\circ} \mathrm{F}\right)\end{array}$ \\
\hline Accuracy vs. Temperature & $\pm 100 \mathrm{ppm} /{ }^{\circ} \mathrm{C}$ typiral \\
\hline Recommended Fuse & $\begin{array}{l}\text { 2032A series } 217 \\
\text { Estading } \\
\text { arrentirifuts }\end{array}$ \\
\hline
\end{tabular}

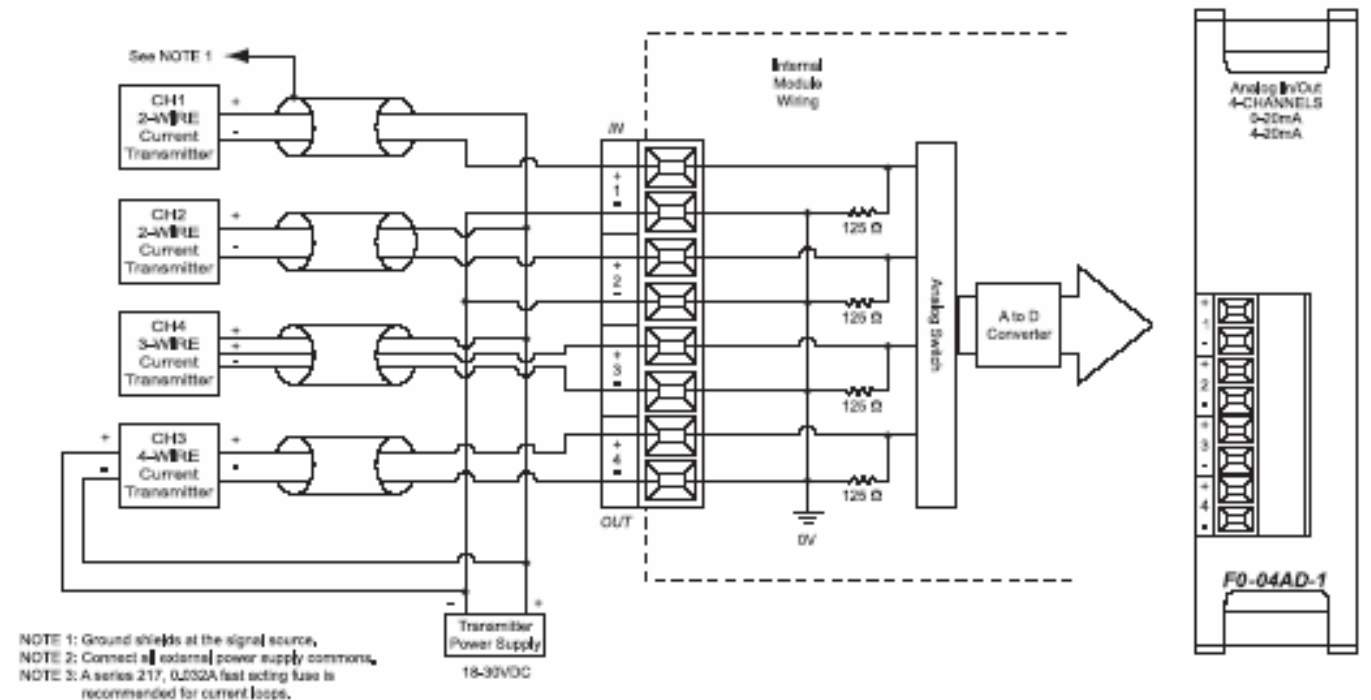




\section{Appendix 15: D0-08CDD1 Digital Output Module Specifications}

This appendix contains information for the D0-08CDD1 digital input/output module used in conjunction with the D0-06DD2 PLC. Though this specification includes both the input and output specifications, only the outputs were used in the system. This device and further information is available from Automation Direct [45]. 


\section{DL05/06 I/0 OPTION MODULES}

\section{D0-08CDD1 $\$ 50.00$}

4-point DC input and

4-point DC output module

\begin{tabular}{|c|c|}
\hline \multicolumn{2}{|c|}{ Do-08cDo1 Input Specififations } \\
\hline Number of Inputs & 4 (sinb'source) \\
\hline Input Voltage Range & $12-2 A N D C$ \\
\hline Operating Voltage Range & $108-264 \mathrm{VDC}$ \\
\hline Peak Vollage & $30.0 . \mathrm{DC}$ \\
\hline Input Current & $\begin{array}{l}\text { Tycicd: } \\
\text { 40mA 12VDC } \\
\text { 8.5mA Q 24VDC }\end{array}$ \\
\hline Maximum Input Current & $11 \mathrm{~m} 2 \otimes 26.4 \mathrm{NDC}$ \\
\hline Input Impedance & $2 S K \Omega @ 12-2 A N D C$ \\
\hline On Voltage Level & $>10.0 \vee D C$ \\
\hline Off Voltage Level & $<2.0 \mathrm{VDC}$ \\
\hline Minimum ON Current & $35 \mathrm{~mA}$ \\
\hline Maximum OFF Cument & $0.5 \mathrm{~mA}$ \\
\hline Off to On Response & $2-8 m s, T y p .4 m s$ \\
\hline On to Off Response & 2-8ms, Typ. $4 \mathrm{~ms}$ \\
\hline Commons & $\begin{array}{l}2 \text { mon-isobsd } \\
\text { (2 pcints/cormmon) }\end{array}$ \\
\hline
\end{tabular}
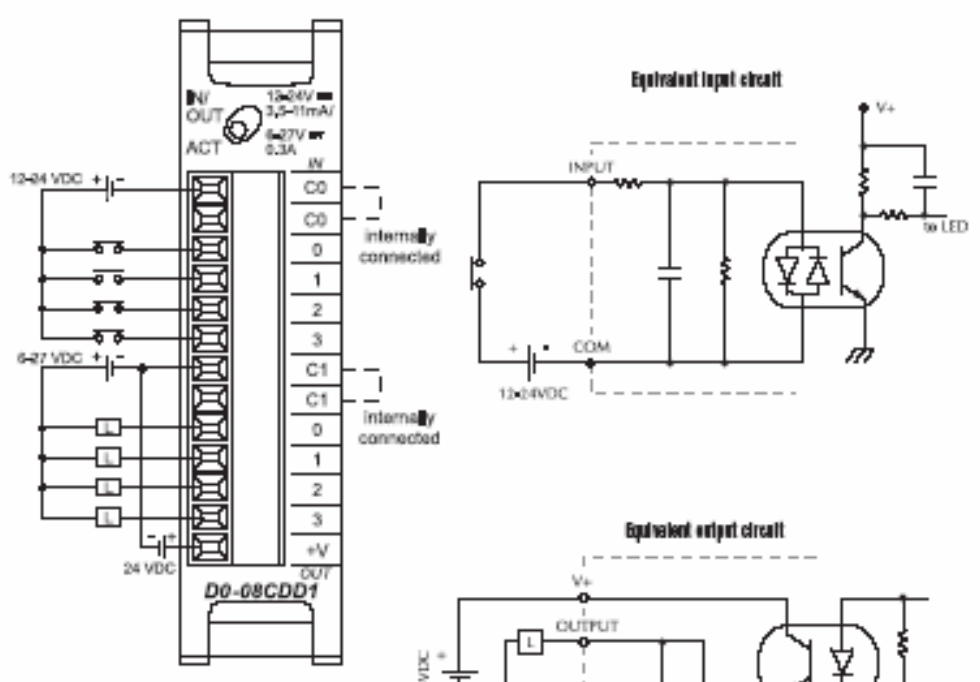

\begin{tabular}{|c|c|}
\hline \multicolumn{2}{|c|}{ DO-08BDD1 Ontput Specifications } \\
\hline Number of Outpus & 4 (sinhing) \\
\hline Operating Voltage Range & 6-2TMDC \\
\hline Output Voltage Range & $5-390 \mathrm{DC}$ \\
\hline Peak Voltage & $50.9 . \mathrm{DC}$ \\
\hline Maximum Output Current & 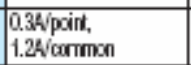 \\
\hline Minimum Output Cument & $0.5 \mathrm{~m} A$ \\
\hline Maximum Leakage Current & $1.5 \mu \mathrm{A} \Theta 30.9 \mathrm{DC}$ \\
\hline On Voltage Drop & 0.5VDC @ 0.3h \\
\hline Maximum Inrush Current & 1A for $10 \mathrm{~ms}$ \\
\hline Off to On Response & $<10 \mu s$ \\
\hline On to Off Response & $<\theta 0 \mu s$ \\
\hline Status Indicators & $\begin{array}{l}\text { Module asfidy. } \\
\text { ona gen len }\end{array}$ \\
\hline Commons & $\begin{array}{l}2 \text { non-isdaled } \\
(2 \text { ponts/common) }\end{array}$ \\
\hline Fuse & No iuse \\
\hline Base Power Required (5V) & 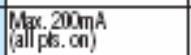 \\
\hline $\begin{array}{l}\text { Extemal DC Power } \\
\text { Required (24V) }\end{array}$ & $\begin{array}{l}20-28 v D C, \max .80 \mathrm{ma} \\
(a i l p k . c n)\end{array}$ \\
\hline
\end{tabular}
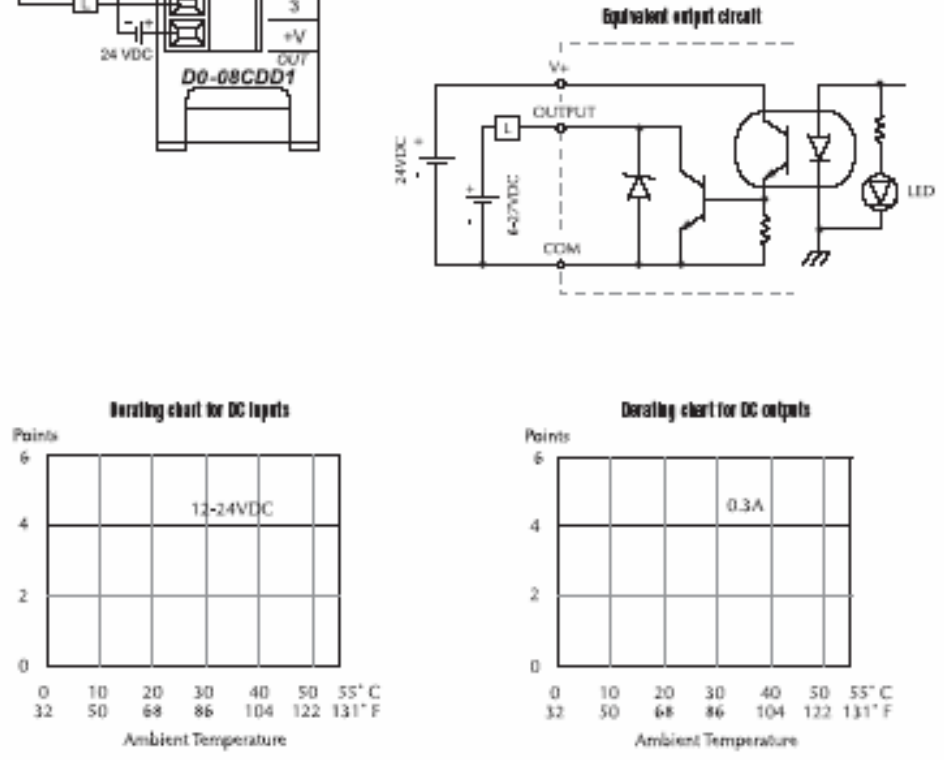


\section{Appendix 16: Quick Troubleshooting Handbook for Project Oculus}

This appendix is a quick troubleshooting handbook that can be used as a reference for the electrical engineer working on Project Oculus. It should be used in conjunction with the circuit diagrams presented in appendices 4 and 6 . Included here are:

(1) GS2-22P0 Motor Controller Program Table: For Project Oculus to operate correctly, the GS2-22P0 should have these values set for each program listed in the table.

(2) CT1-AP-1A Proximity Sensor Equivalent Output Circuit: Output circuit for the proximity sensors used on the Sensor Pallet.

(3) D0-06DD2 Equivalent Input Circuit: Input circuit for the D0-06DD2 PLC normal inputs. Inputs should be connected as illustrated there.

(4) D0-06DD2 Equivalent Output Circuit: Output circuit for the D0-06DD2 PLC normal outputs. Outputs should be connected as illustrated there.

(5) D0-06DD2 General Wiring Diagram: Illustration showing a general wiring diagram for the D0-06DD2 PLC.

(6) CLN-50 to F0-04AD-1 Analog Input Module Circuit: Diagram of the circuit connecting the CLN-50 current sensor output to the F0-04AD-1 analog input module input.

(7) D0-08CDD1 Equivalent Output Circuit: Output circuit for the D0-08CDD1 input/output module used with the D0-06DD2 PLC. Only the outputs on this module are used, so that is the only circuit shown here. The outputs should be connected as illustrated there.

(8) D0-06DD2 PLC LCD Messages: Table showing the possible LCD messages that will appear on the LCD screen of the D0-06DD2 PLC while in Automatic mode operation and what they mean to the user.

(9) D0-06DD2 PLC Input/Output Map: Table showing all possible inputs and outputs for the D0-06DD2 PLC and where these inputs and outputs are mapped to in the system. 


\section{GS2-22P0 Motor Controller Programs}

\begin{tabular}{|l|l|}
\hline \multicolumn{1}{|c|}{ Program } & \multicolumn{1}{c|}{ Value } \\
\hline P 0.00 Motor Nameplate Voltage & $220 \mathrm{~V}$ \\
\hline P 0.02 Motor Base Frequency & $60 \mathrm{~Hz}$ \\
\hline P 0.03 Motor Base RPM & $1750 \mathrm{RPM}$ \\
\hline P 0.04 Maximum Motor RPM & $1800 \mathrm{RPM}$ \\
\hline P 1.00 Stop Methods & 00 (Ramp to Stop) \\
\hline P 1.01 Acceleration Time & 5.0 seconds \\
\hline P 1.02 Deceleration Time & 0.1 seconds \\
\hline P 3.00 Source of Operation Command & $\begin{array}{l}01 \text { (Operation determined by external } \\
\text { control terminals. Keypad STOP is enabled.) }\end{array}$ \\
\hline P 3.01 Multi-Function Input Terminals & $\begin{array}{l}00 \text { DI1 - FWD/STOP } \\
\text { DI2 - REV/STOP }\end{array}$ \\
\hline
\end{tabular}

PNP output

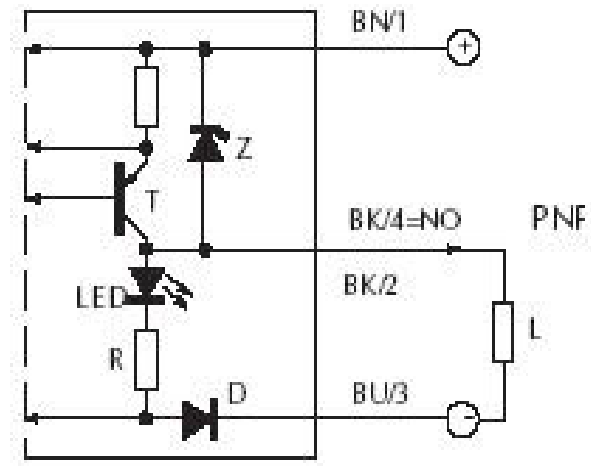

\section{CT1-AP-1A Proximity Sensor Equivalent Output Circuit [36]}

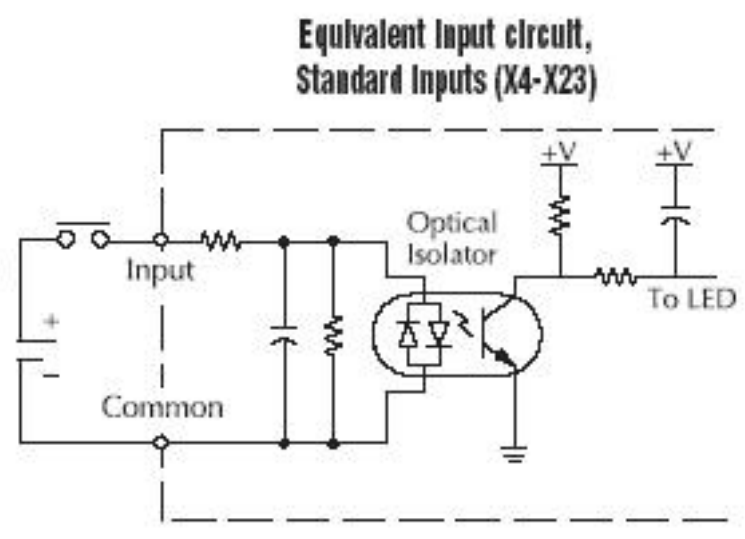

Equivalent Input Circuit on the D0-06DD2 PLC [39] 


\section{Equlvalent output clrcult}

Standard output (Y2-Y17)

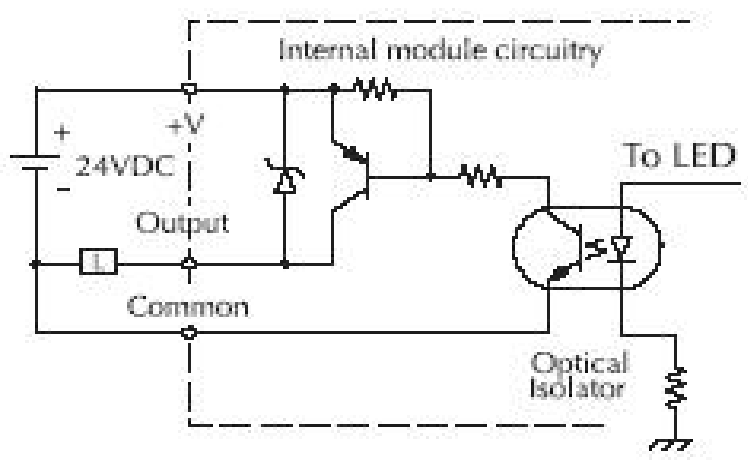

Equivalent Output Circuit on the D0-06DD2 PLC [39]

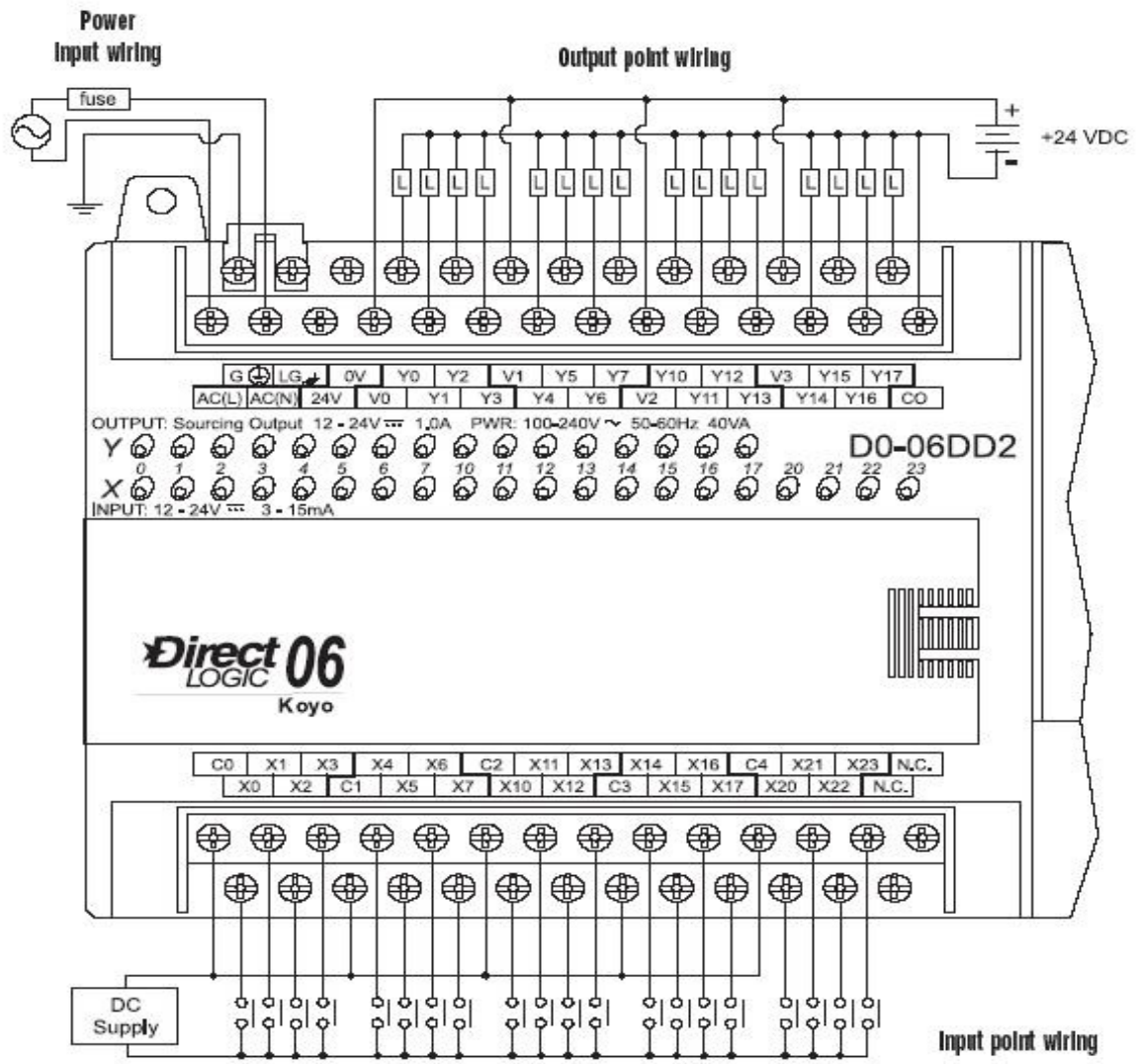

D0-06DD2 PLC General Wiring Diagram [39] 


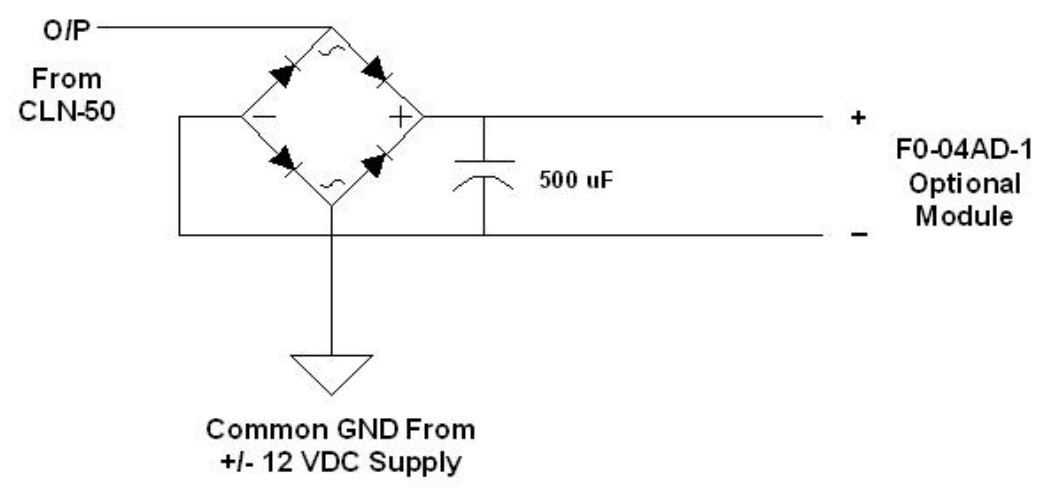

\section{Current Sensor to F0-04AD-1 Analog Input Module Circuit}

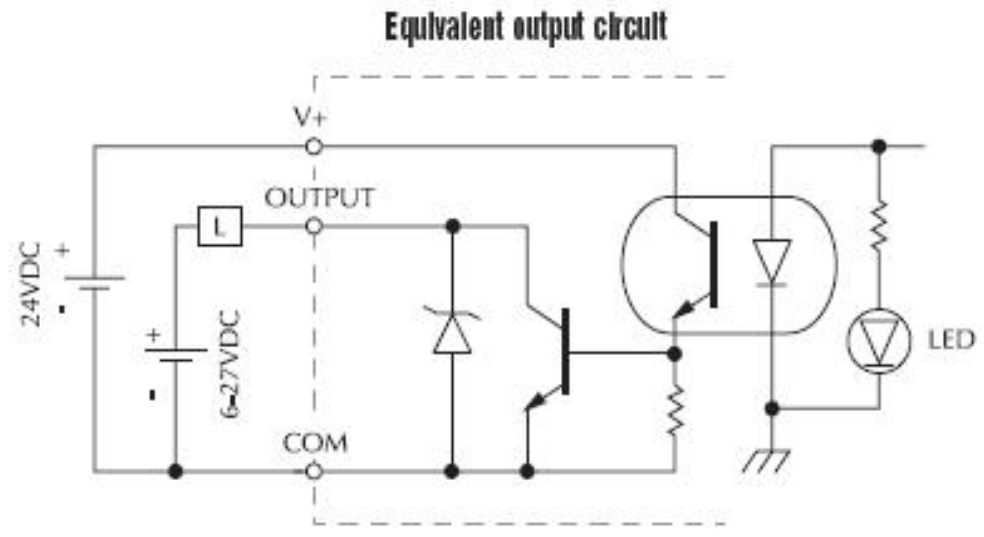

\section{Equivalent Output Circuit for the D0-08CDD1 [45]}

\section{D0-06DD2 PLC LCD Messages}

\begin{tabular}{|l|l|}
\hline \multicolumn{1}{|c|}{ LCD Message } & \multicolumn{1}{c|}{ Meaning } \\
\hline "Fully Stowed" & $\begin{array}{l}\text { Translating plate and rotating arm are in } \\
\text { their resting positions }\end{array}$ \\
\hline "E: Button Push" & $\begin{array}{l}\text { Error: Extend and Stow button have been } \\
\text { pushed simultaneously, which should not } \\
\text { occur }\end{array}$ \\
\hline "Extend Button" & Extend Button has been pressed \\
\hline "Translating Out" & The translating plate is translating outward \\
\hline "Rotating Out" & The rotating arm is rotating outward \\
\hline "Translating Back" & The translating plate is translating backward \\
\hline "Fully Extended" & $\begin{array}{l}\text { Current Sensor has been tripped, should } \\
\text { mean that the Sensor Pod has been pulled up } \\
\text { tightly against the butt plate on the door }\end{array}$ \\
\hline "Stow Button" & Stow Button has been pressed \\
\hline "Rotating In" & The rotating arm is rotating inward \\
\hline
\end{tabular}




\section{D0-06DD2 PLC Input/Output Map}

\begin{tabular}{|c|c|c|c|}
\hline \multicolumn{2}{|c|}{ Inputs } & \multicolumn{2}{|c|}{ Outputs } \\
\hline Input Point & Status & Output Point & Status \\
\hline $\mathrm{X} 0$ & $\begin{array}{l}\text { Not Used - High } \\
\text { Speed Input }\end{array}$ & Y0 & $\begin{array}{l}\text { Not Used - Pulse } \\
\text { Output }\end{array}$ \\
\hline $\mathrm{X} 1$ & $\begin{array}{l}\text { Not Used - High } \\
\text { Speed Input }\end{array}$ & Y1 & $\begin{array}{l}\text { Not Used - Pulse } \\
\text { Output }\end{array}$ \\
\hline $\mathrm{X} 2$ & $\begin{array}{l}\text { Not Used - High } \\
\text { Speed Input }\end{array}$ & Y2 & Not Used \\
\hline $\mathrm{X} 3$ & $\begin{array}{l}\text { Not Used - High } \\
\text { Speed Input }\end{array}$ & Y3 & Not Used \\
\hline $\mathrm{X} 4$ & Extend Button & Y4 & Not Used \\
\hline $\mathrm{X} 5$ & Stow Button & Y5 & Not Used \\
\hline X6 & $\begin{array}{l}\text { Rotation Extend } \\
\text { Sensor }\end{array}$ & Y6 & $\begin{array}{l}\text { Translate Operate } \\
\text { LED Indicator }\end{array}$ \\
\hline $\mathrm{X} 7$ & $\begin{array}{l}\text { Rotation Stow } \\
\text { Sensor }\end{array}$ & Y7 & Not Used \\
\hline $\mathrm{X} 10$ & $\begin{array}{c}\text { Translation Extend } \\
\text { Sensor } \\
\end{array}$ & Y10 & Not Used \\
\hline $\mathrm{X} 11$ & $\begin{array}{l}\text { Translation Stow } \\
\text { Sensor }\end{array}$ & Y11 & $\begin{array}{l}\text { Rotate Operate } \\
\text { LED Indicator }\end{array}$ \\
\hline $\mathrm{X} 12$ & Not Used & Y12 & Not Used \\
\hline $\mathrm{X} 13$ & Not Used & Y13 & $\begin{array}{l}\text { Automatic Mode } \\
\text { LED Indicator }\end{array}$ \\
\hline $\mathrm{X} 14$ & Not Used & Y14 & Not Used \\
\hline $\mathrm{X} 15$ & Not Used & Y15 & Not Used \\
\hline $\mathrm{X} 16$ & Not Used & Y16 & R-TCCW Relay \\
\hline $\mathrm{X} 17$ & Not Used & Y17 & R-TCW Relay \\
\hline $\mathrm{X} 20$ & Not Used & Y100 & GS2-22P0 DI2 \\
\hline $\mathrm{X} 21$ & Not Used & Y101 & GS2-22P0 DI1 \\
\hline $\mathrm{X} 22$ & Not Used & Y102 & Not Used \\
\hline $\mathrm{X} 23$ & Not Used & Y103 & Not Used \\
\hline
\end{tabular}




\section{Curriculum Vitae}

\section{Robert P. Hayes}

Rt. 1 Box 189-G

(304) 298-3709

Keyser, WV 26726

robertwvu@hotmail.com

\section{Objective}

To obtain a full-time position in the computer/electrical engineering field, continuing my experience of working on exciting $R \& D$ projects that make a difference in society

\section{Education}

West Virginia University, Morgantown, WV

Master of Science in Electrical Engineering, emphasis in Digital Systems, Certificate in Computer Forensics

- Thesis: "Control System Design for a C-130 Ro-Ro Sensor Deployment Platform"

- Expected graduation August 2004

- Graduate GPA: 3.78/4.00

- Relevant Courses: Computer/Data Forensics, Information Technology Auditing, Law and Privacy, Fault Tolerant Computing, Information Theory, Computer Systems Architecture, Computer Networking

Bachelor of Science in Computer Engineering, May 2002

Bachelor of Science in Electrical Engineering, May 2002

Computer Science Minor, May 2002

- Undergraduate GPA: 3.77/4.00, Magna Cum Laude

- Relevant Courses: Communication Systems, Biometrics, Fiber Optics, Digital Image Processing

\section{Computer Skills}

C, C++, PSpice, Matlab, Ada, Xilinx, Word, Excel, PowerPoint, Access, Visual Basic 6.0, Visio, Internet Explorer Have built numerous computers, programmed PLC's and PIC chips

\section{Employment History \& Projects}

Graduate Research Assistant, WVU, Morgantown, WV June 2002 - May 2004

1. Worked on DoD/National Guard funded project called Project Oculus with Dr. Jim Smith and Dr. Roy Nutter

- Palletized system consisting of an operator station and surveillance sensor deployment system onboard C-130

- Designed power distribution for the system

- Circuit design to control sensor pod deployment operation

- Programmed a Programmable Logic Controller (PLC) to control automatic mode of sensor pod deployment

2. Automatic analysis of EEG data to classify the sleep state of a rat with Dr. Stephanie Schuckers

- Wrote the analysis program in Matlab

\section{Stockman, Wal-Mart, LaVale, MD June 1999 - May 2003}

- Customer service: helped customers locate desired items and lift heavy merchandise

- Brought shopping carts into the store for customer use

Senior Design Project: Video On Demand (August 2001 - May 2002)

- System allows user to search database of movies on a server and download the movie file via cable modem

- User can play back the movie with functions such as pause, stop, fast-forward, and rewind with remote control

- Designed all user interfaces and MS Access database front ends using Visual Basic 6.0 


\section{Professional Associations}

Eta Kappa Nu, Inducted April 2000 (Treasurer, August 2000 - May 2002) - Electrical Engineering Honor Society Golden Key National Honor Society, Inducted April 1999

National Society of Collegiate Scholars, Inducted April 1999

WVU Honors Program (August 1998 - May 2002)

\section{Scholarships/Awards}

Presidential Scholarship (August 1998 - May 2002) - Paid full tuition for four years

Edwin C. Jones Scholarship (August 2000 - May 2002) - Awarded from the CSEE department at WVU

The National Dean's List (April 1999)

Valedictorian, Frankfort High School, Ridgeley, WV, Class of 1998

\section{References Available Upon Request}

